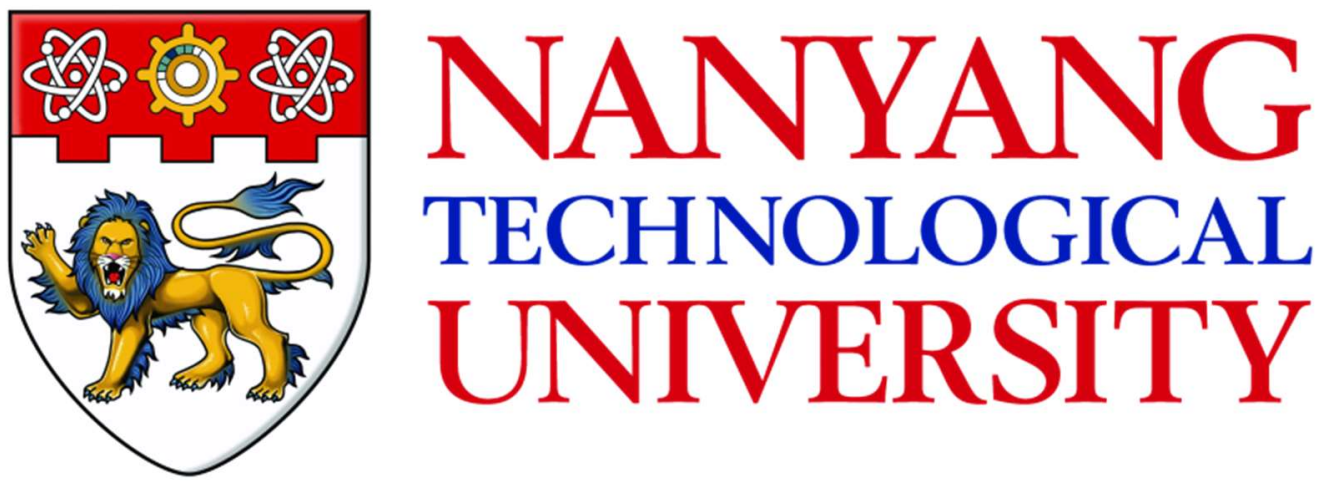

EVALUATION OF TRACE METAL SPECIATION AND BIOAVAILABILITY IN ANAEROBIC SYSTEMS

PHAM MINH THANH

INTERDISCIPLINARY GRADUATE SCHOOL NANYANG ENVIRONMENT \& WATER RESEARCH INSTITUTE 



\title{
EVALUATION OF TRACE METAL SPECIATION AND BIOAVAILABILITY IN ANAEROBIC SYSTEMS
}

\section{PHAM MINH THANH}

\author{
Interdisciplinary Graduate School \\ Nanyang Environment \& Water Research \\ Institute
}

A thesis submitted to the Nanyang Technological University in partial fulfilment of the requirement for the degree of Doctor of Philosophy 



\section{Statement of Originality}

I hereby certify that the work embodied in this thesis is the result of original research and has not been submitted for a higher degree to any other University or Institution.

Date

Student Name 

This thesis is dedicated to

my dear parents and my beloved sister

for being so supportive and encouraging throughout all these years 


\section{Acknowledgements}

I wish to thank all those who, directly or indirectly, helped me to complete this thesis.

First and foremost, I would like to sincerely thank my main supervisor Professor Zhou Yan for her valuable guidance, constant support, and her help on paper and thesis preparation during this study.

I would also like to sincerely thank my co-supervisor Professor David C. Stuckey for sharing with me his incredible knowledge, and for being so supportive to me all these past few years. It was such a great pleasure to learn from him and I really enjoyed our conversations on world politics and travelling.

I also owe immense gratitude to my mentor Doctor Balachandran Ketheesan for the time we worked together. Without his great deal of guidance and support, I would not have accomplished my studies and completed thesis.

I would like to thank my parents, sister and relatives for their constant patience, love and encouragement during this long journey.

And finally, I am very grateful for the financial support I received from the Singapore National Research Foundation Board under the Environment \& Water Technologies Visiting Professor Programme (VPP) and administered by the Environment \& Water Industry Programme Office (EWI) of the PUB. 


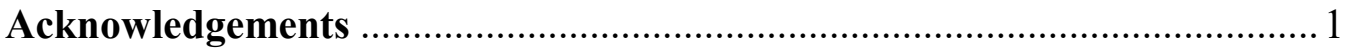

Table of Contents

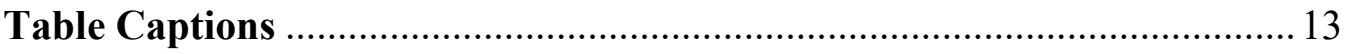

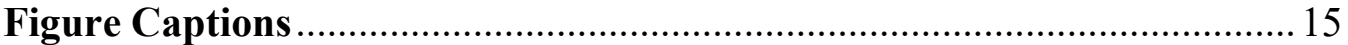

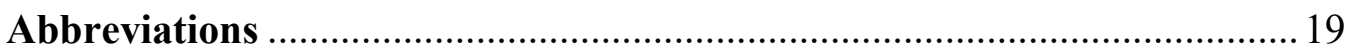

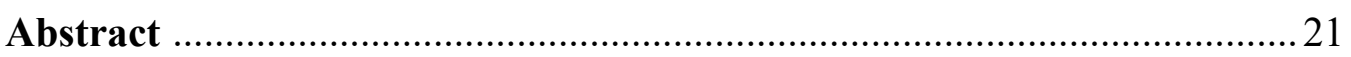

\section{Table of Contents}

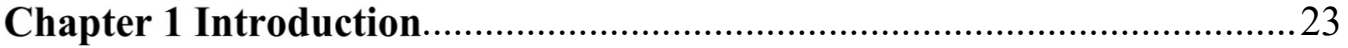

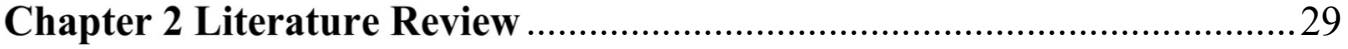

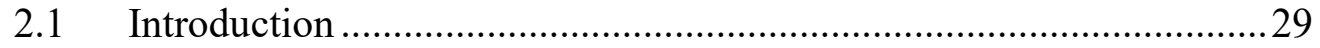

2.2 Importance of trace metals in anaerobic digestion ...........................29

2.3 Trace metal limitation in anaerobic digestion ....................................32

2.4 Trace metal stimulation in anaerobic digestion..................................33

2.5 Trace metal requirements in anaerobic digestion...............................35

2.6 Trace metal supplementation in anaerobic digestion ........................44

2.7 Trace metal speciation in anaerobic digestion ..................................46

2.7.1 The effects of operating parameters on trace metal speciation in

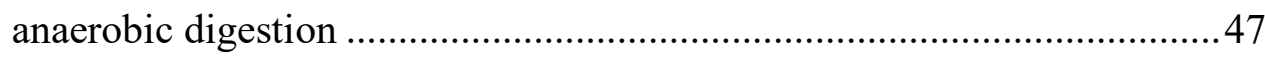

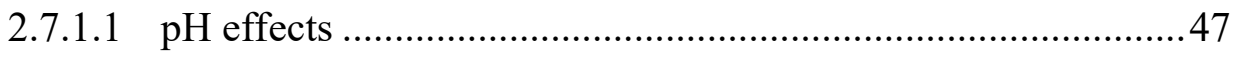

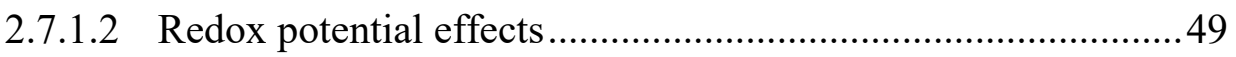


2.7.1.3 Hydraulic retention time effects ............................................ 49

2.8 Trace metal bioavailability in anaerobic digestion ..........................50

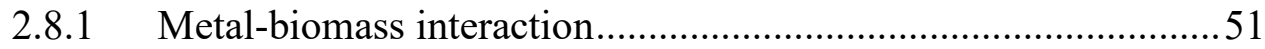

2.8.2 Metal-liquid phase interaction ..............................................52

2.8.3 The effects of chelating agents on trace metal bioavailability in

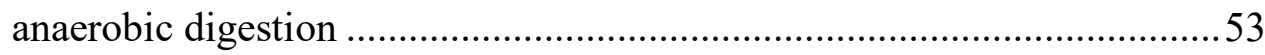

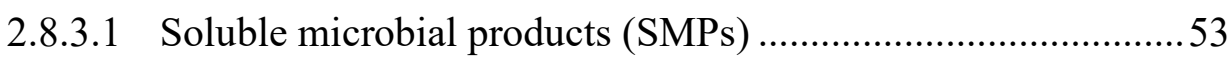

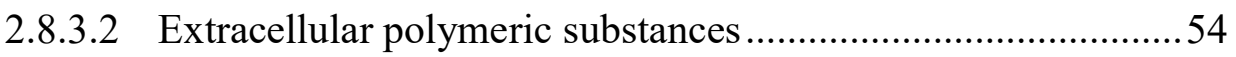

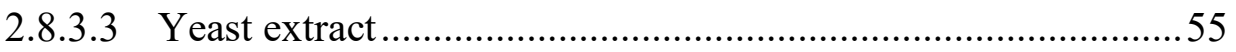

2.8.3.4 Nitrilotriacetic acid and ethylenediaminetetraacetic acid ........56

2.9 Techniques to investigate metal speciation and bioavailability in

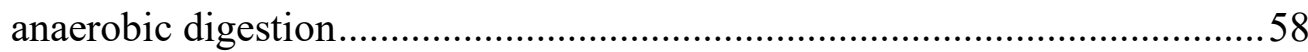

2.9.1 Sequential extraction schemes ..................................................58

2.9.2 Techniques to determine free metal ion concentration ................62

2.9.3 Techniques to determine sulfur speciation ..................................63

2.9.4 Chromatographic and spectroscopic techniques ......................... 64

2.9.5 Chemical equilibrium modelling …............................................ 64

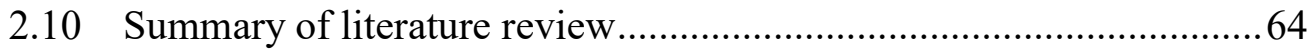

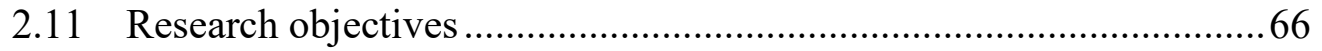

Chapter 3 Experimental Methodology.................................................... 67

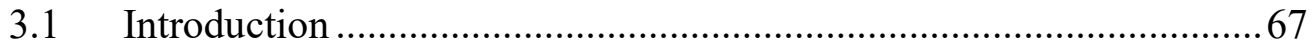

3.2 Set-up of Submerged Anaerobic Membrane Bioreactor system.........67

3.3 Cultivation of anaerobic sludge for the SAMBRs ...........................6 68

3.4 Feed and nutrients for the SAMBRs .............................................. 71

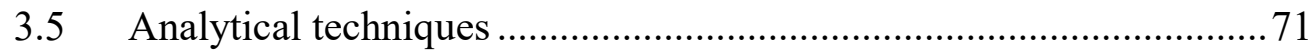

3.5.1 General sample preparation ..................................................... 71 


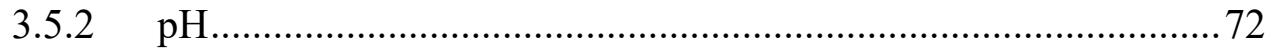

3.5.3 Chemical Oxygen Demand (COD) …........................................ 72

3.5.4 Total and volatile suspended solids (TSS/VSS) ........................73

3.5.5 Volatile Fatty Acids (VFAs) ...................................................... 73

3.5.6 Biogas production and composition.......................................... 74

3.5.7 Biochemical Methane Potential (BMP) analysis ....................... 74

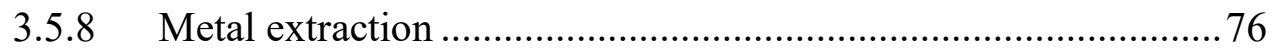

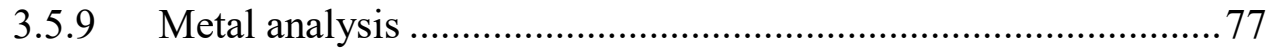

3.5.10 Measurement of EDDS and Fe-EDDS complex.........................78

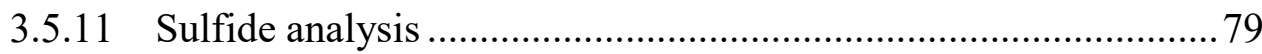

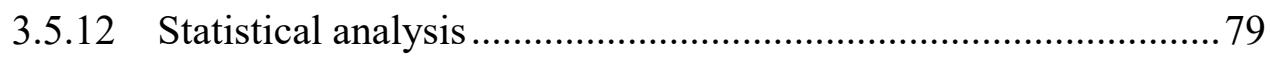

Chapter 4 Iron deficiency and bioavailability in anaerobic batch and submerged membrane bioreactors during organic shock loads.................81

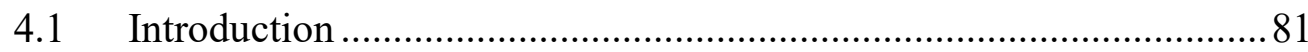

4.2 Experimental and analytical methods .............................................. 83

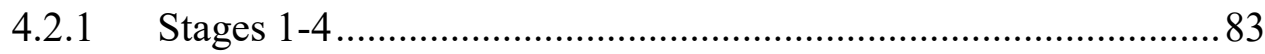

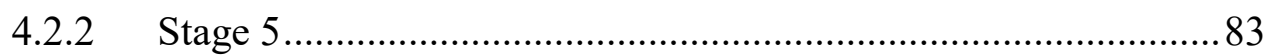

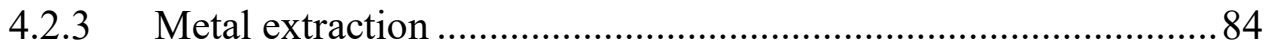

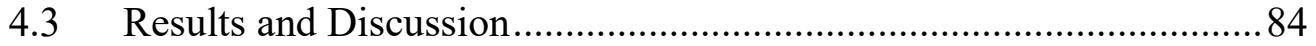

4.3.1 Stage 1: The effects of organic shock loading on the speciation of $\mathrm{Fe}$

4.3.2 Stage 2: Effects of Fe deficiency on the responses to shock

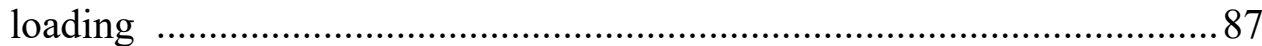

4.3.3 Stage 3: Effects of Fe dosage on the degradation of VFAs .........90

4.3.4 Stage 4: The effects of $\mathrm{Fe}^{2+}$ dose on the degradation kinetics of

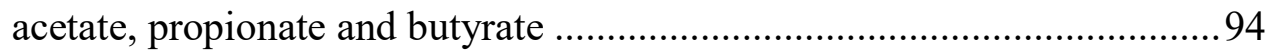

4.3.5 Stage 5: The effects of Fe supplementation in a SAMBR ...........98

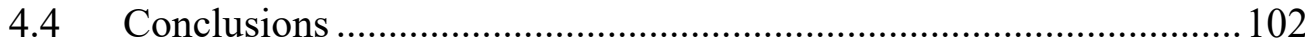


Chapter 5 Effect of Ethylenediamine-N,N'-disuccinic acid (EDDS) on the speciation and bioavailability of $\mathrm{Fe}^{2+}$ in the presence of sulfide

5.1 Introduction

5.2 Experimental and analytical methods

5.2.1 Metal extraction of dried and wet samples with the BCR extraction method.

5.2.2 Effects of metal nutrient supplementation on anaerobic digestion..

5.2.3 Determination of optimal concentration for $\mathrm{Fe}^{2+}$ in anaerobic digestion.

5.2.4 Biodegradation of EDDS in anaerobic digestion

5.2.5 Effect of EDDS on $\mathrm{Fe}^{2+}$ concentration in the presence of sulfide in model media

5.2.6 Effect of EDDS on $\mathrm{Fe}^{2+}$ bioavailability in the presence of sulfide in anaerobic digestion 108

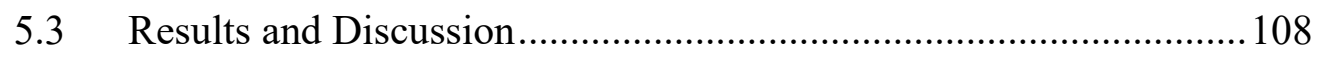

5.3.1 Metal extraction of dried and wet samples with the BCR extraction method. 108

5.3.2 Effects of metal nutrient supplementation on methane production in anaerobic digestion

5.3.3 Determination of optimal concentration for $\mathrm{Fe}^{2+}$ in anaerobic digestion.....

5.3.4 Biodegradation of EDDS in anaerobic digestion

5.3.5 Effect of EDDS on $\mathrm{Fe}^{2+}$ concentration in the presence of sulfide in model media.

5.3.6 Effect of EDDS on $\mathrm{Fe}^{2+}$ bioavailability in anaerobic digestion.123

5.4 Conclusions 


\section{Chapter 6 Dosing of Ethylenediamine-N,N'-disuccinic acid (EDDS) to} improve the bioavailability of $\mathrm{Fe}^{2+}$ in the presence of sulfide in a submerged anaerobic membrane bioreactor.

6.1 Introduction

6.2 Experimental and analytical methods

6.2.1 Dosing strategy for EDDS and Fe in the presence of sulfide in a batch reactor

6.2.2 Effect of sulfide on the speciation and bioavailability of $\mathrm{Fe}^{2+}$ in a SAMBR

6.2.3 Dosing strategy for EDDS and $\mathrm{Fe}^{2+}$ in the presence of sulfide in a SAMBR

6.3 Results and Discussion

6.3.1 Dosing strategy for EDDS and $\mathrm{Fe}^{2+}$ in the presence of sulfide in a batch setup

6.3.2 Effect of sulfide on the speciation and bioavailability of $\mathrm{Fe}^{2+}$ in a SAMBR

6.3.3 Dosage of EDDS to improve the bioavailability of $\mathrm{Fe}^{2+}$ in the presence of sulfide in a SAMBR

6.4 Conclusions

\section{Chapter 7 Effects of trace metal deficiency and supplementary on a}

7.1 Introduction

7.2 Experimental and analytical methods

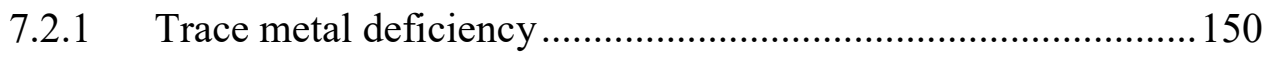

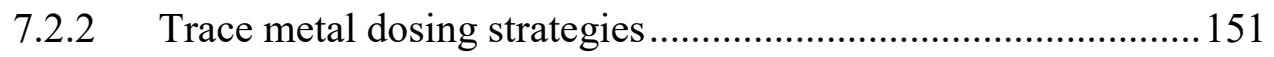

7.3 Results and Discussion.

7.3.1 Trace metal deficiency 
7.3.1.2 The speciation of trace metals .............................................. 157

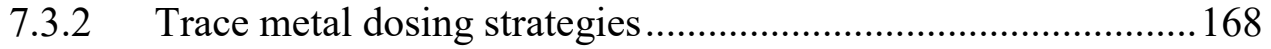

7.3.2.1 The performance of the SAMBR ............................................ 168

7.3.2.2 The speciation of trace metals ............................................. 170

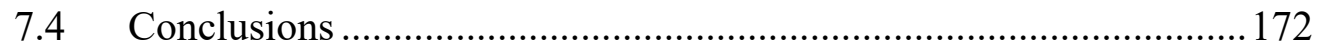

\section{Chapter 8 Effect of operating conditions on speciation and bioavailability} of trace metals in submerged anaerobic membrane bioreactors..............173

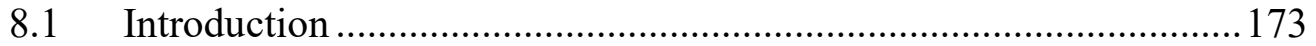

8.2 Experimental and analytical methods ..........................................175

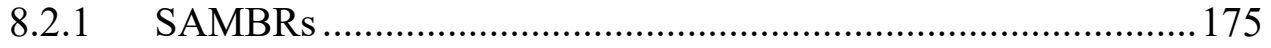

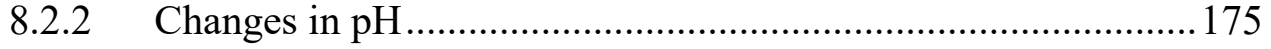

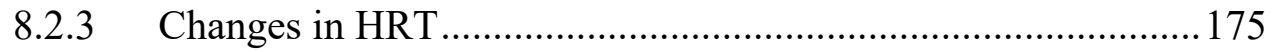

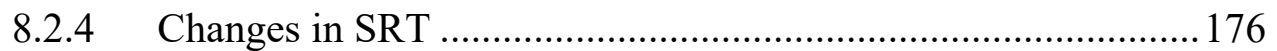

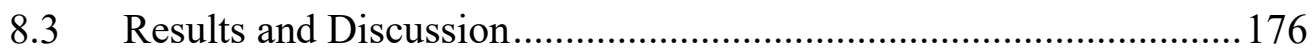

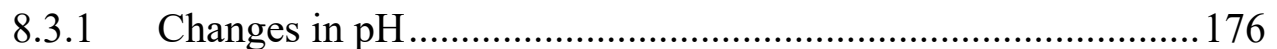

8.3.1.1 Performance of the SAMBR1 at different $\mathrm{pHs}$......................176

8.3.1.2 Dynamic changes in trace metal speciation at different $\mathrm{pHs} .180$

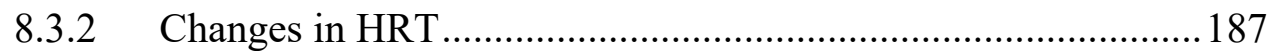

8.3.2.1 Performance of the SAMBR2 under different HRTs .............187

8.3.2.2 Dynamic changes in trace metal speciation under different

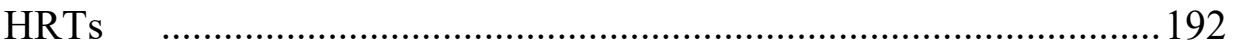

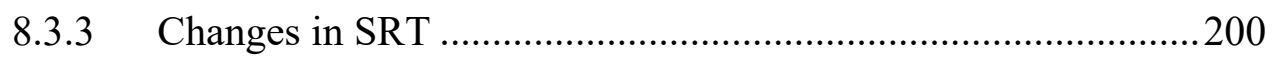

8.3.3.1 Performance of the SAMBR under different SRTs ...............200

8.3.3.2 Dynamic changes in trace metal speciation under different

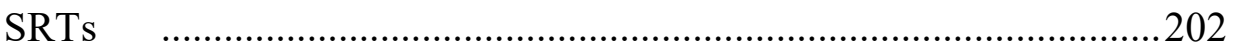

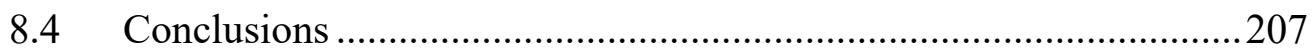


Chapter 9 Conclusions and Future Work ….........................................209

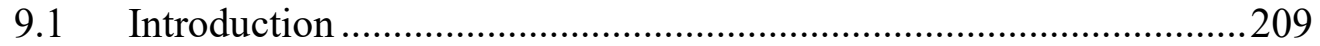

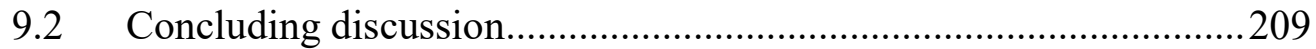

9.2.1 Iron deficiency and bioavailability in anaerobic batch and submerged membrane bioreactors during organic shock loads 210

9.2.2 Effect of Ethylenediamine-N,N'-disuccinic acid (EDDS) on the speciation and bioavailability of $\mathrm{Fe}^{2+}$ in the presence of sulfide

9.2.3 Dosing of Ethylenediamine-N,N'-disuccinic acid (EDDS) to improve the bioavailability of $\mathrm{Fe}^{2+}$ in the presence of sulfide in a submerged anaerobic membrane bioreactor

9.2.4 Trace metal deficiency and dosing strategies in a submerged anaerobic membrane bioreactor

9.2.5 Effect of operating conditions on speciation and bioavailability of trace metals in submerged anaerobic membrane bioreactors

9.3 Conclusions 216

9.4 Recommendations for future work 217

Publications .221

References .223 


\section{Table Captions}

Table 2.1 Required concentration of essential metals for anaerobic digestion systems. 36

Table 3.1 Composition of concentrated feed for SAMBR experiments (40 $\mathrm{gCOD} / \mathrm{L})$. .71

Table 3.2 Chemical composition of biomedia used in BMP bottles (Owen et al., 1979). .75

Table 3.3 Operating conditions required in the revised BCR sequential extraction method (van Hullebusch et al., 2005b) 77

Table 4.1 Steady state performance of the SAMBR at different HRTs........99

Table 4.2 Speciation of Fe in anaerobic sludge in the SAMBR. 99

Table 4.3 Responses of the SAMBR to a glucose spike of 1 gCOD.......... 100

Table 4.4 Responses of the SAMBR to a glucose spike of 2 gCOD.......... 101

Table 5.1 Metal concentrations supplemented to test reactors...................... 106

Table 5.2 Extraction efficiency $(\%)$ for each metal $(\mathrm{n}=3) \ldots \ldots \ldots \ldots \ldots \ldots \ldots \ldots . . . . . . . . .110$

Table 5.3 Methane production rate $\left(\mathrm{mLCH}_{4} / \mathrm{d}\right)$ and time to reach maximum methane production rate (Max Time $h)(n=3)$.

Table 5.4 $\mathrm{Fe}^{2+}$ concentration $\left(\mu \mathrm{gFe}^{2+} / \mathrm{gTSS}\right)$ from sequential extraction at the end of experiment $(n=3)$.

Table 5.5 Measurement of free EDDS and Fe-EDDS complex (mg/L) at different molar ratios in UHPLC $(\mathrm{n}=3)$.

Table 6.1 Fe content $\left(\mu \mathrm{gFe}^{2+} / \mathrm{gTSS}\right)$ from sequential extraction at the end of the batch experiment $(n=3)$ 138

Table 6.2 Measurement of free EDDS and Fe-EDDS complex (mg/L) using UHPLC in the batch experiment $(\mathrm{n}=3)$ 140

Table 6.3 Measurement of free EDDS ( $\mathrm{mg} / \mathrm{L})$ using UHPLC in the SAMBR at Stage $3(\mathrm{Fe}, \mathrm{EDDS}$, and $\mathrm{S})(\mathrm{n}=3)$ 148

Table 6.4 Measurement of Fe-EDDS complex (mg/L) using UHPLC in the SAMBR (Fe, EDDS, and S) at Stage $3(n=3)$. 148 
Table 7.1 Concentrations of TMs for each pulse (mg/L).

Table 7.2 Metal content ( $\mu \mathrm{g} / \mathrm{gTSS})$ in the influent, reactor, and effluent from the SAMBR at different phases $(n=3)$.

Table 7.3 The accumulation and leaching rate of TMs ( $\mu \mathrm{g} / \mathrm{gTSS} . \mathrm{d})$ compared to the loading rate of TMs ( $\mu \mathrm{g} / \mathrm{gTSS} . \mathrm{d})$ at different phases $(n=3)$ 161

Table $8.1 \quad$ Total content $(\mu \mathrm{g} / \mathrm{gTSS})$ of TMs as an average of samples collected at each $\mathrm{pH}$ and leaching rate $(\mu \mathrm{g} / \mathrm{gTSS} . \mathrm{d})$ of TMs determined from total content ( $\mu \mathrm{g} / \mathrm{gTSS})$ at the beginning and the end of each $\mathrm{pH}$ in the SAMBR1. 181

Table 8.2 Total content ( $\mu \mathrm{g} / \mathrm{gTSS})$ of TMs as an average of samples collected at each HRT and leaching rate ( $\mu \mathrm{g} / \mathrm{gTSS} . \mathrm{d})$ of TMs determined from total content ( $\mu \mathrm{g} / \mathrm{gTSS})$ at the beginning and the end of each HRT in the SAMBR2 193

Table 8.3 Total content ( $\mu \mathrm{g} / \mathrm{gTSS}$ ) of TMs as an average of samples collected at each SRT and leaching rate ( $\mu$ g/gTSS.d) of TMs determined from total content ( $\mu \mathrm{g} / \mathrm{gTSS}$ ) at the beginning and the end of each SRT in the SAMBR3. 203

Table A.1 Fe content ( $\mu \mathrm{g} / \mathrm{gTSS})$ from sequential extraction in the SAMBR $(\mathrm{n}=3)$

Table A.2 Metal content ( $\mu \mathrm{g} / \mathrm{gTSS})$ in each fraction from BCR extraction $\operatorname{method}(\mathrm{n}=3)$.

Table A.3 Metal content $(\mu \mathrm{g} / \mathrm{gTSS})$ in each fraction from BCR extraction method at different $\mathrm{pHs}(\mathrm{n}=3)$ 251

Table A.4 Metal content ( $\mu \mathrm{g} / \mathrm{gTSS})$ in each fraction from BCR extraction method at different HRTs $(\mathrm{n}=3)$

Table A.5 Metal content ( $\mu \mathrm{g} / \mathrm{gTSS})$ in each fraction from BCR extraction method at different SRTs $(\mathrm{n}=3)$. 


\section{Figure Captions}

Figure 3.1 Schematic diagram of the SAMBR system (Kunacheva et al., 2017).

Figure 3.2 Experimental setup of the SAMBR system used in this study

Figure 3.3 The flat sheet membrane used in the SAMBRs..............................70

Figure 4.1 VFA production at 1g COD shock in Stage 1................................85

Figure 4.2 VFA production at 3g COD shock in Stage 1................................86

Figure 4.3 Fe speciation at $1 \mathrm{gCOD}$ shock in Stage 1.....................................86

Figure 4.4 Fe speciation at 3 gCOD shock in Stage 1.....................................87

Figure 4.5 Effects of Fe deficiency on VFA accumulation at $1.5 \mathrm{gCOD} / \mathrm{L}$ glucose concentration (100 hours) (Stage 2) ....................................8

Figure 4.6 Effects of Fe deficiency on VFA accumulation at $3 \mathrm{gCOD} / \mathrm{L}$ glucose concentration (100 hours) (Stage 2).

Figure 4.7 Effects of Fe deficiency on methane production at $1.5 \mathrm{gCOD} / \mathrm{L}$ and $3 \mathrm{gCOD} / \mathrm{L}$ glucose concentration (100 hours) (Stage 2).......89

Figure 4.8 Effects of different doses of $\mathrm{Fe}^{2+}$ on biogas production in batch reactors (Stage 3)

Figure 4.9 Speciation of Fe into "relatively bioavailable forms" (Stage 3) at the end of the batch run.

Figure 4.10 Speciation of Fe in its "relatively non-bioavailable forms" (Stage

3 ) at the end of the batch run. 92

Figure 4.11 Effects of $\mathrm{Fe}^{2+}$ on the rate of methane production from different substrates at $1 \mathrm{gCOD} / \mathrm{L}$ (Stage 4$)$. 96

Figure 4.12 Effects of $\mathrm{Fe}^{2+}$ on the rate of methane production from different substrates at $3 \mathrm{gCOD} / \mathrm{L}$ (Stage 4).

Figure 4.13 The distribution characteristics of Fe in batch reactors (Stage 4)... 
Figure 5.1 Extraction recovery as a percentage (\%) for metals in dried and wet samples $(n=3)$.

Figure 5.2 Cumulative methane production (mL) (a) Phase 1, (b) Phase 2, (c)

Phase $3(n=3)$.

Figure 5.3 Sequential extraction for each metal (a-h) at the end of Phase 3 using the BCR method $(\mathrm{n}=3)$

Figure 5.4 Percentage of (Soluble + Exchangeable fraction)/Total metal content $(n=3)$.

Figure 5.5 Methane yields $\left(\mathrm{mLCH}_{4} / \mathrm{gVSS}\right)$ at different $\mathrm{Fe}^{2+}$ concentrations (n $=3)$.

Figure 5.6 Methane yields ( $\left.\mathrm{mLCH}_{4} / \mathrm{gVSS}\right)$ at different EDDS:Fe molar ratios $(\mathrm{n}=3)$.

Figure 5.7 Soluble $\mathrm{Fe}^{2+}$ concentration in the presence of $0.25 \mathrm{mM} \mathrm{S}^{2-}$ at different EDDS:Fe molar ratios with $10 \mathrm{mg} / \mathrm{L} \mathrm{Fe}^{2+}(\mathrm{n}=3) \ldots . . .123$

Figure 5.8 Methane yields ( $\left.\mathrm{mLCH}_{4} / \mathrm{gVSS}\right)$ at different EDDS:Fe molar ratios $(\mathrm{n}=3)$

Figure 5.9 Fe fractions from sequential extraction $(n=3)$

Figure 6.1 Schematic diagram of experimental design for each stage of the SAMBR.

Figure 6.2 Methane yields ( $\left.\mathrm{mLCH}_{4} / \mathrm{gVSS}\right)$ from different sets in the batch experiment after $8 d(n=3)$.

Figure 6.3 Hydrogen concentration in the gas phase (ppm) from the batch experiment over $8 d(n=3)$.

Figure 6.4 Fe fractionation using the BCR method at the end of the batch experiment $(8 d)(n=3)$.

Figure 6.5 Soluble COD in the SAMBR reactor and effluent at different stages $(n=3)$.

Figure 6.6 Methane yields of the SAMBR at different stages.

Figure 6.7 Soluble Fe concentration in the SAMBR influent and effluent at different stages 
Figure 6.8 Speciation of Fe in the SAMBR at different stages

Figure 7.1 Profile of soluble COD in reactor and effluent and the methane yields from the SAMBR $(\mathrm{n}=3)$

Figure 7.2 VFA concentrations as COD (left), and Reactor COD (right) of the SAMBR $(n=3)$. 155

Figure 7.3 VFA concentrations as COD (left), and Effluent COD (right) of the SAMBR at different phases $(\mathrm{n}=3)$ 155

Figure 7.4 Methane yields of the SAMBR at different phases $(n=3) \ldots . . . .156$

Figure 7.5 Speciation of TMs in the SAMBR at different phases $(n=3)$ 168

Figure 8.1 Soluble COD in the reactor and effluent of the SAMBR1 at different $\mathrm{pHs}(\mathrm{n}=3)$.

Figure 8.2 VFA concentration as COD with Reactor COD of the SAMBR1 at different $\mathrm{pHs}(\mathrm{n}=3)$. 178

Figure 8.3 VFA concentration as COD with Effluent COD of the SAMBR1 at different $\mathrm{pHs}(\mathrm{n}=3)$. 178

Figure 8.4 Methane yields of the SAMBR1 at different pHs. 179

Figure 8.5 Speciation of TMs in SAMBR1 at different $\mathrm{pHs}(\mathrm{n}=3)$. 184

Figure 8.6 Soluble COD in SAMBR2 reactor and effluent at different HRTs $(\mathrm{n}=3)$.

Figure 8.7 Cake layer on the membrane surface of the SAMBR2 at the end of $2 \mathrm{~h}$ HRT. 190

Figure 8.8 VFA concentration as COD with Reactor COD of SAMBR2 at different HRTs $(\mathrm{n}=3)$. 190

Figure 8.9 VFA concentration as COD with Effluent COD of SAMBR2 at different HRTs $(\mathrm{n}=3)$. 191

Figure 8.10 Speciation of TMs in the SAMBR2 at different HRTs $(\mathrm{n}=3) . .196$

Figure 8.11 Speciation of TMs in the cake layer of the SAMBR2 at the end of $2 \mathrm{~h}$ HRT experiment $(\mathrm{n}=3)$. 199 
Figure 8.12 Soluble COD in the SAMBR3 reactor and effluent at different

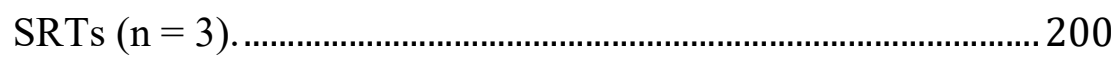

Figure 8.13 Methane yields in the SAMBR3 at different SRTs.................... 202

Figure 8.14 Soluble COD in the SAMBR3 reactor and effluent at different

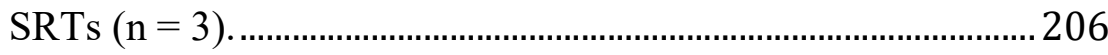




\section{Abbreviations}

$\begin{array}{ll}\text { AD } & \text { Anaerobic Digestion } \\ \text { BCR } & \text { Bureau Communautaire de Reference } \\ \mathrm{CH}_{4} & \text { Methane } \\ \mathrm{CO}_{2} & \text { Carbon Dioxide } \\ \text { EDDS } & \text { Ethylenediamine-N,N'-Disuccinic Acid } \\ \text { EDTA } & \text { EthyleneDiamineTetraacetic Acid } \\ \text { EPS } & \text { Extracellular Polymeric Substances } \\ \text { HRT } & \text { Hydraulic Retention Time } \\ \text { MP-AES } & \text { Microwave Plasma - Atomic Emission Spectroscopy } \\ \text { NTA } & \text { NitriloTriacetic Acid } \\ \text { OLR } & \text { Organic Loading Rate } \\ \text { SAMBR } & \text { Submerged Anaerobic Membrane Bioreactor } \\ \text { SMP } & \text { Soluble Microbial Product } \\ \text { SRT } & \text { Solids Retention Time } \\ \text { TM } & \text { Trace Metal } \\ \text { UASB } & \text { Up-flow Anaerobic Sludge Blanket } \\ \text { UHPLC } & \text { Ultra-High Performance Liquid Chromatography } \\ \text { VFA } & \text { Volatile Fatty Acid } \\ & \end{array}$




\section{Abstract}

The importance of trace metals in anaerobic reactors has already been acknowledged in the literature, however, their bioavailability for microbial uptake which is governed by their speciation, has been poorly understood. There was a lack of information about the interaction between trace metals and organic/inorganic ligands and the operational parameters that affect their speciation in an anaerobic bioreactor. Therefore, the main objectives of this thesis were to investigate the speciation and bioavailability of trace metals in submerged anaerobic membrane bioreactors (SAMBRs) under the following conditions: in the presence of sulfide; with the addition of biodegradable chelating agent EDDS; under nutrient deficiency; under organic shock loads; and under changes in operating parameters i.e. $\mathrm{pH}$, hydraulic retention time (HRT), and solids retention time (SRT). The results showed that acetoclastic methanogens were more constrained by $\mathrm{Fe}^{2+}$ limitations compared to other trophic groups, while an organic shock resulted in leaching of $\mathrm{Fe}^{2+}$ from the residual to organically bound and soluble forms, and the precipitation of $\mathrm{Fe}^{2+}$ as a sulfide salt seemed to reduce its bioavailability to acetoclastic methanogens. Biodegradable chelating agent EDDS when dosed as a metal complex with $\mathrm{Fe}^{2+}$ was able to compete with sulfide and keep the $\mathrm{Fe}^{2+}$ in a soluble form as an FeEDDS complex, hence improving the performance of the SAMBR. Characterization of different EDDS forms by Ultra-Fast Liquid Chromatography (UHPLC) showed the presence of free EDDS and Fe-EDDS complex, and chromatographic analyses confirmed the increase in the $\mathrm{Fe}$ soluble fraction. Organic shocks (glucose spikes) applied to the SAMBR resulted in leaching of $\mathrm{Fe}$ from residual to soluble and organically bound forms. The supplementation of Fe helped to remove the VFAs accumulated during the organic shocks. SAMBR performance was significantly affected by the low $\mathrm{pH}$ (6) and HRT ( $2 \mathrm{~h}$ ), but it was still able to achieve high treatment efficiencies at low SRTs $(25 \mathrm{~d})$. The reduction in these parameters all resulted in a decrease in 
metal content in the SAMBR, and the degree of trace metal loss from the SAMBR varied between metals as it depends on the sensitivity of the trace metals towards the changes, and also their affinity to anaerobic sludge. In all changes of each operating parameter, the trend in speciation of the trace metals generally tended to a shift towards highly bioavailable fractions. 


\section{Chapter 1}

\section{Introduction}

The growing concern about pollution of the environment, especially the aqueous environment is bigger than ever, with more man-made environmental disasters occurring every year. Due to these concerns, discharge standards and legislation for wastewater treatment is becoming tougher and more stringent over time. This not only leads to a dramatic increase in the costs of wastewater treatment for both the municipal and industrial sectors, but also concomitantly results in an increase in the amount of sludge produced from these treatment processes.

The treatment processes for both domestic and industrial wastewaters are primarily carried out using cost effective biological means rather than physicalchemical methods. The heart of biological wastewater treatment is the secondary treatment reactors which remove most of the organic (COD/BOD), much of the N, S, and P (usually), and reduce pathogens. Biological treatment processes can be categorized into two major types, aerobic and anaerobic degradation, depending on whether molecular oxygen is required or not for bacterial growth. Microorganisms in aerobic treatment convert organic matter in the wastewater into carbon dioxide, water, and new biomass in the presence of air. On the other hand, anaerobic treatment processes involve the conversion of the contaminants without oxygen into methane, inorganic products including carbon dioxide and ammonia, and new biomass.

However, in the past, due to historical reasons as well as a number of misunderstandings, aerobic treatment is preferred over anaerobic treatment especially in larger treatment plants. These misunderstandings about the anaerobic processes include the perception that it cannot treat low-strength wastewater $(<1000 \mathrm{mg} / \mathrm{L} \mathrm{COD})$; has a low tolerance for inhibitory compounds; 
cannot be operated at low temperatures $\left(<35^{\circ} \mathrm{C}\right)$ and low HRTs $(<5-10$ days $)$; and has poor removal efficiencies.

However, aerobic treatment has its drawbacks including: bulking sludges (which can cause catastrophic failure of the treatment processes); large energy consumption; emission of greenhouse gases such as nitrous oxide $\left(\mathrm{N}_{2} \mathrm{O}\right)$; and large amounts of waste activated sludge produced (which has to be treated properly before disposal, usually by anaerobic digestion). In addition to these, the utilization of oxygen in aerobic treatment contributes significantly to the plant cost by requiring substantial equipment for aeration, and very high operating and maintenance costs. It is estimated that at a conventional treatment plant, about $40 \%$ of the total electricity consumed is for the aeration units (Matsushige et al., 1990).

To address those environmental concerns with respect to energy, solids generation, greenhouse gas emissions, and resource recovery, there has been a major shift towards the use of anaerobic treatment in the last 50 years as it possesses numerous advantages compared to aerobic treatment. The first advantage is the lower yields of biomass under anaerobic conditions, hence far less sludge is produced, resulting in lower costs for waste solids disposal. In anaerobic treatment there is no requirement for aeration, and hence capital as well as operation and maintenance costs are significantly lower. Methane is also one of the products from the conversion of organic matter by the anaerobic microorganisms, which is a source of renewable energy.

Every living cell including microorganisms rely on only a number of elements that can be divided into macronutrients $(\mathrm{C}, \mathrm{H}, \mathrm{N}, \mathrm{O}, \mathrm{P}, \mathrm{S})$, major cations $(\mathrm{K}, \mathrm{Mg}, \mathrm{Ca})$, and the so-called micronutrients including trace metals (TMs) (Fe, Co, Ni, Zn, Mn, Mo, Se, etc) (Merchant \& Helmann, 2012). Anaerobic bacteria are just like other microorganisms that require TMs as essential components of cofactors and enzymes, however, the supplementation of TMs to enhance metabolism has not been well understood. In practice, to fulfill these nutrient requirements TMs are often supplemented in sufficient 
quantities to support microbial growth, and hence ensure the optimal performance of the treatment processes. On the other hand, TMs should only be dosed below the inhibitory or toxic level as an excessive metal content in the sludge will inhibit the performance of the anaerobic systems, cause harm to the environment, and minimize the quality and applicability of anaerobic products in agriculture, e.g. digestate used as fertilizer. However, the supplemented TMs are not always necessarily bioavailable for the microorganisms to take up (Zitomer et al., 2008).

The concept of bioavailability of metals in anaerobic digestion has been poorly understood up until now. Total metal concentration is generally used to evaluate the effects of metal stimulation and toxicity in anaerobic digestion. However, it has been demonstrated that the measurement of total metal concentration is not sufficient to determine its bioavailability (Hsu \& Lo, 2001; Amir et al., 2005). TM bioavailability depends on their speciation, which in turn is controlled by many factors, including the presence of organic/inorganic ligands, the operating conditions of anaerobic reactors, and the bioreactor configuration (Oleszkiewicz \& Sharma, 1990; He et al., 2009).

In terms of the design of anaerobic bioreactors, the most basic system is the completely mixed process such as continuous flow stirred-tank reactor (CSTR), which has been used extensively in many municipal treatment plants. However, it can only achieve high volumetric loading rates with quite concentrated waste streams with a biodegradable chemical oxygen demand (COD) level between 8,000 and $50,000 \mathrm{mg} / \mathrm{L}$. The anaerobic contact process, an analogy to the aerobic activated sludge system, has been applied to many applications but one problem is the biomass lost to the effluent due to bubble generation and attachment in the settling tank. The popular up-flow anaerobic sludge blanket reactor (UASB) developed by Lettinga et al. (1980), is able to separate solids from the outward-flowing wastewater through the formation of granules. However, serious problems that occur are the formation of granules that float and the lack of granule formation, both of which result in loss of 
biomass from the system (Rittmann \& McCarty, 2001). Therefore, the major challenge for engineers was to be able to accommodate long resident times of the slow growing anaerobic microorganisms, especially the methanogens, which can be done by separating completely the hydraulic retention time (HRT) from the solids retention time (SRT). This led to the development of novel submerged anaerobic membrane bioreactors (SAMBRs) which evolved from aerobic MBRs. SAMBRs are able to retain the slow growing bacteria completely in the reactors, allowing them to grow and persist under unfavorable conditions, e.g. high salinity (Stuckey, 2012). They have been shown to be able to operate at very low HRTs of $3 \mathrm{~h}$, but still can achieve very high COD removals of around 98\% (Hu \& Stuckey, 2006). Therefore, in the near future the most rational approach to treating organic wastewaters is to use a SAMBR as a stand-alone unit which is capable of treating the wastewater directly, with much less sludge produced. However, the performance of these reactors like other anaerobic systems, can be severely limited by operating under suboptimal conditions, e.g. when they are limited by TMs in the feed.

Hence, the overall aim of this study was to explore the speciation and bioavailability of trace metals in a Submerged Anaerobic Membrane Bioreactor (SAMBR) under different operating conditions, in the presence of different types of ligands, and to investigate different dosing strategies to improve the bioavailability of the trace metals, and hence the reactor performance.

This thesis is organized as follows:

Chapter 2 provides a comprehensive review of the basics of the most essential TMs in anaerobic digestion, with the main focus on TM speciation and bioavailability in anaerobic digestion including the current state of art of 
analytical techniques. The objectives of this study are then outlined in this chapter.

Chapter 3 presents the details of the general experimental procedures and analytical methods for all the following chapters.

Chapter 4 studies the deficiency and bioavailability of $\mathrm{Fe}^{2+}$ during organic overloading conditions, and shows how $\mathrm{Fe}^{2+}$ supplementation can help to improve the degradation of accumulated VFAs.

Chapter 5 investigates the effects of sulfide on the speciation of $\mathrm{Fe}^{2+}$ and the dosing of biodegradable chelating agent EDDS to improve the bioavailability of $\mathrm{Fe}^{2+}$ in a batch reactor.

Chapter 6 determines the dosing strategy of the EDDS and $\mathrm{Fe}^{2+}$ as they are added into a SAMBR to improve the bioavailability of $\mathrm{Fe}^{2+}$ and hence the reactor performance.

Chapter 7 examines the deficiency of several TMs in a SAMBR and evaluates different dosing strategies of TMs to improve the reactor performance.

Chapter 8 investigates the effects of $\mathrm{pH}$, hydraulic retention time (HRT), solids retention time (SRT) changes on reactor performance.

Chapter 9 provides a conclusive discussion highlighting the outcome of research study and recommendations for future research based on these findings. 
Chapter 1: Introduction 


\section{Chapter 2}

\section{Literature Review}

Note: this chapter was published in Biotechnology Advances, 2016, volume 34, pages $122-136$.

\subsection{Introduction}

The purpose of this chapter is to provide a critical review of the fundamentals and applications of the main themes discussed in this thesis. A concise explanation of the importance of trace metals (TMs), their limitations, requirements and dosing strategies in anaerobic digestion are outlined. This is then followed by a detailed review on the speciation of TMs, which plays an important part in this research. The effects of $\mathrm{pH}$, redox potential, and hydraulic retention time (HRT), on TM speciation in anaerobic digestion are explained. The interaction between TMs in the liquid and solid phases is described in order to explain their bioavailability in anaerobic digestion. The use of different types of chelating agents to improve the TM bioavailability is also discussed in detail. Finally, the development and application of analytical techniques currently used to investigate the speciation and bioavailability of TMs in anaerobic digestion is also presented. The chapter concludes by summarizing these areas thus leading to detailed objectives of this study.

\subsection{Importance of trace metals in anaerobic digestion}

Biological treatment of wastewaters, including anaerobic treatment, requires not only organic matter, but also essential nutrients for the growth of microorganisms. Some types of wastewater contain a sufficient amount of these nutrients, e.g. swine wastewater (Cestonaro do Amaral et al., 2014). However, 
other types of wastewater might require metal supplementation in order to avoid nutrient deficiency, e.g. methanol wastewater (Fermoso et al., 2008a), maize silage (Evranos \& Demirel, 2014), and wheat stillage (Schmidt et al., 2014).

The metal nutrients can be classified based on their concentration in the cells into major cations $(\mathrm{K}, \mathrm{Mg}, \mathrm{Ca})$, and micronutrients $(\mathrm{Mn}, \mathrm{Fe}, \mathrm{Co}, \mathrm{Cu}, \mathrm{Mo}$, $\mathrm{Ni}, \mathrm{Se}, \mathrm{W})$ (Merchant \& Helmann, 2012). Metal concentration in the cells range from $10^{-7}$ to $10^{-3} \mathrm{M}$ for the major cations, and from $10^{-6}$ to $10^{-15} \mathrm{M}$ for the micronutrients (Williams \& Fraústo da Silva, 2000). The essential micronutrients known as TMs are constituents of cofactors in enzyme systems, and the function of these TMs and their associated enzymes in anaerobic reactions have been summarized by a number of researchers (Jarrell \& Kalmokoff, 1988; Oleszkiewicz \& Sharma, 1990; Schattauer et al., 2011).

TMs considered the most essential in anaerobic digestion are the "transition metals" i.e. Fe, Ni, and Co (Oleszkiewicz \& Sharma, 1990), and their effects on anaerobic digestion have been studied extensively in the literature (Hoban \& Van Den Berg, 1979; Sharma \& Singh, 2001; Pobeheim et al., 2011; Qiang et al., 2012; Shakeri Yekta et al., 2012; Gustavsson et al., 2013a). The importance of Fe depends on its redox properties, and its engagement in energy metabolism (Takashima \& Speece, 1989). Fe is utilized in the transport system of the methanogenic bacteria for the conversion of $\mathrm{CO}_{2}$ to $\mathrm{CH}_{4}$, and functions both as an electron acceptor and donor (Vintiloiu et al., 2013). Fe also acts as a binding component in sulfide precipitation as it is often supplemented into anaerobic reactors, not only to precipitate the sulfide formed, but also to control the level of hydrogen sulfide in the biogas (Gustavsson et al., 2013a). A corrinoid such as vitamin $B_{12}$ contains the Co ion, and can bind to the coenzyme methylase which catalyzes methane formation in both acetoclastic methanogens and hydrogenotrophic bacteria (Schonheit et al., 1979; Kida et al., 2001). Ni was initially considered as not being essential for bacterial growth (Diekert et al., 1981). However, $\mathrm{F}_{430}$, a low molecular weight coenzyme 
discovered in extracts from Methanobacterium thermoautotrophicum, was shown to contain substantial amounts of Ni (Speece et al., 1983; Thauer, 1998; Kida et al., 2001). This coenzyme $\left(\mathrm{F}_{430}\right)$ is contained within the Methylcoenzyme $M$ reductase enzyme, which reduces methyl coenzyme $M$ to methane in all methanogenic pathways (Friedmann et al., 1990).

$\mathrm{Mn}$ acts as an electron acceptor in anaerobic respiration processes (Langenhoff et al., 1997), while Zn takes part in the functioning of enzymes involved in methanogenesis such as coenzyme M methyltransferase (Sauer \& Thauer, 2000), and $\mathrm{Zn}, \mathrm{Cu}$, and $\mathrm{Ni}$ have all been found in a single hydrogenase (Jarrell \& Kalmokoff, 1988). There is limited information available in the literature on the positive effects of $\mathrm{Zn}$ and $\mathrm{Cu}$ on methanogens, but $\mathrm{Zn}$ was found in remarkably high concentrations $(50-630 \mathrm{ppm})$ in 10 methanogenic bacteria, whereas $\mathrm{Cu}$ was only present in some species (Scherer et al., 1983).

Other TMs such as W and Mo are also found in enzymes, such as formate dehydrogenase $(\mathrm{FDH})$, which catalyzes formate production by propionate oxidizers (Dong et al., 1994; Fermoso et al., 2009; Banks et al., 2012), and some methanogenic bacteria contain $\mathrm{W}$ and Mo-containing enzymes for the same purpose (Nies, 1999). Methanobacterium thermoautotrophicum contains two formylmethanofuran dehydrogenase iso-enzymes, a $\mathrm{W}$ containing form and a Mo containing form; the Mo enzyme is synthesized only when Mo is present in the growth medium, while the W enzyme is synthesized when either $\mathrm{W}$ or Mo is available. If the growth medium contains Mo, the $\mathrm{W}$ enzyme will contain Mo rather than W (Hochheimer et al., 1995). All W-containing enzymes have been found in bacteria and archaea, mostly those with an anaerobic metabolism (Nies, 1999).

Although Se is not strictly a TM, it is a very important trace element for anaerobic digestion systems. Early work from Jones and Stadtman (1977) found a direct relationship between the stimulatory effect of selenite on growth, and increased levels of formate dehydrogenase activity in Methanococcus vannielii, a strict anaerobic microorganism. The lack of Se in the influent to an anaerobic 
treatment process can result in growth limitations for some methanogens, a decrease in microbial activity, and ultimately process failure (Chasteen \& Bentley, 2003; Lebuhn et al., 2008; Worm et al., 2009). Therefore, in this review, although the main focus is on the common transition metals i.e. $\mathrm{Fe}$, Co, $\mathrm{Ni}, \mathrm{Cu}, \mathrm{Mn}, \mathrm{Mo}$, and $\mathrm{W}$, other non-metallic elements like Se will also be discussed.

\subsection{Trace metal limitation in anaerobic digestion}

Although the requirement for TMs is extremely low, a deficiency in essential TMs can cause the enzymes and coenzymes required for metabolism not to be properly synthesized. This severely limits the growth of microorganisms, and leads to process instability and consequently process failure (Parkin \& Owen, 1986; Rajeshwari et al., 2000). The effects of essential TM depletion on anaerobic digestion have been well reported in the literature (Zandvoort et al., 2002; Osuna et al., 2003; Zandvoort et al., 2003; Paulo et al., 2004; Zandvoort et al., 2006b; Fermoso et al., 2008a; Fermoso et al., 2008b).

Gonzalez-Gil et al. (1999) found that when $\mathrm{Ni}$ and Co were added continuously at a rate of 0.05 to $0.2 \mu \mathrm{mol} / \mathrm{h}$ to a full-scale expanded granular bed reactor treating wastewater containing methanol and formaldehyde, the temporary inhibition phase was not observed, and the rate of methane production increased exponentially. They then hypothesized that these effects were due to micronutrient limitations.

The deficiency of Fe and Ni during anaerobic digestion of wheat stillage resulted in a rapid accumulation of VFAs (Schmidt et al., 2014). The exclusion of $\mathrm{Co}, \mathrm{Zn}$ and $\mathrm{Ni}$ from the methanol-based feed of an UASB reactor induced lower specific methanogenic activity (SMA), and the accumulation of VFAs (Paulo et al., 2004; Fermoso et al., 2008a; Fermoso et al., 2008b).

Mo, W, and Se all seemed to have a long-term effect on methanogenic activity (Worm et al., 2009; Schmidt et al., 2014), and a deficiency of Se was found to be the reason for the accumulation of propionic acid during the 
anaerobic digestion of food waste operating at high ammonia concentrations (Banks et al., 2012).

Among different trophic groups in anaerobic digestion, methanogens are the most sensitive to TM deficiency, and hence less effective in competing for these TMs compared to acid-formers (Goodwin et al., 1990). This is due to their slow growth rates and more stringent growth requirements. White and Stuckey (2000) proposed that to prevent limitations in methanogenic activity, the acetate utilization rates required per gram of VSS should be used to estimate whether nutrient supplementation may be required. The threshold value appeared to be 0.25 gAcetate/gVSS.d.

Organic shock loading can cause temporary nutrient deficiencies to anaerobic bacteria, which then lowers the performance of anaerobic digestion. Hawkes et al. (1992) demonstrated that during an $8 \mathrm{~h}$ organic shock load, the effluent COD level in a metal dosed UASB reactor increased linearly from $1500 \mathrm{mg} / \mathrm{L}$ to around $3500 \mathrm{mg} / \mathrm{L}$, while the effluent COD level in a non-metal dosed UASB reactor increased at a much higher rate from $1500 \mathrm{mg} / \mathrm{L}$ to around $8500 \mathrm{mg} / \mathrm{L}$. At an organic loading rate of $17.4 \mathrm{kgCOD} / \mathrm{m}^{3} . \mathrm{d}$, Voolapalli and Stuckey (1999) found that under nutrient deficiency homoacetogenic organisms dominated, whereas methanogenic growth was limited.

\subsection{Trace metal stimulation in anaerobic digestion}

In the literature there are a number of reviews on the stimulatory effect of TM supplementation in anaerobic digestion (Oleszkiewicz \& Sharma, 1990; Zandvoort et al., 2006a; Fermoso et al., 2008b; Demirel \& Scherer, 2011; Chen et al., 2014b). The required concentrations for the essential metals, i.e. Fe, Ni, $\mathrm{Co}, \mathrm{Zn}, \mathrm{Mo}, \mathrm{Se}$, and $\mathrm{W}$ that show stimulatory effects on anaerobic digestion systems are summarized in Table 2.1 in Section 2.5 (see Trace metal requirements in anaerobic digestion). As can be seen in Table 2.1, several factors including reactor type, substrate, organic loading rate (OLR), and 
operating temperature can influence the actual TM requirement that has stimulatory effects in anaerobic digestion systems.

TM supplementation is one method to increase VFA utilization, and the inclusion of Fe was found to have a stimulatory effect on acetate utilization by methanogens (Speece, 1962). When Espinosa et al. (1995) increased the organic loading on a UASB reactor treating cane molasses stillage from 5 to $21.5 \mathrm{kgCOD} / \mathrm{m}^{3} . \mathrm{d}$, an accumulation of VFAs, principally propionic acid, was observed. The addition of Fe (100 mg/L), Ni (15 mg/L), Co (10 mg/L), and Mo $(0.2 \mathrm{mg} / \mathrm{L})$ reduced the level of acetic acid and propionic acid significantly (1100 to $158 \mathrm{mg} / \mathrm{L}$ and $5291 \mathrm{mg} / \mathrm{L}$ to $251 \mathrm{mg} / \mathrm{L}$, respectively). Lin et al. (1998) carried out a systematic study on the effect of TM supplementation on the anaerobic degradation of butyric acid. The results showed that the stimulatory effects were in the following order: $\mathrm{Cu}^{2+}<\mathrm{Fe}^{3+}<\mathrm{Zn}^{2+}<\mathrm{Ni}^{2+}<\mathrm{Mn}^{2+}$, and the normal- and iso-HBu degradation activities of the methanogens increased by $14-25 \%$ and $17-43 \%$, respectively. Kim et al. (2002) reported that the supplementation of $\mathrm{Ca}, \mathrm{Fe}, \mathrm{Co}$, and $\mathrm{Ni}$ to a thermophilic non-mixed reactor was required in order to achieve a high conversion of propionate at high concentrations of VFAs. Fe addition of $10 \mu \mathrm{M}$ almost doubled the methanogenic activity of the sludge in a UASB reactor in the conversion of methanol (Zandvoort et al., 2003). After addition of $\mathrm{Fe}, \mathrm{Ni}$, and $\mathrm{Co}$, the propionate and acetate utilization rates in thermophilic and mesophilic digesters increased as much as 50\% and 35\%, respectively (Zitomer et al., 2008).

Supplementation of $\mathrm{Co}$ and $\mathrm{Ni}$ has been demonstrated to increase biogas production during the anaerobic digestion of organic matter such as sulfur-rich stillage (Gustavsson et al., 2013a), while Ni alone has been found to increase methane production to $10 \mathrm{gAcetate} / \mathrm{gVSS}$.d (Speece et al., 1983). Co addition to a UASB increased methane production by a factor of three, stimulating both acetogens and methanogens. On the other hand, a combined supplementation of $\mathrm{Ni}$ and Co was found to increase methane production from methanol conversion by methanogens (Zitomer et al., 2008). 
Patel et al. (1993) determined the effect of $\mathrm{FeCl}_{3}, \mathrm{NiCl}_{2}, \mathrm{CoCl}_{2}, \mathrm{CuCl}_{2}$, and $\mathrm{ZnCl}_{2}$, on the anaerobic digestion of water hyacinth-cattle dung, and found that among the salts studied, the addition of $\mathrm{FeCl}_{3}$ increased gas production more than $60 \%$ with high methane content.

Guiot et al. (1995) investigated shock loading in a multiplate anaerobic reactor treating cheese whey effluent at $68 \mathrm{~h} \mathrm{HRT}$ and a $9.5 \mathrm{kgCOD} / \mathrm{m}^{3} . \mathrm{d}$ OLR, and they found a substantial reduction in the biomass-specific activity for acetate $(5.3 \mathrm{mmol} / \mathrm{gVSS} . \mathrm{d})$. This indicated that metal supplementation was important for the acetoclastic methanogens, and also for the other methanogens (formate- and hydrogen-consumers) and acidogens.

\subsection{Trace metal requirements in anaerobic digestion}

The optimum and range of TMs in anaerobic digestion have been reported in a number of studies, and Table 2.1 provides a summary of the minimum required concentrations for the essential TMs, including $\mathrm{Fe}, \mathrm{Ni}, \mathrm{Co}, \mathrm{Mo}, \mathrm{Se}$, and $\mathrm{W}$. The TM requirement is normally determined by the depletion approach, in which the reactor is operated with one element depleted while still augmenting the other elements (Fermoso et al., 2008a; Schmidt et al., 2014). The reported concentration of TMs required during anaerobic digestion differs significantly, depending on the substrate type, operating temperature (mesophilic or thermophilic), digestion operating mode (mono or co-digestion), and also type of methanogens, which in turn leads to a diversity of biochemical processes involved in metal dynamics. 
Table 2.1 Required concentration of essential metals for anaerobic digestion systems.

\begin{tabular}{|c|c|c|c|c|c|c|}
\hline Metal & $\begin{array}{c}\text { Required } \\
\text { concentration }\end{array}$ & Reactor & Substrate & OLR & $\begin{array}{c}\text { Operating } \\
\text { temperature }\end{array}$ & Reference \\
\hline \multirow{8}{*}{$\mathrm{Fe}$} & $\begin{array}{c}0.20 \mathrm{mg} / \mathrm{gCOD} \\
\text { removed }\end{array}$ & Methane fermenter & Glucose & $2 \mathrm{gCOD} / \mathrm{L} . \mathrm{d}$ & Mesophilic & (Takashima et al., 2011) \\
\hline & $\begin{array}{c}0.45 \mathrm{mg} / \mathrm{gCOD} \\
\text { removed }\end{array}$ & Methane fermenter & Glucose & $2 \mathrm{gCOD} / \mathrm{L} . \mathrm{d}$ & Thermophilic & (Takashima et al., 2011) \\
\hline & $\begin{array}{c}0.276 \mathrm{mg} / \mathrm{gCOD} \\
\text { removed }\end{array}$ & Methane fermenter & $\begin{array}{l}\text { High-solid food } \\
\text { waste }\end{array}$ & $1.9-6.3 \mathrm{gCOD} / \mathrm{L} . \mathrm{d}$ & Thermophilic & (Qiang et al., 2013) \\
\hline & & & & $1.62-1.8 \mathrm{gCOD} / \mathrm{L} . \mathrm{d}$ & & \\
\hline & $0.43-0.66 \mathrm{mg} / \mathrm{L}$ & UASB, ABR, HABR & $\begin{array}{c}\text { Synthetic sucrose } \\
\text { based }\end{array}$ & $\begin{array}{c}\text { for UASB } \\
2.16-2.4 \mathrm{gCOD} / \mathrm{L} . \mathrm{d} \\
\text { for } \mathrm{ABR}, \mathrm{HABR}\end{array}$ & $35^{\circ} \mathrm{C}$ & (Patidar \& Tare, 2008) \\
\hline & $5.0 \mathrm{mg} / \mathrm{L}$ & Semi- continuous digester & Food waste & $1-4 \mathrm{gVS} / \mathrm{L} . \mathrm{d}$ & $37 \pm 1^{\circ} \mathrm{C}$ & (Zhang et al., 2015a) \\
\hline & $0.55 \mathrm{mg} / \mathrm{L}$ & UASB & Methanol & $2.6-7.8 \mathrm{gCOD} / \mathrm{L} . \mathrm{d}$ & $30^{\circ} \mathrm{C}$ & (Zandvoort et al., 2003) \\
\hline & $1233 \mathrm{mg} / \mathrm{L}$ & Semi- continuous digester & Wheat stillage & $10 \mathrm{gCOD} / \mathrm{L} . \mathrm{d}$ & $38^{\circ} \mathrm{C}$ & (Schmidt et al., 2014) \\
\hline
\end{tabular}


Chapter 2: Literature Review

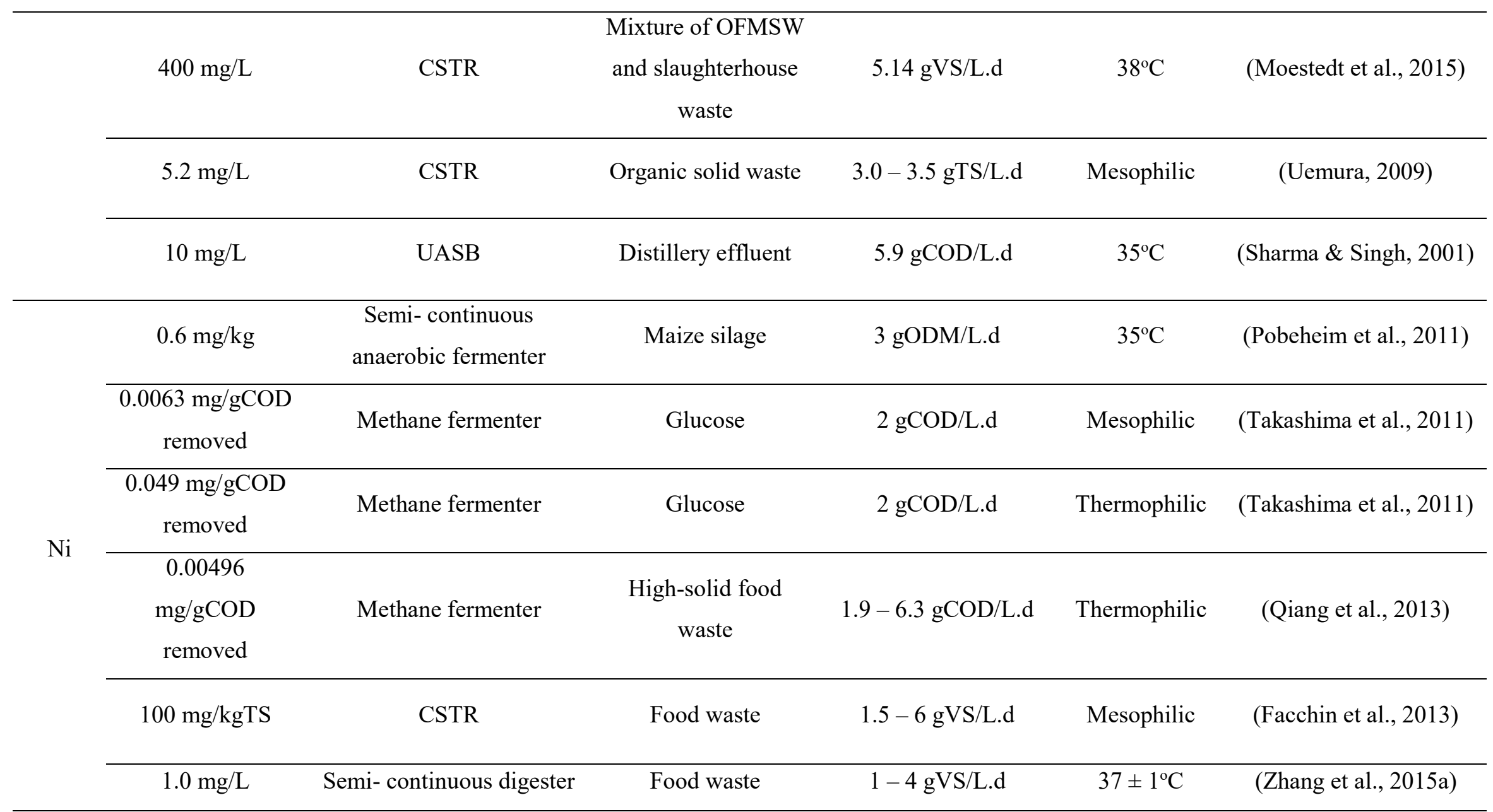


Chapter 2: Literature Review

\begin{tabular}{|c|c|c|c|c|c|}
\hline $0.04 \mathrm{mg} / \mathrm{L}$ & CSTR & Organic solid waste & $3.0-3.5 \mathrm{gTS} / \mathrm{L} . \mathrm{d}$ & Mesophilic & (Uemura, 2009) \\
\hline $0.029 \mathrm{mg} / \mathrm{L}$ & $\begin{array}{c}\text { Anaerobic granular sludge } \\
\text { bioreactors }\end{array}$ & Methanol & $5-15$ gCOD/L.d & $30^{\circ} \mathrm{C}$ & (Fermoso et al., 2008b) \\
\hline $0.5 \mathrm{mg} / \mathrm{L}$ & $\begin{array}{c}\text { Batch anaerobic mono- } \\
\text { digester }\end{array}$ & Maize silage & N/A & $37^{\circ} \mathrm{C}$ & $\begin{array}{c}\text { (Evranos \& Demirel, } \\
\text { 2014) }\end{array}$ \\
\hline $0.1 \mathrm{mg} / \mathrm{L}$ & $\begin{array}{l}\text { Semi-continuously fed } \\
\text { biogas tank reactors }\end{array}$ & Grain stillage & $4-4.6 \mathrm{gCOD} / \mathrm{L} . \mathrm{d}$ & $37^{\circ} \mathrm{C}$ & $\begin{array}{c}\text { (Gustavsson et al., } \\
\text { 2013a) }\end{array}$ \\
\hline $0.1 \mathrm{mg} / \mathrm{L}$ & UASB & Distillery effluent & $5.9 \mathrm{gCOD} / \mathrm{L} . \mathrm{d}$ & $35^{\circ} \mathrm{C}$ & (Sharma \& Singh, 2001) \\
\hline & & & $1.62-1.8 \mathrm{gCOD} / \mathrm{L} . \mathrm{d}$ & & \\
\hline $0.29-0.4 \mathrm{mg} / \mathrm{L}$ & UASB, ABR, HABR & $\begin{array}{c}\text { Synthetic sucrose } \\
\text { based }\end{array}$ & $\begin{array}{c}\text { for UASB } \\
2.16-2.4 \mathrm{gCOD} / \mathrm{L} . \mathrm{d} \\
\text { for } \mathrm{ABR}, \mathrm{HABR}\end{array}$ & $35^{\circ} \mathrm{C}$ & (Patidar \& Tare, 2008) \\
\hline $6.1 \mathrm{mg} / \mathrm{kg}$ & Semi- continuous digester & Wheat stillage & $10 \mathrm{~g} / \mathrm{L} . \mathrm{d}$ & $38^{\circ} \mathrm{C}$ & (Schmidt et al., 2014) \\
\hline $0.5 \mathrm{mg} / \mathrm{kg}$ & CSTR & $\begin{array}{l}\text { Mixture of OFMSW } \\
\text { and slaughterhouse } \\
\text { waste }\end{array}$ & $5.14 \mathrm{gVS} / \mathrm{L} . \mathrm{d}$ & $38^{\circ} \mathrm{C}$ & (Moestedt et al., 2015) \\
\hline
\end{tabular}


Chapter 2: Literature Review

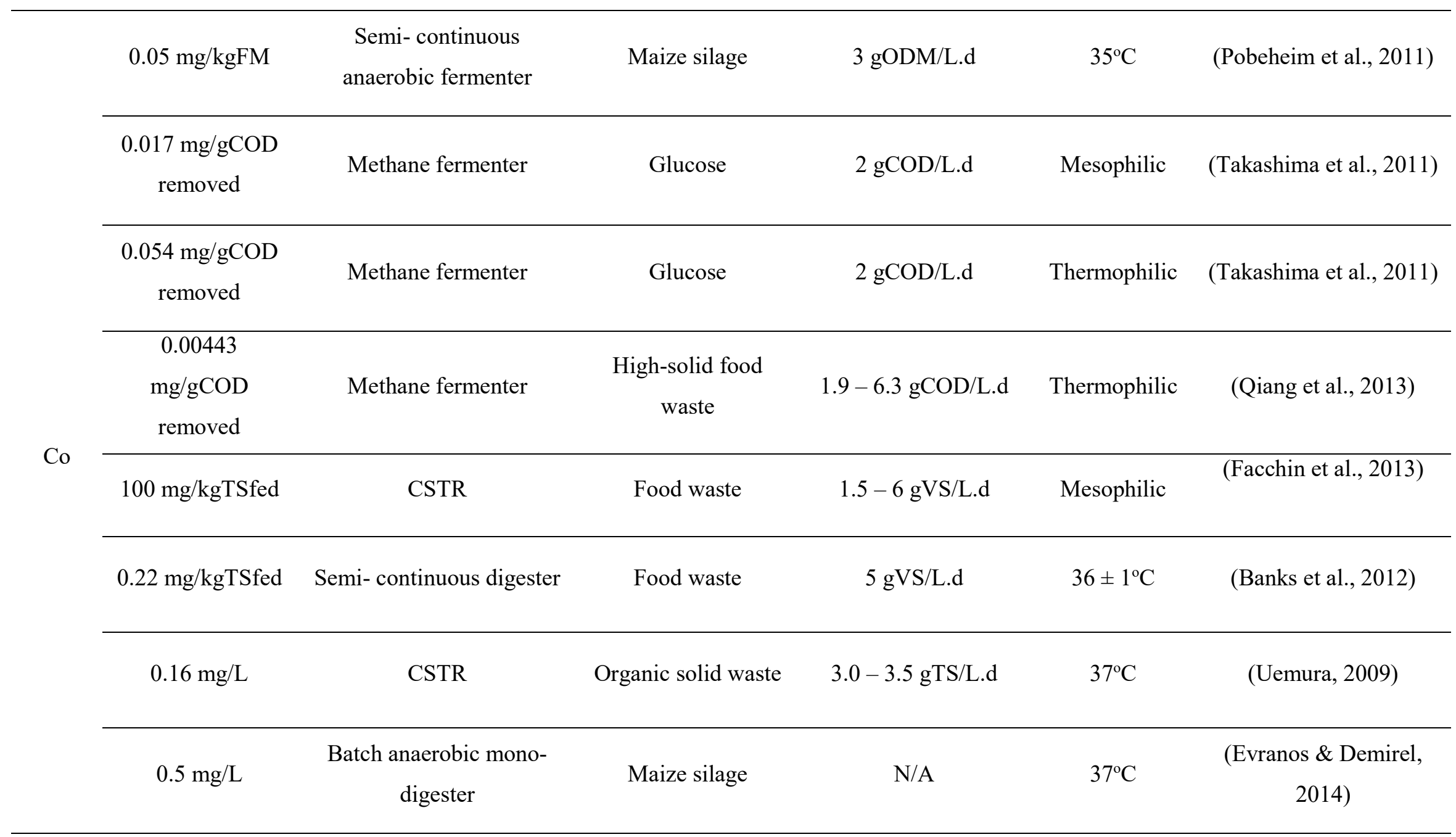


Chapter 2: Literature Review

\begin{tabular}{|c|c|c|c|c|c|}
\hline & & & $1.62-1.8 \mathrm{gCOD} / \mathrm{L} . \mathrm{d}$ & & \\
\hline $0.13-0.29 \mathrm{mg} / \mathrm{L}$ & UASB, ABR, HABR & $\begin{array}{l}\text { Synthetic sucrose } \\
\text { based }\end{array}$ & $\begin{array}{c}\text { for UASB } \\
2.16-2.4 \mathrm{gCOD} / \mathrm{L} . \mathrm{d} \\
\text { for } \mathrm{ABR}, \mathrm{HABR}\end{array}$ & $35^{\circ} \mathrm{C}$ & (Patidar \& Tare, 2008) \\
\hline $0.1-0.3 \mathrm{mg} / \mathrm{L}$ & $\begin{array}{l}\text { Semi-continuously fed } \\
\text { biogas tank reactors }\end{array}$ & Grain stillage & $4-4.6 \mathrm{gCOD} / \mathrm{L} . \mathrm{d}$ & $37^{\circ} \mathrm{C}$ & $\begin{array}{c}\text { (Gustavsson et al., } \\
\text { 2013a) }\end{array}$ \\
\hline $0.5 \mathrm{mg} / \mathrm{L}$ & UASB & Distillery effluent & $5.9 \mathrm{gCOD} / \mathrm{L} . \mathrm{d}$ & $35^{\circ} \mathrm{C}$ & (Sharma \& Singh, 2001) \\
\hline $1.0 \mathrm{mg} / \mathrm{L}$ & Semi- continuous digester & Food waste & $1-4 \mathrm{gVS} / \mathrm{L} . \mathrm{d}$ & $37 \pm 1^{\circ} \mathrm{C}$ & (Zhang et al., 2015a) \\
\hline $1.82 \mathrm{mg} / \mathrm{L}$ & UASB & Methanol & $2.6-7.8 \mathrm{gCOD} / \mathrm{L} . \mathrm{d}$ & $30^{\circ} \mathrm{C}$ & (Zandvoort et al., 2004) \\
\hline $2.5 \mathrm{mg} / \mathrm{kg}$ & Semi- continuous digester & Wheat stillage & $10 \mathrm{gCOD} / \mathrm{L} . \mathrm{d}$ & $38^{\circ} \mathrm{C}$ & (Schmidt et al., 2014) \\
\hline $0.5 \mathrm{mg} / \mathrm{kg}$ & CSTR & $\begin{array}{l}\text { Mixture of OFMSW } \\
\text { and slaughterhouse } \\
\text { waste }\end{array}$ & $5.14 \mathrm{gVS} / \mathrm{L} . \mathrm{d}$ & $38^{\circ} \mathrm{C}$ & (Moestedt et al., 2015) \\
\hline
\end{tabular}


Chapter 2: Literature Review

\begin{tabular}{|c|c|c|c|c|c|c|}
\hline \multirow{5}{*}{$\mathrm{Zn}$} & $\begin{array}{c}0.049 \mathrm{mg} / \mathrm{gCOD} \\
\text { removed }\end{array}$ & Methane fermenter & Glucose & $2 \mathrm{gCOD} / \mathrm{L} . \mathrm{d}$ & Mesophilic & (Takashima et al., 2011) \\
\hline & $\begin{array}{l}0.24 \mathrm{mg} / \mathrm{gCOD} \\
\text { removed }\end{array}$ & Methane fermenter & Glucose & $2 \mathrm{gCOD} / \mathrm{L} . \mathrm{d}$ & Thermophilic & (Takashima et al., 2011) \\
\hline & & & & $1.62-1.8 \mathrm{gCOD} / \mathrm{L} . \mathrm{d}$ & & \\
\hline & $0.15-0.19 \mathrm{mg} / \mathrm{L}$ & UASB, ABR, HABR & $\begin{array}{c}\text { Synthetic sucrose } \\
\text { based }\end{array}$ & $\begin{array}{c}\text { for UASB } \\
2.16-2.4 \mathrm{gCOD} / \mathrm{L} . \mathrm{d}\end{array}$ & $35^{\circ} \mathrm{C}$ & (Patidar \& Tare, 2008) \\
\hline & & & & for $\mathrm{ABR}, \mathrm{HABR}$ & & \\
\hline \multirow{3}{*}{ Mo } & $6 \mathrm{mg} / \mathrm{kgTSfed}$ & CSTR & Food waste & $1.5-6 \mathrm{gVS} / \mathrm{L} . \mathrm{d}$ & Mesophilic & (Facchin et al., 2013) \\
\hline & $5 \mathrm{mg} / \mathrm{kg}$ & Semi- continuous digester & Wheat stillage & $10 \mathrm{~g} / \mathrm{L} . \mathrm{d}$ & $38^{\circ} \mathrm{C}$ & (Schmidt et al., 2014) \\
\hline & $0.25 \mathrm{mg} / \mathrm{L}$ & $\begin{array}{c}\text { Batch anaerobic mono- } \\
\text { digester }\end{array}$ & Maize silage & N/A & $37^{\circ} \mathrm{C}$ & $\begin{array}{c}\text { (Evranos \& Demirel, } \\
\text { 2014) }\end{array}$ \\
\hline \multirow{2}{*}{$\mathrm{Se}$} & $10 \mathrm{mg} / \mathrm{kgTSfed}$ & CSTR & Food waste & $1.5-6 \mathrm{gVS} / \mathrm{L} . \mathrm{d}$ & Mesophilic & (Facchin et al., 2013) \\
\hline & $0.16 \mathrm{mg} / \mathrm{kgTSfed}$ & Semi- continuous digester & Food waste & $5 \mathrm{gVS} / \mathrm{L} . \mathrm{d}$ & $36 \pm 1^{\circ} \mathrm{C}$ & (Banks et al., 2012) \\
\hline
\end{tabular}


Chapter 2: Literature Review

\begin{tabular}{|c|c|c|c|c|c|c|}
\hline & $0.2 \mathrm{mg} / \mathrm{L}$ & Semi- continuous digester & Food waste & $1-4 \mathrm{gVS} / \mathrm{L} . \mathrm{d}$ & $37 \pm 1^{\circ} \mathrm{C}$ & (Zhang et al., 2015a) \\
\hline \multirow{2}{*}{ W } & $10 \mathrm{mg} / \mathrm{kgTSfed}$ & CSTR & Food waste & $1.5-6 \mathrm{gVS} / \mathrm{L} . \mathrm{d}$ & Mesophilic & (Facchin et al., 2013) \\
\hline & $0.5 \mathrm{mg} / \mathrm{kg}$ & Semi- continuous digester & Wheat stillage & $10 \mathrm{~g} / \mathrm{L} \cdot \mathrm{d}$ & $38^{\circ} \mathrm{C}$ & (Schmidt et al., 2014) \\
\hline
\end{tabular}

CSTR - Continuously-stirred tank reactor; USAB - Upflow anaerobic sludge blanket reactor; ABR - Anaerobic baffled reactor;

HABR - Hybrid anaerobic baffled reactor; OFMSW - Organic fraction of municipal solid waste; ODM - Organic dry matter 
Different substrates have different metal contents, for example wheat stillage has different properties compared to other stillage (e.g. sugar beet, sugar cane, and corn), and it is not suitable for anaerobic digestion due to its high concentration of sulfur, and TM deficiency (Westerholm et al., 2012; Schmidt et al., 2014). Hence, its required concentration for TMs will be higher than for other stillage, while swine wastewater contains a high content of $\mathrm{Cu}$ and $\mathrm{Zn}$ (Cestonaro do Amaral et al., 2014).

Mesophilic and thermophilic anaerobic systems may also have significantly different nutrient requirements. For example, Takashima et al. (2011) reported the minimum requirements for, $\mathrm{Ni}, \mathrm{Co}, \mathrm{Zn}$, and $\mathrm{Fe}$ in thermophilic glucose fermentation to be $0.40,0.45,2.0$, and $3.5 \mathrm{mg} / \mathrm{L}$, respectively. These required amounts are ten times more than those required for mesophilic acetate fermentation (Takashima \& Speece, 1989), implying a hypothetical decrease in bioavailability or increase in nutrient requirements at thermophilic temperatures. Similarly Uemura (2009) also found that nutrient requirements are higher in thermophilic anaerobic digestion than in mesophilic anaerobic digestion of organic solid waste.

Another factor that can affect metal speciation and bioavailability, and hence the metal dosing strategy, is the reactor configuration. For example, a submerged anaerobic membrane reactor (SAMBR) is different to a conventional up-flow sludge anaerobic sludge blanket reactor (UASB) due to its ability to decouple hydraulic retention time (HRT) and solids retention time (SRT) (Hu, 2004). Stuckey (2012) suggested that the low solids production and solids free effluent in a SAMBR could enable nutrient recycling; therefore, the nutrient requirements for a SAMBR might be less than for an UASB. In addition, Voolapalli and Stuckey (1998) suggested that nutrient limitations might have contributed to greater floc sizes, and bigger flocs may increase the mass transfer resistance of nutrients from the bulk, which could happen in a granular sludge reactor such as UASB. However, there is limited information available in the literature to explain how reactor configuration can influence 
metal speciation and bioavailability.

The requirement of TMs has been investigated for many different types of microbial biomass i.e. co-cultures, biofilms, granular sludge, and pure cultures (Schönheit et al., 1979; Koesnandar et al., 1991; Jarvis et al., 1997; GonzalezGil et al., 1999; Basiliko \& Yavitt, 2001; Kida et al., 2001). Such variations in the required amounts of TMs are explained by the unique TMs requirement for different methanogenic pathways. In general, $\mathrm{Fe}, \mathrm{Ni}$, and $\mathrm{Zn}$ requirements are roughly equal for $\mathrm{CO}_{2}$ reduction, acetoclastic, and methylotrophic pathways. However, $\mathrm{Mo}$ and $\mathrm{W}$ requirements are higher for $\mathrm{CO}_{2}$ reduction and methylotrophic pathways, whereas Co requirements are higher for the methylotrophic pathway (Krzycki \& Zeikus, 1980; Glass \& Orphan, 2012).

\subsection{Trace metal supplementation in anaerobic digestion}

Although metal deficiency in anaerobic processes is not a rare phenomenon, the significance of TM supplementation is still hugely underestimated (Zandvoort et al., 2006a). In terms of reactor operating modes, Gonzalez-Gil et al. (1999) found that when an anaerobic expanded granular sludge bed (EGSB) reactor was operated in a continuous mode, the amount of Co and Ni required to eliminate the limitations of metal bioavailability was less than that in a batch mode ( $4 \mu \mathrm{M}$ compared to $40 \mu \mathrm{M}$ for both $\mathrm{Ni}$ and $\mathrm{Co})$ due to more biological ligands being produced, and the continuous supplementation of nutrients makes sure that free metals are available for biomass to uptake at any time.

In terms of dosing strategies, TMs can be supplemented continuously (Zandvoort et al., 2002), pre-loaded (Zandvoort et al., 2004), or pulsed into anaerobic reactors (Zandvoort et al., 2004). A continuous supplementation of $\mathrm{CoCl}_{2}$ at a low concentration $(0.62 \mu \mathrm{mol} / \mathrm{L} . \mathrm{d})$ to a methanol-fed UASB reactor only increased the SMA up to $215 \mathrm{mgCOD}-\mathrm{CH}_{4} / \mathrm{gVSS} . d$ (Zandvoort et al., 2002). Pre-loading of $1 \mathrm{mM} \mathrm{CoCl}$ for $24 \mathrm{~h}$ was also shown to overcome Co limitations in the methanol UASB reactor, but a significant amount of Co 
escaped into the effluent (Zandvoort et al., 2004). Fermoso et al. (2008c) found that pulse dosing of a low quantity of $\mathrm{CoCl}_{2}(5 \mu \mathrm{mol} / \mathrm{L})$, a compromise between continuous and pre-loading dosing, also prevented metal limitations, without supplementing Co continuously, and had around $90 \%$ Co retention.

TMs can be supplemented individually, or in combination, to anaerobic digesters. Evranos and Demirel (2014) found that during the anaerobic monodigestion of maize silage, the maximum methane yields of $429 \mathrm{mLCH}_{4} / \mathrm{gVSS}$ added was achieved when Mo, Co, and Ni were supplemented at the same time at concentrations of $0.25,0.5$ and $0.5 \mathrm{mg} / \mathrm{L}$, respectively.

EDTA is known to complex and reduce the bioavailability of TMs (Aquino \& Stuckey, 2007). However, EDTA has been used for phytoremediation of heavy metal contaminated soils to improve the bioavailability and plant metal uptake in the soil (Paulo et al., 2004). The use of EDTA in anaerobic reactors to improve metal bioavailability can be different depending on reactor configuration, and hence metal retention capability. For example, EDTA used as a ligand for Co dosing to UASB reactors has been investigated by Fermoso et al. (2008c), and they found that when supplemented as Co-EDTA ${ }^{2-}$ only $8 \%$ of the Co supplemented was retained, compared to $90 \%$ retention when it was supplemented as $\mathrm{CoCl}_{2}$, making EDTA unsuitable for Co dosing. This is due to the high solubility of Co-EDTA ${ }^{2-}$ added to a continuous UASB system which resulted in Co wash-out. However, in two batch experiments, Vintiloiu et al. (2013) found that Ni complexed with EDTA prior to supplementation can significantly enhance its bioavailability. In a batch system, the EDTA may act as a chelating agent, buffering free ion concentration, which can then be taken up by microorganisms.

The requirement and dosing strategy for TMs also depends on the portion of the supplemented TM that is bioavailable to the microorganisms for uptake. Although metals are available in the reactor at high total concentrations, the stimulating effects of these metals can still be observed, indicating that the metals can be present in a non-bioavailable form (Zandvoort et al., 2006a). For 
instance, added Ni $(10 \mu \mathrm{M})$ increased the biogas production from anaerobic digestion of chicken manure when nickel was already present in the effluent $(253 \mu \mathrm{M})$ prior to "extra" Ni being supplemented (Williams et al., 1986).

Therefore, in order to reduce the amount of TMs required and maximize the methanogenic activity, it is important to understand how their speciation affects their bioavailability.

\subsection{Trace metal speciation in anaerobic digestion}

The total metal content in anaerobic cultures is not sufficient to indicate their bioavailability and toxicity (Oleszkiewicz \& Sharma, 1990; Amir et al., 2005). It is now apparent that the chemical speciation of TMs must be assessed and then considered in order to be able to predict bioavailability. Soluble metals supplied from the feed can be transformed into other forms, including; adsorbed metals, metal-carbonate, -phosphate, -sulfide precipitates in order of their decreasing bioavailability.

Among these fractions, the precipitation of metal-sulfide is considered to be the most critical process in anaerobic digestion. Sulfide in an anaerobic digester originates from sulfide, sulfate, and sulfur-containing organic compounds in the feed (Callander \& Barford, 1983a). There are many studies which confirm the influence of sulfide formation/dissolution on TM distribution in anaerobic digestion (Gonzalez-Gil et al., 1999; van der Veen et al., 2007; Gustavsson et al., 2013b). The speciation and bioavailability of TMs are strongly influenced by the sulfide chemistry (van der Veen et al., 2007); the effects of sulfide on metal bioavailability will be discussed in more detail in Section 2.8.2.

Anaerobic digestion of biological phosphorus removal sludge was found to result in the extensive precipitation of $\mathrm{Ca}$ and $\mathrm{Mg}$, markedly reducing the soluble and easily exchangeable fractions of these metals. However, unexpectedly, the enrichment of $\mathrm{P}$ actually increased the soluble concentrations of $\mathrm{Cu}, \mathrm{Zn}, \mathrm{Cr}, \mathrm{Ni}$, and $\mathrm{Co}$. This phenomenon was related to the increasing 
concentrations of soluble organic matter being released into the liquid phase being available for complexation with TMs (Carliell Marquet, 2002).

Different metals have different bio-uptake processes due to different kinetic and equilibrium processes. For example, it was found that $\mathrm{Fe}^{2+}$ solubility was controlled by FeS precipitation/dissolution, whereas $\mathrm{Co}^{2+}$ solubility was controlled by the formation of microbial compounds. The presence of one metal can also have an impact on the speciation and thus the bioavailability of another; high Fe concentrations in an anaerobic digester can promote co-precipitation, adsorption, and ion substitution of Co and Ni on FeS (Gustavsson et al., 2013a; Shakeri Yekta et al., 2014). The presence of $\mathrm{K}$ in molasses stillage was found to be responsible for the removal of exchangeable forms of essential TMs such as $\mathrm{Ni}^{2+}, \mathrm{Zn}^{2+}$, and $\mathrm{Cu}^{2+}$ from a UASB sludge matrix (Ilangovan, 1993). The potassium salt, $\mathrm{KNO}_{3}$, can cause the displacement of metal ions in the sediment/sludge matrix bound by electrostatic attraction (Mulligan et al., 2009).

\subsubsection{The effects of operating parameters on trace metal speciation in anaerobic digestion}

The bioavailability of metals for microbial uptake and growth is dependent on metal speciation, which is controlled by the operating parameters i.e. $\mathrm{pH}$, redox-potential, and hydraulic retention time (HRT). Dong et al. (2013) studied changes in metal speciation during the high-solids anaerobic digestion of sewage sludge. There was a strong correlation between heavy metal speciation and changes in several operating parameters, including VS/TS, $\mathrm{pH}$, and VFA concentration. Due to the complex aqueous chemistry and syntrophic biological processes in anaerobic systems, changes in these operating parameters will affect the distribution and bioavailability of TMs.

\subsubsection{1 pH effects}

Medium $\mathrm{pH}$ can have dramatic impacts on solution-phase metal concentration. Specifically, in media that contains phosphate as a buffer, a 
minor change in $\mathrm{pH}$ can affect metal solubility, and hence metal bioavailability by several orders of magnitude (Sandrin \& Maier, 2003). In general, at high pHs metals have a tendency to form insoluble metal phosphates and carbonates (Rensing \& Maier, 2003), whereas at low pHs the initial leaching of metals from the sludge occurs, and hence their solubility increases (Zandvoort et al., 2005; Gonzalez-Gil et al., 2012). Most of the studies in the literature focus on the effect of $\mathrm{pH}$ reduction on metal bioavailability.

Marcato et al. (2009) studied the effect of $\mathrm{pH}$ on the bioavailability of $\mathrm{Zn}$ and $\mathrm{Cu}$ in anaerobically digested and raw pig slurry. They demonstrated a gradual dissolution of $\mathrm{Zn}$ from the slurry into solution when the $\mathrm{pH}$ decreased below about 6.0, until dissolved $\mathrm{Zn}$ accounted for $40 \%$ of the total $\mathrm{Zn}$ at $\mathrm{pH} 2.7$. Also, $\mathrm{Zn}$ was much more sensitive to $\mathrm{pH}$ variations than $\mathrm{Cu}$ as anaerobic sludge had a very strong affinity for $\mathrm{Cu}$. At neutral $\mathrm{pH}$, van Hullebusch et al. (2005b) reported that $\mathrm{Co}$ and $\mathrm{Ni}$ were not only found in the organic/sulfide fractions, but also in significant amounts in the residual fraction of granular anaerobic sludge. However, Gonzalez-Gil et al. (2012) found that at low pH (5), this residual fraction was absent and considerable amounts of $\mathrm{Ni}$ and Co were present in the bioavailable fractions (exchangeable and carbonates).

Zandvoort et al. (2005) also determined the effect of pH shocks on TM dynamics in USAB reactors, and found that the $\mathrm{pH}$ shocks did not affect the total metal concentration in the sludge significantly. However, a $30 \mathrm{~d} \mathrm{pH}$ shock $(\mathrm{pH}$ 5) resulted in a shift of $\mathrm{Co}, \mathrm{Ni}$, and $\mathrm{Fe}$ from the residual to the organic/sulfides fraction, which can be due to the adsorption and coprecipitation of $\mathrm{Ni}$ and $\mathrm{Co}$ to FeS. At shorter $\mathrm{pH}$ shocks ( $\mathrm{pH} 5$ for 4 days), significant losses of $\mathrm{Co}(18 \%)$ and $\mathrm{Fe}(29 \%)$ with the effluent from the organic/sulfide fraction were observed, and this was likely to be due to the dissolution of Fe sulfide and a concomitant release of Co.

Lopes et al. (2008) studied the influence of low $\mathrm{pH}$ on nutrient dynamics in anaerobic sludge granules, and found that reducing the $\mathrm{pH}$ led to increased solubilisation of metals from the sludge, with $\mathrm{Fe}$ and $\mathrm{Mn}$ leached most 
extensively. Therefore, a change in $\mathrm{pH}$ can affect metal speciation as reducing the $\mathrm{pH}$ can lead to dissolution/leaching of metals, and hence improve metal bioavailability.

\subsubsection{Redox potential effects}

Under reducing conditions metal speciation in sediments and anaerobic samples is different. Generally, for anaerobic samples, under anaerobic conditions i.e. redox potential $<-300 \mathrm{mV}$ and neutral $\mathrm{pH}$, TMs are more difficult to mobilize and mainly precipitate as sulfides and carbonates (Marcato et al., 2009). On the other hand, for sediment samples the redox gradients due to transitions from oxic to suboxic and anoxic conditions result in changes in metal speciation and the dominance of Fe-Mn oxide. Therefore, all of the studies on the effects of redox potential on metal speciation are carried out for sediment samples. Tack et al. (1996) confirmed that the redox potential can have a significant effect on metal speciation in a reduced dredged sediment. They found a higher solubility of $\mathrm{Cu}(10-90 \mathrm{mg} / \mathrm{kgTS})$ at higher redox potentials $(+60$ to $+370 \mathrm{mV})$ at a $\mathrm{pH}$ between 1 and 2 ; in comparison, the solubility of $\mathrm{Cu}$ was nearly zero at -220 to $-150 \mathrm{mV}$. However, Okbah et al. (2008) found that when the redox potential reduced from 77 to -133 and -170 $\mathrm{mV}$ in two sediment samples, a significant amount of the Fe-Mn oxide fraction transformed to the water-soluble and exchangeable fractions, suggesting that reducing conditions were more favorable for metals bound to these fractions.

\subsubsection{Hydraulic retention time effects}

As discussed in Section 2.6, the metal retention capability is dependent on reactor configuration which in turn is coupled to the hydraulic retention time (HRT). Cestonaro do Amaral et al. (2014) studied the distribution of $\mathrm{Cu}$ and $\mathrm{Zn}$ in swine wastewater during anaerobic digestion over different HRTs. They found that when the HRT was dropped from $17.86 \mathrm{~d}$ to $5.32 \mathrm{~d}$, the metal retention capacity of the bioreactors reduced. While other metal fractions 
remained the same or decreased, the less bioavailable oxidizable fraction comprised of metals associated with organic matter or sulfide increased, indicating that the metals became less bioavailable to anaerobic microorganisms. This finding is important for the operation of anaerobic reactors; for example, under hydraulic shock loads when the HRT is reduced, a higher dose of TMs is required to compensate for the fraction of the metals which become less bioavailable.

\subsection{Trace metal bioavailability in anaerobic digestion}

Although there has been a lot of work on metal speciation in natural systems, the linkage between metal speciation and metal bioavailability in anaerobic reactors has not been well understood. There are very few and limited review studies on the TM bioavailability in anaerobic reactors (Worms et al., 2006; Zandvoort et al., 2006a).

There is still much confusion about TM bioavailability. Although the total metal content which may be provided should be sufficient, the metals may not be present in a bioavailable form that can be utilized by the microorganisms (Zitomer et al., 2008). Even full bioavailability does not mean that the required metals are all utilized by the bacterial population (Oleszkiewicz \& Sharma, 1990). The bioavailability of TMs in bioreactors depends on the complex interactions between metals in the solid and liquid phases in the bioreactors. Transport of free metal ions through the cell membrane is assumed to be the main mechanism for metal uptake by microorganisms. On the other hand, before the essential metals can make contact with the biomass, they are subjected to a number of biochemical processes in the liquid phase such as sulfide precipitation and the formation of inorganic and organic complexes (Zandvoort et al., 2006a). Therefore, it is essential to understand the interaction of metals with biomass and the liquid phase. 


\subsubsection{Metal-biomass interaction}

Most microorganisms can form biofilms, and the TMs present in anaerobic digestion will interact with these biofilms through physical, chemical, or biological processes; van Hullebusch et al. (2003) provided an extensive review on the mechanisms and analytical tools able to study the fate of metals within biofilms. The distribution, immobilization, and remobilization of metals depend on the sorption properties of the biofilms, determined by many factors including $\mathrm{pH}$, redox potential, and concentration of ligands present within the biofilm matrix. Sheng et al. (2008) carried out an investigation on metalbacteria adhesion using two anaerobic sulfate-reducing bacteria under different parameters, i.e. metal nutrients, ionic strength, and $\mathrm{pH}$ of the solution. The bacteria-metal adhesion force measured by atomic force microscopy (AFM) decreased in the presence of TMs in solution, and increased at a stronger ionic strength in solution. The bacteria-metal adhesion force reached its maximum value when the $\mathrm{pH}$ of the solution approached the isoelectric point of the bacteria, i.e. at the zero-point charge.

In another comprehensive review, Worms et al. (2006) provided a different approach to studying metal-biomass interactions by emphasizing the importance of the chemical, biological, and physical processes occurring at and near the biological interface in controlling TM bioavailability through shifts in the limiting bio-uptake fluxes. Examples are biological (transport across the membrane), chemical (dissociation kinetics of metal complexes), and physical (diffusion) processes. These processes are not entirely independent, and can limit TM internalization; microorganisms can adapt by modifying the ratelimiting flux to prevent both TM deficiency and toxicity.

Therefore, by considering all of these physical, chemical and biological processes occurring near the biological interface, or within the biofilm matrix, the predictions of metal speciation and bioavailability will become more accurate. 


\subsubsection{Metal-liquid phase interaction}

Sulfide is important due to the formation of dissolved metal complexes, which are very strong and poorly soluble. It has been shown that the bioavailability of TMs in anaerobic digestion is mostly controlled by sulfide formation/dissolution (Gonzalez-Gil et al., 1999; van der Veen et al., 2007). Since metal sulfides have a very low solubility product, this results in a remarkably low free metal ion concentration, and hence they are expected to be non-bioavailable to anaerobic microorganisms (Callander \& Barford, 1983a; Callander \& Barford, 1983b; Martell \& Smith, 1989). Barber and Stuckey (2000) found that sulfide precipitation reduced TM bioavailability in the following order (most deficient first): $\mathrm{Fe}>\mathrm{Co}>\mathrm{Ni}$. However, Jansen et al. (2007) found that methanogenic activity was related to the dissolved metal concentration, and this was replenished by a rapid dissolution of freshly formed metal sulfides. Gustavsson et al. (2013a) studied the bioavailability of Co and Ni during the anaerobic digestion of sulfur-rich stillage, and found that $100 \%$ of $\mathrm{Ni}$ and $80-90 \%$ of Co was in the organic matter/sulfides fraction. However, Ni still had significant stimulatory effects, which is in agreement with the assumption that $\mathrm{Ni}$-sulfide can become a storage of and source for $\mathrm{Ni}$ as hypothesized by Jansen et al. (2007). Limitations in methanogenic activity tend to occur in the case of stabilization of the precipitates due to co-precipitation or ageing, decreasing the rate of dissolution. However, in the dynamic anaerobic environment, it is expected that less stable amorphous metal-sulfide phases will dominate, and concomitantly higher dissolution rates will occur (Jansen et al., 2007).

Other important inorganic ligands such as $\mathrm{PO}_{4}{ }^{3-}$ and $\mathrm{CO}_{3}{ }^{2-}$ are widely present in the liquid phase of anaerobic reactors, and their concentrations may vary substantially in practice (Bartacek et al., 2008a). Although the complexes of these inorganic ligands are less strong than the metal sulfide complexes, the importance of carbonate and phosphate complexes on metal bioavailability has been demonstrated in a number of studies on anaerobic media (Bartacek et al., 
2008a; Fermoso et al., 2009; Gustavsson et al., 2013a). Gustavsson et al. (2013a) found that when Co was added to anaerobic reactors treating a sulfur-rich stillage, the dissolved concentration of Co measured was much higher than what was estimated from the equilibrium constant, which may be explained by the complexation of Co with sulfide or organic ligands like SMPs as discussed by Jansen et al. (2007). The role of SMPs as a chelating agent on the bioavailability of TMs will be discussed in Section 2.8.3.1.

\subsubsection{The effects of chelating agents on trace metal bioavailability in anaerobic digestion}

The bioavailability of TMs not only relies on the total metal concentration and the environmental conditions influencing speciation as discussed above, but also on their precipitation as sulfide, carbonate, and phosphate salts; chelation/complexation with organic and inorganic ligands including those synthesized or released by microorganisms to facilitate metal uptake (siderophores), and the kinetics of precipitation and complexation reactions. In this section, the effects of both natural chelating agents i.e. soluble microbial products (SMPs), extracellular polymeric substances (EPS), yeast extract, and synthetic chelating agents i.e. nitrilotriacetic acid (NTA) and ethylenediaminetetraacetic acid (EDTA) on TM bioavailability will be discussed in detail.

\subsubsection{Soluble microbial products (SMPs)}

It is well known that bacteria excrete a range of organic compounds known as SMPs into solution due to biomass decay and substrate metabolism (normally with biomass growth) (Barker \& Stuckey, 1999). There are several factors that cause SMP production, and nutrient deficiency and metal toxicity are two of these (Barber \& Stuckey, 2000; Aquino \& Stuckey, 2003; Aquino \& Stuckey, 2004).

SMPs have chelating capacities due to the functional groups found in 
them, including carboxylates, hydroxyls, phenols, sulfhydryls (-SH), and amines (Kuo \& Parkin, 1996). These chelating groups can act as ligands, and complex most of the common metals present in wastewaters and sludges (e.g. $\mathrm{Cu}, \mathrm{Fe}, \mathrm{Ni}$, and $\mathrm{Zn}$ ). A methodology was developed by Callander and Barford (1983a) to assess each of the individual effects of precipitation, chelation, and bioavailability of TMs in anaerobic digestion. In a later study, Callander and Barford (1983b) found a significant difference between the measured soluble metal ion $\mathrm{Fe}^{2+}$ and the calculated concentration based on equilibrium and solubility product constants, suggesting that natural chelating agents such as SMPs formed in the anaerobic digester play an important role in making metal ions available to microorganisms. The complexation of metals with SMPs in anaerobic reactors such as the upflow anaerobic sludge blanket bioreactor (UASB), anaerobic baffled reactor (ABR), and hybrid anaerobic baffled reactor (HABR) have been shown to play a significant role in ensuring soluble metal bioavailability. Patidar and Tare (2008) studied the effects of sulfide toxicity on SMP production and metal bioavailability in three anaerobic reactors; a UASB, $\mathrm{ABR}$, and HABR. The results showed that with an increasing sulfide concentration in the three reactors (up to $90 \mathrm{mg} / \mathrm{L}$ as free $\mathrm{H}_{2} \mathrm{~S}$ ), the anaerobic microorganisms also increase SMP production to maintain higher soluble concentrations of TMs through complexation, and reduce the effect of sulfide toxicity. Kuo and Parkin (1996) found that $300 \mathrm{mg} / \mathrm{L}$ of SMP in an anaerobic system can chelate up to $0.75 \mathrm{mM}$ of $\mathrm{Ni}$.

The affinity for complexation with SMPs is not the same for different metals. Barber and Stuckey (2000) studied the bioavailability of TMs in an anaerobic baffled reactor (ABR) and found that the affinity for complexation of the metals is in the following order: $\mathrm{Ni}>\mathrm{Co}>>\mathrm{Fe}$.

\subsubsection{Extracellular polymeric substances}

According to a definition by Pal and Paul (2008), extracellular polymeric substances (EPS) of microbial origin are a complex mixture of biopolymers 
comprising nucleic acids, polysaccharides, proteins, lipids, humic substances, uronic acids, etc. EPS formation results from bacterial secretions, shredding of cell lysates, cell surface materials and adsorption of organic constituents from the environment. Regardless of origin, EPS can be loosely bound to the cell surface, or bacteria may be embedded in the EPS. FTIR analysis confirmed the presence of ionisable functional groups such as phosphate, carboxyl, and hydroxyl/amino groups in the EPS samples from an anaerobic membrane bioreactor (AnMBR), and these are related to proton binding sites for metals (Liu et al., 2015). Metals have been reported to have a different binding capacity with EPS from anaerobic granular sludge (Artola et al., 1997; d'Abzac et al., 2010). There are a number of EPS extraction protocols that can be applied to study metal-EPS interactions. d'Abzac et al. (2010) compared four chemical and four physical extraction protocols from anaerobic granular sludges. The results showed that the chemical protocols resulted in contamination of the samples by the chemical extracting agents, which modify the binding properties of the EPS extracts. On the other hand, the composition of the physically extracted EPS samples is similar and would be preferred as less detrimental methods to investigated proton and metal binding properties. However, the physical schemes require more advanced analysis to examine unwanted macromolecules disruption that can have an effect on the metal binding properties. Recently, Bourven et al. (2015) developed a method using semi-preparative and analytical chromatographic columns that allow for separation of the EPS fraction according to its MW distribution. This separation allows researchers to study both the EPS composition as well as its metal-EPS binding capability.

\subsubsection{Yeast extract}

Gonzalez-Gil et al. (2003) found that yeast extract can increase the bioavailability of $\mathrm{Ni}$ and Co dramatically; this was due to the formation of strong organic complexes with the yeast extract, which facilitates the 
dissolution of metal sulfides. However, direct supplementation of yeast extract to full-scale anaerobic reactors may not be an economical practice (Hu et al., 2008a).

\subsubsection{Nitrilotriacetic acid and ethylenediaminetetraacetic acid}

Synthetic chelating agents such as nitrilotriacetic acid (NTA) and ethylenediaminetetraacetic acid (EDTA) are sometimes included in nutrient solutions to prevent TM precipitation (Callander \& Barford, 1983a; Grčman et al., 2001). When the concentration of these chelating agents and the stability constants of their complexation with metals are high enough, metal ion concentrations can be reduced to levels below those corresponding to the solubility products of $\mathrm{S}^{2-}, \mathrm{CO}_{3}{ }^{2-}$, and $\mathrm{PO}_{4}{ }^{3-}$ to prevent precipitation (Callander \& Barford, 1983a).

$\mathrm{Hu}$ et al. (2008a) studied the effect of NTA on the bioavailability of Ni during the methane fermentation of a sulfate-containing wastewater. They found that when the sulfide concentration doubled from 0.25 to 0.5 and $1 \mathrm{mM}$, by adding $10 \mu \mathrm{M}$ NTA methane production increased by 10,30 and $48 \%$, respectively. In addition, the sulfide and carbonate fraction of $\mathrm{Ni}$ in the biomass dropped by 58.0 and $28.8 \%$. This data showed that the NTA complexed Ni, preventing Ni from precipitating with the sulfide, promoted Ni internalization, and hence enhancing the bioavailability of Ni for methanogens. However, the effect of NTA on the bioavailability of other essential TMs such as Co, Zn, and Mn is unknown.

The role of an EDTA metal complex in metal bioavailability in anaerobic digestion is very interesting. As already discussed in Section 2.6, the effect of an EDTA metal complex on metal bioavailability depends on the reactor configuration, i.e. a batch or continuous system. In addition, the concentration of the EDTA metal complex can also have different effects on metal bioavailability. Bartacek et al. (2012) found that if injected in high amounts, the complexation of Co with EDTA $\left([\mathrm{CoEDTA}]^{2-}\right)$ resulted in lower toxicity than 
the free $\mathrm{Co}\left(\right.$ i.e. $\mathrm{CoCl}_{2}$ ) in methanogenic granular sludge, which was the same finding obtained with Ni (Bartacek et al., 2010). This phenomenon was explained by the strong binding of metals to EDTA, and this complex cannot cross bacterial cell walls (Worms et al., 2006), hence making the metals less bioavailable to microorganisms. On the other hand, in the same study, when small amounts of [CoEDTA $]^{-2}$ were injected into batch bottles it stimulated the methanogenic activity of a Co limited granular sludge by increasing the SMA value (mg COD-CH$/ \mathrm{gVSS} . \mathrm{d}$ ) by $233 \%$, whereas the SMA did not increase at all after the first $\mathrm{CoCl}_{2}$ pulse addition. Bartacek et al. (2012) suggested this was due to the fast metal transport by the complex (minutes to tens of minutes), compared to the non-complexed free species (tens of minutes up to hours). Therefore, the complexed metal species can penetrate more quickly into the whole volume of the anaerobic granule. On the other hand, the free metal species precipitate with the matrix, and hence can accumulate inside the granule to a very high concentration and can be kept in the granular sludge for a longer time.

Aquino and Stuckey (2007) studied the effects of both natural chelating agents (i.e. SMPs) and synthetic chelating agents (i.e. NTA, EDTA, and citrate) on the bioavailability and toxicity of $\mathrm{Fe}$ and $\mathrm{Cu}$ on methanogenesis. Their results showed that $1 \mathrm{mM}$ of EDTA complexed the metals, making them unavailable to methanogens, and hence reduced the methane production rate. SMPs are usually excreted to scavenge metal nutrients, and the addition of SMPs increased $\mathrm{Cu}$ bioavailability through the direct uptake of $\mathrm{Cu}$-SMPs complexes. $\mathrm{Cu}$ toxicity was reduced by adding stoichiometric amounts of NTA to complex it, making most of the $\mathrm{Cu}$ soluble. 


\subsection{Techniques to investigate metal speciation and bioavailability in anaerobic digestion}

\subsubsection{Sequential extraction schemes}

The need to understand metal distribution (speciation) in order to predict the mobility and bioavailability of trace metals (TMs) during anaerobic digestion has led to the development of a large number of experimental schemes designed to fractionate metals into specific forms (Lester et al., 1983). Based on the metal fractionation, the mobility of TMs can be evaluated and then combined with information on the activity of anaerobic microorganisms to determine the bioavailability of TMs. Single and sequential extraction schemes have been developed and broadly implemented to determine which chemical forms the TMs are present in and, indirectly, of their potential bioavailability. However, these schemes have been criticized due to the following issues; time consuming; lack of uniformity in the procedure; lack of selectivity of extracting reagents; lack of quality control, and; the significant influence of operational parameters such as temperature, $\mathrm{pH}$, extracting time, reagent concentration, stirring system, the ratio of solid mass to volume of extractants; and so on (Förstner, 1993; Hursthouse, 2001; Gleyzes et al., 2002; Hsu et al., 2015).

Filgueiras et al. (2002) provided a very comprehensive review on different sequential extraction schemes used to fractionate metals in different environmental samples, e.g. soil, sediment, sewage sludge, and fly ash. The main differences between them were the extractant reagents, extraction conditions, and number of fractions. Given the wide range of schemes used, The Commission of the European Communities Bureau of Reference (known as BCR), now the Standards, Measurement and Testing Programme, began a programme in 1987 in an attempt to harmonize the methodology used in different schemes (Ure et al., 1993). The BCR scheme extracts metals into three fractions, i.e. exchangeable, Fe and Mn oxides, and organic matter and sulfides. The modified BCR scheme (Sahuquillo et al., 1999) has been shown to extract 
the Fe-based components of the reducible fraction (Mossop \& Davidson, 2003). The original and modified BCR has been used to fractionate metals in anaerobic sludge in many studies (Quevauviller et al., 1994; Rauret et al., 2000; Virkutyte et al., 2005; Alonso et al., 2006; Fuentes et al., 2008; Dąbrowska \& Rosińska, 2012).

The Tessier scheme (Tessier et al., 1979) is one of the most widely applied schemes, and the original and modified Tessier scheme (Osuna et al., 2004) has been applied to sewage sludge (Legret, 1993; Perez Cid et al., 2002; Lasheen \& Ammar, 2009; Dong et al., 2013) and anaerobic granular sludge (Osuna et al., 2004; van Hullebusch et al., 2005a). The Tessier scheme partitions metals into three fractions i.e. exchangeable, carbonates, and organic matter. The main difference between the BCR and Tessier schemes is the first fraction; the metal content extracted from the acid soluble fraction in the BCR scheme should be equivalent to the sum of metal contents extracted from the acid soluble and exchangeable fractions in the Tessier scheme.

The third popular scheme was developed by Stover et al. (1976), and fractionates metals into five different fractions i.e. soluble/exchangeable, adsorbed, organically bound, carbonate, and sulfide fractions. This scheme was then modified by Lake et al. (1985) and used in many studies on metal extraction for anaerobic sludges (Rudd et al., 1988; Carliell \& Wheatley, 1997; Carliell Marquet, 2002; Aquino \& Stuckey, 2007; Hu et al., 2008a).

For comparison, van Hullebusch et al. (2005b) applied these three popular schemes to determine the fractionation of $\mathrm{Ni}, \mathrm{Co}, \mathrm{Cu}, \mathrm{Mn}, \mathrm{Fe}$, and $\mathrm{Zn}$ in anaerobic granular sludge from UASB reactors. The results showed that the modified Tessier scheme seemed to be the most applicable scheme to determine the metal fractionation in anaerobic granular sludge. Although the BCR scheme gave similar trends and good reproducibility, it seemed to be limited to anaerobic matrixes as the extraction step for the reducible fraction can leak the TMs out to the organic/sulfides fraction, and hence may overestimate the recovery of the oxide fraction. In addition, Fe and Mn oxides are not commonly 
found in anaerobic sludge (van der Veen et al., 2007). However, van der Veen et al. (2007) found that the oxidizable or so-called organic/sulfide fraction of the modified Tessier scheme does not represent metal sulfides well as a significant amount of Fe was extracted in the residual fraction with unknown composition, although there was an excessive amount of sulfide in the sludge. Shakeri Yekta et al. (2012) suggested that the organic/sulfide extraction step dissolved $\mathrm{FeS}$ as $24-27 \%$ of Fe remained unextracted but it was dissolved by the acid volatile sulfide (AVS) extraction step. The transformation of Fe from a sulfide mineral was likely due to the formation of a secondary phase of Fe i.e. jarosite. This change in $\mathrm{Fe}$ and $\mathrm{S}$ speciation might lead to inaccurate results for the speciation of other TMs i.e. Co and $\mathrm{Ni}$, known to associate with this $\mathrm{Fe}$ phase. Because of the higher number of extraction steps, the Stover scheme gave a poorer total recovery, especially the sulfur from the sulfide fraction compared to the Tessier and BCR schemes (van Hullebusch et al., 2005b). The reagents used in this scheme were not absolutely selective for a single form; EDTA extracted more than $90 \%$ of the precipitates of $\mathrm{Cu}, \mathrm{Pb}$, and $\mathrm{Zn}$ carbonates, but only $68 \%$ of the Cd carbonate (Lester et al., 1983). Furthermore, this scheme was also found to lack in selectivity for $\mathrm{Ni}$, and hence was not sensitive enough to detect small changes in metal speciation that might be significant with respect to digester performance (Carliell Marquet, 2002).

Other less popular schemes include the Sposito procedure (Sposito et al., 1982) used by (McGrath and Cegarra (1992); Pichtel and Anderson (1997); Amir et al. (2005)), and the scheme developed by Qiao and Ho (1997) used by (Hsu and Lo (2001); Song and Greenway (2004); Nomeda et al. (2008)).

All of the above schemes were carried out in a batch procedure, but (Wisotzky and Cremer (2003a); Wisotzky and Cremer (2003b)) developed a sequential extraction method in columns, which reduces the extraction time, guarantees anaerobic conditions and improves the precision of the extraction procedure. Sample preparation for all sequential extraction schemes is very similar; the sludge sample is centrifuged and the pellets are dried in aluminum 
pans at $105^{\circ} \mathrm{C}$ for at least $24 \mathrm{~h}$ (van der Veen et al., 2007; Ortner et al., 2014) and then stored in a desiccator at room temperature. Dried samples are ground in a porcelain mortar and then sieved through a stainless steel sieve with a nominal size of $0.4 \mathrm{~mm}$. The powder samples are then stored in polyethylene bags in a desiccator until use in subsequent extraction steps. However, pretreatment by oven drying and milling is not recommended due to the time required, and an artificial shifting in metal speciation towards insoluble fractions (Rudd et al., 1988; Ortner et al., 2014).

For the determination of total metal content in sludge and residual fraction after the sequential extraction procedure, acid digestion is the most common method applied to digest the sample. The popular procedures for acid digestion include: total digestion with concentrated nitric acid (65\%) e.g. EPA 3051 procedure $\left(5 \mathrm{ml} \mathrm{HNO}_{3}\right.$ for 0.5 gTSS) (EPA, 1994) used by Liu and Sun (2013); concentrated nitric acid (65\%) combined with concentrated hydrogen chloride (37\%) e.g. aqua regia procedure $\left(7.5 \mathrm{~mL} \mathrm{HCl}: 2.5 \mathrm{~mL} \mathrm{HNO}_{3}\right.$ for 0.5 gTSS) developed in an European Standard (Standard, 2000) and used by (Virkutyte et al. (2005); Long et al. (2009); Bartacek et al. (2012); Dąbrowska and Rosińska (2012)); and nitric acid combined with hydrogen chloride and hydrogen fluoride ( $5 \mathrm{~mL} \mathrm{HNO}_{3}: 4 \mathrm{~mL} \mathrm{HCl}: 1 \mathrm{~mL} \mathrm{HF}$ for $0.5 \mathrm{gTSS}$ ) (Alonso et al., 2006). However, HF is less common as it is hazardous and can degrade glassware and adulterate analytical results. The aqua regia procedure was found to be very effective compared to the EPA method 3051, especially for metals deposited in a silicate matrix (e.g. Ni, Cr, Pb) (Florian et al., 1998). The aqua regia procedure has been applied in the most popular sequential extraction schemes (e.g. BCR, Tessier, and Stover) to determine the total metal content and residual fraction.

Most of the current studies use a microwave-assisted acid digestion technique to determine the metal content in sediments, sludges, and soils (Mossop \& Davidson, 2003; van Hullebusch et al., 2005b). The use of closed pressurized vessels together with microwave heating under temperature 
programming allows for a very short decomposition time for different matrices, and an increase in accuracy (Florian et al., 1998).

Autoclave digestion is another technique developed for Nordic countries and validated in the European project 'Horizontal' on the basis of Nordic standards for the digestion of sludge and sediment samples. The Swedish Standard Method (SS-028311) also extracts metals from the sludge with $7 \mathrm{M}$ $\mathrm{HNO}_{3}$ in an autoclave (at $120^{\circ} \mathrm{C}$ for $30 \mathrm{~min}$ ). This method has been used in several studies on metal speciation in anaerobic reactors (Shakeri Yekta et al., 2012; Gustavsson et al., 2013b). Other less common techniques used to digest soil and sludge samples include a digestion block with a mixture of $\mathrm{HCl}$ and $\mathrm{HNO}_{3}\left(8 \mathrm{~mL}: 2 \mathrm{~mL}\right.$ ) for $0.5 \mathrm{~g}$ sample for $1 \mathrm{~h}$ at $105^{\circ} \mathrm{C}$ (McGrath \& Cunliffe, 1985), and in a water bath with a mixture of $\mathrm{HNO}_{3}, \mathrm{HF}, \mathrm{HClO}_{4}, \mathrm{HCl}$ in $(4: 1: 1: 1)$ ratio, respectively, for $3 \mathrm{~h}$ (Lasheen \& Ammar, 2009).

After digestion the sample is filtered, made up to an appropriate volume with deionized water, and measured by atomic absorption spectrometry (AAS), flame or inductively coupled plasma-atomic emission spectrometry (ICP-AES), or inductively coupled plasma-mass spectrometry (ICP-MS), or microwave plasma atomic emission spectrometry (MP-AES).

\subsubsection{Techniques to determine free metal ion concentration}

The stimulation of TMs cannot be assessed only from the total metal content in the liquid phase, but requires the assessment of metal speciation, especially free metal concentration (Bartacek et al., 2008a). However, this approach is only valid when the equilibrium state is established and the physical-chemical processes (precipitation, sorption, chemical speciation, etc) are faster than the parallel biological processes (metal uptake and methane production) (Bartacek et al., 2010). To measure the amount of 'free' metal ion in aqueous solutions, there are a number of available techniques. The Wageningen Donnan Membrane Technique (WDMT) was developed by Temminghoff et al. (2000) in order to study Co speciation in anaerobic granular sludge. One 
drawback of this technique is the long data acquisition time ( $4 \mathrm{~d}$ to establish equilibrium, $5 \mathrm{~d}$ for WDMT measurement) (Bartacek et al., 2008b).

Diffusive gradients in thin film (DGT) and diffusional equilibrium in thin film (DET) are among the most promising in situ techniques for measuring aqueous metal species for bioavailability assessment purposes (Meylan et al., 2004; van der Veeken et al., 2008; Yezek et al., 2008; Liu et al., 2013; Chen et al., 2014a). They are capable of measuring labile species of metals, such as free metal ions, inorganic complexes, and a small portion of organic complexes ( $\mathrm{Li}$ et al., 2005; Ren et al., 2015). However, similar to ISE, the use of DGT/DET in wastewater has been rare (Buzier et al., 2006).

\subsubsection{Techniques to determine sulfur speciation}

It has been shown that the TM speciation and bioavailability in anaerobic digestion processes strongly depends on the chemistry of sulfur (S) (Jansen et al., 2007; van der Veen et al., 2007; Fermoso et al., 2009), and there are a number of analytical techniques to determine changes in S speciation. Sulfur Kedge X-ray absorption near-edge spectroscopy (XANES) is an effective tool to identify and quantify many different $S$ compounds, their binding forms, and oxidation states in a sample, which are useful to determine the fate of S species in anaerobic digestion (Shakeri Yekta et al., 2012).

Acid volatile sulfide (AVS) analysis is a classic technique to measure the sulfide fraction reactive metals in anoxic samples, based on volatilization of the reduced S bound in mineral fractions, mainly FeS (Jong \& Parry, 2004; van der Veen et al., 2007); $1 \mathrm{M} \mathrm{HCl}$ is used as the extracting reagent. Rickard and Morse (2005) carried out a comprehensive review of AVS extraction which discussed the following drawbacks of the AVS-SEM technique: (1) very different dissolved and solid sulfide components may be making largely varying contributions to evolved $\mathrm{H}_{2} \mathrm{~S}$, and (2) minor variations in the extraction method for AVS can result in different results for the same samples. 


\subsubsection{Chromatographic and spectroscopic techniques}

Chromatographic techniques such as Ion Chromatography - Conductivity Detector (IC-CD), Gas Chromatography - Flame Ionization Detector (GC-FID) and spectroscopic techniques such as X-ray Diffraction Spectroscopy (XRD), Fourier Transform Infrared Spectroscopy (FTIR), and X-ray absorption near edge structure (XANES) spectroscopy have also been used to study the speciation of metals in anaerobic sludge (Lenz et al., 2006a; Zhu et al., 2014).

\subsubsection{Chemical equilibrium modelling}

Chemical equilibrium models have been developed to predict metal speciation, and hence metal bioavailability in environmental systems, although the environmental systems are always dynamic and rarely at equilibrium (Worms et al., 2006). The geochemical equilibrium models such as Visual MINTEQ, Visual MINTEQA2 and PHREEQC have the capability to predict metal speciation by estimating precipitation, equilibrium aqueous speciation and dissolution of minerals, adsorption, complexation, solid phase saturation states, etc at thermodynamic equilibrium (Virkutyte et al., 2005; Bartacek et al., 2008a; Ortner et al., 2014). By comparing the predictions with the actual metal distribution measured experimentally, i.e. sequential extraction, it is possible to observe the changes in metal speciation caused by the biomass and natural and microbial chelators, hence, the mechanisms by which biomass take up essential metals could be deduced (Aquino \& Stuckey, 2007).

\subsection{Summary of literature review}

- Reactor configuration is considered as a key design criterion that determines the retention capacity of trace metals in a bioreactor. Most of the studies on trace metal speciation and bioavailability in the literature were carried out for anaerobic digesters. Anaerobic membrane bioreactors (AnMBRs) are becoming very popular due to their complete biomass retention, high efficiencies of COD removal, and separation of HRT and 
SRT. However, there is little research available on the fate of trace metals in the AnMBRs;

- $\mathrm{Fe}^{2+}$ is often dosed to reduce the sulfide level in anaerobic digesters, however, the bioavailability of metal sulfides is still debated in the literature. Furthermore, there has been no research on the effect sulfide has on the bioavailability of $\mathrm{Fe}^{2+}$ in a continuous system like an AnMBR;

- Conventional chelating agents such as EDTA and NTA have shown to be able to improve the bioavailability of trace metals in the presence of sulfide, but they have very low biodegradability. To date, a very limited number of studies have been carried out to determine if biodegradable chelating agents such as EDDS can be alternatives;

- Chelating agents have been dosed to anaerobic reactors either as a metal complex or simultaneously with the trace metals, but which dosing strategy is more suitable depends on not only the added concentrations of both chelating agents and the metals, but also the reactor configuration. So far, there has no quantitative analytical technique available to determine the speciation of the chelating agents i.e. EDDS in anaerobic systems in order to evaluate the effectiveness of their dosing strategy;

- Many studies in the literature have shown the effects of the increase in organic loading rate and the metal deficiency on the performance of AnMBRs. However, the significance of the accumulated trace metals in seed sludge has not been emphasized in these conditions. There is an essential need to determine what is the most effective dosing strategy for trace metals and how these metals transform over time;

- The changes in operating parameters such as pH, HRT, and SRT are also known to affect the performance of AnMBRs. There is little information available to understand their impacts on the speciation and bioavailability of trace metals and how they correlate with the reactor performance. 


\subsection{Research objectives}

Based on the literature review above, the aim of this project was to evaluate the speciation and improve the bioavailability of trace metals in a SAMBR. The specific objectives were:

- To investigate the effects of $\mathrm{Fe}^{2+}$ and its bioavailability for controlling VFAs during organic shock loads in batch reactors and a submerged anaerobic membrane bioreactor (SAMBR);

- To assess the effect of sulfide on the speciation and bioavailability of $\mathrm{Fe}^{2+}$ in a batch setup and in a SAMBR;

- To determine the dosing strategies for EDDS to improve the bioavailability of $\mathrm{Fe}^{2+}$ in the presence of sulfide in a SAMBR;

- To determine the possibility of pulse dosing of TMs to improve the performance of a SAMBR under trace metal deficiency;

- To study the effect of changes in $\mathrm{pH}$, hydraulic retention time (HRT), and solids retention time (SRT) on the speciation and bioavailability of trace metals in a SAMBR. 


\section{Chapter 3}

\section{Experimental Methodology}

\subsection{Introduction}

This chapter presents a description of the submerged anaerobic membrane bioreactor (SAMBR) system, experimental setups, followed by details of seed sludge, synthetic feed and the nutrients used for the SAMBR. It also describes the sample preparation procedures and analytical methods for the fractionation techniques employed to extract the trace metals (TMs) in the anaerobic systems studied, as well as the chromatographic analysis to quantify the chelating agent. The specific experimental procedures will be described in the following chapters.

\subsection{Set-up of Submerged Anaerobic Membrane Bioreactor system}

Figures 3.1 and 3.2 illustrate the operation and experimental set-up of the submerged anaerobic membrane bioreactor (SAMBR) system used for this study (Kunacheva et al., 2017). The SAMBR was designed by Hu and Stuckey (2006), and has been used in a number of previous studies (Akram \& Stuckey, 2008; Vyrides et al., 2010; Trzcinski et al., 2011; Zhou et al., 2016). The labscale SAMBR was made from polymethyl methacrylate (Plexiglas) and had an effective volume of $3.2 \mathrm{~L}$. A microfiltration flat sheet membrane $(222 \mathrm{~mm}$ (W) $\times 315 \mathrm{~mm}(\mathrm{~L}) \times 6 \mathrm{~mm}(\mathrm{~T}))$ as shown in Figure 3.3, was made of chlorinated polyethylene by Kubota with a surface area of $0.116 \mathrm{~m}^{2}$ and a maximum pore size of 0.4 and average of $0.2 \mu \mathrm{m}$ was used.

The reactor was divided into two different zones by a baffle which helped to direct the liquid flow upwards past the membrane, and then downwards 
through the biogas sparger. The membrane was submerged into the reactor and the reactor was placed in a water bath which maintained the temperature at $35 \pm$ $1^{\circ} \mathrm{C}$. Biogas in the headspace of the reactor was re-circulated through a stainless steel tube diffuser with four holes which generated coarse bubbles in order to mix the biomass in the reactor and scour the surface of the membrane to prevent membrane fouling. A vacuum pump (B100 SEC, Charles Austin) was used to recycle biogas from the headspace back to the diffuser, and the sparging rate was controlled by a gas flowmeter (RMA-22-SSV, Dwyer) at 4-5 L per minute (LPM).

An online data logging system was set up to continuously monitor $\mathrm{pH}$, ORP, and temperature using a pH/ORP probe (Mettler Toledo, M300) and transmembrane pressures (TMP) using a digital pressure gauge (Ashcroft). A pressure transmitter (PMP 1400, RS components) and a turbine type flowmeter (Model 101-3) were provided to transmit pressure and flow signals to a personal computer (PC). This arrangement was followed by peristaltic pumps which operated at uniform speed to provide a constant reflux through the membrane. Part of the effluent removed through the membrane was recycled back to the reactor, while the remaining liquid was discharged from the system as the effluent stream. The HRT was controlled using another pump on the effluent stream after the flux pump.

\subsection{Cultivation of anaerobic sludge for the SAMBRs}

Seed sludge for anaerobic reactors was obtained from a municipal wastewater treatment plant digesters (Ulu Pandan Water Reclamation Plant, Singapore), and cultivated in 5L continuously mixed laboratory batch reactors for more than 3 months. The seed reactors were fed once a week in fill-anddraw mode ( $7 \mathrm{~d}$ HRT), and the feed was based on that used by Ketheesan et al. (2016), consisted of glucose (333 $\mathrm{mgCOD} / \mathrm{L})$, peptone (99 $\mathrm{mgCOD} / \mathrm{L})$, meat extract (33 mgCOD/L), sodium bicarbonate $(812.5 \mathrm{mg} / \mathrm{L}), \mathrm{K}_{2} \mathrm{HPO}_{4}(10 \mathrm{mg} / \mathrm{L})$, and essential metal nutrients including $\mathrm{CoCl}_{2} \cdot 6 \mathrm{H}_{2} \mathrm{O}(0.29 \mathrm{mg} / \mathrm{L}), \mathrm{FeCl}_{2} \cdot 4 \mathrm{H}_{2} \mathrm{O}$ 
(1.96 mg/L), $\mathrm{MnCl}_{2} .4 \mathrm{H}_{2} \mathrm{O}(0.09 \mathrm{mg} / \mathrm{L}), \mathrm{Na}_{2} \mathrm{MoO}_{4} .2 \mathrm{H}_{2} \mathrm{O}(0.04 \mathrm{mg} / \mathrm{L})$, and $\mathrm{NiCl}_{2} .6 \mathrm{H}_{2} \mathrm{O}(0.05 \mathrm{mg} / \mathrm{L})$.

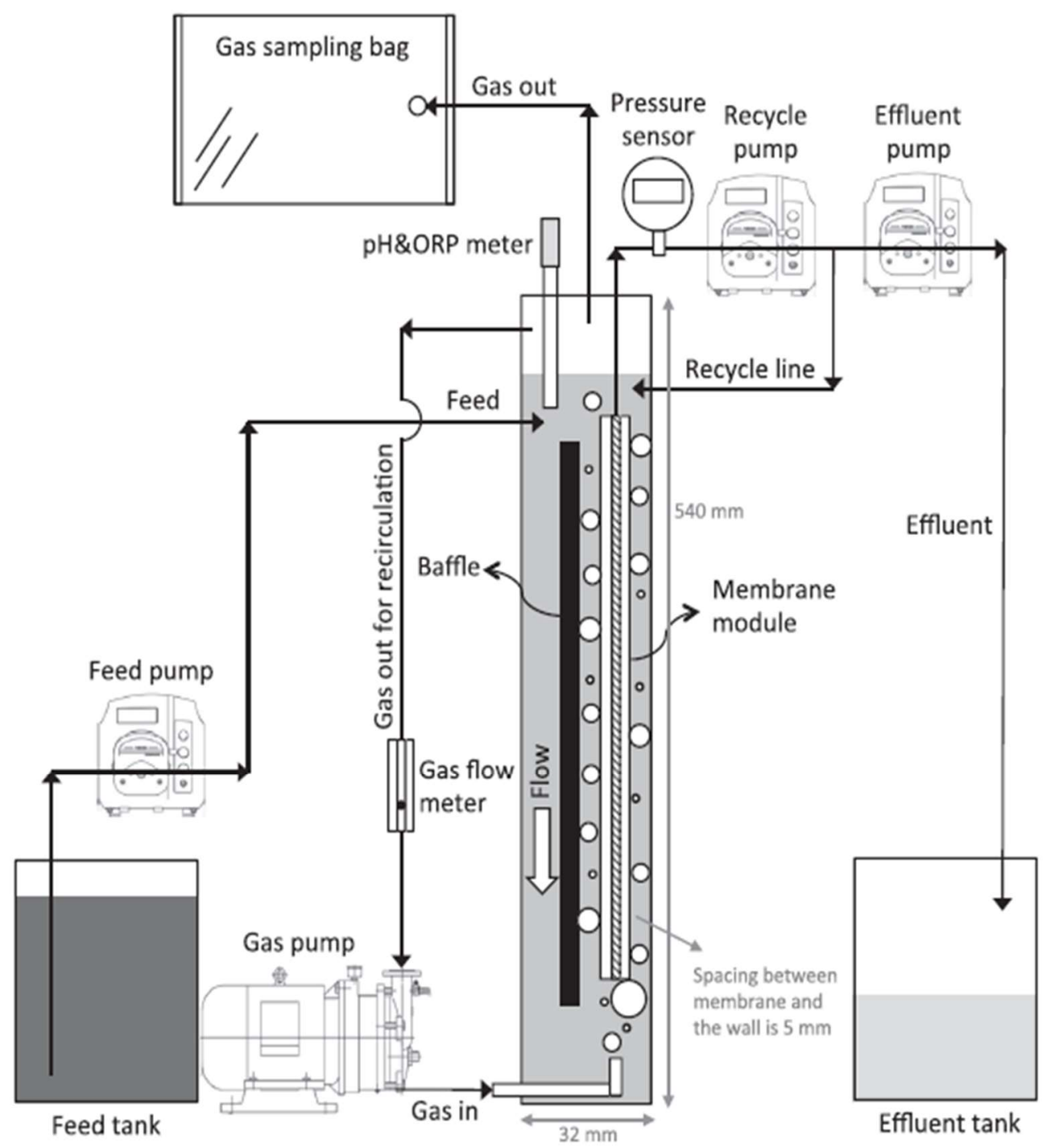

Figure 3.1 Schematic diagram of the SAMBR system (Kunacheva et al., 2017). 


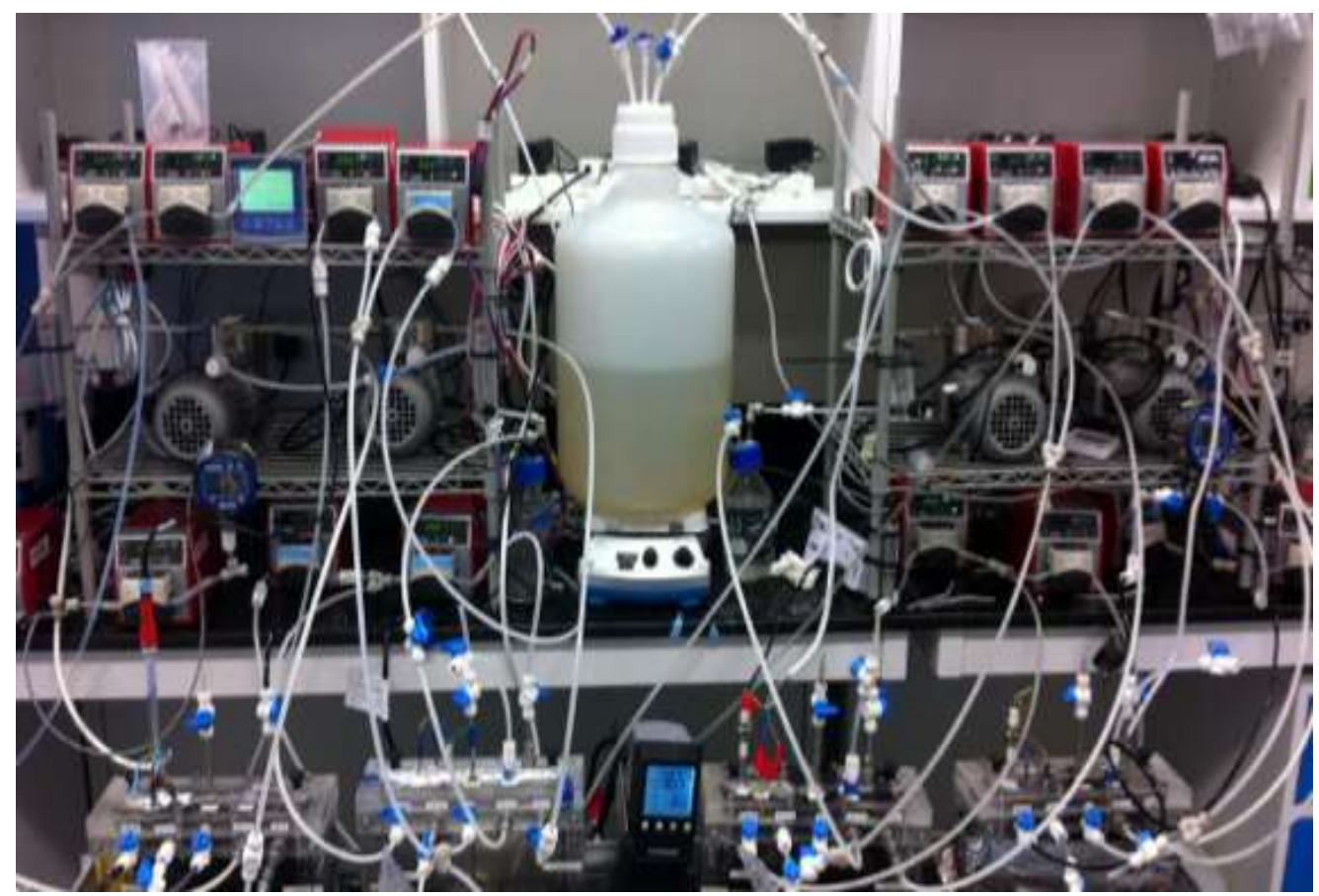

Figure 3.2 Experimental setup of the SAMBR system used in this study.

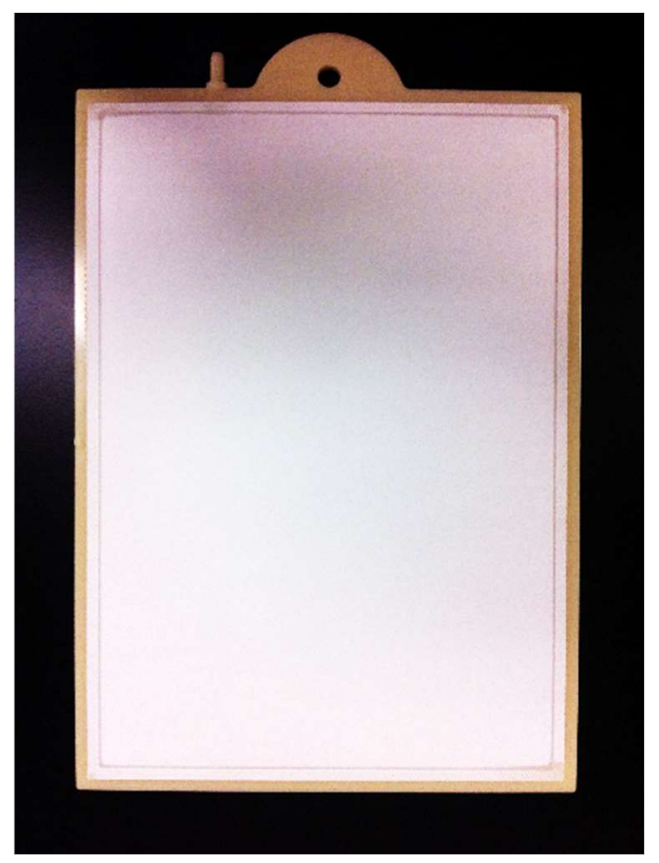

Figure 3.3 The flat sheet membrane used in the SAMBRs. 


\subsection{Feed and nutrients for the SAMBRs}

A carbohydrate-protein substrate was supplemented with metal nutrients to serve as the synthetic wastewater. The SAMBRs wastewater was maintained at approximately $500 \pm 20 \mathrm{mgCOD} / \mathrm{L}$, and was based on that used by Akram and Stuckey (2008). The composition of the feed media is as shown in Table 3.1. Feed was prepared by adding peptone, meat extract, $\mathrm{K}_{2} \mathrm{HPO}_{4}, \mathrm{NaHCO}_{3}$ and nutrients to tap water, and autoclaving at $121^{\circ} \mathrm{C}$ for $30 \mathrm{~min}$. They were mixed together after cooling to room temperature, before connecting the feed bottle to the pumps. Eight times concentrated feed was prepared to avoid daily preparation which was laborious and time consuming. The feed was diluted 80 times by adding tap water before entering the reactor.

Table 3.1 Composition of concentrated feed for SAMBR experiments (40

$$
\mathrm{gCOD} / \mathrm{L}) \text {. }
$$

\begin{tabular}{cccc}
\hline $\begin{array}{c}\text { Carbon source and macro-nutrients } \\
(\mathbf{g} / \mathbf{L})\end{array}$ & \multicolumn{2}{c}{ Metal nutrients $\mathbf{( g / \mathbf { L } )}$} \\
\hline Glucose & 26.70 & $\mathrm{FeCl}_{2} .4 \mathrm{H}_{2} \mathrm{O}$ & 0.157 \\
\hline Peptone & 7.99 & $\mathrm{CoCl}_{2} .6 \mathrm{H}_{2} \mathrm{O}$ & 0.0238 \\
\hline Meat extract & 2.68 & $\mathrm{NiCl}_{2} .6 \mathrm{H}_{2} \mathrm{O}$ & 0.0045 \\
\hline $\mathrm{K}_{2} \mathrm{HPO}_{4}$ & 0.80 & $\mathrm{MnCl}_{2} .4 \mathrm{H}_{2} \mathrm{O}$ & 0.0075 \\
\hline $\mathrm{NaHCO}_{3}$ & 65 & $\mathrm{Na}_{2} \mathrm{MoO}_{4} .2 \mathrm{H}_{2} \mathrm{O}$ & 0.00375 \\
\hline & & $\mathrm{ZnCl}_{2}$ & 0.0031
\end{tabular}

\subsection{Analytical techniques}

\subsubsection{General sample preparation}

A large quantity of samples was generated over the various periods of reactor operation, and a wide variety of parameters were measured. 
Consequently, the data presented at any point was obtained from a replicate analysis of each liquid sample. The definition of soluble for this study was any material passing through $0.45 \mu \mathrm{m}$ filters, hence prior to any analysis all samples were first centrifuged and then filtered to remove any suspended solids and ensure a clear supernatant, to facilitate accurate analysis. Most samples were centrifuged at 12,000 rpm (model $5810 \mathrm{R}$, Eppendorf) for $10 \mathrm{~min}$ and filtered through disposable $0.45 \mu \mathrm{m}$ syringe filters (Membrane Solutions) except the samples for VFAs and EDDS measurement which were filtered through disposable $0.2 \mu \mathrm{m}$ syringe filters (PALL, Acrodisc $($ )). When larger volumes of sample (i.e. $>100 \mathrm{~mL}$ ) were handled a bigger centrifuge was used, and in this case samples were centrifuged at $4000 \mathrm{rpm}$ (model $5810 \mathrm{R}$, Eppendorf) for 20 min, and then filtered through $0.45 \mu \mathrm{m}$ glass fiber filter paper (Advantec) using a vacuum apparatus.

\subsection{2 pH}

$\mathrm{pH}$ was measured offline using a $\mathrm{pH}$ meter (Mettler Toledo, M300), and online in the SAMBRs using a $\mathrm{pH}$ probe (Mettler Toledo, M300) calibrated with buffer solutions of $\mathrm{pH} 7$ and $\mathrm{pH} 4$. Values obtained for $\mathrm{pH}$ were accurate to within \pm 0.02 .

\subsubsection{Chemical Oxygen Demand (COD)}

The measurement of COD was based on the 'closed reflux, colorimetric method', described in section 5220-D of APHA (1992), which requires the preparation of digestion solution and sulphuric acid reagent. Digestion solution for high range COD was first prepared by adding $10.216 \mathrm{~g}$ of $\mathrm{K}_{2} \mathrm{Cr}_{2} \mathrm{O}_{7}$, previously dried at $103^{\circ} \mathrm{C}, 167 \mathrm{~mL}$ of concentrated $\mathrm{H}_{2} \mathrm{SO}_{4}$ and $33.3 \mathrm{~g}$ of $\mathrm{HgSO}_{4}$ to $500 \mathrm{~mL}$ of distilled water. The mixture was then left to cool to room temperature before diluting to $1000 \mathrm{~mL}$. The digestion solution for low range COD was prepared the same as for high range but only used $1.022 \mathrm{~g}$ of 
$\mathrm{K}_{2} \mathrm{Cr}_{2} \mathrm{O}_{7}$. The sulphuric acid reagent was prepared by adding $\mathrm{Ag}_{2} \mathrm{SO}_{4}$ technical grade powder to concentrated $\mathrm{H}_{2} \mathrm{SO}_{4}$ at the rate of $5.5 \mathrm{~g} \mathrm{Ag}_{2} \mathrm{SO}_{4} / \mathrm{kg} \mathrm{H}_{2} \mathrm{SO}_{4}$.

The COD protocol consisted of adding, in this order, $2.5 \mathrm{~mL}$ of sample/diluted sample, $1.5 \mathrm{~mL}$ of digestion solution and $3.5 \mathrm{~mL}$ of sulphuric acid reagent into COD tubes. The tubes were tightly sealed and mixed properly. The mixtures were then refluxed in a COD reflux reactor (Model ECO 16, VELP Scientifica) at $150^{\circ} \mathrm{C}$ for $2 \mathrm{~h}$. After cooling the samples were analyzed on a Shimadzu UV/Vis scanning spectrophotometer (UV-2600) (triplicate) at a wavelength of $600 \mathrm{~nm}$ for high range COD and $420 \mathrm{~nm}$ for low range COD. Potassium hydrogen phthalate (KHP) was used to prepare standard solutions in the range $10-1000 \mathrm{mg} / \mathrm{L}$. The detection limit was $5 \mathrm{mg} / \mathrm{L}$ and the standard deviation based on triplicates was within $\pm 5 \%$.

\subsubsection{Total and volatile suspended solids (TSS/VSS)}

TSS and VSS were used to estimate the biomass concentration in the anaerobic systems. A $5 \mathrm{~mL}$ sample (triplicate) was added to a pre-weighed foil tray and left overnight in an oven pre-set at $105^{\circ} \mathrm{C}$ (Memmert, Model UM500) to allow for the evaporation of water. The dried sample was left to cool in a desiccator after which the resulting weight was recorded to calculate the TSS value. The tray was then placed in a furnace (Model P330, Nabertherm) at $550^{\circ} \mathrm{C}$ for $1 \mathrm{~h}$ to allow for the combustion and evaporation of the organic fraction. After cooling in a desiccator the final weight of the tray was recorded, and a calculation to determine the VSS was then performed as given in Standard Methods (APHA, 1992). The coefficient of variance for 5 identical samples was within $\pm 5 \%$.

\subsubsection{Volatile Fatty Acids (VFAs)}

VFAs (C1-C5) were determined using a Shimadzu Prominence ultra-fast liquid chromatography (UFLC, SPD-20AD) with a UV diode array detector $(\mathrm{DAD}, \mathrm{SPD}-\mathrm{M} 20 \mathrm{~A})$ at $210 \mathrm{~nm}$ using an Aminex ${ }^{\circledR} \mathrm{HPX}-87 \mathrm{H}(300 \times 7.8 \mathrm{~mm})$ 
column. Analysis time was $25 \mathrm{~min}$ for each sample operating under isocratic and isothermal conditions with a sample volume of $20 \mu \mathrm{L}$ (triplicate); the column was maintained at $55^{\circ} \mathrm{C}$, and the eluent was $0.005 \mathrm{M} \mathrm{H}_{2} \mathrm{SO}_{4}$ at a flow rate of $0.8 \mathrm{~mL} / \mathrm{min}$. Before analysis samples were centrifuged at $12000 \mathrm{rpm}$ for $20 \mathrm{~min}$ and filtered through $0.2 \mu \mathrm{m}$ filters.

A total of seven VFAs including formic acid, acetic acid, propionic acid, butyric acid, and valeric acid were quantified with this method. The detection limit was $3 \mathrm{mg} / \mathrm{L}$, and the coefficient of variance (COV $=\mathrm{SD} /$ average value) of ten identical samples was within $\pm 2 \%$.

\subsubsection{Biogas production and composition}

Biogas volume from the SAMBRs was measured with a gas-sampling bag using a gas pump with a flow meter, while biogas volume for the serum bottles was measured using calibrated wetted glass syringes. The composition of biogas (methane, oxygen, nitrogen, and carbon dioxide) and gas phase hydrogen (triplicate for the batch bottles) was determined using a Shimadzu GC-TCD (2010 Plus) fitted with an Agilent J\&W Column $(60 \mathrm{~m} \times 0.53 \mathrm{~mm} \times$ $30 \mu \mathrm{m})$ and VICI Valcoplot column $(15 \mathrm{~m} \times 0.53 \mathrm{~mm} \times 20 \mu \mathrm{m})$. The carrier gas was Helium set at a flow rate of $156 \mathrm{~mL} / \mathrm{min}$, column temperature was $35^{\circ} \mathrm{C}$, detector temperature was $100^{\circ} \mathrm{C}$, and injector temperature was $40^{\circ} \mathrm{C}$. The coefficient of variance $(\mathrm{CV})$ for biogas composition of ten identical samples was within $\pm 3 \%$. The methane yields from the batch and SAMBR experiment were defined as the volume of methane $\left(\mathrm{mLCH}_{4}\right)$ produced by unit mass of active biomass (gVSS) per unit time (d) i.e. $\mathrm{mLCH}_{4} / \mathrm{gVSS} . \mathrm{d}$, which has often been used on anaerobic digestion to determine the activity of anaerobic bacteria (Cho et al., 2005; Souto et al., 2010; Hussain \& Dubey, 2015).

\subsubsection{Biochemical Methane Potential (BMP) analysis}

The bioassay analysis was conducted in serum bottles using the technique developed by Owen et al. (1979), with the composition of the biomedia being 
given in Table 3.2. Seed sludge was transferred to $50 \mathrm{~mL}$ tubes and centrifuged at $4000 \mathrm{rpm}$ for $20 \mathrm{~min}$ at $4^{\circ} \mathrm{C}$ and the supernatant discarded. Biomedia was added to each centrifuge tube to mix with the solid pellets. The contents of the tubes were then transferred into serum bottles under anaerobic conditions while continuously flushing the bottles with nitrogen at a flow rate of approximately $0.5 \mathrm{~L} / \mathrm{min}$. Concentrated substrate and buffer $\left(\mathrm{NaHCO}_{3}\right)$ was then added to each serum bottle before capping it with leak proof Teflon seals. All serum bottles were equilibrated at $35^{\circ} \mathrm{C}$, and zeroed $15 \mathrm{~min}$ after substrate addition.

Methanogenic activity $\left(\mathrm{mLCH}_{4} / \mathrm{gVSS} . \mathrm{d}\right)$ was detected by measuring the composition and amount of biogas produced over time in bottles using GCTCD and calibrated wetted glass syringes, as described in Section 3.5.6. Triplicate samples were carried out for each set of experiments, and the COV in this case was $\pm 3 \%$.

Table 3.2 Chemical composition of biomedia used in BMP bottles (Owen et al., 1979).

\begin{tabular}{|c|c|c|c|c|c|}
\hline & $\begin{array}{l}\text { Volume } \\
\text { of stock } \\
\text { solution }\end{array}$ & $\begin{array}{c}\text { Amount of } \\
\text { stock solution } \\
\text { for } 1.8 \mathrm{~L} \\
\text { biomedia }\end{array}$ & Compounds & $\begin{array}{l}\text { Conc. in stock } \\
\text { solution }(\mathrm{g} / \mathrm{L})\end{array}$ & $\begin{array}{c}\text { Final conc. } \\
\text { in medium } \\
(\mathrm{mg} / \mathrm{L})\end{array}$ \\
\hline S1 & $100 \mathrm{~mL}$ & $1.8 \mathrm{~mL}$ & Resazurin & 1.0 & 1.0 \\
\hline S2 & $100 \mathrm{~mL}$ & $5.4 \mathrm{~mL}$ & $\left(\mathrm{NH}_{4}\right)_{2} \mathrm{HPO}_{4}$ & 26.7 & 80.1 \\
\hline \multirow[t]{7}{*}{ S3 } & $1000 \mathrm{~mL}$ & $27 \mathrm{~mL}$ & Trace Elements solution: & & \\
\hline & & & $\mathrm{CaCl}_{2} \cdot 2 \mathrm{H}_{2} \mathrm{O}$ & 16.7 & 250.5 \\
\hline & & & $\mathrm{NH}_{4} \mathrm{Cl}$ & 26.6 & 399 \\
\hline & & & $\mathrm{MgCl}_{2} \cdot 6 \mathrm{H}_{2} \mathrm{O}$ & 120 & 1800 \\
\hline & & & $\mathrm{KCl}$ & 86.7 & 1300 \\
\hline & & & $\mathrm{MnCl}_{2} \cdot 4 \mathrm{H}_{2} \mathrm{O}$ & 1.33 & 19.95 \\
\hline & & & $\mathrm{CoCl}_{2} \cdot 6 \mathrm{H}_{2} \mathrm{O}$ & 2 & 30 \\
\hline
\end{tabular}




\begin{tabular}{|c|c|c|c|c|c|}
\hline & & & $\mathrm{H}_{3} \mathrm{BO}_{3}$ & 0.38 & 5.7 \\
\hline & & & $\mathrm{CuCl}_{2} \cdot 2 \mathrm{H}_{2} \mathrm{O}$ & 0.18 & 2.7 \\
\hline & & & $\mathrm{Na}_{2} \mathrm{MoO}_{4}$ & 0.17 & 2.55 \\
\hline & & & $\mathrm{ZnCl}_{2}$ & 0.14 & 2.1 \\
\hline S4 & $50 \mathrm{~mL}$ & $1.8 \mathrm{~mL}$ & $\mathrm{FeCl}_{2} \cdot 4 \mathrm{H}_{2} \mathrm{O}$ & 370 & 370 \\
\hline S5 & $50 \mathrm{~mL}$ & $1.8 \mathrm{~mL}$ & $\mathrm{Na}_{2} \mathrm{~S} \cdot 9 \mathrm{H}_{2} \mathrm{O}$ & 500 & 500 \\
\hline \multirow[t]{11}{*}{ S6 } & $1000 \mathrm{~mL}$ & $18 \mathrm{~mL}$ & Vitamin Solution: & & \\
\hline & & & Biotin (vitamin $\mathrm{H}$ ) & 0.002 & 0.02 \\
\hline & & & Folic acid (dihydrate) & 0.002 & 0.02 \\
\hline & & & $\begin{array}{c}\text { Pyridoxine hydrochloride } \\
\text { (vitaminB6) }\end{array}$ & 0.01 & 0.1 \\
\hline & & & Riboflavine (vitamin B2) & 0.005 & 0.05 \\
\hline & & & Thiamine (vitamin B1) & 0.005 & 0.05 \\
\hline & & & Nicotinic acid & 0.005 & 0.05 \\
\hline & & & Pantothenic acid & 0.005 & 0.05 \\
\hline & & & $\begin{array}{c}\text { Cyanocobalamine } \\
\text { (vitamin B12) }\end{array}$ & 0.0001 & 0.001 \\
\hline & & & p-aminobenzoic acid & 0.005 & 0.05 \\
\hline & & & lipoic acid (thioctic acid) & 0.005 & 0.05 \\
\hline S7 & & & $\mathrm{NaHCO}_{3}$ & & 4667 \\
\hline
\end{tabular}

\subsubsection{Metal extraction}

The BCR sequential extraction procedure proposed by Ure et al. (1993), and then modified by Sahuquillo et al. (1999), was used to determine metal speciation; a description of the BCR procedure is given in Table 3.3. The extraction used $\mathrm{CH}_{3} \mathrm{COOH}, \mathrm{NH}_{2} \mathrm{OH}-\mathrm{HCl}, \mathrm{H}_{2} \mathrm{O}_{2}$ and $\mathrm{CH}_{3} \mathrm{COONH}_{4}$ to sequentially fractionate metals into three fractions: soluble/exchangeable, $\mathrm{Fe}$ and Mn oxides, organic matter and sulfide, respectively. The pseudo-total metal content in the sludge, and the residual fraction after sequential extraction, was 
obtained by digesting with aqua regia solution $\left(\mathrm{HCl}: \mathrm{HNO}_{3} \quad 3: 1 \mathrm{v} / \mathrm{v}\right)$ in a microwave digester (Anton Paar, Multiwave 300).

Table 3.3 Operating conditions required in the revised BCR sequential extraction method (van Hullebusch et al., 2005b).

\begin{tabular}{|c|c|c|c|}
\hline \multirow[t]{2}{*}{ Fraction } & \multirow[t]{2}{*}{ Extracting Agent } & \multicolumn{2}{|c|}{ Extraction conditions } \\
\hline & & Shaking time ${ }^{a}$ & Temperature \\
\hline $\begin{array}{c}\text { F1. Exchangeable }+ \\
\text { water and acid } \\
\text { soluble }\end{array}$ & $\begin{array}{c}40 \mathrm{~mL} \mathrm{CH}_{3} \mathrm{COOH}(0.11 \mathrm{M} \\
\mathrm{pH}=7)\end{array}$ & $16 \mathrm{~h}$ & $20^{\circ} \mathrm{C}$ \\
\hline $\begin{array}{l}\text { F2. Iron and } \\
\text { manganese } \\
\text { oxides }\end{array}$ & $\begin{array}{c}40 \mathrm{~mL} \mathrm{NH}_{2} \mathrm{OH}-\mathrm{HCl}(0.5 \\
\mathrm{M}, \mathrm{pH}=1.5)\end{array}$ & $16 \mathrm{~h}$ & $20^{\circ} \mathrm{C}$ \\
\hline $\begin{array}{c}\text { F3. Organic matter } \\
\text { and sulfides }\end{array}$ & $\begin{array}{c}20 \mathrm{~mL} \mathrm{H}_{2} \mathrm{O}_{2}(30 \%, \mathrm{pH}=2) \\
50 \mathrm{~mL} \mathrm{CH}_{3} \mathrm{COONH}_{4} \\
(1 \mathrm{M}, \mathrm{pH}=2)\end{array}$ & $1,2,16 \mathrm{~h}$ & $20,85,20^{\circ} \mathrm{C}$ \\
\hline F4. Residual & $\begin{array}{l}10 \mathrm{~mL} \text { demineralised } \\
\quad \text { water, } 10 \mathrm{~mL} \text { aqua } \\
\text { regia }\left(\mathrm{HCl}: \mathrm{HNO}_{3}, 3: 1\right)\end{array}$ & $26 \mathrm{~min}$ & $\begin{array}{r}\text { Microwave- } \\
\text { oven }^{\mathrm{b}}\end{array}$ \\
\hline
\end{tabular}

${ }^{\text {a }}$ Shaking was applied at $30 \mathrm{rpm}$.

${ }^{b}$ Extraction of the residual fraction in the microwave was equal to the pseudo-total extraction method.

\subsubsection{Metal analysis}

The concentrations of metals in the liquid phase were measured by using microwave plasma atomic emission spectrometry (MP-AES; AGILENT model 4200) (triplicate). The liquid fractions for metal analysis were first centrifuged at 10,000 rpm for $10 \mathrm{~min}$, and then filtered through $0.45 \mu \mathrm{m}$ disposable syringe filters (Membrane Solutions) to remove any residual solids prior to MP-AES 
analysis. The detection limit was $0.01 \mathrm{mg} / \mathrm{L}$, and the COV of ten identical samples was within $\pm 1 \%$. The metal content measured in this study was expressed as $\mu \mathrm{g}$ of metal/gTSS, which has also been used in most of studies in the literature as TSS is often used as a parameter for the study of metal sorption onto anaerobic sludge (Osuna et al., 2004; van Hullebusch et al., 2005a; van Hullebusch et al., 2006; Fermoso et al., 2010).

\subsubsection{Measurement of EDDS and Fe-EDDS complex}

The separation of EDDS and Fe-EDDS complex was carried out on a Shimadzu UHPLC system, equipped with a SPD-M20A Photo Diode Array Detector. The method developed by Narola et al (2011) to determine the disodium EDTA in meropenum drug substance was adapted and modified in this study to determine the EDDS and Fe-EDDS complex in the test reactors.

The analytical column used in this study was a Kinetex $2.6 \mu \mathrm{m} \mathrm{XB-C18}$ column $(150 \times 4.6 \mathrm{~mm})$. The mobile phase was prepared by dissolving $4.1 \mathrm{mg}$ of sodium acetate trihydrate, $0.64 \mathrm{mg}$ Tetrabutyl ammonium bromide, adjusting the $\mathrm{pH}$ to 4.0 with concentrated glacial acetic acid, and then making up the volume to $1 \mathrm{~L}$ with deionized water. The flow rate was $0.8 \mathrm{~mL} / \mathrm{min}$, and the retention time was $7.5 \mathrm{~min}$, while the column temperature was maintained at $25^{\circ} \mathrm{C}$. The detector UV wavelength was $243 \mathrm{~nm}$, and the injection volume was $20 \mu \mathrm{L}$.

Standards for EDDS were prepared from a commercial EDDS solution (Enviomet C140), which was provided by Innospec (USA). Standards for the Fe-EDDS complex were prepared by mixing EDDS with $\mathrm{Fe}^{2+}$ as $\mathrm{FeCl}_{2} .4 \mathrm{H}_{2} \mathrm{O}$ in excess overnight in the dark to prevent photo-degradation (Tandy et al., 2005). Calibrations for EDDS and Fe-EDDS complex were performed with 5 standards for each, and the $\mathrm{R}^{2}$ value was 0.997 and 0.998 , respectively. The coefficient of variance $(\mathrm{CV})$ of ten identical samples was within $\pm 3 \%$. The samples were filtered through $0.2 \mu \mathrm{m}$ before measuring in the Ultra-High Performance Liquid Chromatography (UHPLC) in triplicates. 


\subsubsection{Sulfide analysis}

Soluble sulfide was analysed following the HACH spectrophotometric Methylene Blue Method (Method 8131) (triplicate); the detection limit was 5 $\mu \mathrm{g} / \mathrm{L} \mathrm{S}^{2-}$ and the COV of ten identical samples was within $\pm 5 \%$.

\subsubsection{Statistical analysis}

The significance of experimental results was determined by the independent sample t-test when necessary. Statistical significance was set at $p<$ 0.05 . 
Chapter 3: Experimental Methodology 
Chapter 4: Iron deficiency and bioavailability in anaerobic batch and submerged membrane bioreactor during organic shock loads

\section{Chapter 4}

\section{Iron deficiency and bioavailability in anaerobic batch and submerged membrane bioreactors during organic shock loads}

\section{Outline:}

4.1 Introduction

4.2 Experimental and analytical methods

4.3 Results and discussion

4.4 Conclusions

Note: this chapter was published in Bioresource Technology, 2016, volume 211, pages 136-145.

\subsection{Introduction}

The dependency of anaerobic digestion (AD) on metal nutrients, including $\mathrm{Fe}^{2+}$, has been mentioned in the literature review. The role of $\mathrm{Fe}^{2+}$ in anaerobic digestion processes depends on its redox properties, and its engagement in energy metabolism (Takashima \& Speece, 1989). It has been reported that the stimulating effect of $\mathrm{Fe}^{2+}$ is attributed to its ability to improve acetate utilization by methanogens (Speece, 1962), and its role in the transport system of methanogens for the conversion of $\mathrm{CO}_{2}$ to $\mathrm{CH}_{4}$ (Vintiloiu et al., 2013). Therefore, $\mathrm{Fe}^{2+}$ can play an important role in improving the degradation of VFAs (Zandvoort et al., 2003; Zitomer et al., 2008). 
Chapter 4: Iron deficiency and bioavailability in anaerobic batch and submerged membrane bioreactor during organic shock loads

The occurrence of organic shock loading (sudden changes in feed strength) is of prime importance in $\mathrm{AD}$ as this can result in process instability, including a drop in $\mathrm{pH}$, and a drop in COD removal and accumulation of volatile fatty acids (VFAs) that can ultimately lead to AD process failure (Akram \& Stuckey, 2008). Hawkes et al. (1992) demonstrated that effluent COD levels in a metal supplemented UASB reactor showed a linear response to the duration of organic shock loading, while the performance of a non-metal supplemented reactor reduced substantially, with the accumulation of propionate. In the literature, some other studies have also reported that the utilization of propionate (Espinosa et al., 1995; Zitomer et al., 2008), acetate (Osuna et al., 2003) and butyrate (Lin et al., 1998) as substrate for mesophilic/thermophilic anaerobic bioreactors improved with the addition of metal nutrients such as $\mathrm{Fe}^{2+}, \mathrm{Ni}, \mathrm{Co}$ and Mo. However, none of the previous studies have specifically looked at the significance of $\mathrm{Fe}^{2+}$ bioavailability during organic shock loads.

As discussed in the literature, operating conditions can have a significant impact on the speciation and bioavailability of TMs in anaerobic bioreactors, and during organic shock loads operating conditions change from steady state conditions. There has been not much attention given to the understanding of the relationship between metal dynamics and bioavailability during organic shock loads, which is essential for the early determination of metal nutrient limitations, and hence managing these reactors more efficiently.

Therefore, considering the essential roles of $\mathrm{Fe}^{2+}$ in anaerobic digestion processes, the scope of the experiments in this chapter was limited to the speciation and bioavailability of $\mathrm{Fe}^{2+}$ during organic overloading conditions in a submerged anaerobic membrane bioreactor (SAMBR), and how the supplementation of $\mathrm{Fe}^{2+}$ can improve the removal of accumulated VFAs during the shock loads. 
Chapter 4: Iron deficiency and bioavailability in anaerobic batch and submerged membrane bioreactor during organic shock loads

\subsection{Experimental and analytical methods}

\subsubsection{Stages 1-4}

Stages 1-4 were performed in $125 \mathrm{~mL}$ serum bottles $(100 \mathrm{~mL}$ working volume) in batch/semi-batch mode. Since the seed reactors were fed once every three days, the seed sludge for the batch/semi-batch tests were obtained on Day 3 , just before feeding the seed reactors. The initial biomass was set to $3 \mathrm{gTSS} / \mathrm{L}$ in all the serum bottle reactors; the bottles were then placed in a shaker at $35^{\circ} \mathrm{C}$, and the $\mathrm{pH}$ of the media adjusted to $7.0 \pm 0.1$ at the start using diluted $\mathrm{NaOH}$ or $\mathrm{HCl}$. All tests were run in triplicate $(\mathrm{CV}= \pm 5 \%)$.

\section{Stage 1:}

The seed sludge obtained from seed reactor two (SR2) was centrifuged, and culture media added with sodium bicarbonate $(2,000 \mathrm{mg} / \mathrm{L})$ and $\mathrm{K}_{2} \mathrm{HPO}_{4}(80$ $\mathrm{mg} / \mathrm{L})$.

\section{Stage 2-4:}

Seed sludge obtained from SR1 was centrifuged and culture media added as follows: sodium bicarbonate $(2,000 \mathrm{mg} / \mathrm{L}), \mathrm{K}_{2} \mathrm{HPO}_{4}(80 \mathrm{mg} / \mathrm{L}), \mathrm{CoCl}_{2} \cdot 6 \mathrm{H}_{2} \mathrm{O}$ $(2.38 \mathrm{mg} / \mathrm{L}), \quad \mathrm{FeCl}_{2} .4 \mathrm{H}_{2} \mathrm{O} \quad(15.8 \mathrm{mg} / \mathrm{L}), \quad \mathrm{MnCl}_{2} . \quad 4 \mathrm{H}_{2} \mathrm{O} \quad(0.75 \mathrm{mg} / \mathrm{L})$, $\mathrm{Na}_{2} \mathrm{MoO}_{4} .2 \mathrm{H}_{2} \mathrm{O}(0.75 \mathrm{mg} / \mathrm{L}), \mathrm{NiCl}_{2} .6 \mathrm{H}_{2} \mathrm{O}(0.9 \mathrm{mg} / \mathrm{L})$, and $\mathrm{MgCl}_{2}(2 \mathrm{mg} / \mathrm{L})$. In order to test the deficiency of $\mathrm{Fe}^{2+}$, all other selected metals were supplemented into each test reactor except $\mathrm{Fe}^{2+}$.

\subsubsection{Stage 5}

Stage 5 studies were in a continuously fed SAMBR which was operated at $35^{\circ} \mathrm{C}$, and steady state was maintained at $8 \mathrm{~h}$ HRT with a synthetic feed strength of $500 \mathrm{mg} \mathrm{COD} / \mathrm{L}$. The SRT (solids retention time) was set at $150 \mathrm{~d}$, and the biomass ranged from $4-4.1 \mathrm{gVSS} / \mathrm{L}$ during the test period. The organic shock loadings were simulated by glucose spikes equivalent to 1 $\mathrm{gCOD} / \mathrm{L}$ and $2 \mathrm{gCOD} / \mathrm{L}$ total concentrations in the SAMBR. 
Chapter 4: Iron deficiency and bioavailability in anaerobic batch and submerged membrane bioreactor during organic shock loads

\subsubsection{Metal extraction}

Sequential metal extraction for this experiment was carried out using the procedure proposed by Stover et al. (1976), and then modified by Lake et al. (1985), to determine the metal concentration in dewatered sludge. The extraction used $\mathrm{KNO}_{3}, \mathrm{KF}, \mathrm{Na}_{4} \mathrm{P}_{2} \mathrm{O}_{7}, \mathrm{EDTA}$, and $\mathrm{HNO}_{3}$ to sequentially fractionate metals into soluble/exchangeable, adsorbed, organic bound, carbonate, and sulfide forms, respectively. The EDTA extractable fraction can also represent the metals precipitated as metal phosphates (Carliell \& Wheatley, 1997). The residual fraction was obtained by digesting the residual sludge with $\mathrm{HNO}_{3}$ at $80^{\circ} \mathrm{C}$ in heating blocks.

\subsection{Results and Discussion}

\subsubsection{Stage 1: The effects of organic shock loading on the speciation of $\mathrm{Fe}$}

The objective of Stage 1 experiments was to examine the dynamics of $\mathrm{Fe}$ speciation under different organic shock loads using the seed grown under Fesufficient conditions, and sequentially extract it to determine the availability of TMs in solid matrices. There are a number of methods proposed to sequentially extract TMs from anaerobic sludge (Stover et al., 1976; Tessier et al., 1979; Lake et al., 1985; Osuna et al., 2004). However, the scheme proposed by Stover et al. (1976) and modified by Lake et al. (1985) was used in this study since metals bound to Fe/Mn oxides in Tessier's scheme, and the organic/sulfide fraction of the modified Tessier's scheme (Osuna et al., 2004) do not clearly differentiate between metal sulfide fractions commonly found in AD.

The trend of VFA accumulation, $\mathrm{pH}$ changes, and the dynamics of $\mathrm{Fe}$ speciation (mgFe/gTSS) are shown in Figures 4.1-4.4 when the reactors were subjected to glucose spikes (organic shocks) equivalent to $1 \mathrm{gCOD} / \mathrm{L}$ and 3 $\mathrm{gCOD} / \mathrm{L}$ final concentration in the reactor. As can be seen in all cases, Fe initially accumulated (7.95 \pm 0.05$)$ in the seed sludge as sulfides, carbonates/phosphates and non-defined forms (residuals) due to a prolonged 
Chapter 4: Iron deficiency and bioavailability in anaerobic batch and submerged membrane bioreactor during organic shock loads

supply of $\mathrm{Fe}^{2+}$ in the feed. Generally, residuals are assumed to contain minerals that may hold Fe within their crystalline structure (Tessier et al., 1979). Ortner et al. (2014) also pointed out that non-bioavailable forms of Fe were the highest in anaerobic sludge (30\% to $70 \%$ ) compared to other metals such as $\mathrm{Co}, \mathrm{Cu}$, Mo, Ni and $\mathrm{Zn}$. In the current study, a rapid accumulation of VFAs and a subsequent $\mathrm{pH}$ drop resulted in the mobilization of $\mathrm{Fe}^{2+}$ from sulfide forms to "relatively bioavailable forms" such as soluble and organically bound Fe with the $1 \mathrm{gCOD} / \mathrm{L}$ shock. With the $3 \mathrm{gCOD} / \mathrm{L}$ shock the reactor $\mathrm{pH}$ dropped to 5.5, and almost $9 \%$ of Fe in the residual form leached out to soluble and organically bound forms, and at the end of 48 hours this was equivalent to a dose of about $4.5 \mathrm{mg} / \mathrm{L} \mathrm{FeCl} 2.4 \mathrm{H}_{2} \mathrm{O}$, although no external $\mathrm{Fe}^{2+}$ was dosed initially. Adding acid to sewage sludge can lead to an exchange of protons (from the acid) based on the following reaction: $\mathrm{FeS}(\mathrm{s})+\mathrm{H}^{+}=\mathrm{HS}^{-}+\mathrm{Fe}^{2+}\left(\log \mathrm{K}_{\mathrm{sp}}=3.0\right)$ (Stylianou et al., 2007). Gonzalez-Gil et al. (2012) showed that the residual fraction was almost absent at low $\mathrm{pH}(5)$, and large amounts of $\mathrm{Ni}$ and Co were translocated to exchangeable and carbonate fractions in anaerobic sludge. Thus, Stage 1 studies clearly demonstrated that the accumulation of Fe in the seed sludge should be accounted for by supplementing $\mathrm{Fe}^{2+}$ during organic shock loads.

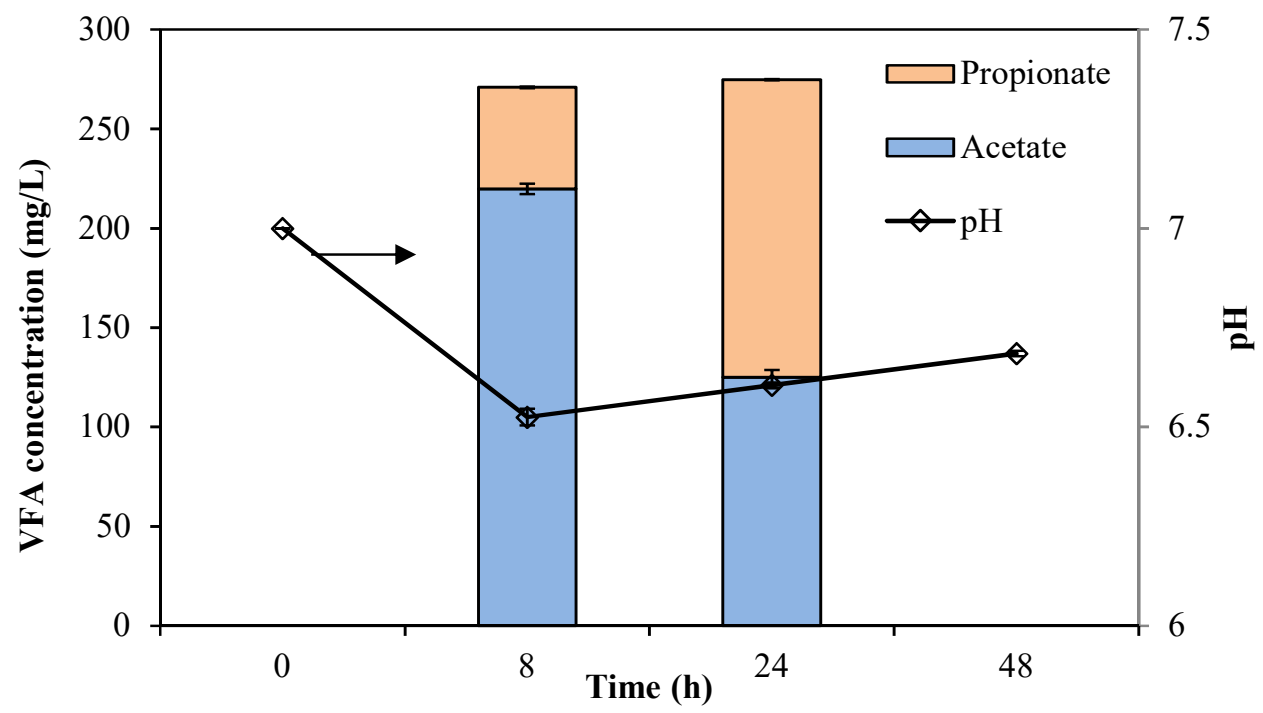

Figure 4.1 VFA production at $1 \mathrm{~g}$ COD shock in Stage 1. 
Chapter 4: Iron deficiency and bioavailability in anaerobic batch and submerged membrane bioreactor during organic shock loads

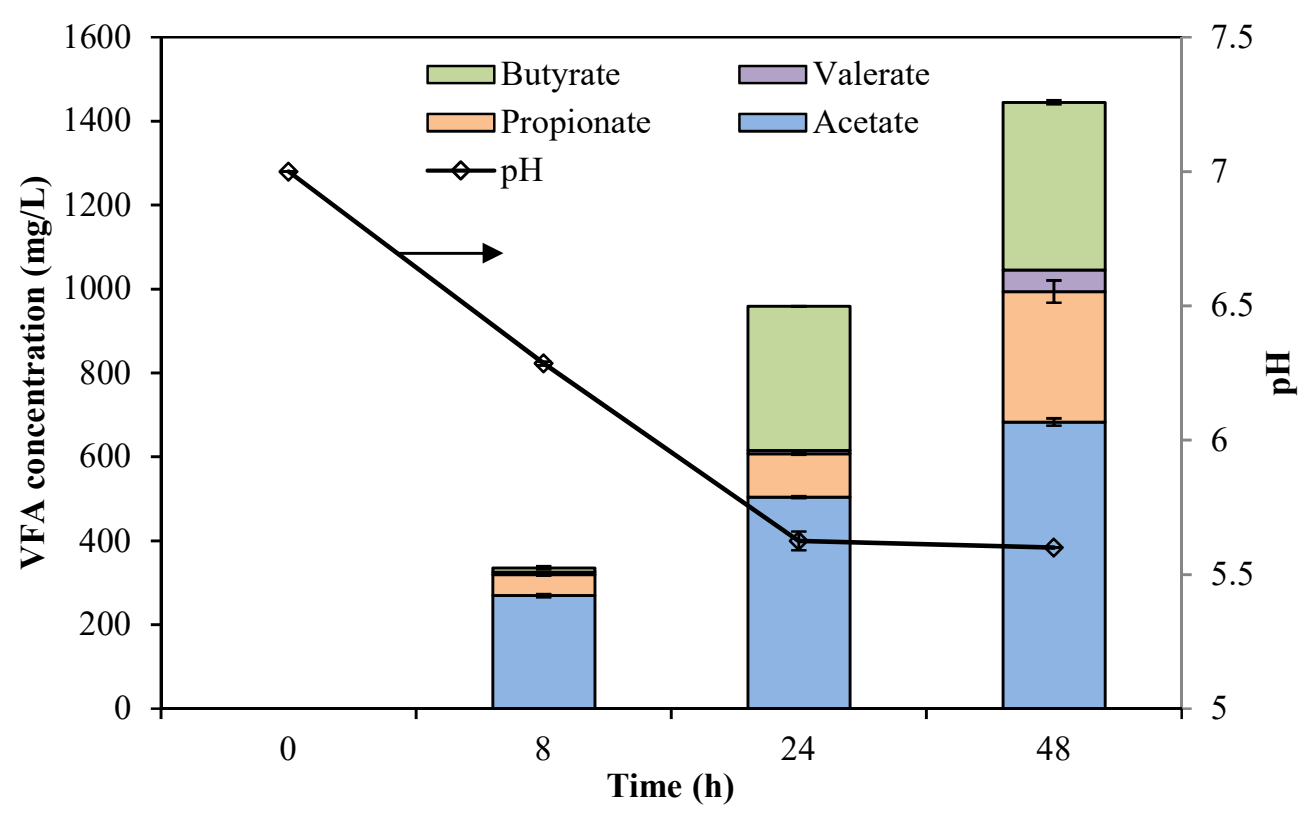

Figure 4.2 VFA production at 3g COD shock in Stage 1.

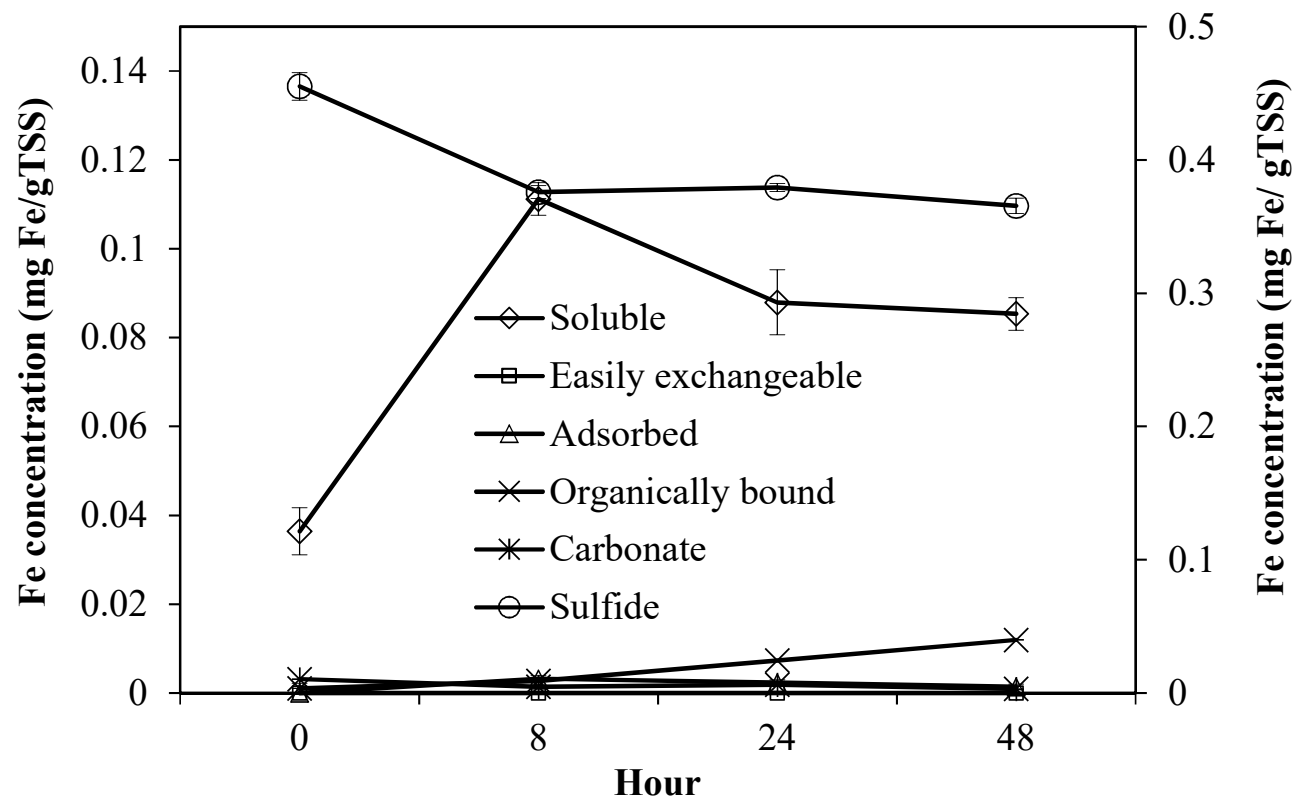

Figure 4.3 Fe speciation at $1 \mathrm{gCOD}$ shock in Stage 1 . 
Chapter 4: Iron deficiency and bioavailability in anaerobic batch and submerged membrane bioreactor during organic shock loads

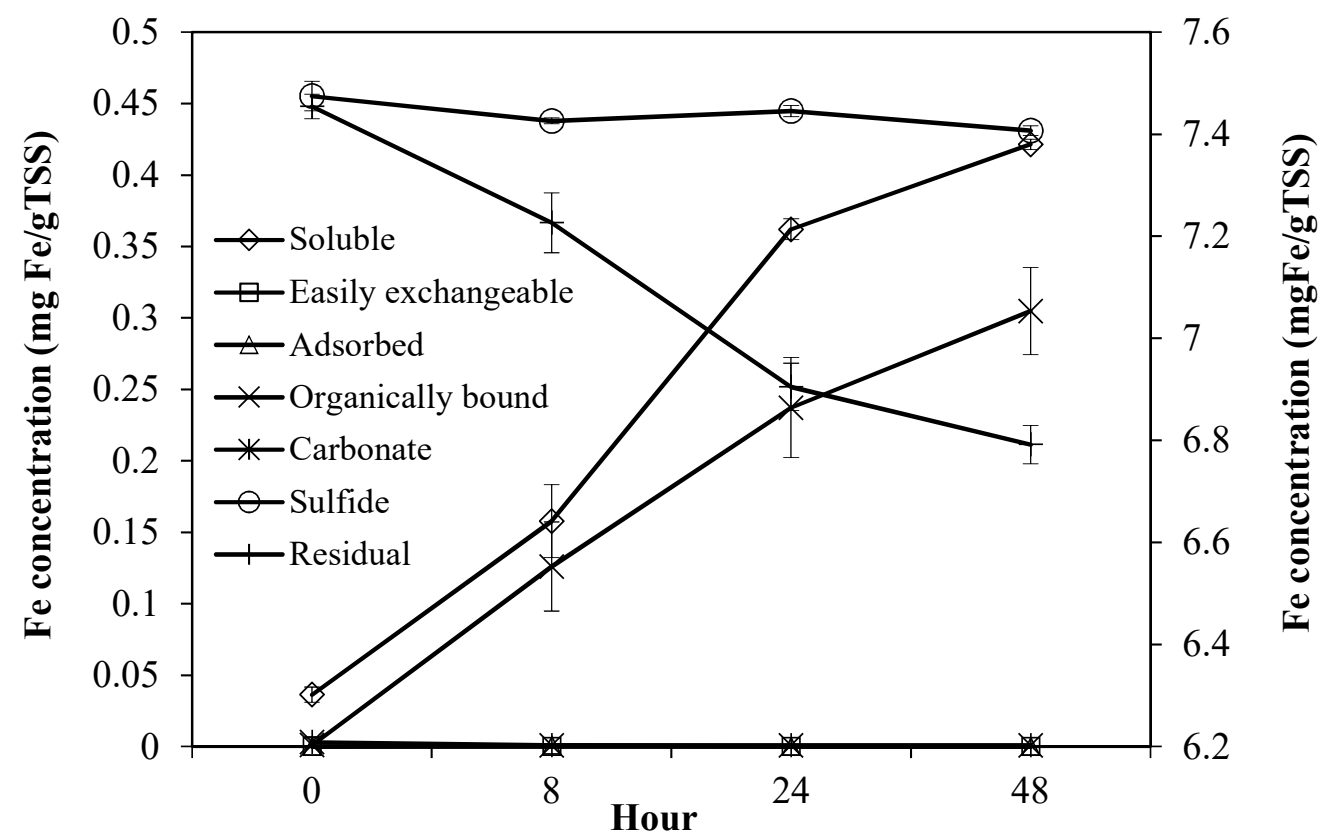

Figure 4.4 Fe speciation at $3 \mathrm{gCOD}$ shock in Stage 1.

\subsubsection{Stage 2: Effects of Fe deficiency on the responses to shock loading}

In Stage 2, the responses of batch reactors to organic shocks were tested under Fe-sufficient $\left(15.8 \mathrm{mg} / \mathrm{L}\right.$ as $\mathrm{FeCl}_{2} .4 \mathrm{H}_{2} \mathrm{O}$ ) and Fe-deficient (no $\mathrm{Fe}$ supplementation) conditions using seed grown under Fe-deficient conditions. Figures 4.5, 4.6, and Figure 4.7 show their responses in terms of VFAs, and rate of methane production, respectively, when subjected to glucose spikes of 1.5 $\mathrm{gCOD} / \mathrm{L}$ and $3 \mathrm{gCOD} / \mathrm{L}$. It can be seen that Fe deficiency had a statistically significant effect on VFA accumulation in the cases of $1.5 \mathrm{gCOD} / \mathrm{L}(\mathrm{p}<0.05)$, $3 \mathrm{gCOD} / \mathrm{L}(\mathrm{p}<0.05)$, as well as methane production in both cases. While total VFA concentration was $<20 \mathrm{mg} / \mathrm{L}$ in the case of $1.5 \mathrm{gCOD} / \mathrm{L}$, a doubling in organic load (3 $\mathrm{gCOD} / \mathrm{L})$ resulted in an almost 15 -fold increase in total VFAs, irrespective of whether the seed was Fe limited; propionate and acetate accumulated predominantly with the $3 \mathrm{gCOD} / \mathrm{L}$ shock. 
Chapter 4: Iron deficiency and bioavailability in anaerobic batch and submerged membrane bioreactor during organic shock loads

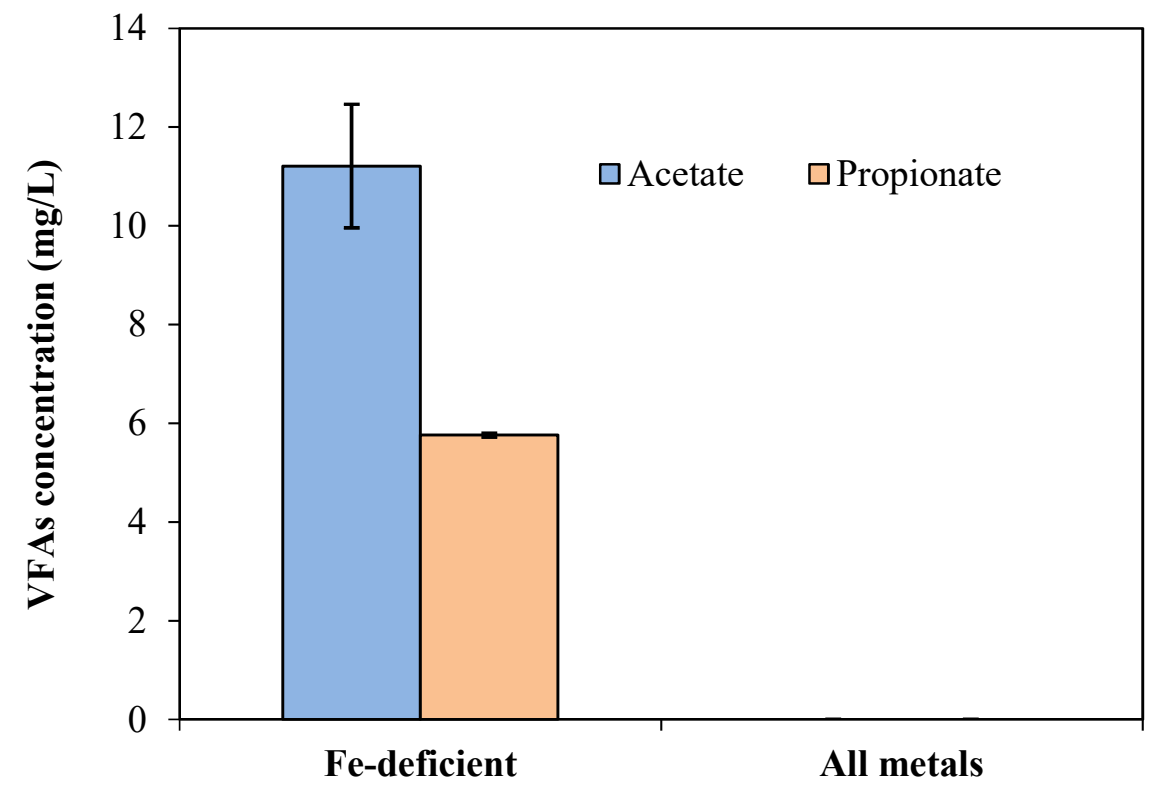

Figure 4.5 Effects of Fe deficiency on VFA accumulation at $1.5 \mathrm{gCOD} / \mathrm{L}$ glucose concentration (100 hours) (Stage 2).

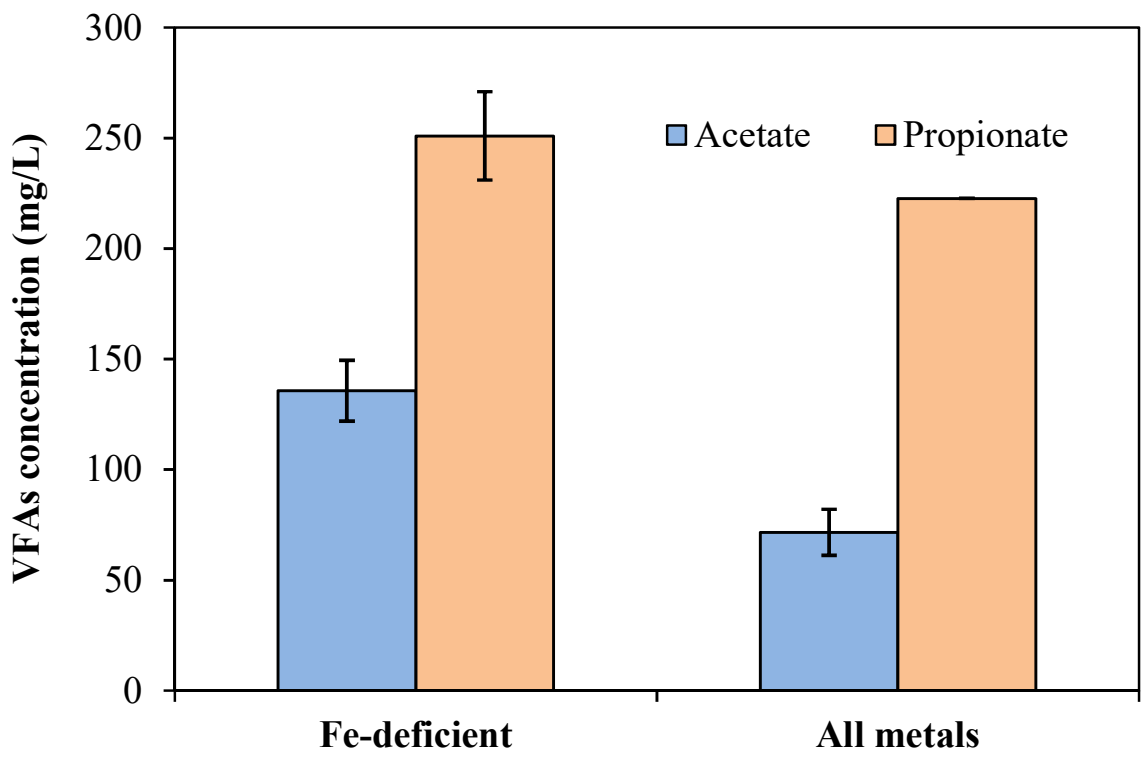

Figure 4.6 Effects of Fe deficiency on VFA accumulation at $3 \mathrm{gCOD} / \mathrm{L}$ glucose concentration (100 hours) (Stage 2). 
Chapter 4: Iron deficiency and bioavailability in anaerobic batch and submerged membrane bioreactor during organic shock loads

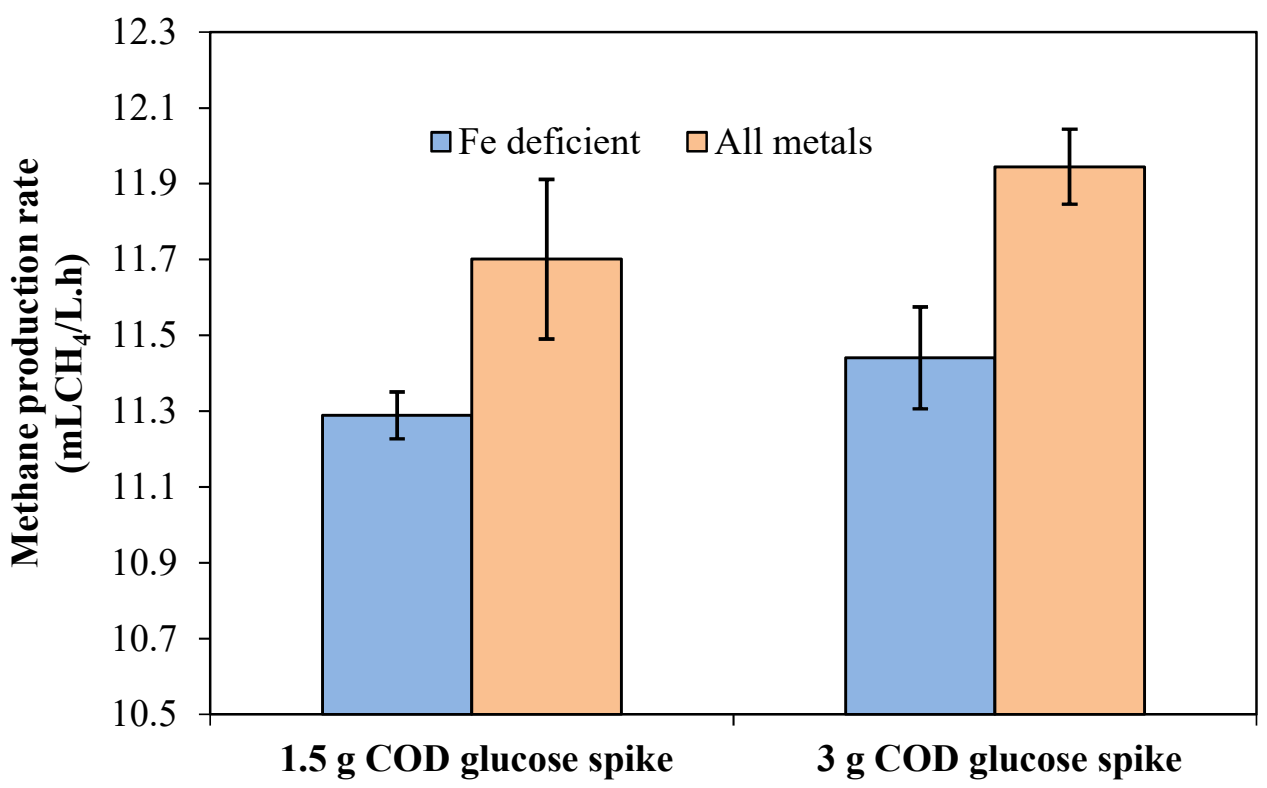

Figure 4.7 Effects of Fe deficiency on methane production at $1.5 \mathrm{gCOD} / \mathrm{L}$ and $3 \mathrm{gCOD} / \mathrm{L}$ glucose concentration (100 hours) (Stage 2).

It is clear from the literature that kinetic differences between acidogenic/acetogenic bacteria and slow growing methanogenic archaea will result in the accumulation of methanogenic precursors such as VFAs, $\mathrm{H}_{2}$, and $\mathrm{CO}_{2}$ at higher organic overloads (Leitão et al., 2006). When hydrogenotrophic methanogens cannot keep up with the high acetate/hydrogen production at higher organic loadings, butyrate and propionate are preferably produced by the acidogens as a feed-back mechanism to reduce hydrogen pressure in the system (Ketheesan \& Stuckey, 2015). With the $3 \mathrm{gCOD} / \mathrm{L}$ shock, kinetic differences and thermodynamic considerations can significantly influence the accumulation of VFAs, irrespective of $\mathrm{Fe}$ supplementation. However, higher VFA accumulation, and a lower rate of methane production, in Fe deficient reactors signify the synergetic effects of Fe limitations with $3 \mathrm{gCOD} / \mathrm{L}$. It could be postulated that there was competition for TMs amongst fermentative bacteria, acetogens and methanogens, assumingly due to the difference in microbial growth rates. This competition can create temporary nutrient limitations, and furthermore, the activity of propionate oxidizing bacteria, acetoclastic 
Chapter 4: Iron deficiency and bioavailability in anaerobic batch and submerged membrane bioreactor during organic shock loads

methanogens, and probably hydrogenotrophic methanogens can potentially be affected by Fe deficiency and retard the degradation of acetate and propionate during shock loading. The supplementation of $\mathrm{Fe}^{2+}$ with other metals such as $\mathrm{Ni}$ and Co has been shown to accelerate the degradation of propionate and acetate in several studies; Zitomer et al. (2008) observed a 50\% and 35\% increase in propionate and acetate utilization rates, respectively, after supplementation of $\mathrm{Ni}, \mathrm{Co}$ and $\mathrm{Fe}$ into thermophilic digesters. Furthermore, Uemura (2009) observed process failure due to severe acidification in mesophilic digesters, and the system only recovered after the addition of nutrients such as $\mathrm{Ni}, \mathrm{Co}$ and $\mathrm{Fe}$.

\subsubsection{Stage 3: Effects of Fe dosage on the degradation of VFAs}

Stage 2 studies confirmed the effects of Fe deficiency on the degradation of acetate and propionate during organic shock loads. However, Stage 2 studies did not give any clear idea about the optimum dosage of $\mathrm{Fe}^{2+}$, and its effects. Since propionate to methane conversion in $\mathrm{AD}$ involves several pathways such as propionate to acetate conversion by non-methanogenic propionate oxidizing bacteria, and acetate to methane conversion by acetoclastic methanogens, propionate was selected as a model substrate in Stage 3 to determine the optimum dose of $\mathrm{Fe}^{2+}$ in the test reactors. As shown in Figure 4.8, different doses of $\mathrm{Fe}^{2+}(0-100 \mathrm{mg} / \mathrm{L})$ were simultaneously spiked into propionate loaded reactors $(1.5 \mathrm{gCOD} / \mathrm{L})$ to evaluate their effects on methane production. A statistically significant $(\mathrm{p}<0.05)$ improvement in the kinetics of propionate to methane conversion was observed with a $\mathrm{Fe}^{2+}$ concentration of $10-30 \mathrm{mg} / \mathrm{L}$, although $10 \mathrm{mg} / \mathrm{L}$ (equivalent to $3.34 \mathrm{mgFe}^{2+} / \mathrm{gTSS}$ ) was found to be optimum. However, $\mathrm{Fe}^{2+}$ concentrations above $50 \mathrm{mg} / \mathrm{L}$ inhibited propionate conversion rates: metals such as Fe disrupt enzyme function and structure by binding with thiol and other groups on proteins, or by replacing naturally occurring metals in enzyme prosthetic groups (Chen et al., 2008). 
Chapter 4: Iron deficiency and bioavailability in anaerobic batch and submerged membrane bioreactor during organic shock loads

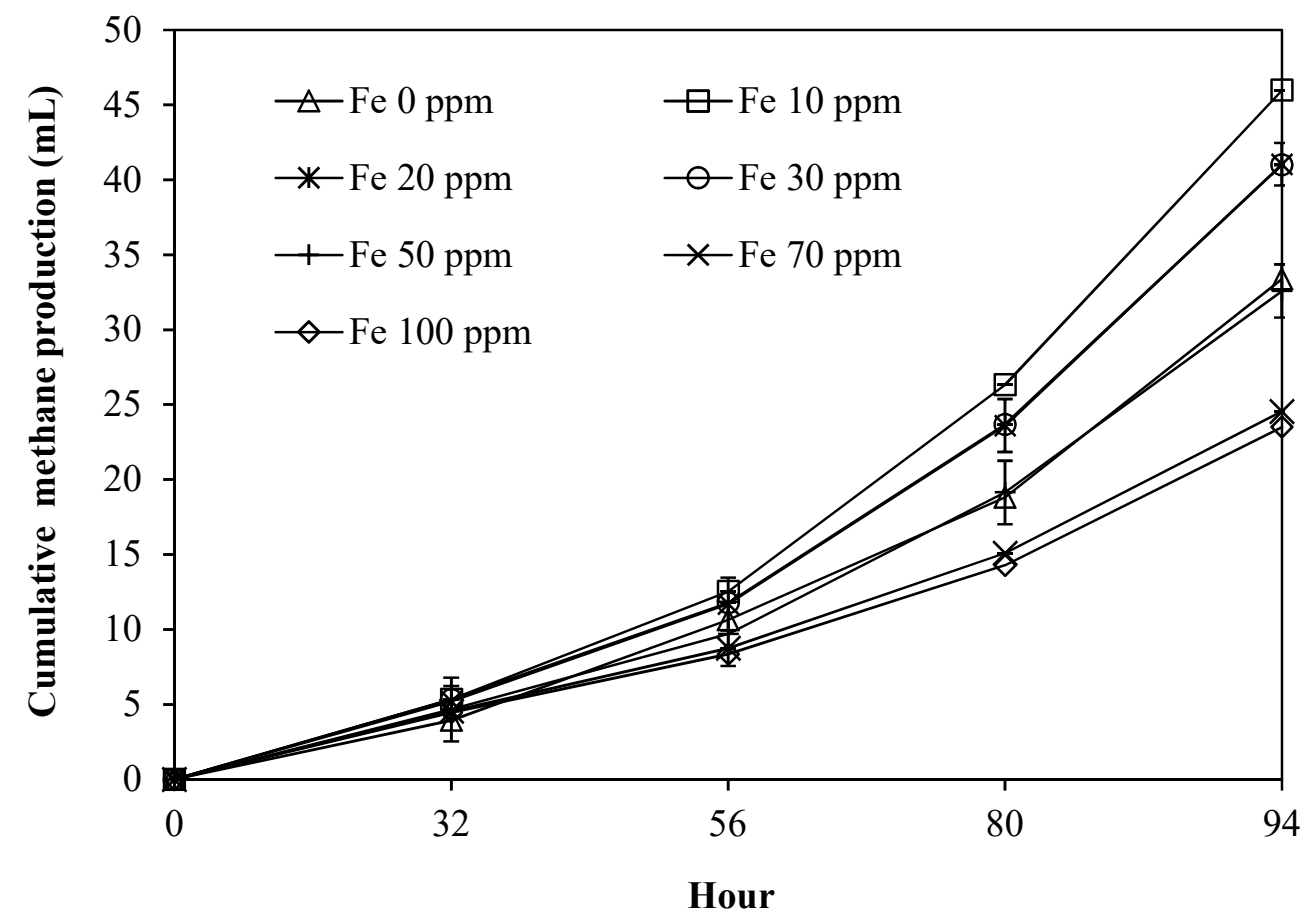

Figure 4.8 Effects of different doses of $\mathrm{Fe}^{2+}$ on biogas production in batch reactors (Stage 3).

Figures 4.9 and 4.10 show Fe speciation in the batch reactors at the end of Stage 3; the soluble Fe concentration was extremely low $(<0.01 \mathrm{mg} / \mathrm{L})$ in all cases, irrespective of its initial concentration. About $70-80 \%$ of the $\mathrm{Fe}^{2+}$ added precipitated as sulfides, leaving a lower proportion of the Fe bound to organics and carbonates in the $\mathrm{Fe}^{2+}$ supplemented reactors. The initial sludge contained $1.68 \mathrm{mgFe}^{2+} / \mathrm{gTSS}$, in which $43 \%$ of the Fe was available as sulfides. Callander and Barford (1983a) showed that Fe and other metals including Ni and Co can also precipitate as sulfides as long as the total concentration of such metals does not exceed the total sulfide $\left(\mathrm{H}_{2} \mathrm{~S}+\mathrm{HS}^{-}+\mathrm{S}^{2-}\right)$ level; otherwise, such metals can be precipitated as carbonates (not for Ni). Espinosa et al. (1995) reported that about $80 \%$ of the added metals were retained by the sludge in a laboratory UASB treating molasses stillage, and $\mathrm{Fe}$ and $\mathrm{Ni}$ were mainly precipitated as carbonates and sulfides. 
Chapter 4: Iron deficiency and bioavailability in anaerobic batch and submerged membrane bioreactor during organic shock loads

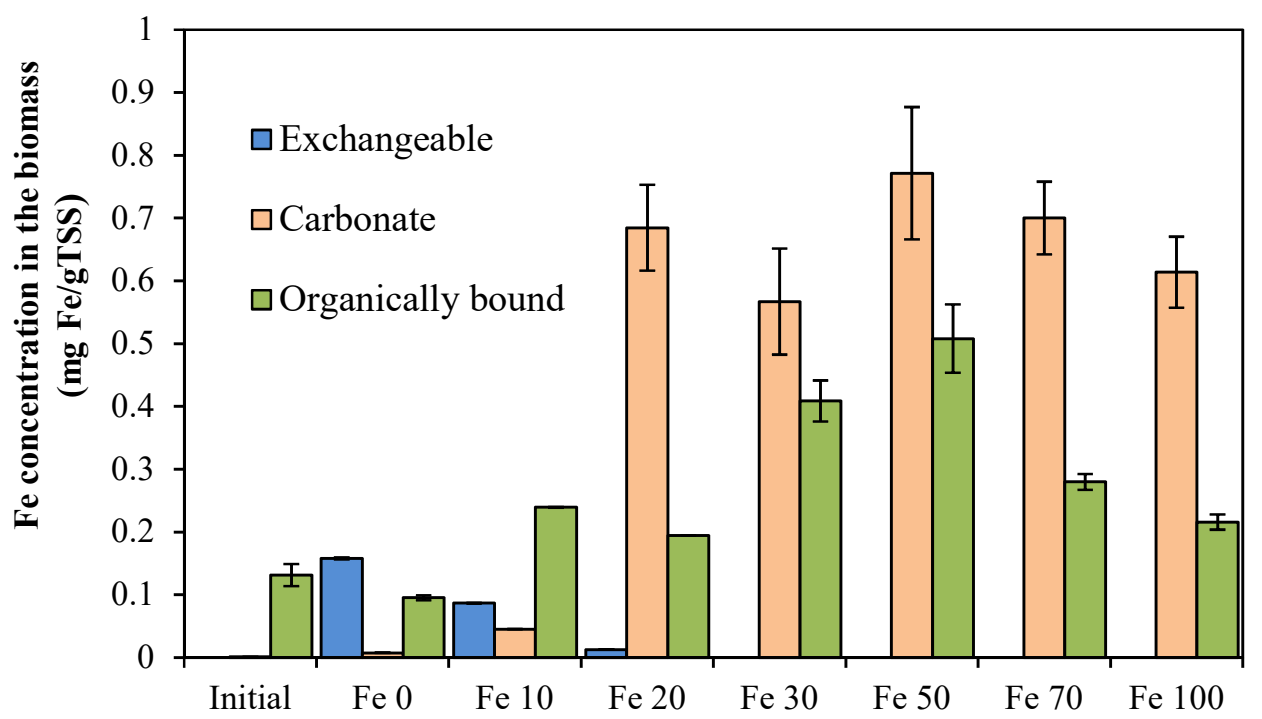

Figure 4.9 Speciation of Fe into "relatively bioavailable forms", (Stage 3) at the end of the batch run.

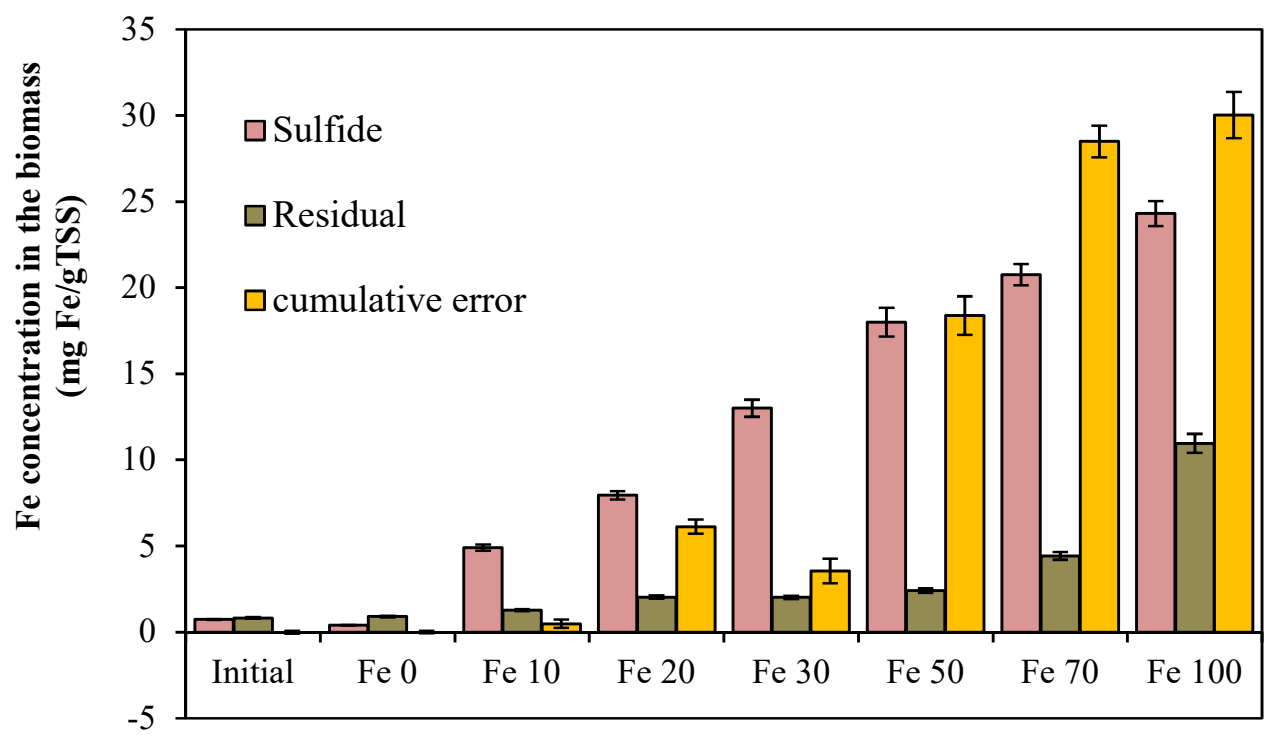

Figure 4.10 Speciation of Fe in its "relatively non-bioavailable forms",

(Stage 3) at the end of the batch run.

Another interesting observation from Stage 3 was the easily exchangeable Fe fraction available in Fe $0 \mathrm{mg} / \mathrm{L}, 10 \mathrm{mg} / \mathrm{L}$ and $20 \mathrm{mg} / \mathrm{L}$ which is considered 
Chapter 4: Iron deficiency and bioavailability in anaerobic batch and submerged membrane bioreactor during organic shock loads

to be highly mobile/bioavailable compared to other forms. While the easily exchangeable fraction accounted for almost $23 \%$ of the total available Fe with Fe $0 \mathrm{mg} / \mathrm{L}$, it only represented $0.15 \%$ of total Fe with $20 \mathrm{mg} / \mathrm{L}$. Considering the speciation of $\mathrm{Fe}$ in the initial sludge and $\mathrm{Fe} 0 \mathrm{mg} / \mathrm{L}$, it is probable that the $\mathrm{Fe}$ available in the form of organically bound fraction can be converted to easily exchangeable fractions under Fe limited conditions due to the chemical equilibria, while increased $\mathrm{Fe}^{2+}$ supplementation does not mean that more $\mathrm{Fe}$ will be in an easily exchangeable form.

The level of dissolved sulfide is also important in anaerobic reactors as sulphate entering can be reduced to sulfide by sulphate reducing bacteria (SRB). While SRB may compete with methanogens for available substrates such as acetate/propionate, sulfide can be toxic to anaerobic microorganisms at elevated concentrations (Chen et al., 2008): however, dissolved sulfide concentrations in our study only ranged between $3-4 \mathrm{mg} / \mathrm{L}$, which was far below the toxicity level. The addition of metals such as $\mathrm{Fe}, \mathrm{Co}$, and $\mathrm{Ni}$ could lead to the precipitation of metal sulfides. However, in the present study higher methane production with $10 \mathrm{mg} / \mathrm{L} \mathrm{Fe}$ compared to $0 \mathrm{mg} / \mathrm{L} \mathrm{Fe}$ suggests that this improvement was due to $\mathrm{Fe}^{2+}$ supplementation rather than the reduction in sulfide levels.

It can be seen from Figures 4.9 and 4.10 that the Fe toxicity in the cases of 50,70 and $100 \mathrm{mg} / \mathrm{L} \mathrm{Fe}^{2+}$ supplementation is attributable to the availability of Fe in sulfide and residual forms. Thus, it can be assumed that Fe available in the sulfide/residual forms can also be bioavailable to microorganisms to cause inhibition, although the results do not clearly distinguish between the role of the residual and sulfide fractions. Notably, a high proportion of the residual fraction, and cumulative errors (indicating the discrepancy between the total $\mathrm{Fe}^{2+}$ input and the Fe extracted using the sequential extraction method) in the mass balance of $\mathrm{Fe}$ at higher $\mathrm{Fe}^{2+}$ dosages $(>50 \mathrm{mg} / \mathrm{L})$ indicates the complexity of sequential extraction at high $\mathrm{Fe}^{2+}$ dosages. In fact, a lower level of soluble Fe, and discrepancies in mass balances at higher $\mathrm{Fe}^{2+}$ loading in Stage 3 studies 
Chapter 4: Iron deficiency and bioavailability in anaerobic batch and submerged membrane bioreactor during organic shock loads

suggested that Fe could have been lost during the filtration steps as Fe can bind to colloidal particles which are produced during organic shock loading (Aquino \& Stuckey, 2007).

The speciation of metal nutrients in anaerobic reactors is complex and often exhibits non ideal behavior, thus theoretical predictions of equilibrium concentrations often fail to correlate well with actual measurements (Ortner et al., 2014). Callander and Barford (1983a) found that the theoretical estimation of soluble Fe was 100 fold lower than the one measured in the reactor. One possible explanation for this was that Fe could be partially bound to complexing agents such as siderophores which are excreted by microbes to enhance the solubility and uptake of $\mathrm{Fe}$ ions; thus ionic equilibria is not reflected by the real situation in reactors (Ortner et al., 2014).

\subsubsection{Stage 4: The effects of $\mathrm{Fe}^{2+}$ dose on the degradation kinetics of acetate, propionate and butyrate}

In Stage 4, the effects of $\mathrm{Fe}^{2+}$ deficiency were tested against different VFAs such as acetate, propionate and butyrate to obtain more insight into the effects of $\mathrm{Fe}^{2+}$ limitations on different trophic groups in $\mathrm{AD}$. Hence, batch reactors were subjected to two consecutive organic over loads (equivalent to final concentrations of 1 and $3 \mathrm{gCOD} / \mathrm{L}$ ) within a 100 hour interval, and $\mathrm{Fe}^{2+}$ equivalent to $10 \mathrm{mg} / \mathrm{L}$ (equivalent to $3.34 \mathrm{mgFe}^{2+} / \mathrm{gTSS}$ ) was spiked simultaneously with $1 \mathrm{gCOD} / \mathrm{L}$. The rate of methane production was then observed in both cases (Figures 4.8) for different substrates such as acetate, propionate and butyrate. It can be seen that a longer lag period was observed in the case of methane evolution from butyrate degradation, although the average rate of methane production from acetate and butyrate at the end of $60 \mathrm{~h}$ was not statistically significant ( $30.3 \pm 0.62$ and $29 \pm 1.48 \mathrm{mLCH}_{4} / \mathrm{gVSS} . \mathrm{d}$, respectively) in Fe-sufficient conditions. Theoretically, one mole of butyrate is converted to two moles of acetate and hydrogen, and the accumulation of end products such as acetate and $\mathrm{H}_{2}$ could thermodynamically inhibit butyrate degradation (de 
Chapter 4: Iron deficiency and bioavailability in anaerobic batch and submerged membrane bioreactor during organic shock loads

Bok et al., 2004). These factors could have presumably delayed methane production from butyrate. In terms of Fe limitation, the stimulatory effect of $\mathrm{Fe}^{2+}$ was only statistically significant in the case of acetate indicate that the acetoclastic methanogens were more constrained by Fe limitations compared to the other trophic groups.

Figure 4.11 and 4.12 shows the average rate of methane production from acetate, propionate and butyrate with $3 \mathrm{gCOD} / \mathrm{L}$. While $\mathrm{Fe}^{2+}$ supplementation in the acetate loaded batch reactor resulted in a 2.1-3.9 fold increase in the rate of methane production, the rate of methane production from propionate only increased by 1.2-1.5 fold, compared to the non-Fe supplemented reactors, within the first $60 \mathrm{~h}$. However, the stimulatory effect of $\mathrm{Fe}^{2+}$ supplementation on butyrate to methane conversion was not statistically significant $(108 \pm 1.9$ $\mathrm{mLCH}_{4} / \mathrm{gVSS}$.d without $\mathrm{Fe} ; 104 \pm 4 \mathrm{mLCH}_{4} / \mathrm{gVSS}$.d with $\mathrm{Fe}$ ) at the end of $30 \mathrm{~h}$. This could be due to thermodynamic considerations as butyrate is converted to acetate, and this may be rate limiting the overall conversion of butyrate to methane. Osuna et al. (2003) also reported that the continuous addition of metals ( $\mathrm{Co}, \mathrm{Fe}, \mathrm{Ni}, \mathrm{Mn}, \mathrm{Mo}$ and $\mathrm{Se})$ to the influent stimulated the degradation of acetate and propionate compared to the sludge grown under nutrient deprived conditions. However, metal nutrient limitations did not seem to stimulate the conversion of butyrate to methane in that case. It can be seen from Figure 4.11 and 4.12 that the rate of methane production from propionate and butyrate improved significantly in the case of $3 \mathrm{gCOD} / \mathrm{L}$, compared to $1 \mathrm{gCOD} / \mathrm{L}$, with or without $\mathrm{Fe}^{2+}$ addition. In previous work, successive additions of propionate, butyrate and acetate were tested in an anaerobic reactor to evaluate its methanogenic activity, and it was observed that the degradation time of all the VFAs in the second feeding was shorter than in the first feeding (Öztürk, 1991). Hence, adaptation of specific substrate-degrading bacteria/archaea could have possibly shortened the degradation time of VFAs. Ultimately, the population of archaea present in the test culture determines the kinetics of methane 
Chapter 4: Iron deficiency and bioavailability in anaerobic batch and submerged membrane bioreactor during organic shock loads

production, and specific methanogenic activity tests (SMA) give a reasonable measure of this.

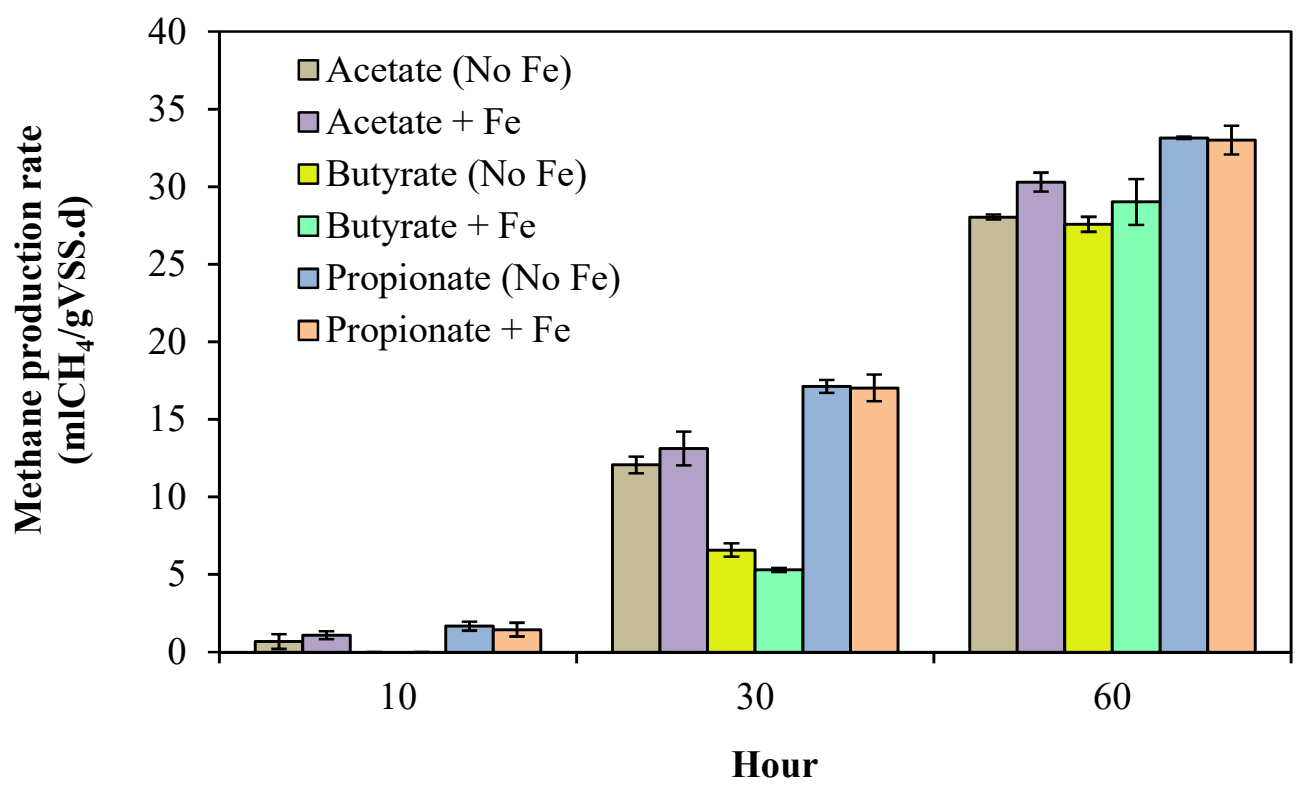

Figure 4.11 Effects of $\mathrm{Fe}^{2+}$ on the rate of methane production from different substrates at $1 \mathrm{gCOD} / \mathrm{L}$ (Stage 4).

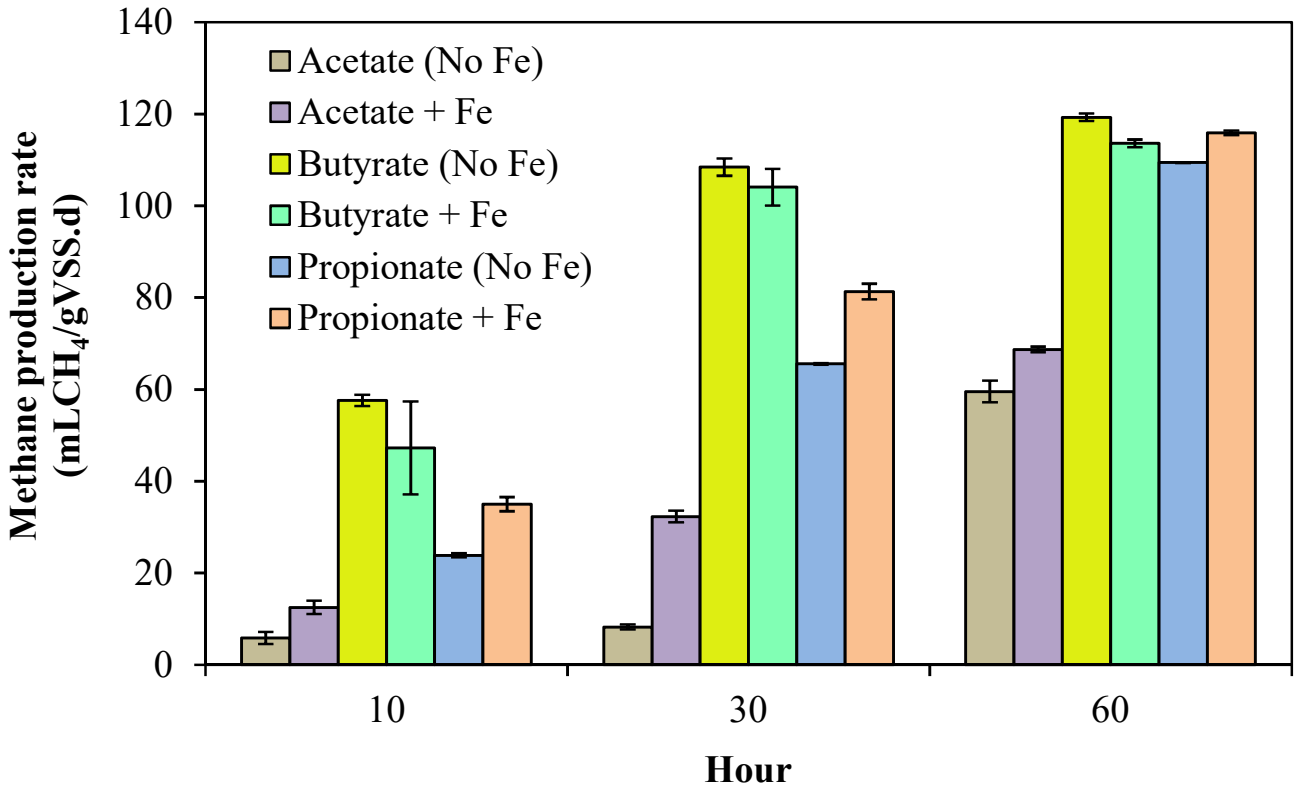

Figure 4.12 Effects of $\mathrm{Fe}^{2+}$ on the rate of methane production from different substrates at $3 \mathrm{gCOD} / \mathrm{L}$ (Stage 4). 
Chapter 4: Iron deficiency and bioavailability in anaerobic batch and submerged membrane bioreactor during organic shock loads

It has been documented that the majority of anaerobic propionateoxidizing bacteria use the methyl-malonyl-CoA pathway, yielding acetate, $\mathrm{CO}_{2}$ and $\mathrm{H}_{2}$ (de Bok et al., 2004). Therefore, propionate to methane conversion involves the activity of propionate oxidizing bacteria as well as the hydrogenotrophic and acetoclastic methanogens. However, acetate can be directly converted into methane by acetoclastic methanogens; therefore, it could be postulated that acetoclastic methanogens were more constrained by $\mathrm{Fe}$ limitations compared to the other trophic groups. In a previous study, Schmidt et al. (2014) reported that Fe deficiency affected the activities of both methanogenic archaea and propionate oxidizing bacteria in an anaerobic system.

Figure 4.13 shows the various physical/chemical forms of $\mathrm{Fe}$ in the acetate and propionate reactors at the end of the experiment, and suggests that the additional $\mathrm{Fe}$ was mainly precipitated either as sulfides, or bound to organics. Notably, only a lower proportion of Fe $(<0.01 \mathrm{mgFe} / \mathrm{gTSS})$ was precipitated as carbonate/phosphate bound-Fe (EDTA fraction). Hence, it could be postulated that the $\mathrm{Fe}$ in sulfide and organically bound forms can also be bioavailable to methanogens, although there has been considerable disagreement about the bioavailability of metal sulfides in AD. Zehnder (1983) suggested that the availability of Fe to methanogens could be restricted when sulfide was present. In contrast, Gustavsson et al. (2013b) reported that the precipitation of $\mathrm{Co}$ and $\mathrm{Ni}$ as sulfides did not inhibit the microbial uptake of $\mathrm{Co}$ and Ni. Our Stage 4 studies also revealed that the soluble Fe concentration in the reactor, as well as the Fe in easily exchangeable and adsorbed forms in the sludge, were almost zero at the end of the batch test. Gustavsson et al. (2013b) suggested that the soluble/bioavailable intermediates are labile and short-lived, and therefore difficult to detect. 
Chapter 4: Iron deficiency and bioavailability in anaerobic batch and submerged membrane bioreactor during organic shock loads

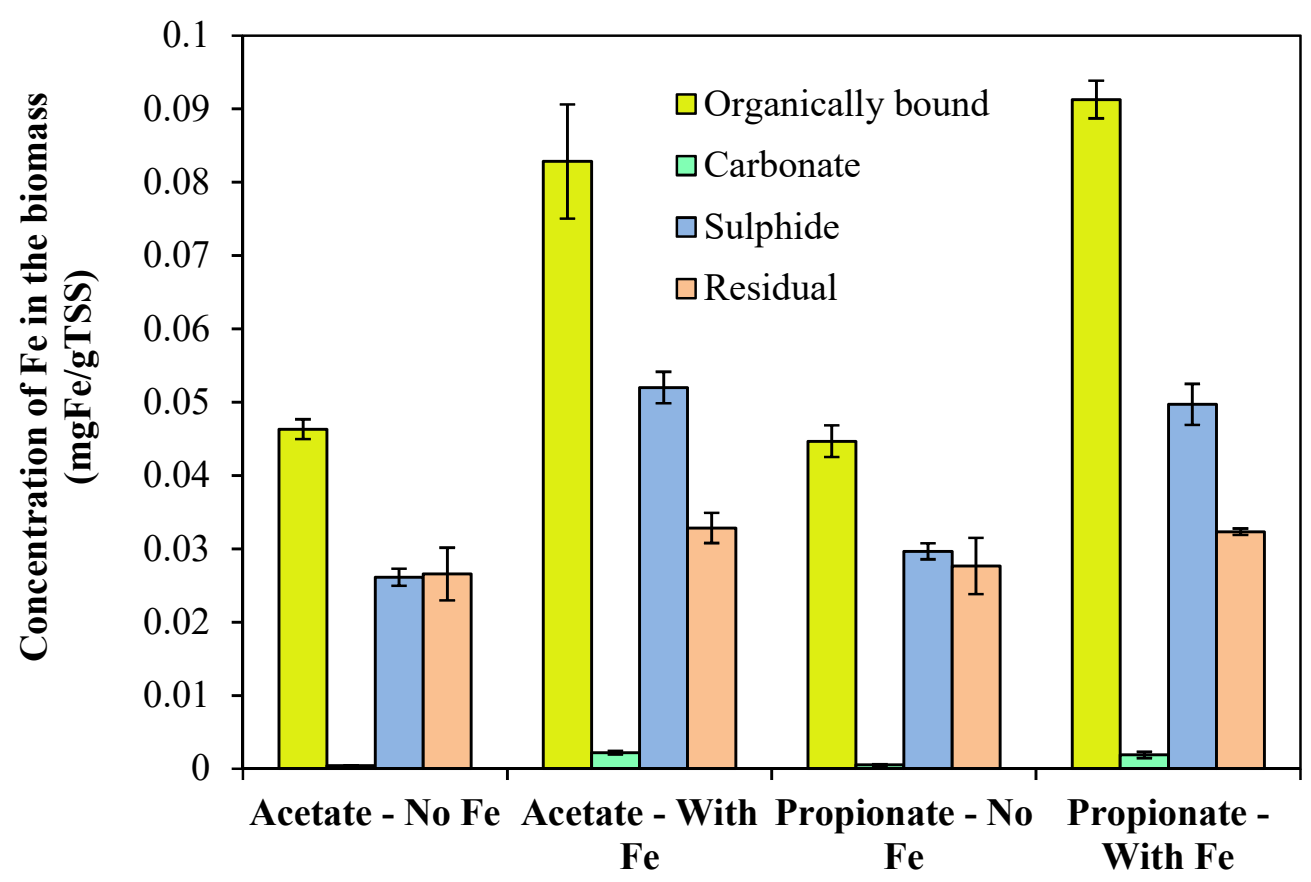

Figure 4.13 The distribution characteristics of Fe in batch reactors (Stage 4).

\subsubsection{Stage 5: The effects of Fe supplementation in a SAMBR}

The objective of Stage 5 was to demonstrate the effects of $\mathrm{Fe}^{2+}$ supplementation in a continuously fed SAMBR during organic shock load conditions. Table 4.1 shows the steady state performance of the SAMBR at different HRTs; this was initially set at $48 \mathrm{~h}$ for two weeks, and then reduced to $8 \mathrm{~h}$ step-wise over two months. The reactor was stable (low VFAs) at each HRT before it was reduced to ensure a smooth transition from $48 \mathrm{~h}$ HRT to $8 \mathrm{~h}$ HRT; thus VFA accumulation was almost negligible in all cases, and the $\mathrm{pH}$ ranged between 6.9 to 7.1. Table 4.2 shows the speciation of Fe in the SAMBR at steady state $(8 \mathrm{~h} \mathrm{HRT})$ and a solid retention time (SRT) of $150 \mathrm{~d}$; the bioavailability of $\mathrm{Fe}$ in the soluble form reflects the continuous feeding of $\mathrm{Fe}^{2+}$ in the influent, and Fe was still present in both sulfide and residual forms in the biomass. Prior to any organic shock, the reactor was maintained at steady state conditions ( $8 \mathrm{~h} \mathrm{HRT}$ and $500 \mathrm{mg} / \mathrm{L}$ feed strength). Considering the metalretaining ability of anaerobic sludge, the SAMBR response to organic shocks 
Chapter 4: Iron deficiency and bioavailability in anaerobic batch and submerged membrane bioreactor during organic shock loads

was first tested without $\mathrm{Fe}$ supplementation, followed by tests with supplementation. With supplementation, $\mathrm{Fe}^{2+}$ was spiked immediately after the organic shock and the effluent was stopped for 5 min to prevent the immediate loss of soluble $\mathrm{Fe}$ in the effluent. Tables 4.3 and 4.4 show the SAMBR responses during glucose shocks of $1 \mathrm{~g}$ and $2 \mathrm{gCOD}$, with and without $\mathrm{Fe}^{2+}$ supplementation.

Table 4.1 Steady state performance of the SAMBR at different HRTs.

\begin{tabular}{cccc}
\hline HRT (h) & $\begin{array}{c}\text { OLR } \\
\text { (gCOD/ L.d) }\end{array}$ & COD removal (\%) & VFA (mg/L) \\
\hline 48 & 0.25 & 94 & - \\
36 & 0.33 & 94 & - \\
24 & 0.5 & 96 & - \\
12 & 1.0 & 96 & $2-3$ \\
10 & 1.2 & 97 & $2-3$ \\
8 & 1.5 & 97 & $2-3$ \\
\hline
\end{tabular}

Table 4.2 Speciation of Fe in anaerobic sludge in the SAMBR.

\begin{tabular}{cc}
\hline Form & $\begin{array}{c}\text { Concentration } \\
\text { (mgFe/gTSS) }\end{array}$ \\
\hline Soluble (reactor) & $0.55 \pm 0.05$ \\
Exchangeable & 0 \\
Adsorbed & 0 \\
Carbonate & $0.06 \pm 0.02$ \\
Sulfide & $0.47 \pm 0.05$ \\
Organically bound & $0.03 \pm 0.02$ \\
Residual & $0.35 \pm 0.01$ \\
\hline
\end{tabular}


Chapter 4: Iron deficiency and bioavailability in anaerobic batch and submerged membrane bioreactor during organic shock loads

It can be seen that acetic and propionic acids mainly accumulated in all cases (Table 4.3 and 4.4), with a concomitant drop in $\mathrm{pH}$. A rapid reduction in VFAs, and maintaining the $\mathrm{pH}$ within favourable limits are essential strategies to recover reactor performance. As shown in Tables 4.3 and 4.4, the effects of $\mathrm{Fe}^{2+}$ supplementation were statistically significant (COV for VFA measurements was $\pm 2 \%$ ) in the case of $1 \mathrm{gCOD}$ compared to $2 \mathrm{gCOD}$ for the rapid removal of VFAs. In the first case, almost $50 \%$ of the acetate was reduced by $\mathrm{Fe}^{2+}$ supplementation in the first hour, and completely removed within two hours. However, a slower response was observed in the case of propionic acid, and only $60 \%$ of the accumulated propionic acid was eliminated by $\mathrm{Fe}^{2+}$ supplementation in $2 \mathrm{~h}$. In anaerobic environments propionate is oxidized to acetate, bicarbonate and $\mathrm{H}_{2}$ /formate, and its degradation by acetogenic bacteria is thermodynamically unfavourable $\left(\Delta \mathrm{G}^{\mathrm{o}}>0\right)$, and only becomes possible when these products are removed by methanogens (de Bok et al., 2004). In a previous study, Espinosa et al. (1995) reported that the addition of Fe, Ni, Co and Mo to the influent reduced the level of propionic acid from 5,210 mg/L to $626 \mathrm{mg} / \mathrm{L}$ in a laboratory scale UASB reactor fed with cane molasses stillage, but this took $12 \mathrm{~d}$.

Table 4.3 Responses of the SAMBR to a glucose spike of 1 gCOD.

\begin{tabular}{|c|c|c|c|c|c|c|c|}
\hline \multirow[b]{2}{*}{ Case } & \multirow{2}{*}{$\begin{array}{l}\text { glucose } \\
\text { spike (as } \\
\text { gCOD) }\end{array}$} & \multirow{2}{*}{$\begin{array}{l}\text { Fe dosage } \\
\text { (as mg/L in } \\
\text { SAMBR) }\end{array}$} & \multirow{2}{*}{$\begin{array}{l}\text { Time } \\
\text { (h) }\end{array}$} & \multicolumn{3}{|c|}{ VFA (mg/L) } & \multirow[t]{2}{*}{ pH } \\
\hline & & & & Acetate & Propionate & Others & \\
\hline \multirow{3}{*}{ Case 1} & \multirow{3}{*}{$1 \mathrm{~g}$} & \multirow{3}{*}{0} & 0 & 0 & 0 & 0 & 7.02 \\
\hline & & & 1 & 36.9 & 46.9 & 3.56 & 6.7 \\
\hline & & & 2 & 24.3 & 23.2 & 13.9 & 6.83 \\
\hline \multirow{3}{*}{ Case 2} & \multirow{3}{*}{$1 \mathrm{~g}$} & \multirow{3}{*}{10} & 0 & 0 & 0 & 0 & 7.01 \\
\hline & & & 1 & 19.1 & 48.2 & 11.5 & 6.86 \\
\hline & & & 2 & 0 & 9.6 & 5.50 & 6.85 \\
\hline
\end{tabular}


Chapter 4: Iron deficiency and bioavailability in anaerobic batch and submerged membrane bioreactor during organic shock loads

Table 4.4 Responses of the SAMBR to a glucose spike of 2 gCOD.

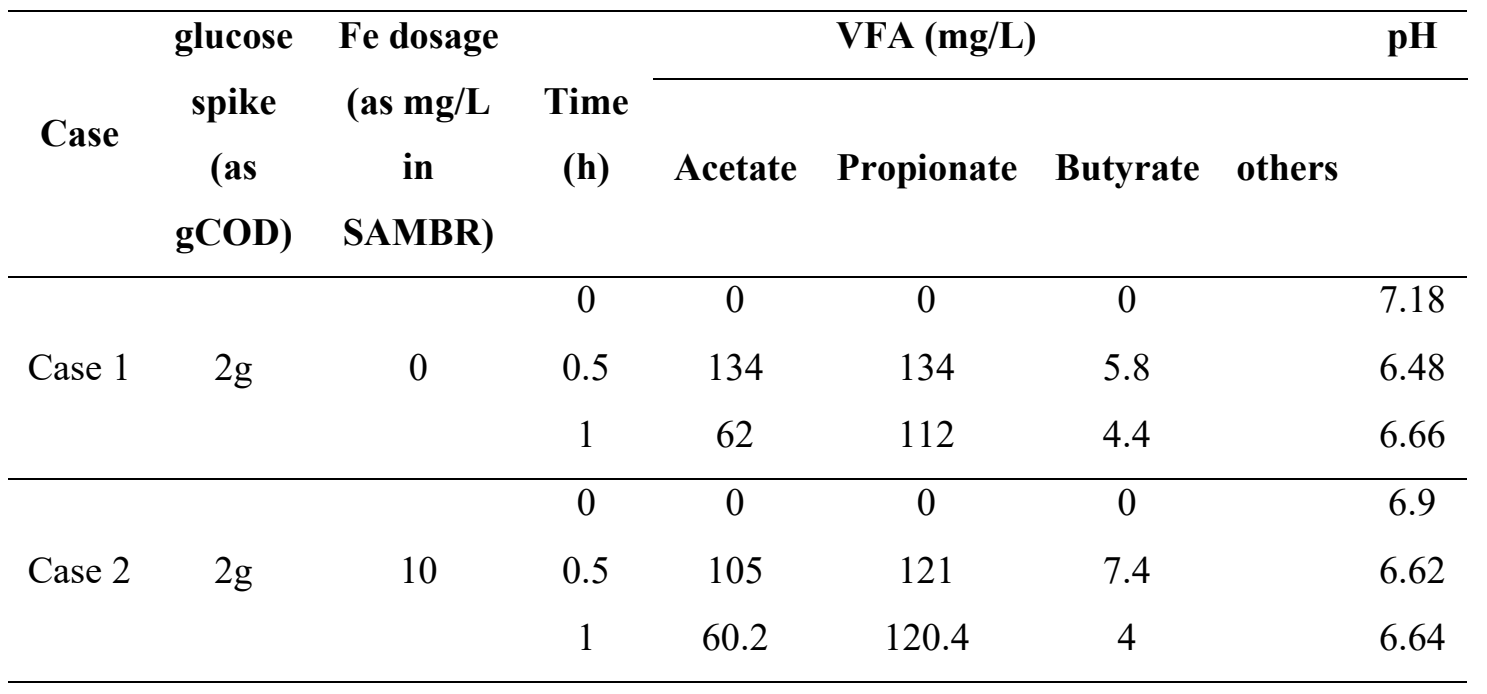

When the SAMBR was subjected to a spike of 2 gCOD, reductions in acetic acid (from $134 \mathrm{mg} / \mathrm{L}$ to $105 \mathrm{mg} / \mathrm{L}$ ) and propionic acids (from $134 \mathrm{mg} / \mathrm{L}$ to $121 \mathrm{mg} / \mathrm{L}$ ) were observed in the first $30 \mathrm{~min}$ after $\mathrm{Fe}^{2+}$ supplementation, however, no statistically significant improvements were observed after $1 \mathrm{hr}$. These results showed that propionate accumulation was significant compared to acetate in the case of $2 \mathrm{gCOD} / \mathrm{L}$. Notably, the $\mathrm{pH}$ dropped to 6.48 and 6.62 in both Fe-deficient and $\mathrm{Fe}^{2+}$ supplemented conditions (in $30 \mathrm{~min}$ ), respectively, although the $30 \mu \mathrm{m}$ flocs in the SAMBR would ameliorate this effect through mass transfer considerations. However, it is possible that the limiting effects of Fe on the degradation of VFAs could have been overwhelmed by an unfavourable $\mathrm{pH}$ drop.

Understanding metal dynamics and speciation is more complicated in continuous bioreactors compared with batch reactors. An "optimum" dose of metals should be continuously fed to the reactor to ensure maximum substrate conversion, and to prevent disturbances in reactor performance, however, continuously supplying metal nutrients can lead to an accumulation of metals by the biomass. Long SRTs could result in a substantial accumulation of metal 
Chapter 4: Iron deficiency and bioavailability in anaerobic batch and submerged membrane bioreactor during organic shock loads

salts, mainly as sulfides and residuals (Stage 5), on the other hand, the metal content of the sludge will decrease due to leaching if the supply of metals to the reactor is stopped. Zandvoort et al. (2006a) demonstrated that metal loss from the biomass (especially $\mathrm{Fe}, \mathrm{Co}$ and $\mathrm{Ni}$ ) was proportional to their initial content in the sludge when their supply was halted. They suggested that part of the observed decline could be attributed to a "dilution effect" as a result of bacterial growth which has to be supported by metals available in the inoculum sludge. Another study by Zandvoort et al. (2004) showed that both preloading (supplementation of cobalt to sludge prior to feeding), and in situ (supplementation of cobalt to feed) loading was effective in achieving increased reactor performance of a methanol fed UASB reactor operating under cobalt limitations. However, they found that in situ dosing needed substantially lower amounts of cobalt, while resulting in significantly smaller losses of cobalt in the effluent. Thus understanding the dynamics of $\mathrm{Fe}$ in anaerobic sludge and the timely addition of $\mathrm{Fe}^{2+}$ during organic shock loads could enable quicker recovery of reactor performance through more rapid VFA removal.

\subsection{Conclusions}

With seed sludge grown under Fe-sufficient conditions, an organic shock resulted in leaching of Fe from the residual to organically bound and soluble forms. With Fe-deficient seed sludge, addition of $\mathrm{Fe}^{2+}$ to an acetate loaded batch reactor resulted in a 2.1-3.9-fold increase in the rate of methane production, while from propionate methane increased 1.2-1.5 fold compared to the non-Fe supplemented reactors. Accumulation of $\mathrm{Fe}$ in the seed sludge should be accounted for by supplementing $\mathrm{Fe}^{2+}$ during organic shock loads. 
Chapter 5: Effect of Ethylenediamine-N,N'-disuccinic acid (EDDS) on the speciation and bioavailability of $\mathrm{Fe}^{2+}$ in the presence of sulfide

\section{Chapter 5}

\section{Effect of Ethylenediamine- $N, N^{\prime}$-disuccinic acid (EDDS) on the speciation and bioavailability of $\mathrm{Fe}^{2+}$ in the presence of sulfide}

\section{Outline:}

5.1 Introduction

5.2 Experimental and analytical methods

5.3 Results and discussion

5.4 Conclusions

Note: this chapter was published in Bioresource Technology, 2017, volume 229, pages $169-179$.

\subsection{Introduction}

As discussed in the literature review, precipitation of the metal sulfide plays a very important role in the fate of TMs in anaerobic digestion as it can limit TM bioavailability for microbial uptake, and hence increase the required dosage of TMs.

To prevent the precipitation of TMs with sulfide in anaerobic bioreactors it is possible to add chelating agents, which will complex with the TMs and keep them in a soluble form. It has been shown that the TM bioavailability in anaerobic digestion can be improved by adding natural chelating agents e.g. soluble microbial products (SMPs) (Aquino \& Stuckey, 2007) or synthetic chelating agents e.g. Ethylene diaminetetraacetic acid (EDTA) and 
Chapter 5: Effect of Ethylenediamine-N,N'-disuccinic acid (EDDS) on the speciation and bioavailability of $\mathrm{Fe}^{2+}$ in the presence of sulfide

Nitrilotriacetic acid (NTA) (Fermoso et al., 2008c; Hu et al., 2008a; Bartacek et al., 2012; Vintiloiu et al., 2013). Although EDTA and NTA have higher complexing capabilities with TMs than SMPs, these materials are poorly biodegradable and could pose a threat to the environment when ultimately discharged in the effluent (Tandy et al., 2004). Alternatively, readily biodegradable chelating agents such as Ethylenediamine-N,N'-disuccinic acid (EDDS), Imino disuccinic acid (IDS), and Glutamic acid diacetic acid (GLDA) can be used; however, there is limited research looking at the viability of using such chelating agents in anaerobic systems.

Due to its biodegradability, EDDS has been an alternative for traditional chelating agents in several commercial products e.g. industrial detergents. In environmental applications, EDDS has been used for induced phytoextraction and soil washing to remove heavy metals such as $\mathrm{Pb}, \mathrm{Zn}, \mathrm{Cu}$, and $\mathrm{Cd}$ (Kos \& Leštan, 2003; Zhao et al., 2010; Satyro et al., 2014; Ferraro et al., 2015; Beiyuan et al., 2016). However, to date there is only one study that has demonstrated the use of EDDS to increase metal bioavailability in anaerobic digestion (Zhang et al., 2015b). In this study, the optimum dose of EDDS was not justified, and the effect of EDDS addition was only determined on a combination of TMs i.e. Fe, $\mathrm{Co}$, and $\mathrm{Ni}$, rather than on any individual TM.

Therefore, the objective of this study was to evaluate the effect of sulfide on the bioavailability of $\mathrm{Fe}^{2+}$, and to determine how supplying the biodegradable chelating agent EDDS could improve $\mathrm{Fe}^{2+}$ bioavailability, and hence increase the methane yields in anaerobic digestion. The effect of EDDS on $\mathrm{Fe}^{2+}$ bioavailability in the presence of sulfide was first investigated in a model media, and then extended to an actual anaerobic digestion process. In order to give deeper insights into the relationship between metal speciation and metal complexation, the applicability of the Community Bureau of Reference (BCR) extraction method was systematically assessed in dried/wet sludge conditions, and a new UHPLC method was developed for the determination of free-EDDS and Fe-EDDS complex. 
Chapter 5: Effect of Ethylenediamine-N,N'-disuccinic acid (EDDS) on the speciation and bioavailability of $\mathrm{Fe}^{2+}$ in the presence of sulfide

\subsection{Experimental and analytical methods}

\subsubsection{Metal extraction of dried and wet samples with the BCR extraction method}

This experiment was aimed at comparing the speciation and recovery of metals from dried and wet anaerobic sludge samples with the BCR method. For dried samples, the sludge was centrifuged at 4,000 rpm for $15 \mathrm{~min}$ and then the pellets were dried in aluminium pans at $105^{\circ} \mathrm{C}$ overnight. Dried pellets were then ground in a porcelain mortar to reduce particle size, and then stored in a desiccator at room temperature. During the extraction step, $0.6 \mathrm{~g}$ of dried sample was placed into a $50 \mathrm{~mL}$ centrifuge tube. For wet samples, a volume of anaerobic sludge equivalent to $0.5 \mathrm{gTSS}$ was centrifuged at 4,000 rpm for 15 min in a $50 \mathrm{~mL}$ centrifuge tube. The sequential extraction for both dried and wet sludge was carried out in quadruplicate, and the concentration of metals from each extraction step was measured using MP-AES.

\subsubsection{Effects of metal nutrient supplementation on anaerobic digestion}

This experiment was aimed at comparing the effects of selected metal nutrients on methane production with anaerobic sludge. The "Control" set did not have substrate added or metal nutrients, while the "No Metal" set contained only substrate, but the test reactors were supplemented with a group of metal nutrients that were characterized by similar chemical properties, i.e. set 1 : $\mathrm{Fe}+$ $\mathrm{Co}+\mathrm{Ni}$ (transitional metals), set 2: $\mathrm{Cu}+\mathrm{Mn}+\mathrm{Zn}$ (other TMs), and set 3: $\mathrm{Ca}+$ $\mathrm{Mg}$ (macronutrients). The substrate was glucose, the $\mathrm{F} / \mathrm{M}$ ratio was fixed at 1:1 ( $2 \mathrm{gCOD}$ as glucose to $2 \mathrm{gVSS}$ ), and $\mathrm{NaHCO}_{3}$ was added as a buffer.

The experiment was carried out in a batch automatic methane potential test system (AMPTS II, Bioprocess Control AB, Sweden) in triplicate. The tests were performed in standard $500 \mathrm{~mL}$ bottles, and the working volume of each test reactor was $400 \mathrm{~mL}$. The reactors were flushed with nitrogen gas passing through tubing to ensure anaerobic conditions prior to start-up, and the 
Chapter 5: Effect of Ethylenediamine-N,N'-disuccinic acid (EDDS) on the speciation and bioavailability of $\mathrm{Fe}^{2+}$ in the presence of sulfide

temperature was controlled at $35^{\circ} \mathrm{C}$. Stirrers in all the reactors were set at $60 \mathrm{~s}$ on and $30 \mathrm{~s}$ off at $46 \mathrm{rpm}$ during the whole experiment. Metal speciation was assessed using the BCR method with wet samples.

The overall batch tests were carried out in phases; during Phase 1 the metal nutrients were added at the concentrations in the nutrient recipe (Table 5.1) used by $\mathrm{Hu}$ (2004) and Souto et al. (2010). During Phases 2 and 3, the same dose of substrate was injected again into the test reactors, while the metal concentrations were doubled and trebled from the initial concentrations, respectively, in order to magnify the effects of metal supplementation on methane production.

Table 5.1 Metal concentrations supplemented to test reactors.

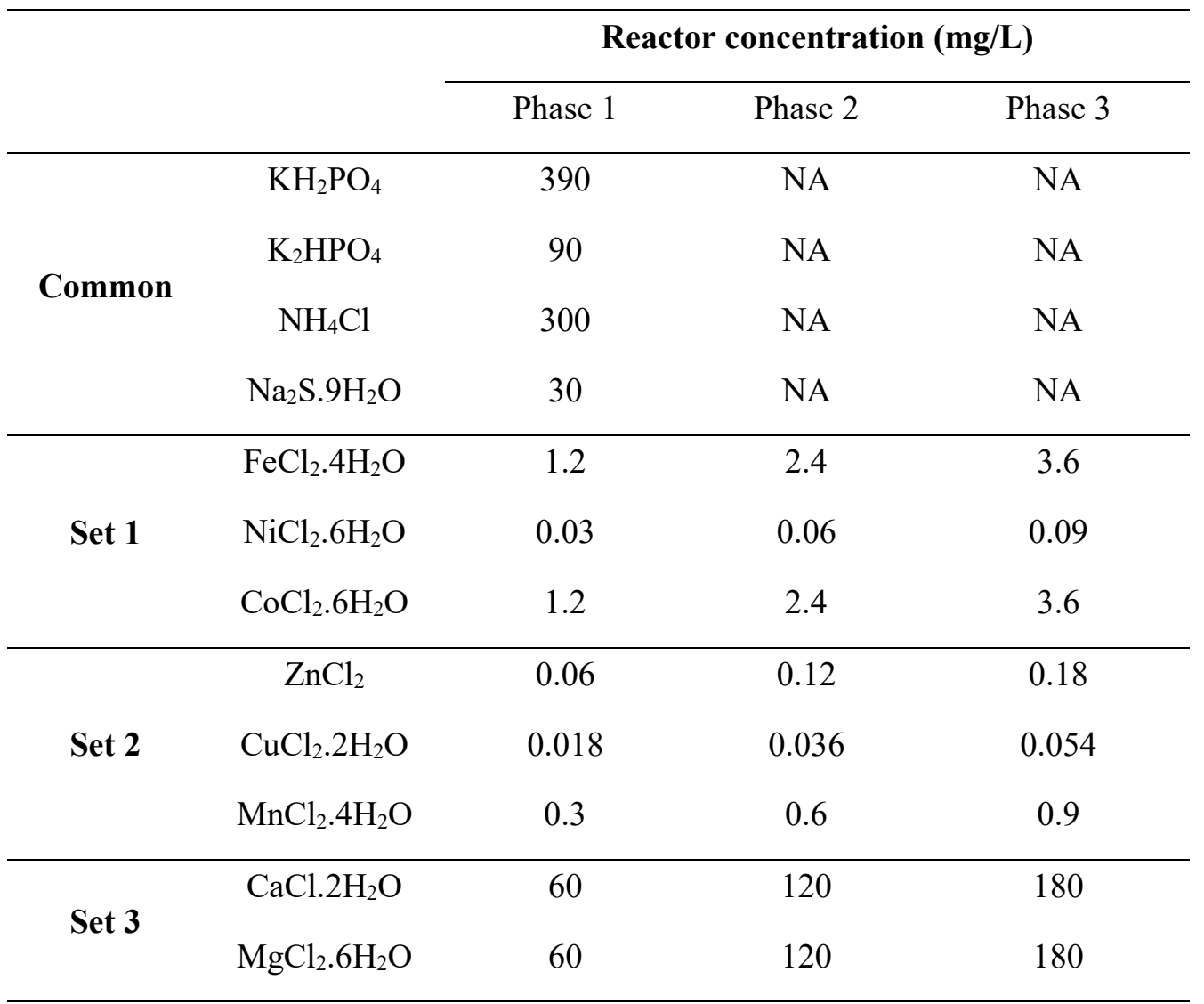

NA - Not Added

The supplemented concentrations are for the whole compounds 
Chapter 5: Effect of Ethylenediamine-N,N'-disuccinic acid (EDDS) on the speciation and bioavailability of $\mathrm{Fe}^{2+}$ in the presence of sulfide

\subsubsection{Determination of optimal concentration for $\mathrm{Fe}^{2+}$ in anaerobic digestion}

The aim of this study was to evaluate the speciation and bioavailability of $\mathrm{Fe}^{2+}$ in anaerobic digestion. The experiment was performed in batch reactors with $60 \mathrm{~mL}$ serum bottles ( $45 \mathrm{~mL}$ working volume). The initial biomass was $3 \mathrm{~g}$ $\mathrm{TSS} / \mathrm{L}$ in all test reactors, and different $\mathrm{Fe}^{2+}$ concentrations were evaluated i.e. 5, 10, 20, 30, and $50 \mathrm{mg} / \mathrm{L}$ as $\mathrm{FeCl}_{2} .4 \mathrm{H}_{2} \mathrm{O}$. Glucose (1.5 gCOD/L) and $\mathrm{NaHCO}_{3}$ ( $2 \mathrm{~g} / \mathrm{L})$ were added as substrate and buffer, respectively. The $\mathrm{pH}$ of all test bottles was adjusted to $7.0 \pm 0.1$ using diluted $\mathrm{NaOH}$ or $\mathrm{HCl}$, and the bottles were then incubated in a shaker at $35^{\circ} \mathrm{C}$ and $170 \mathrm{rpm}$.

\subsubsection{Biodegradation of EDDS in anaerobic digestion}

Since EDDS is a readily biodegradable chelating agent, it can be a source of carbon for anaerobic microorganisms, and hence can contribute to methane production. Therefore, in order to determine if the methane production from EDDS biodegradation was significant or not, a batch experiment was carried out in $60 \mathrm{~mL}$ serum bottles (45 mL working volume). A range of EDDS concentrations were tested, i.e. 5.24, 13.09, and $52.36 \mathrm{mg} / \mathrm{L}$, which were equivalent to the molar ratio to $\mathrm{Fe}^{2+}$ optimal concentration, i.e. $0.1: 1,0.25: 1$, and 1:1. Glucose $(1.5 \mathrm{gCOD} / \mathrm{L})$ and $\mathrm{NaHCO}_{3}(2 \mathrm{~g} / \mathrm{L})$ were added to all bottles as substrate and buffer, respectively, while EDDS was not added to the "Control" set.

\subsubsection{Effect of EDDS on $\mathrm{Fe}^{2+}$ concentration in the presence of sulfide in model media}

The aim of this study was to evaluate the effect of EDDS on $\mathrm{Fe}^{2+}$ in the presence of sulfide in a model media. The model media was prepared by centrifuging anaerobic sludge from a seed reactor and then filtering the supernatant through a $0.45 \mu \mathrm{m}$ filter. The experiment was carried out in $125 \mathrm{~mL}$ serum bottles with a $90 \mathrm{~mL}$ working volume. $\mathrm{Fe}^{2+}$ was added at the optimal 
Chapter 5: Effect of Ethylenediamine-N,N'-disuccinic acid (EDDS) on the speciation and bioavailability of $\mathrm{Fe}^{2+}$ in the presence of sulfide

concentration of $10 \mathrm{mg} / \mathrm{L}\left(3.34 \mathrm{mgFe} \mathrm{ge}^{2+} / \mathrm{gTSS}\right)$, and EDDS was pre-mixed with $\mathrm{Fe}^{2+}$ at different molar ratios i.e. 0.1:1, 0.25:1, 0.5:1, 0.75:1, and 1:1 overnight in the dark to prevent photo-degradation. Sulfide was added to all the test reactors at $8 \mathrm{mg} / \mathrm{L}$ as $\mathrm{Na}_{2} \mathrm{~S} .9 \mathrm{H}_{2} \mathrm{O}$, which is below its toxicity level (Mountfort \& Asher, 1979), and acetate/acetic acid solution was added to provide buffering capacity. The $\mathrm{pH}$ of all test bottles was then adjusted to $7.0 \pm 0.1$ at the start of the test using diluted $\mathrm{HCl}$, and the bottles were flushed with nitrogen for 2 minutes to ensure anaerobic conditions. Sampling was carried out immediately at the beginning, and six times within $40 \mathrm{~h}$.

\subsubsection{Effect of EDDS on $\mathrm{Fe}^{2+}$ bioavailability in the presence of sulfide in anaerobic digestion}

The experiment was performed in a batch setup with $60 \mathrm{~mL}$ serum bottles (45 mL working volume). The experimental conditions of this experiment were the same as for the experiments in Section 2.8 .4 i.e. $10 \mathrm{mg} / \mathrm{L} \mathrm{Fe}^{2+}(3.34$ $\mathrm{mgFe} \mathrm{g}^{2+} / \mathrm{gTSS}$ ); EDDS:Fe molar ratios 0.1:1, 0.25:1, 0.5:1, 0.75:1, and 1:1; 1.5 gCOD/L glucose; $2 \mathrm{~g} / \mathrm{L} \mathrm{NaHCO}_{3}$, except anaerobic sludge was used instead of model media. Sulfide was added at $8 \mathrm{mg} / \mathrm{L}$ as $\mathrm{Na}_{2} \mathrm{~S} .9 \mathrm{H}_{2} \mathrm{O}$ into all bottles except the "No S" set. The bottles were flushed with nitrogen for 2 minutes to ensure anaerobic conditions, and BCR sequential chemical extraction was carried out at the end of the experiment.

\subsection{Results and Discussion}

\subsubsection{Metal extraction of dried and wet samples with the BCR extraction method}

Sequential extraction is one of the important techniques which has been used extensively to determine the speciation of metals in different environmental samples. However, most of the studies in the literature involved extraction using dried samples, which are normally ground and sieved to 
Chapter 5: Effect of Ethylenediamine-N,N'-disuccinic acid (EDDS) on the speciation and bioavailability of $\mathrm{Fe}^{2+}$ in the presence of sulfide

achieve a homogeneous size. Rudd et al. (1988) and Ortner et al. (2014) compared the extraction of dried and wet samples using the Stover and Tessier methods, and found that dried samples not only required more preparation time, but also could cause an artificial shifting in metal speciation, e.g. the formation of metal oxides, although more reproducible results were obtained than with wet samples.

Figure 5.1 compares the extraction efficiencies of the most common metals present in anaerobic digesters, i.e. $\mathrm{Fe}, \mathrm{Ni}, \mathrm{Co}, \mathrm{Cu}, \mathrm{Zn}, \mathrm{Mn}, \mathrm{Ca}$, and $\mathrm{Mg}$ for both dried and wet samples. The extraction efficiency (\%) denotes the sum of the metal concentrations from all fractions over the pseudo-total concentration in $\mu \mathrm{g} / \mathrm{gTSS}$ (Table 5.2). The results show that the BCR method exhibits good recovery for all the metals for both dried and wet sample i.e. 89.0\% to $113.5 \%$, with the exception of $\mathrm{Co}$ and $\mathrm{Cu}$ for the dried sample i.e. $71.0 \%$ and $40.5 \%$, respectively. The findings from this experiment indicated that the extraction of metals using the BCR method with wet samples could not only produce comparable but also better extraction efficiencies than a dried sample. While the use of wet samples for metal extraction reduced the time required for sample preparation, it also eliminated the possibility of artificial altering the metal speciation. The later advantage is very important in the study of metal speciation and bioavailability as some of the TMs, particularly $\mathrm{Fe}^{2+}$, seems to be very sensitive to oxidation during the drying process (Ortner et al., 2014), and hence could possibly overestimate the fraction of Fe-Mn oxides. Therefore, wet sample extraction was found to be more suitable for the study of metal speciation and bioavailability in anaerobic digestion, and was used throughout this study. 
Chapter 5: Effect of Ethylenediamine-N,N'-disuccinic acid (EDDS) on the speciation and bioavailability of $\mathrm{Fe}^{2+}$ in the presence of sulfide

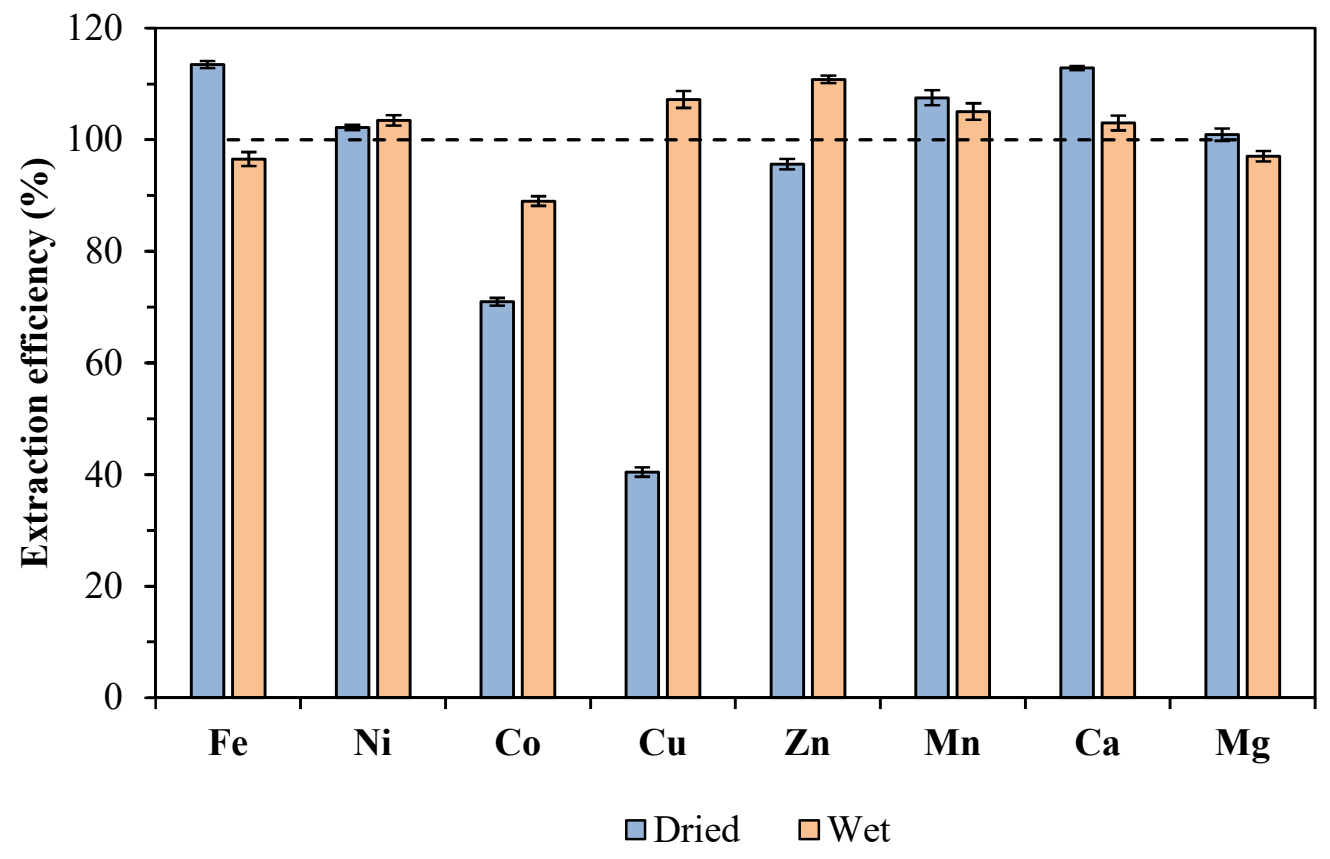

Figure 5.1 Extraction recovery as a percentage (\%) for metals in dried and wet samples $(\mathrm{n}=3)$.

Table 5.2 Extraction efficiency (\%) for each metal $(n=3)$.

\begin{tabular}{ccc}
\hline \multirow{2}{*}{ Metal } & \multicolumn{2}{c}{ Extraction efficiency (\%) } \\
\cline { 2 - 3 } & Dried sample & Liquid sample \\
\hline $\mathrm{Fe}$ & $113.5 \pm 0.6$ & $96.6 \pm 1.2$ \\
$\mathrm{Ni}$ & $102.2 \pm 0.5$ & $103.5 \pm 0.9$ \\
$\mathrm{Co}$ & $71.0 \pm 0.7$ & $89.0 \pm 0.9$ \\
$\mathrm{Cu}$ & $40.5 \pm 0.8$ & $107.2 \pm 1.5$ \\
$\mathrm{Zn}$ & $95.6 \pm 0.9$ & $110.8 \pm 0.7$ \\
$\mathrm{Mn}$ & $107.5 \pm 1.3$ & $105.1 \pm 0.5$ \\
$\mathrm{Ca}$ & $112.9 \pm 0.4$ & $103.0 \pm 1.3$ \\
$\mathrm{Mg}$ & $100.9 \pm 1.1$ & $97.1 \pm 0.9$ \\
\hline
\end{tabular}


Chapter 5: Effect of Ethylenediamine-N,N'-disuccinic acid (EDDS) on the speciation and bioavailability of $\mathrm{Fe}^{2+}$ in the presence of sulfide

\subsubsection{Effects of metal nutrient supplementation on methane production in anaerobic digestion}

The methane production rate $\left(\mathrm{mLCH}_{4} / \mathrm{d}\right)$ for each set was determined from the slope of the cumulative methane production graph from time zero to the plateau region. From Figure 5.2 it can be seen that the $\mathrm{Ca}+\mathrm{Mg}$ addition set had the highest rate of methane production in all three phases i.e. 58.9 $\mathrm{mLCH}_{4} / \mathrm{d}$ (Phase 1), $64.8 \mathrm{mLCH}_{4} / \mathrm{d}$ (Phase 2), and $59.2 \mathrm{mLCH}_{4} / \mathrm{d}$ (Phase 3) (Table 5.3) compared to other sets from each phase, with the P values less than 0.05 . Thus, the results confirm the importance of macro-nutrients in anaerobic digestion (White \& Stuckey, 2000; Merchant \& Helmann, 2012; Romero-Güiza et al., 2016). The set with the second highest rate of methane production was the $\mathrm{Fe}+\mathrm{Ni}+\mathrm{Co}$ set i.e. 40.2, 40.6, and $41.7 \mathrm{mLCH}_{4} / \mathrm{d}$, in phases 1,2 and 3 respectively. These transitional metals are considered the most essential TMs in anaerobic digestion (Oleszkiewicz \& Sharma, 1990). The methane production rate for the last metal set $\mathrm{Cu}+\mathrm{Zn}+\mathrm{Mn}$ was not statistically different to the No Metal set.

For the $\mathrm{Ca}+\mathrm{Mg}$ set, the maximum methane production rate was observed in Phase 2 i.e. $64.8 \mathrm{mLCH}_{4} / \mathrm{d}$ when the concentrations were doubled i.e. 180 $\mathrm{mg} / \mathrm{L}$ as $\mathrm{CaCl} .2 \mathrm{H}_{2} \mathrm{O}$ and $\mathrm{MgCl}_{2} \cdot 6 \mathrm{H}_{2} \mathrm{O}$. Accordingly, the time required to reach the maximum rate of methane production (Max Time) was also the shortest in Phase 2 i.e. $64 \mathrm{~h}$ (Table 5.3); this indicated that the optimal concentrations for $\mathrm{Ca}$ and $\mathrm{Mg}$ could be from 180 to $250 \mathrm{mg} / \mathrm{L}$ (Owen et al., 1979).

For the $\mathrm{Fe}+\mathrm{Ni}+\mathrm{Co}$ set, when their concentrations increased the methane production rate also increased (statistically significantly) from $40.2 \mathrm{mLCH}_{4} / \mathrm{d}$ to $41.7 \mathrm{mLCH}_{4} / \mathrm{d}$. Accordingly, the maximum time (Max Time) to peak gas production decreased from $115 \mathrm{~h}$ to $96 \mathrm{~h}$ (Table 5.3). Therefore, the optimal concentrations for $\mathrm{Fe}, \mathrm{Ni}$, and $\mathrm{Co}$ might be even higher than the dosage in Phase 3 i.e. 3.6, 0.09, and $3.6 \mathrm{mg} / \mathrm{L}$, respectively. For the $\mathrm{Cu}+\mathrm{Zn}+\mathrm{Mn}$ set, the trend was in contrast to the $\mathrm{Fe}+\mathrm{Ni}+\mathrm{Co}$ set as the methane production rate decreased from $38.3 \mathrm{mLCH}_{4} / \mathrm{d}$ to $32.6 \mathrm{mLCH}_{4} / \mathrm{d}$ when the dosage increased. 
Chapter 5: Effect of Ethylenediamine-N,N'-disuccinic acid (EDDS) on the speciation and bioavailability of $\mathrm{Fe}^{2+}$ in the presence of sulfide

The Max Time increased from $121 \mathrm{~h}$ to $123 \mathrm{~h}$ (Table 5.3) which showed some inhibitory effects of $\mathrm{Cu}, \mathrm{Zn}$, or $\mathrm{Mn}$ above their optimal concentrations. The overall results confirm that the rate of methane production was co-limited by one/several metals, and that the systematic addition of limiting metals could improve the rate of methane production and yields.

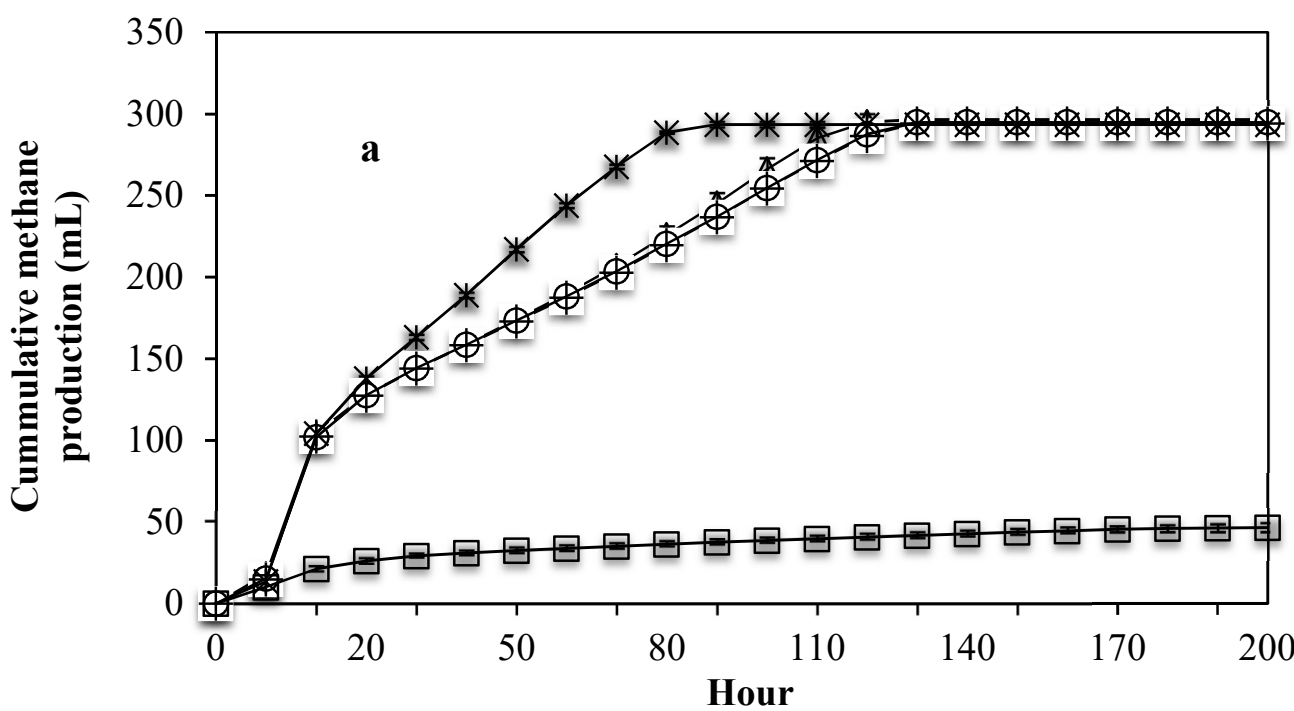

$\triangle \mathrm{Fe}+\mathrm{Co}+\mathrm{Ni} \quad+-\mathrm{Cu}+\mathrm{Zn}+\mathrm{Mn} \quad *-\mathrm{Ca}+\mathrm{Mg} \quad-$ No metal $\square-\mathrm{Control}$

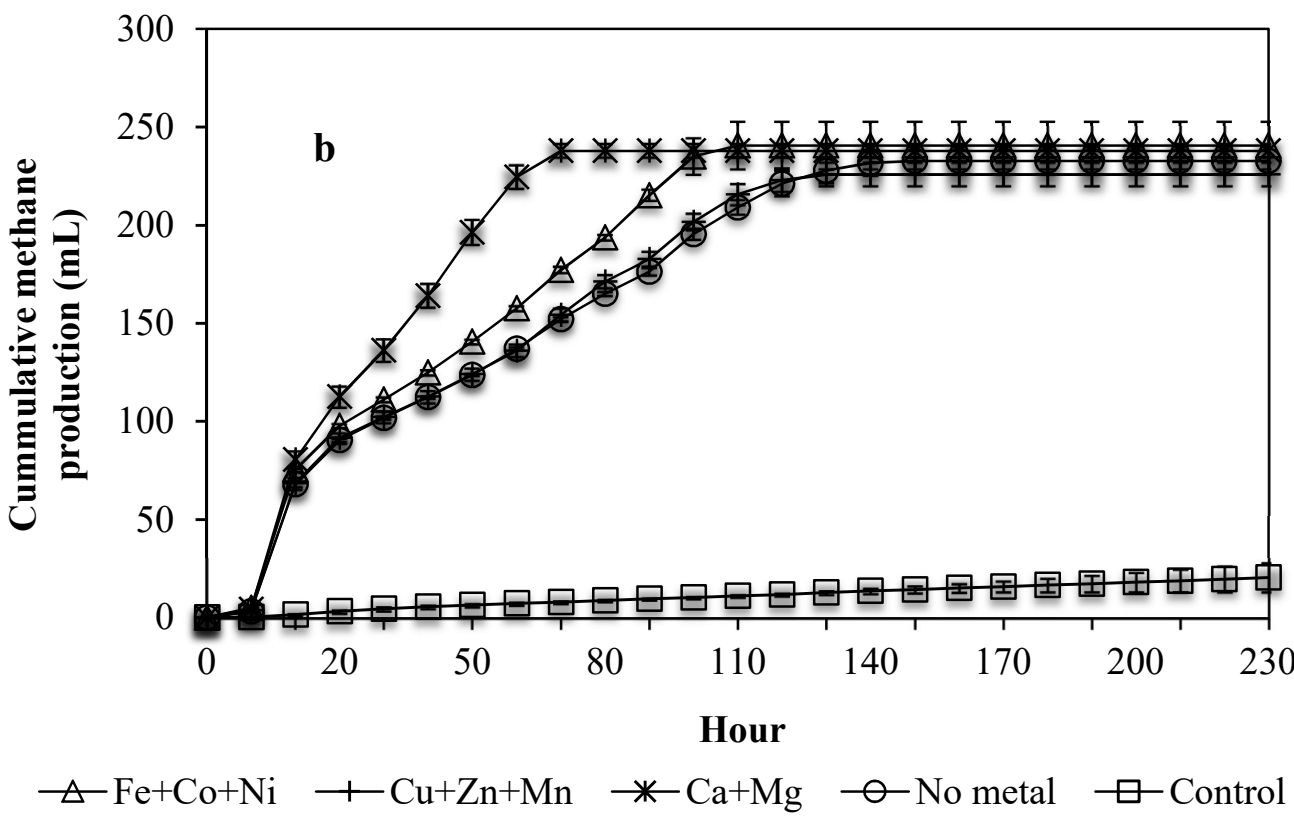


Chapter 5: Effect of Ethylenediamine-N,N'-disuccinic acid (EDDS) on the speciation and bioavailability of $\mathrm{Fe}^{2+}$ in the presence of sulfide

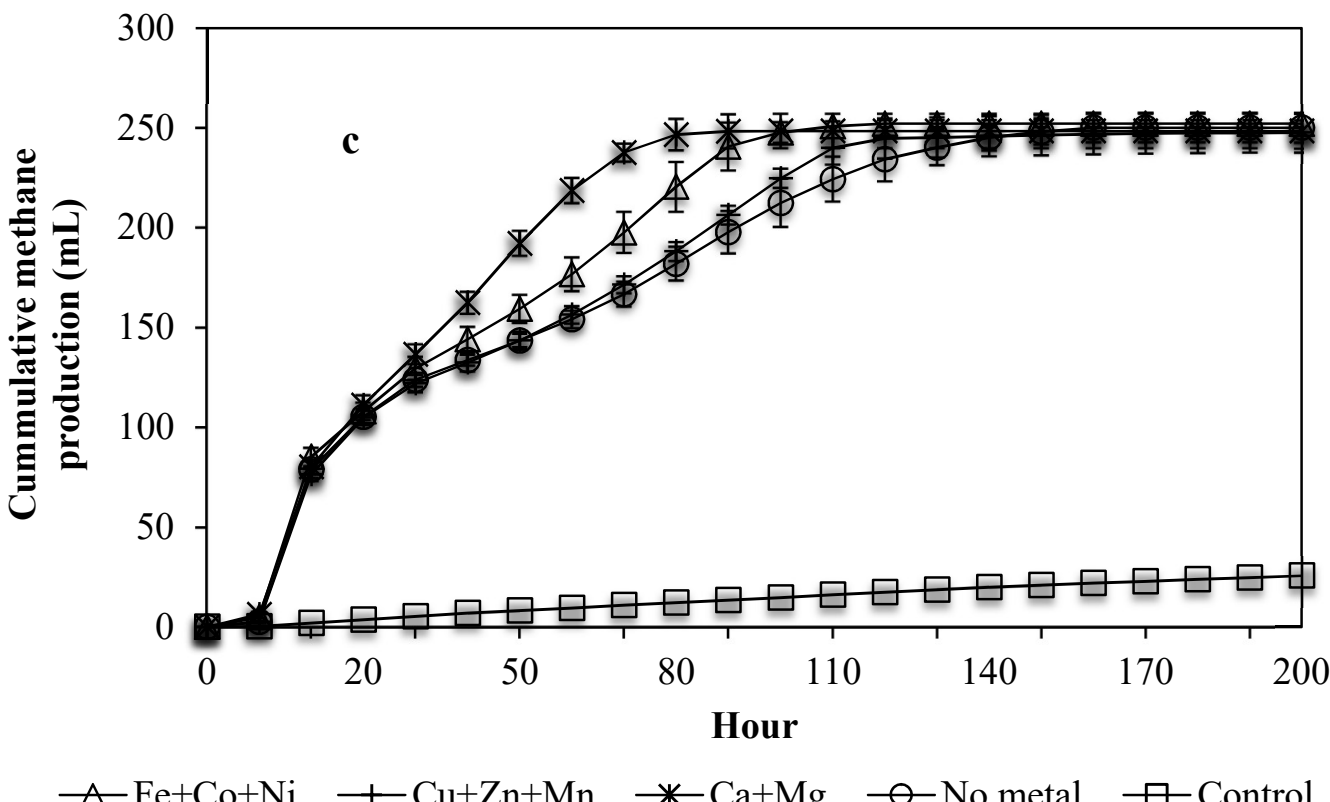

Figure 5.2 Cumulative methane production (mL) (a) Phase 1, (b) Phase 2, (c) Phase $3(n=3)$.

Table 5.3 Methane production rate $\left(\mathrm{mLCH}_{4} / \mathrm{d}\right)$ and time to reach maximum methane production rate (Max Time $h)(n=3)$.

\begin{tabular}{|c|c|c|c|c|c|c|c|c|}
\hline & \multicolumn{2}{|c|}{$\mathrm{Fe}+\mathrm{Ni}+\mathrm{Co}$} & \multicolumn{2}{|c|}{$\mathbf{C u}+\mathbf{Z n}+\mathbf{M n}$} & \multicolumn{2}{|c|}{$\mathrm{Ca}+\mathbf{M g}$} & \multicolumn{2}{|c|}{ No Metal } \\
\hline & $\begin{array}{c}\mathrm{mLCH}_{4} / \\
\mathrm{d}\end{array}$ & $\begin{array}{c}\text { Max } \\
\text { Time } \\
\text { (h) }\end{array}$ & $\begin{array}{c}\mathrm{mLCH}_{4} / \\
\mathrm{d}\end{array}$ & $\begin{array}{c}\text { Max } \\
\text { Time } \\
\text { (h) }\end{array}$ & $\begin{array}{c}\mathrm{mLCH}_{4} \\
/ \mathrm{d}\end{array}$ & $\begin{array}{c}\text { Max } \\
\text { Time } \\
\text { (h) }\end{array}$ & $\begin{array}{c}\mathrm{mLCH}_{4} \\
/ \mathrm{d}\end{array}$ & $\begin{array}{l}\text { Max } \\
\text { Time } \\
\text { (h) }\end{array}$ \\
\hline Phase 1 & 40.2 & 115 & 38.3 & 121 & 58.9 & 83 & 38.4 & 122 \\
\hline Phase 2 & 40.6 & 104 & 32.7 & 123 & 64.8 & 64 & 31.0 & 134 \\
\hline Phase 3 & 41.7 & 96 & 32.6 & 123 & 59.2 & 75 & 27.7 & 143 \\
\hline
\end{tabular}


Chapter 5: Effect of Ethylenediamine-N,N'-disuccinic acid (EDDS) on the speciation and bioavailability of $\mathrm{Fe}^{2+}$ in the presence of sulfide

At the end of Phase 3, chemical sequential extraction using the BCR method with wet samples was carried out to fractionate the metals remaining in each test bottle. Figure 5.3 (a-h) shows the fractionation, while Figure 5.4 compares the percentage of the sum of Soluble (Sol) and Exchangeable (F1) fractions to the total content for all the metals. The Soluble and Exchangeable fractions are considered the most bioavailable fractions for microbial uptake. It can be seen that the metal speciation in the most bioavailable fraction correlated well with the methane production rate in each of the metal groups. The $\mathrm{Ca}+$ $\mathrm{Mg}$ set had the highest percentage, i.e. $81.5 \%(\mathrm{Ca})$ and $81.9 \%(\mathrm{Mg})$, following by the $\mathrm{Fe}+\mathrm{Co}+\mathrm{Ni}$ set i.e. $12.6 \%(\mathrm{Fe}), 45.8 \%(\mathrm{Co})$ and $49.6 \%(\mathrm{Ni})$, and $\mathrm{Cu}+$ $\mathrm{Mn}+\mathrm{Zn}$ set i.e. $1.3 \%(\mathrm{Cu}), 12.3 \%(\mathrm{Mn})$ and $58.1 \%(\mathrm{Zn})$. This similar trend between metal speciation and methane production rate showed that the availability of metals in the more bioavailable fractions led to a higher metal uptake, and hence a higher methane production rate.

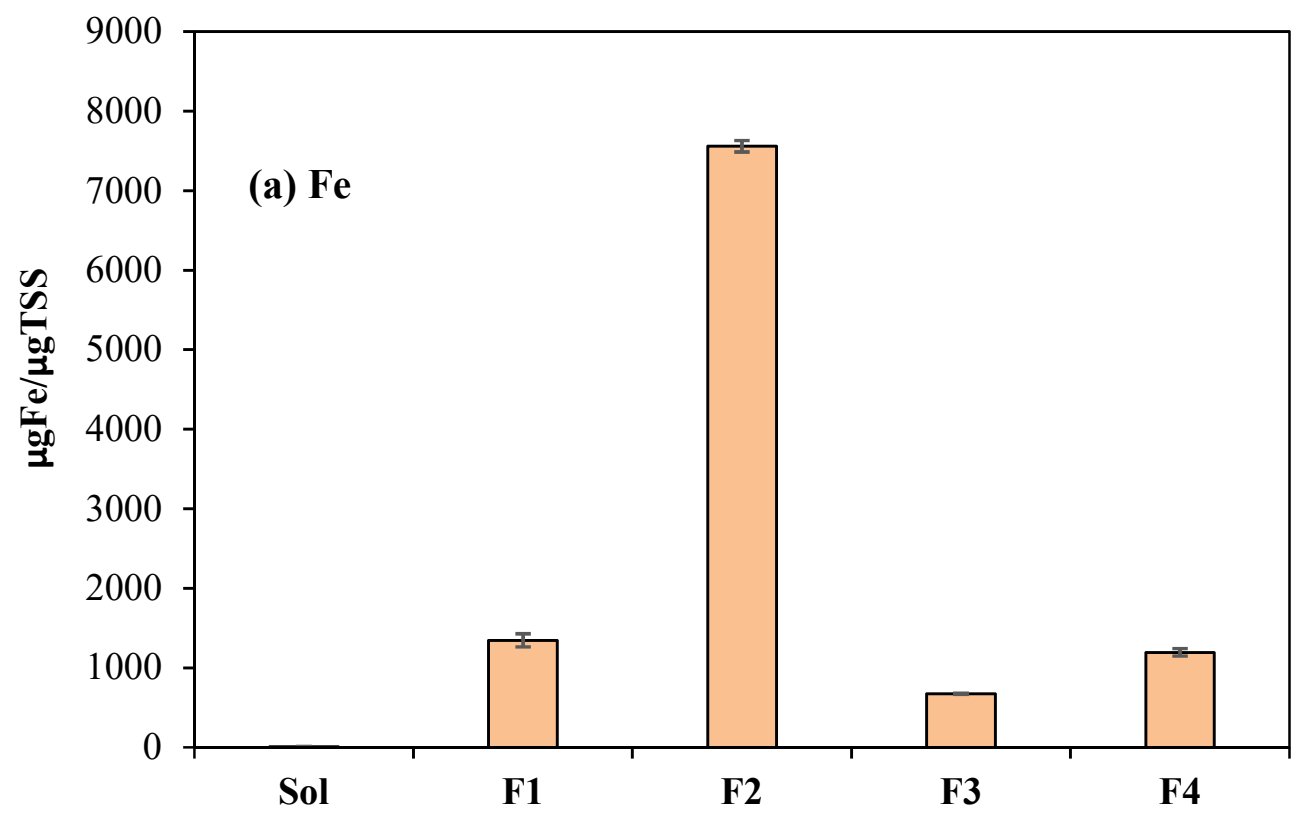


Chapter 5: Effect of Ethylenediamine-N,N'-disuccinic acid (EDDS) on the speciation and bioavailability of $\mathrm{Fe}^{2+}$ in the presence of sulfide
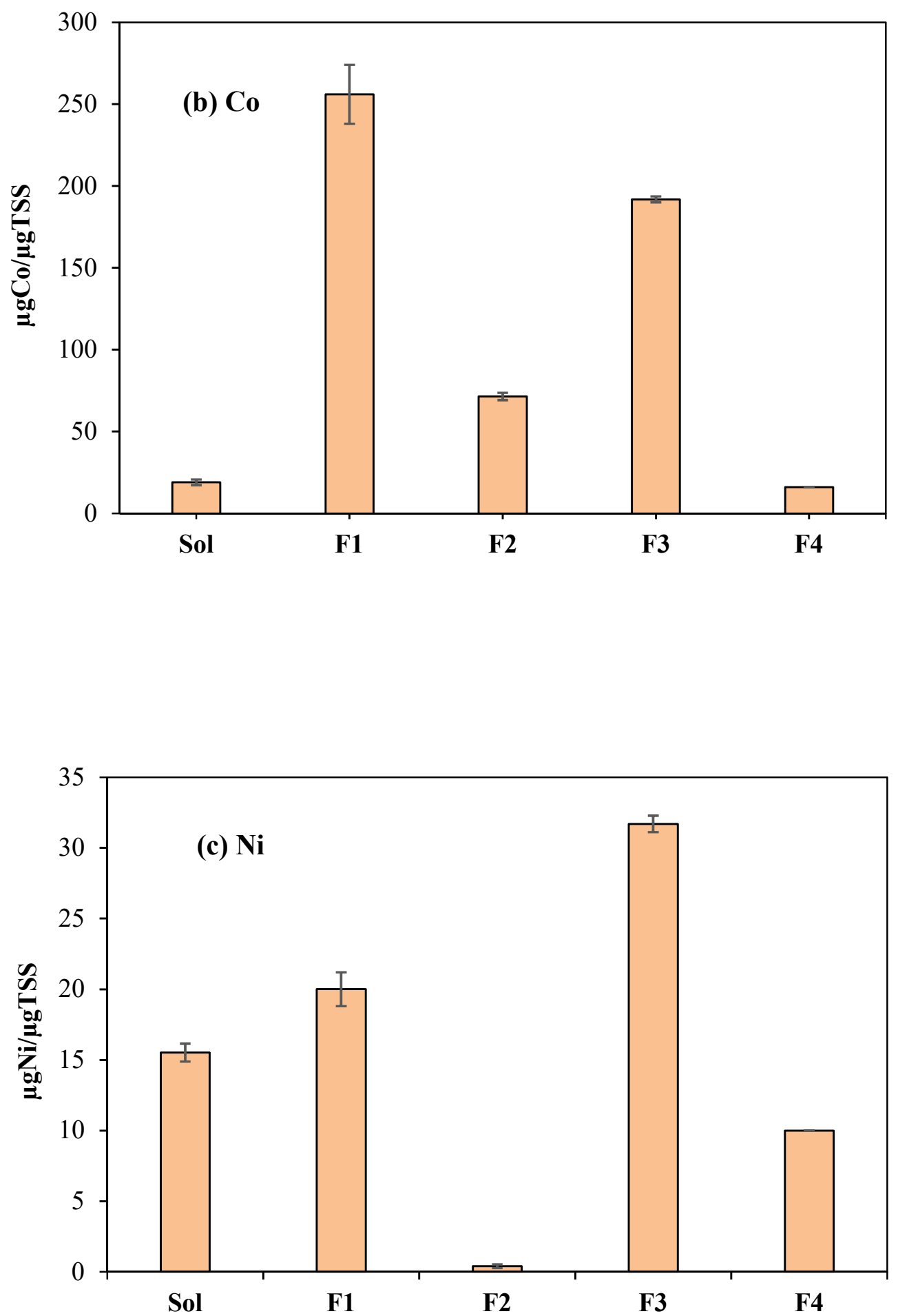
Chapter 5: Effect of Ethylenediamine-N,N'-disuccinic acid (EDDS) on the speciation and bioavailability of $\mathrm{Fe}^{2+}$ in the presence of sulfide
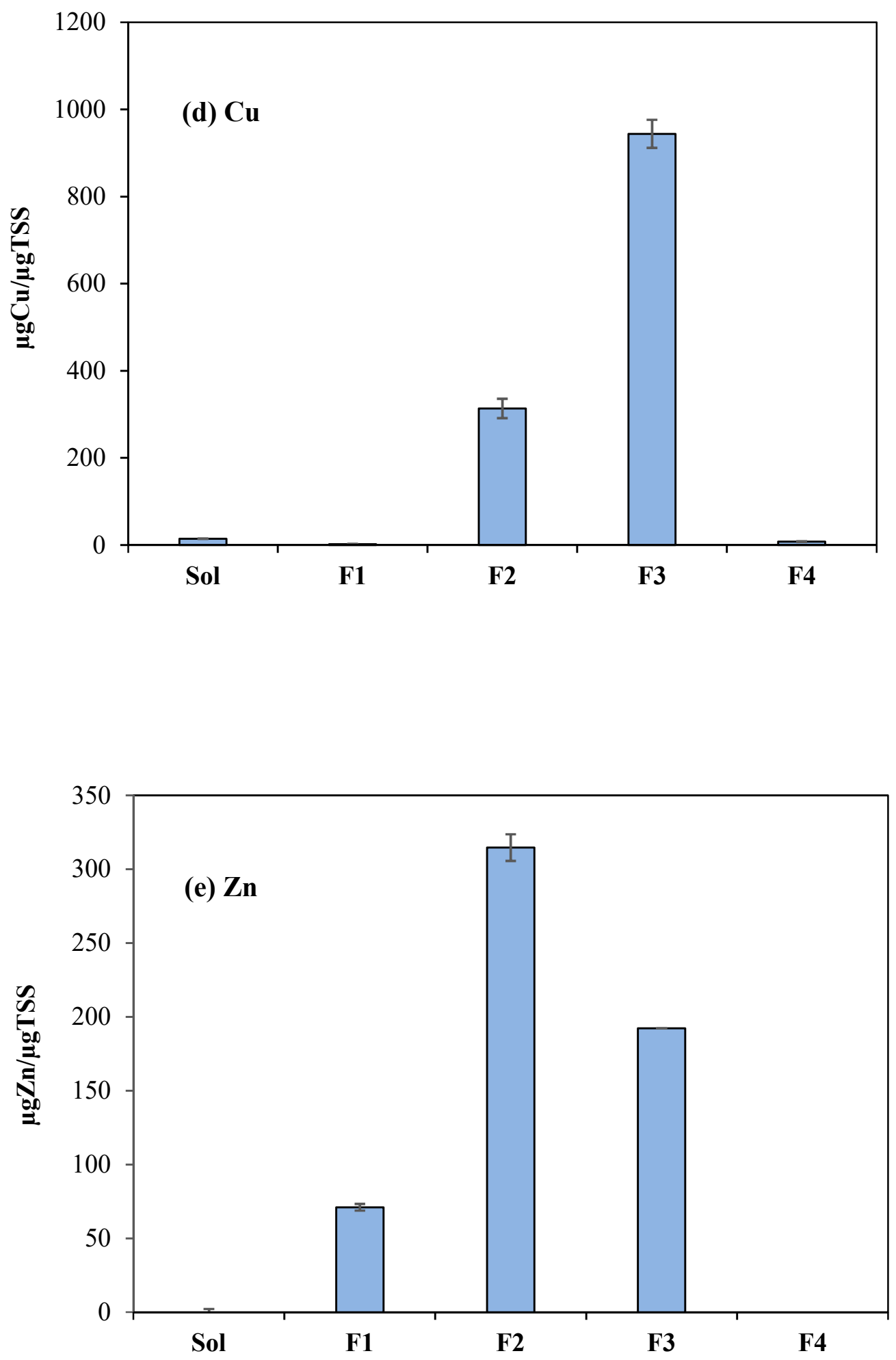
Chapter 5: Effect of Ethylenediamine-N,N'-disuccinic acid (EDDS) on the speciation and bioavailability of $\mathrm{Fe}^{2+}$ in the presence of sulfide
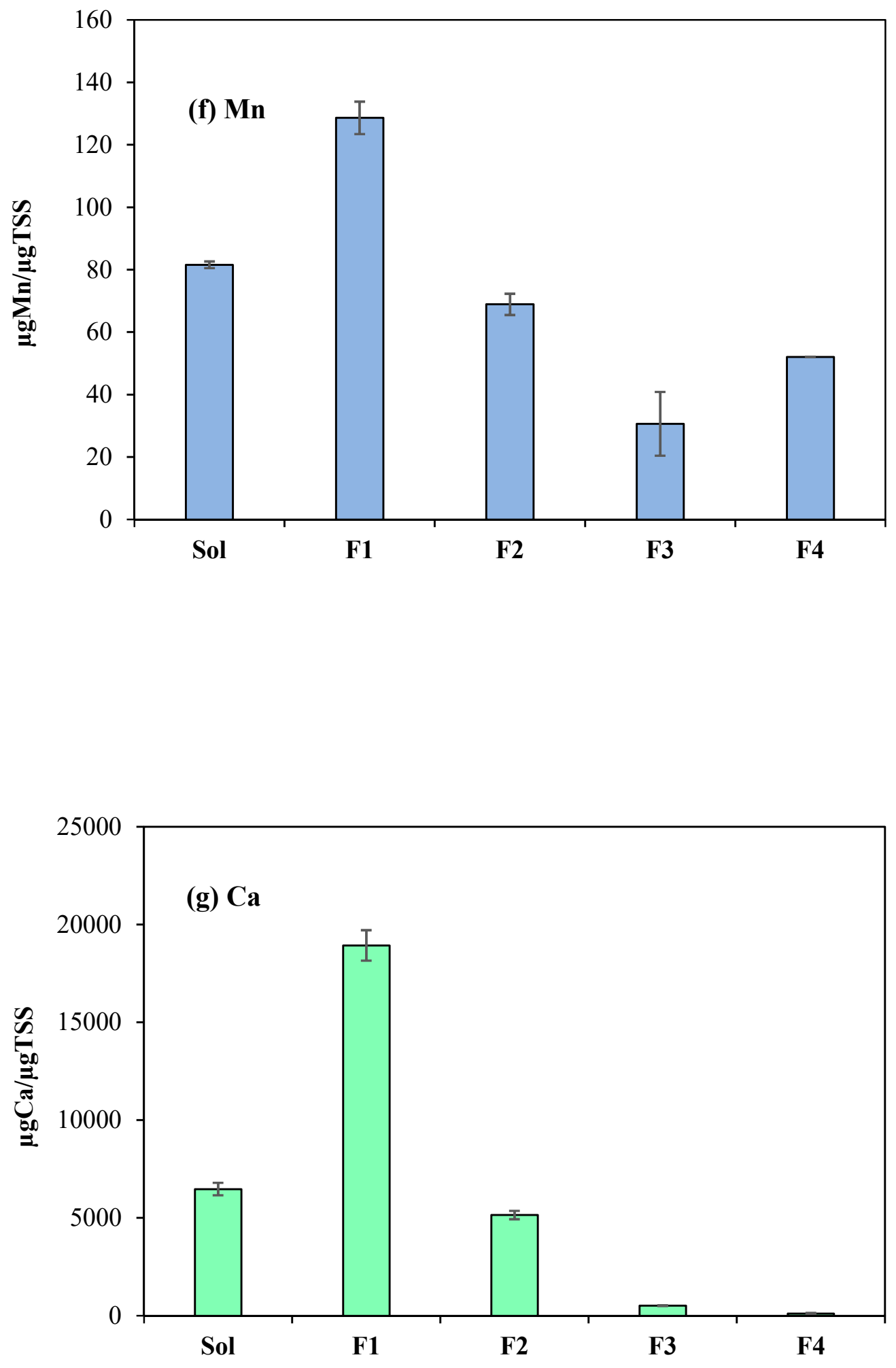
Chapter 5: Effect of Ethylenediamine-N,N'-disuccinic acid (EDDS) on the speciation and bioavailability of $\mathrm{Fe}^{2+}$ in the presence of sulfide

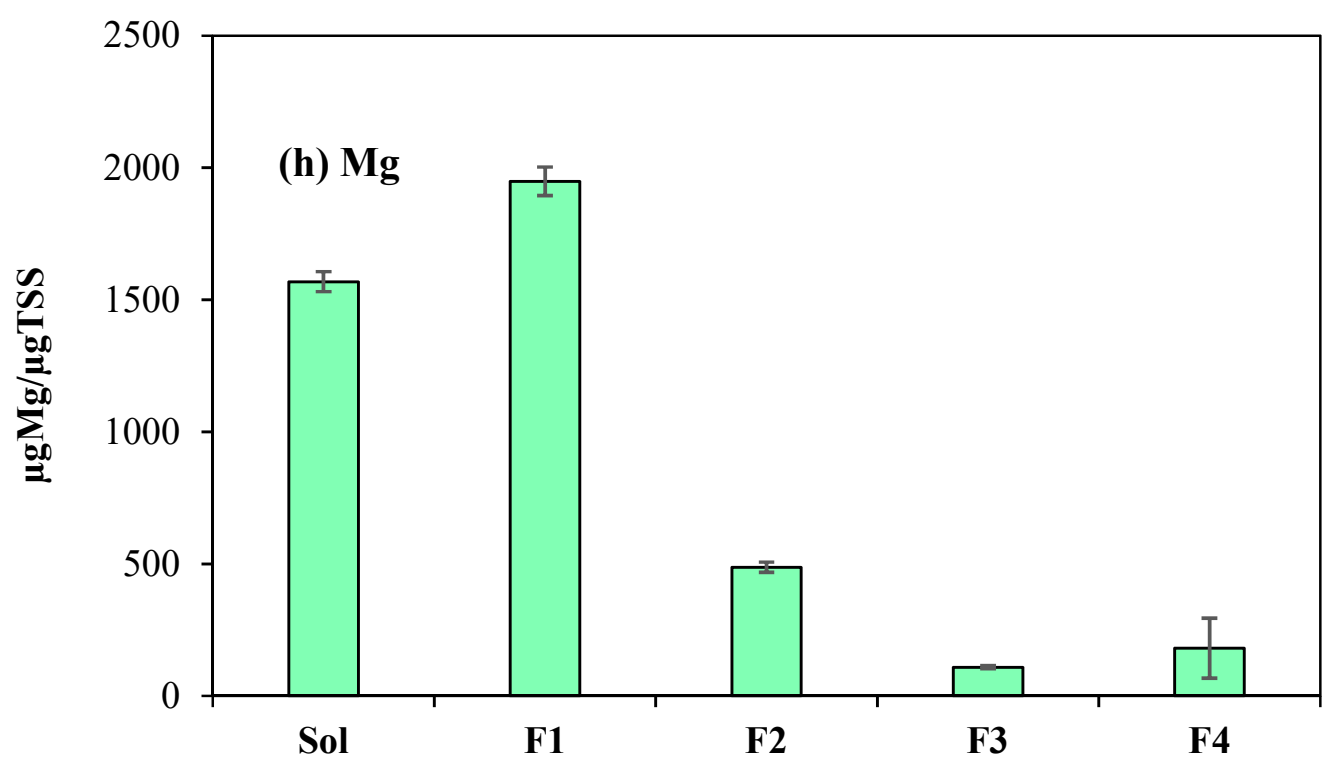

Sol - Soluble, F1 - Exchangeable, F2 - Fe/Mn oxides, F3 - Organic matter, F4 - Residual

Figure 5.3 Sequential extraction for each metal (a-h) at the end of Phase 3 using the BCR method $(n=3)$.

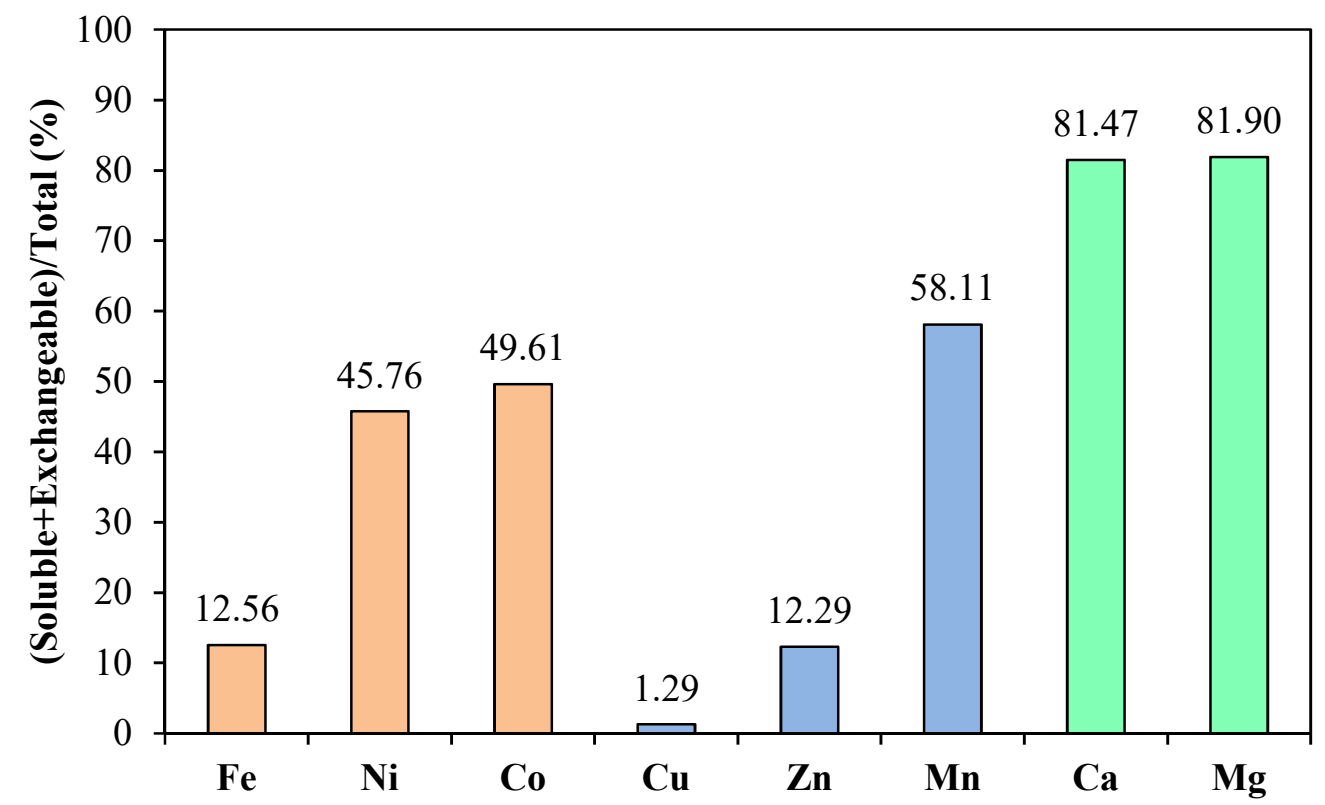

Figure 5.4 Percentage of (Soluble + Exchangeable fraction)/Total metal content $(\mathrm{n}=3)$. 
Chapter 5: Effect of Ethylenediamine-N,N'-disuccinic acid (EDDS) on the speciation and bioavailability of $\mathrm{Fe}^{2+}$ in the presence of sulfide

\subsubsection{Determination of optimal concentration for $\mathrm{Fe}^{2+}$ in anaerobic digestion}

Iron $(\mathrm{Fe})$ is one of the most important TMs in anaerobic digestion, together with $\mathrm{Co}$ and $\mathrm{Ni}$. The importance of $\mathrm{Fe}^{2+}$ in anaerobic digestion depends on its redox properties, and its involvement in energy metabolism (Takashima \& Speece, 1989). The stimulating effect of $\mathrm{Fe}^{2+}$ is attributed to its ability to improve acetate utilization by methanogens (Speece, 1962), and its role in the transport system of methanogens for the conversion of $\mathrm{CO}_{2}$ to $\mathrm{CH}_{4}$ (Vintiloiu et al., 2013). Therefore, $\mathrm{Fe}^{2+}$ plays an important role in improving the degradation of VFAs (Zandvoort et al., 2003; Zitomer et al., 2008; Ketheesan et al., 2016). Since the reported optimal concentration for TMs including $\mathrm{Fe}^{2+}$ varies significantly between studies, which could be due to different experimental conditions i.e. substrate type, seed sludge source, and temperature (Thanh et al., 2016), the aim of this experiment was to determine the optimal concentration for $\mathrm{Fe}^{2+}$ required for the seed sludge from anaerobic bioreactors in this study.

The seed sludge used for this experiment was grown in $\mathrm{Fe}^{2+}$ - deficient conditions, and the level of $\mathrm{Fe}^{2+}$ in the seed sludge was found to be 0.08 $\mathrm{mgFe}^{2+} / \mathrm{gTSS}$, which was well below the lowest added $\mathrm{Fe}^{2+}$ concentration i.e. $1.53 \mathrm{mgFe}^{2+} / \mathrm{gTSS}\left(5 \mathrm{mg} / \mathrm{L} \mathrm{Fe}^{2+}\right.$ ). Figure 5.5 shows the methane yields $\left(\mathrm{mLCH}_{4} / \mathrm{gVSS}\right)$ at different $\mathrm{Fe}^{2+}$ concentrations. The results show that the supplementation of $\mathrm{Fe}^{2+}$ at different concentrations had different effects on methane production; at low concentrations supplementation of $\mathrm{Fe}^{2+}$ stimulated methane production. Methane yields increased compared to the control set (no Fe added) (65.5 $\left.\mathrm{mLCH}_{4} / \mathrm{gVSS}\right)$ when $\mathrm{Fe}^{2+}$ concentration increased from 5 to 10 then $20 \mathrm{mg} / \mathrm{L}$, but it reached the maximum at $10 \mathrm{mg} / \mathrm{L}\left(68.5 \mathrm{mLCH}_{4} / \mathrm{gVSS}\right)$. A statistical analysis (t-test) indicated that the increase in methane yields was statistically significant at $10 \mathrm{mg} / \mathrm{L} \mathrm{Fe}^{2+}$ concentration. However, at higher $\mathrm{Fe}^{2+}$ concentrations, i.e. 30 and $50 \mathrm{mg} / \mathrm{L}$, a slight inhibitory effect on the methanogens was observed as the methane yields i.e. $62.8 \mathrm{mLCH}_{4} / \mathrm{gVSS}(50$ $\mathrm{mg} / \mathrm{L} \mathrm{Fe}^{2+}$ ) dropped significantly compared to the control set i.e. 65.5 
Chapter 5: Effect of Ethylenediamine-N,N'-disuccinic acid (EDDS) on the speciation and bioavailability of $\mathrm{Fe}^{2+}$ in the presence of sulfide

$\mathrm{mLCH}_{4} / \mathrm{gVSS}$. It is believed that when the free ion concentration of a metal exceeds some threshold value, possible inhibiting mechanisms could disrupt enzyme function and structure by binding with thiol and other groups on protein molecules, or by replacing natural metals in enzyme prosthetic groups (Chen et al., 2014b).

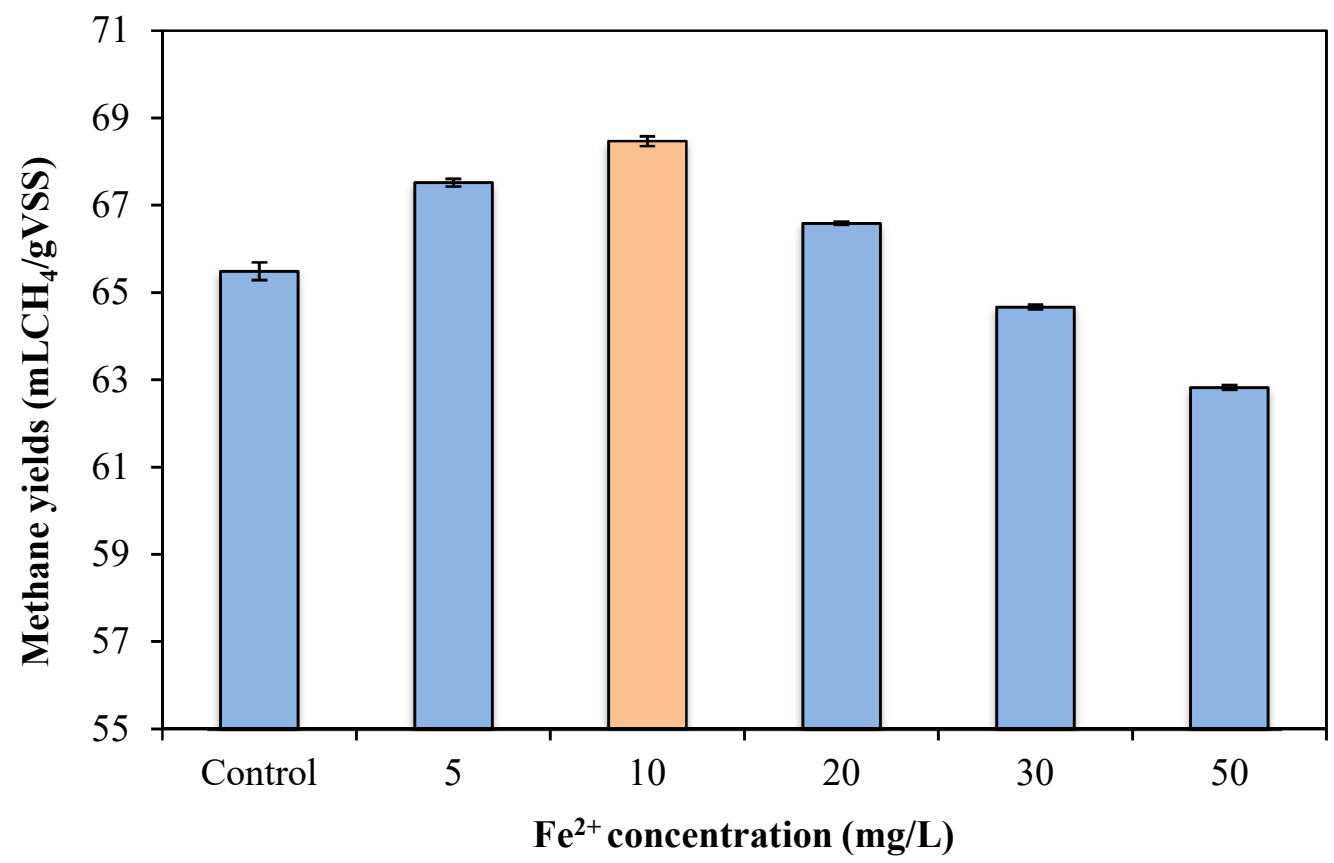

Figure 5.5 Methane yields $\left(\mathrm{mLCH}_{4} / \mathrm{gVSS}\right)$ at different $\mathrm{Fe}^{2+}$ concentrations

$$
(n=3) \text {. }
$$

The results from this experiment showed that the optimal concentration for $\mathrm{Fe}^{2+}$ in anaerobic digestion was $10 \mathrm{mg} / \mathrm{L}\left(3.34 \mathrm{mgFe}^{2+} / \mathrm{gTSS}\right)$, and this was in agreement with the findings of Sharma and Singh (2001). As mentioned in the literature review (Table 2.1), the reported optimal concentration for $\mathrm{Fe}^{2+}$ varies significantly, i.e. $0.55 \mathrm{mg} / \mathrm{L}$ (Zandvoort et al., 2003) to $100 \mathrm{mg} / \mathrm{L}$ (Zhang et al., 2015b), and these differences depend on the substrate type, operating temperature (mesophilic or thermophilic), digestion operating mode (mono or 
Chapter 5: Effect of Ethylenediamine-N,N'-disuccinic acid (EDDS) on the speciation and bioavailability of $\mathrm{Fe}^{2+}$ in the presence of sulfide

co-digestion), and also type of methanogens. Therefore, the optimal concentration for TMs can only be reported and applied for a specific study.

\subsubsection{Biodegradation of EDDS in anaerobic digestion}

As can be seen in Figure 5.6, when the EDDS concentration increased from $0.1: 1$ to $0.25: 1$, and then to $1: 1 \mathrm{EDDS}: \mathrm{Fe}^{2+}$ molar ratio at $10 \mathrm{mg} / \mathrm{L} \mathrm{Fe}^{2+}$, the methane yields decreased from $93.7 \mathrm{mLCH}_{4} / \mathrm{gVSS}$ to $91.1 \mathrm{mLCH}_{4} / \mathrm{gVSS}$, and to $90.4 \mathrm{mLCH}_{4} / \mathrm{gVSS}$, respectively, after $106 \mathrm{~h}$. However, the methane yields observed from all of the EDDS concentrations were not significantly different compared to the control set (no EDDS) $\left(88.9 \mathrm{mLCH}_{4} / \mathrm{gVSS}\right)$ with a $\mathrm{P}$ value of $0.068,0.106$, and 0.359 for the $0.1: 1,0.25: 1$, and $1: 1$ molar ratios, respectively. In another independent experiment, the time required for a similar amount of EDDS at a 1:1 molar ratio to $10 \mathrm{mg} / \mathrm{L} \mathrm{Fe}^{2+}\left(3.34 \mathrm{mgFe} e^{2+} / \mathrm{gTSS}\right)$ to be completely biodegraded in anaerobic cultures was found to be around 7 days $(168 \mathrm{~h})$, which is longer than the duration of this experiment $(106 \mathrm{~h})$. Therefore, it can be concluded that within $106 \mathrm{~h}$, when EDDS was added in a 1:1 EDDS: $\mathrm{Fe}^{2+}$ molar ratio to the methane bioassay, the contribution of its biodegradation to methane production was not statistically significant. 
Chapter 5: Effect of Ethylenediamine-N,N'-disuccinic acid (EDDS) on the speciation and bioavailability of $\mathrm{Fe}^{2+}$ in the presence of sulfide

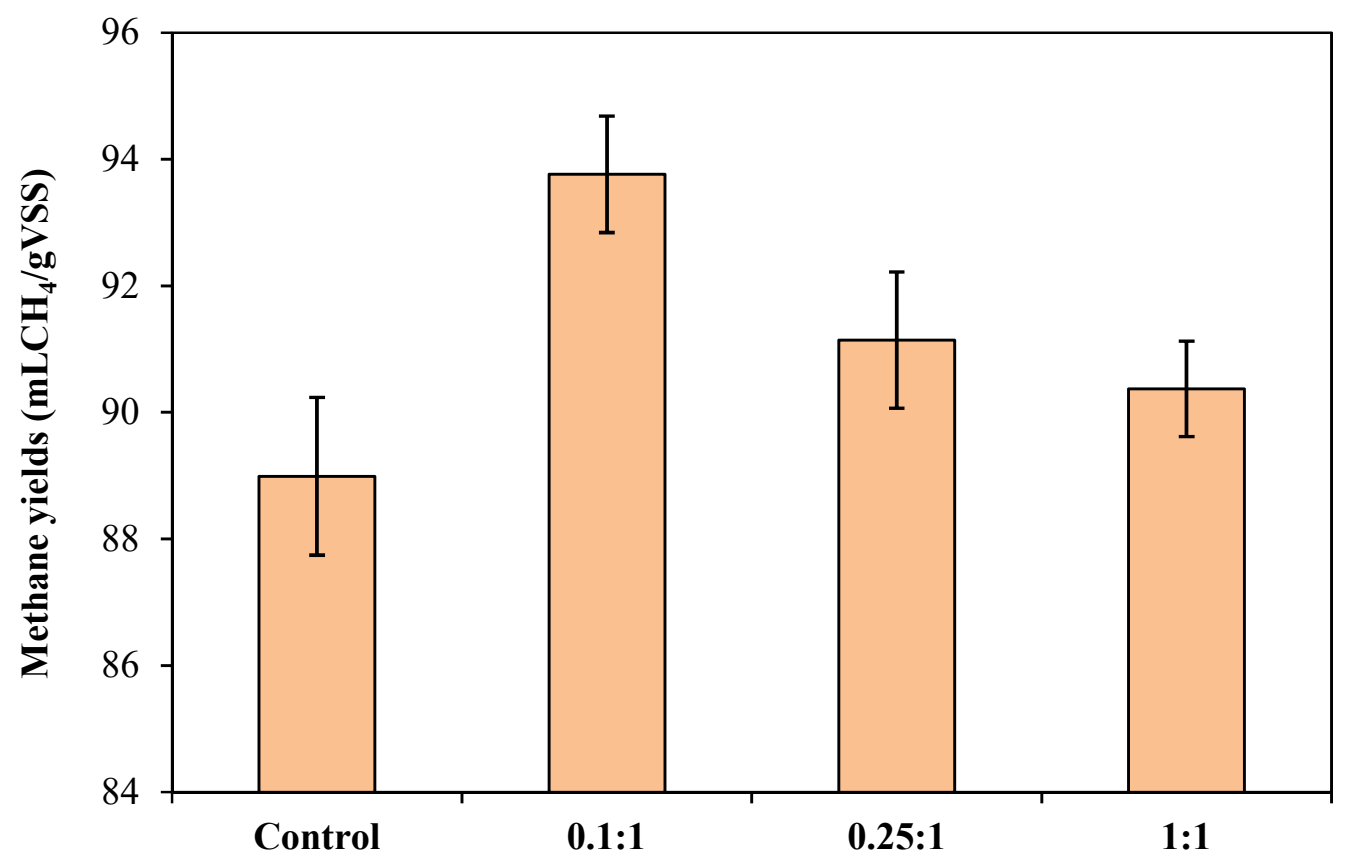

Figure 5.6 Methane yields ( $\left.\mathrm{mLCH}_{4} / \mathrm{gVSS}\right)$ at different EDDS:Fe molar ratios $(n=3)$.

\subsubsection{Effect of EDDS on $\mathrm{Fe}^{2+}$ concentration in the presence of sulfide in model media}

Figure 5.7 shows the remaining soluble $\mathrm{Fe}^{2+}$ concentration without EDDS and with EDDS at different molar ratios to $10 \mathrm{mg} / \mathrm{L} \mathrm{Fe}^{2+}\left(3.34 \mathrm{mgFe}{ }^{2+} / \mathrm{gTSS}\right)$. The results confirmed that at time zero (immediately after $\mathrm{pH}$ adjustment), the soluble $\mathrm{Fe}^{2+}$ concentration in all sets was reduced significantly as the $\mathrm{Fe}^{2+}$ was precipitated as FeS. As expected, without EDDS soluble $\mathrm{Fe}^{2+}$ was zero within the first $2 \mathrm{~h}$, however, as the EDDS:Fe molar ratio increased, the $\mathrm{Fe}^{2+}$ concentration remaining in the soluble form also increased from $0.09 \mathrm{mg} / \mathrm{L}$ to $3.32 \mathrm{mg} / \mathrm{L}$. In other words, the addition of EDDS was able to keep the $\mathrm{Fe}^{2+}$ in a soluble form up to $33.6 \%$ at a 1:1 molar ratio in the presence of $8 \mathrm{mg} / \mathrm{L} \mathrm{S}^{2-}$. The remaining soluble $\mathrm{Fe}^{2+}$ concentration at all molar ratios seemed to be constant after $10 \mathrm{~h}$. The results from this experiment showed that the addition of EDDS was able to keep $\mathrm{Fe}^{2+}$ in a soluble form as the Fe-EDDS complex, even in the presence of sulfide. 
Chapter 5: Effect of Ethylenediamine-N,N'-disuccinic acid (EDDS) on the speciation and bioavailability of $\mathrm{Fe}^{2+}$ in the presence of sulfide

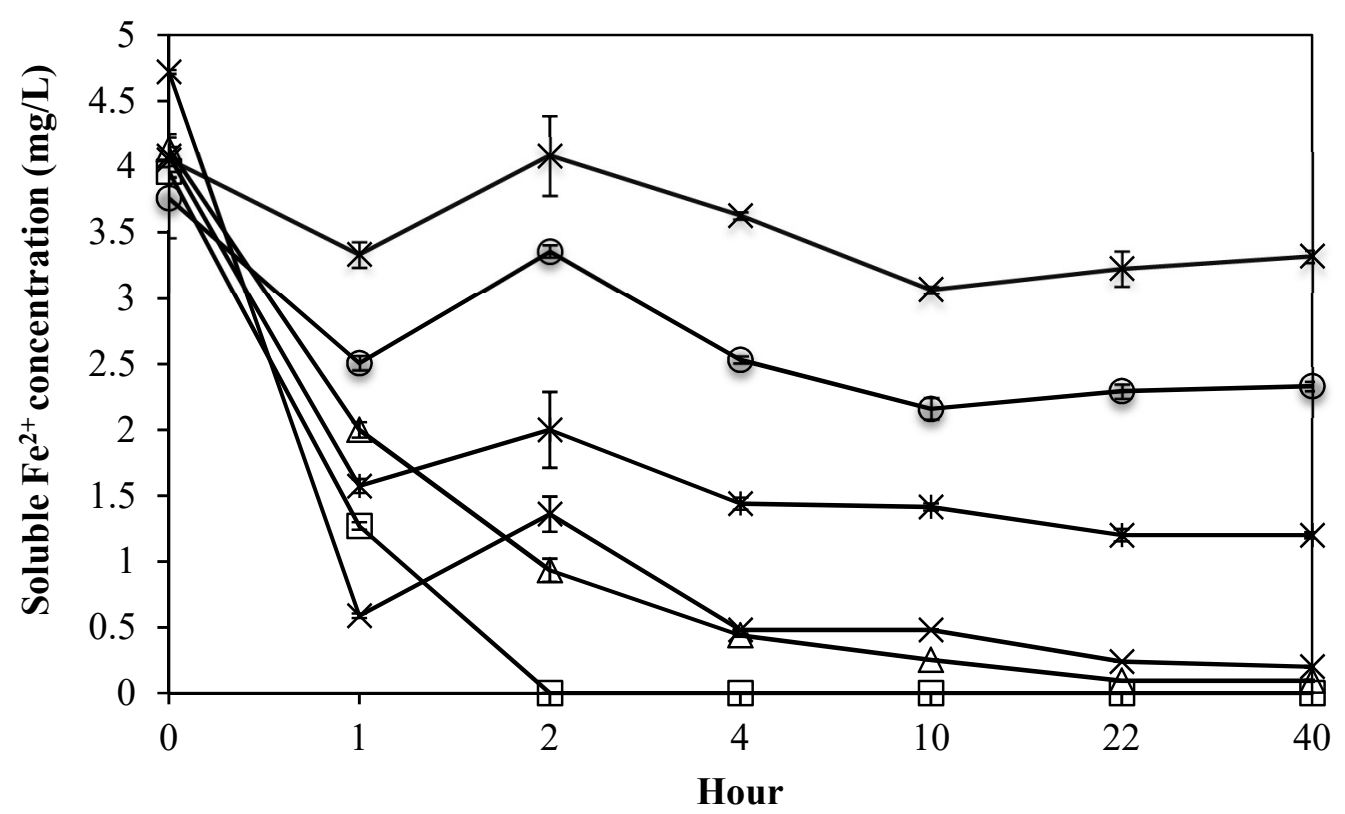

$\square$ No EDDS $\triangle 0.1: 1 \rightarrow 0.25: 1 \rightarrow 0.5: 1 \multimap 0.75: 1 \multimap 1: 1$

Figure 5.7 Soluble $\mathrm{Fe}^{2+}$ concentration in the presence of $0.25 \mathrm{mM} \mathrm{S}^{2-}$ at different EDDS:Fe molar ratios with $10 \mathrm{mg} / \mathrm{L} \mathrm{Fe}^{2+}(\mathrm{n}=3)$.

\subsubsection{Effect of EDDS on $\mathrm{Fe}^{2+}$ bioavailability in anaerobic digestion}

From Figure 5.8 it can be seen without sulfide (No S set), the addition of Fe increased the methane yields from $129.7 \mathrm{mLCH}_{4} / \mathrm{gVSS}$ (Control set) to $135.6 \mathrm{mLCH}_{4} / \mathrm{gVSS}$. However, in the presence of sulfide and without EDDS (No EDDS set), there was no statistically significant increase in methane yields observed between this set and the Control. When EDDS was added and its concentration increased (Fe:EDDS molar ratio increased), the methane yields also increased from $135.5 \mathrm{mLCH}_{4} / \mathrm{gVSS}$ at $0.1: 1$ to a maximum of 146.9 $\mathrm{mLCH}_{4} / \mathrm{gVSS}$ at a $1: 1$ molar ratio. At the $1: 1$ molar ratio, methane yields $\left(\mathrm{mLCH}_{4} / \mathrm{gVSS}\right)$ increased by $13.3 \%, 11.8 \%$, and $8.33 \%$, compared to the Control, No EDDS, and No S set, respectively. In addition, the rate of methane production $\left(\mathrm{mLCH}_{4} / \mathrm{gVSS} . \mathrm{d}\right)$ was increased by $11.2 \%, 10.4 \%$, and $7.2 \%$, compared to the Control, No EDDS, and No S set, respectively. As discussed in Section 3.4, within $106 \mathrm{~h}$. the contribution of methane production from the 
Chapter 5: Effect of Ethylenediamine-N,N'-disuccinic acid (EDDS) on the speciation and bioavailability of $\mathrm{Fe}^{2+}$ in the presence of sulfide

degradation of EDDS was not statistically significant, and this experiment was carried out within $100 \mathrm{~h}$; hence, the increase in methane yields and methane production rate at the 1:1 molar ratio was undoubtedly from the positive effect of EDDS on the bioavailability of $\mathrm{Fe}^{2+}$.

Sequential extraction revealed good recovery for $\mathrm{Fe}^{2+}$ in all sets, i.e. $93.2 \%$ to $106.3 \%$. Figure 5.9 and Table 5.4 show the fraction and the concentration of $\mathrm{Fe}$ from each extraction step. It can be seen that $\mathrm{Fe}^{2+}$ was not present in the soluble fraction in all three Control sets when EDDS was not added. For the Control 3 set (with S and no EDDS), the sum of two fractions Sol and F1, was lower than the other two Control sets $(20.6 \%$ compared to $25.9 \%$ and $25.0 \%$ ). Furthermore, the least bioavailable fraction (F4) for the Control 3 set was higher than the other Control sets (11.9\% compared to $2.08 \%$ and $8.9 \%$ ). This was presumably due to the presence of the sulfide that led to the precipitation of $\mathrm{Fe}^{2+}$, hence reducing its solubility and bioavailability.

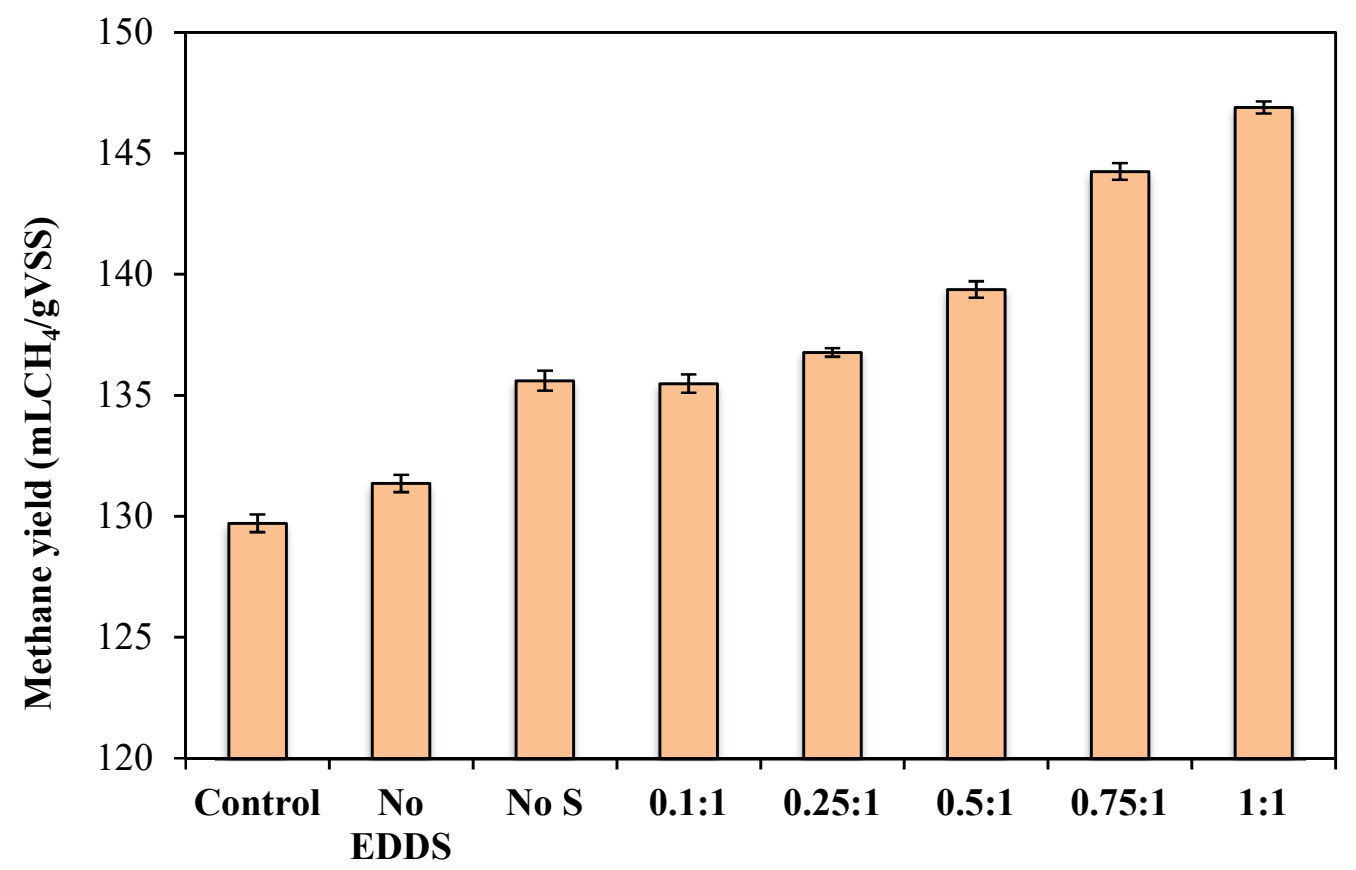

Sulfide was added to all bottles except the "No S set".

Figure 5.8 Methane yields ( $\left.\mathrm{mLCH}_{4} / \mathrm{gVSS}\right)$ at different EDDS:Fe molar ratios $(n=3)$. 
Chapter 5: Effect of Ethylenediamine-N,N'-disuccinic acid (EDDS) on the speciation and bioavailability of $\mathrm{Fe}^{2+}$ in the presence of sulfide

On the other hand, with the addition of EDDS, the soluble fraction of $\mathrm{Fe}^{2+}$ increased with an increase in the EDDS:Fe molar ratio i.e. from $0.07 \%$ at $0.1: 1$ to $1.73 \%$ at $1: 1$. Similarly, the sum of the Sol and F1 fractions also increased from $22.3 \%$ at $0.1: 1$, to the maximum of $29.8 \%$ at a $1: 1$ molar ratio. In addition, the residual fraction F4 showed a decreasing trend; $10.8 \%$ at a $0.1: 1$ molar ratio, to $6.94 \%$ at a $1: 1$ molar ratio. These findings show that EDDS kept $\mathrm{Fe}^{2+}$ in the bioavailable fraction (soluble and exchangeable) as an Fe-EDDS complex, and prevented $\mathrm{Fe}^{2+}$ becoming less bioavailable.

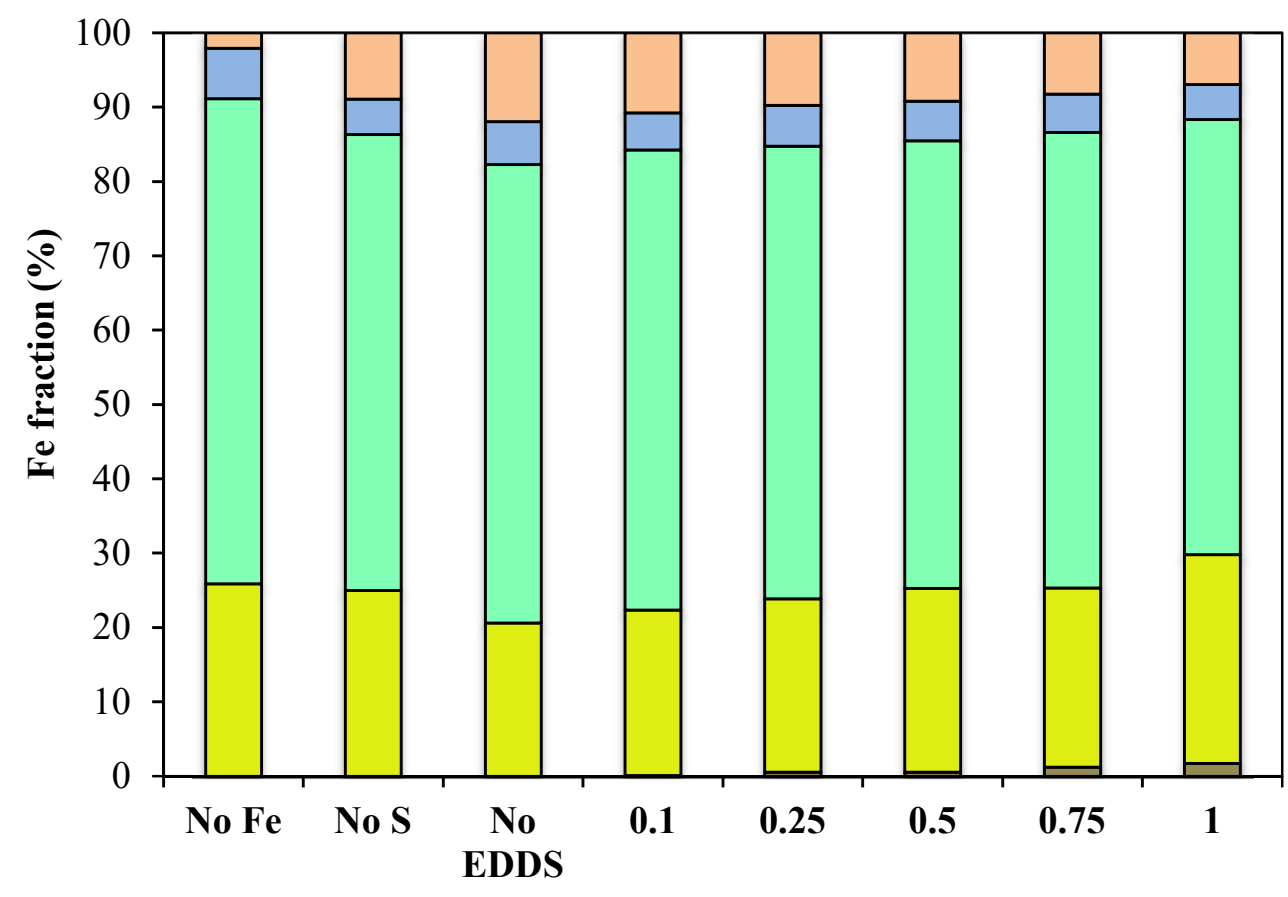

Sol - Soluble, F1 - Exchangeable, F2 - Fe/Mn oxides, F3 - Organic matter, F4 - Residual

Figure 5.9 Fe fractions from sequential extraction $(\mathrm{n}=3)$. 
Chapter 5: Effect of Ethylenediamine-N,N'-disuccinic acid (EDDS) on the speciation and bioavailability of $\mathrm{Fe}^{2+}$ in the presence of sulfide

Table 5.4 $\mathrm{Fe}^{2+}$ concentration $\left(\mu \mathrm{gFe}^{2+} / \mathrm{gTSS}\right)$ from sequential extraction at the end of experiment $(n=3)$.

\begin{tabular}{cccccccc}
\hline & Sol & F1 & F2 & F3 & F4 & $\begin{array}{c}\text { Sum of } \\
\text { fractions }\end{array}$ & $\begin{array}{c}\text { Total by } \\
\text { acid } \\
\text { digestion }\end{array}$ \\
\hline No Fe & 0.0 & 3135.5 & 7910.1 & 820.1 & 252.5 & 12118.2 & 12820.4 \\
No S & 0.0 & 3323.7 & 8166.1 & 637.5 & 1185.2 & 13312.5 & 13948.5 \\
No EDDS & 0.0 & 2847.9 & 8527.4 & 796.7 & 1650.4 & 13822.5 & 13965.4 \\
$\mathbf{0 . 1}: 1$ & 9.7 & 3099.6 & 8624.6 & 688.4 & 1502.5 & 13924.8 & 13129.7 \\
$\mathbf{0 . 2 5 : 1}$ & 70.6 & 3209.6 & 8366.1 & 758.0 & 1342.2 & 13746.6 & 14021.5 \\
$\mathbf{0 . 5 : 1}$ & 70.7 & 3358.8 & 8169.0 & 725.7 & 1247.8 & 13571.9 & 13795.8 \\
$\mathbf{0 . 7 5 : 1}$ & 169.1 & 3361.2 & 8533.2 & 724.2 & 1147.4 & 13935.1 & 13110.2 \\
$\mathbf{1 : 1}$ & 236.1 & 3839.9 & 7999.5 & 646.1 & 948.5 & 13670.0 & 14205.2 \\
\hline
\end{tabular}

Sol - Soluble, F1 - Exchangeable, F2 - Fe/Mn oxides, F3 - Organic matter, F4 - Residual

The measurement of free EDDS and the Fe-EDDS complex (Table 5.5) by UHPLC confirmed that the increase in the molar ratio of EDDS resulted in an increase in the concentration of both free EDDS and Fe-EDDS complex. The total concentration of EDDS remaining in the soluble form increased from $48.9 \%$ at a $0.1: 1$ molar ratio, to $80.4 \%$ at a $1: 1$ molar ratio. This result supports the findings on the increase in methane yields, and the increase in $\mathrm{Fe}^{2+}$ in the soluble fraction when the molar ratio increased. This was due to the increase in the amount of the Fe-EDDS complex which was bioavailable for microbial uptake. Therefore, it can be concluded that a higher dose of EDDS was able to compete with sulfide and keep the $\mathrm{Fe}^{2+}$ in a soluble form as the Fe-EDDS complex, resulting in a higher methane yields. 
Chapter 5: Effect of Ethylenediamine-N,N'-disuccinic acid (EDDS) on the speciation and bioavailability of $\mathrm{Fe}^{2+}$ in the presence of sulfide

Table 5.5 Measurement of free EDDS and Fe-EDDS complex (mg/L) at different molar ratios in UHPLC $(n=3)$.

\begin{tabular}{cccccc}
\hline & $\mathbf{0 . 1 : 1}$ & $\mathbf{0 . 2 5 : 1}$ & $\mathbf{0 . 5 : 1}$ & $\mathbf{0 . 7 5 : 1}$ & $\mathbf{1 : 1}$ \\
\hline Free EDDS & 1.1 & 1.8 & 3.0 & 5.2 & 6.0 \\
Fe-EDDS complex & 3.1 & 9.9 & 22.8 & 36.3 & 50.4 \\
Total EDDS & 6.3 & 15.7 & 31.4 & 47.0 & 62.7 \\
$\begin{array}{c}\text { \% of added mass } \\
\text { EDDS }\end{array}$ & 48.9 & 63.3 & 72.7 & 77.2 & 80.4 \\
\hline
\end{tabular}

\subsection{Conclusions}

$\mathrm{Fe}^{2+}$ supplementation stimulated methane yields at $10 \mathrm{mg} / \mathrm{L} \quad(3.34$ $\left.\mathrm{mgFe} \mathrm{F}^{2+} / \mathrm{gTSS}\right)$ in anaerobic digestion, while the presence of $8 \mathrm{mg} / \mathrm{L}$ sulfide led to the precipitation of $\mathrm{FeS}$, which limited microbial uptake in the short term. EDDS was found to be able to improve the bioavailability of $\mathrm{Fe}^{2+}$ by keeping the metal in soluble/bioavailable form, and enabling the bio-uptake of the FeEDDS complex. When EDDS was added at a 1:1 molar ratio to $\mathrm{Fe}^{2+}$ at 10 $\mathrm{mg} / \mathrm{L}$, the rate of methane production was increased by $11.17 \%$, while the methane yields increased by $13.3 \%$. Due to its superior biodegradability, EDDS can be an excellent alternative to the conventional chelating agents i.e. EDTA and NTA to improve trace metal bioavailability. 
Chapter 5: Effect of Ethylenediamine-N,N'-disuccinic acid (EDDS) on the speciation and bioavailability of $\mathrm{Fe}^{2+}$ in the presence of sulfide 
Chapter 6: Dosing of Ethylenediamine-N,N'-disuccinic acid (EDDS) to improve the bioavailability of $\mathrm{Fe}^{2+}$ in the presence of sulfide in a submerged anaerobic membrane bioreactor

\section{Chapter 6}

\section{Dosing of Ethylenediamine-N, $N^{\prime}$-disuccinic acid (EDDS) to improve the bioavailability of $\mathrm{Fe}^{2+}$ in the presence of sulfide in a submerged anaerobic membrane bioreactor}

\section{Outline:}

\subsection{Introduction}

6.2 Experimental and analytical methods

6.3 Results and discussion

6.4 Conclusions

Note: this chapter was published in Chemical Engineering Journal, 2017, volume 330, pages 175-182.

\subsection{Introduction}

The importance of $\mathrm{Fe}^{2+}$ in the degradation of VFAs and the effect of sulfide on the bioavailability of $\mathrm{Fe}^{2+}$ has been discussed in the literature review. The results from Chapter 5 showed that in a batch system, biodegradable chelating agent EDDS was able to improve the bioavailability $\mathrm{Fe}^{2+}$ in the presence of sulfide. However, the effect of adding a chelating agent on metal bioavailability is very complex as it depends on many factors, including the type of chelating agent, the added concentration, and the reactor configuration. 
Chapter 6: Dosing of Ethylenediamine-N,N'-disuccinic acid (EDDS) to improve the bioavailability of $\mathrm{Fe}^{2+}$ in the presence of sulfide in a submerged anaerobic membrane bioreactor

Reactor configuration (batch or continuous) has an important role in determining how the chelating agent should be dosed as it controls the retention of the TMs. Chelating agents can be added either as a complex with the metals (Fermoso et al., 2008c; Bartacek et al., 2012; Vintiloiu et al., 2013), or simultaneously with the metals (Hu et al., 2008a; Hu et al., 2008b). Fermoso et al. (2008c) investigated the use of EDTA as a ligand for Co dosing to UASB reactors. They found that when supplemented as Co-EDTA complex, only 8\% of the Co supplemented was retained, whereas 90\% retention of Co was achieved when it was supplemented as $\mathrm{CoCl}_{2}$. This is because when added to a continuous UASB system, the highly soluble metal complex Co-EDTA was washed out. However, Vintiloiu et al. (2013) found that when $\mathrm{Ni}$ was complexed with EDTA prior to supplementation to a batch system, there was a significant increase in Ni bioavailability. The reason for this in the batch system was that EDTA was able to chelate free ion concentration, which can be taken up by the anaerobic microorganisms. The innovative submerged anaerobic membrane bioreactor (SAMBR) is also a continuous system which is better than the USAB system in terms of biomass retention capability due to the presence of a membrane, and there will be no TMs associated with the biomass escaping into the effluent.

The aim of the experiments in this chapter was, therefore, to evaluate the dynamics of $\mathrm{Fe}^{2+}$ and the presence of sulfide on its speciation and bioavailability in a SAMBR. The dosing strategies for EDDS and $\mathrm{Fe}^{2+}$, either as a complex or individual ion, was investigated in batch reactors, and then applied to the SAMBR to determine which strategy was more effective in improving the bioavailability of $\mathrm{Fe}^{2+}$ and hence the performance of the SAMBR. 
Chapter 6: Dosing of Ethylenediamine-N,N'-disuccinic acid (EDDS) to improve the bioavailability of $\mathrm{Fe}^{2+}$ in the presence of sulfide in a submerged anaerobic membrane bioreactor

\subsection{Experimental and analytical methods}

\subsubsection{Dosing strategy for EDDS and Fe in the presence of sulfide in a batch reactor}

This experiment was aimed at determining whether $\mathrm{Fe}^{2+}$ and EDDS are more effective when they are supplemented as a metal-chelator complex (FeEDDS), or simultaneously (Fe+EDDS), and was performed in batch reactors using $125 \mathrm{~mL}$ serum bottles (100 mL working volume). Seed sludge was withdrawn from parent anaerobic reactor. In all test bottles, the initial biomass and the $\mathrm{F} / \mathrm{M}$ ratio were set to $3 \mathrm{gVSS} / \mathrm{L}$ and $0.5 \mathrm{gCOD} / \mathrm{gVSS}$; glucose $(1.5$ $\mathrm{gCOD} / \mathrm{L})$ and $\mathrm{NaHCO}_{3}(2 \mathrm{~g} / \mathrm{L})$ were added as substrate and buffer, respectively. $\mathrm{Fe}^{2+}$ was supplemented at its optimal concentration, i.e. $10 \mathrm{mg} / \mathrm{L}$ as $\mathrm{FeCl}_{2} \cdot 4 \mathrm{H}_{2} \mathrm{O}$ (3.34 $\left.\mathrm{mgFe}^{2+} / \mathrm{gTSS}\right)$, and EDDS was added at the optimal molar ratio to $\mathrm{Fe}^{2+}$, i.e. 1:1 ratio, as determined from previous work (Thanh et al., 2017). In the FeEDDS set, the metal complex was prepared by mixing the respective amounts of $\mathrm{Fe}^{2+}$ and EDDS overnight in the dark to prevent photo-degradation before adding it to the test bottles; in the Fe+EDDS set, $\mathrm{Fe}^{2+}$ and EDDS were added simultaneously to the test bottles. Three control sets were prepared, i.e. Control 1 - substrate only, Control 2 - substrate and EDDS, Control 3 - substrate and

$\mathrm{Fe}^{2+}$. Sulfide solution was prepared in an oxygen-free environment, and then added to all bottles at $8 \mathrm{mg} / \mathrm{L}$ as $\mathrm{Na}_{2} \mathrm{~S}_{2} 9 \mathrm{H}_{2} \mathrm{O}$, which is below its toxic level (Mountfort \& Asher, 1979). The $\mathrm{pH}$ of all test bottles was adjusted to $7.0 \pm 0.1$ using diluted $\mathrm{NaOH}$ or $\mathrm{HCl}$. The bottles were flushed with nitrogen for $2 \mathrm{~min}$ to ensure anaerobic conditions, sealed and incubated in a shaker at $35^{\circ} \mathrm{C}$ and 170 $\mathrm{rpm}$. All tests were run in triplicates $(\mathrm{CV}= \pm 5 \%)$, and carried out over 8 days. 
Chapter 6: Dosing of Ethylenediamine-N,N'-disuccinic acid (EDDS) to improve the bioavailability of $\mathrm{Fe}^{2+}$ in the presence of sulfide in a submerged anaerobic membrane bioreactor

\subsubsection{Effect of sulfide on the speciation and bioavailability of $\mathrm{Fe}^{2+}$ in a}

\section{SAMBR}

The aim of this experiment was to determine what effects the presence of sulfide could have on the dynamics of speciation, and hence the bioavailability of $\mathrm{Fe}^{2+}$ in a SAMBR. The set-up of the SAMBR used for this study was described in detail by Zhou et al. (2016). The SAMBR was treating synthetic wastewater with the feed composition based on that used by Akram and Stuckey (2008). The operating conditions for the SAMBR were set as 500 $\mathrm{mgCOD} / \mathrm{L}$ feed, $6 \mathrm{~h} \mathrm{HRT}$, and $100 \mathrm{~d}$ SRT. The $\mathrm{pH}$ in the system was maintained in the range of 6.9 and 7.1 using $1 \mathrm{M} \mathrm{NaHCO}_{3}$, while the oxidationreduction potential (ORP) was in the range of $-463 \pm 4 \mathrm{mV}$ throughout the experiment.

Since the scope of this study was limited to $\mathrm{Fe}^{2+}$ only, the feed for the SAMBR contained $\mathrm{Fe}^{2+}$ as the only TM to eliminate the possibility of its interaction with other TMs. The experimental design for each stage of the SAMBR is described in Figure 6.1. During the first stage (Stage 1), $\mathrm{Fe}^{2+}$ was added to the SAMBR at the optimal concentration of $10 \mathrm{mg} / \mathrm{L}$ as $\mathrm{FeCl}_{2} \cdot 4 \mathrm{H}_{2} \mathrm{O}$, which is equivalent to $0.22 \mathrm{mg} / \mathrm{gTSS} . \mathrm{d}$. During the second stage (Stage 2), the same level of sulfide as in the batch experiment described above was added to the feed, i.e. $8 \mathrm{mg} / \mathrm{L}$ as $\mathrm{Na}_{2} \mathrm{~S} .9 \mathrm{H}_{2} \mathrm{O}$. The feed was then sparged with nitrogen and sealed to ensure anaerobic condition. Each stage of this experiment was carried out over 10 days.

\subsubsection{Dosing strategy for EDDS and $\mathrm{Fe}^{2+}$ in the presence of sulfide in a SAMBR}

After Stage 2, the most effective dosing strategy for EDDS and Fe determined from experiment 6.2.1 was applied to the SAMBR in the final stage of this study (Stage 3) (Figure 6.1). The same experimental conditions as experiment 6.2.2 were used, but $\mathrm{Fe}^{2+}$ and EDDS were added to the feed either 
Chapter 6: Dosing of Ethylenediamine-N,N'-disuccinic acid (EDDS) to improve the bioavailability of $\mathrm{Fe}^{2+}$ in the presence of sulfide in a submerged anaerobic membrane bioreactor

as a complex (Fe+EDDS), or simultaneously (Fe-EDDS), at a 1:1 molar ratio with the optimal $\mathrm{Fe}^{2+}$ concentration, i.e. $10 \mathrm{mg} / \mathrm{L}$ (0.22 mg/gTSS.d) (Figure 6.1). The concentrated feed was kept in a cold room, and new feed was freshly prepared every day. The feed bottle was also sparged with nitrogen and covered with aluminum foil to prevent photo-degradation of the EDDS, and the experiment was carried out in 9 days.

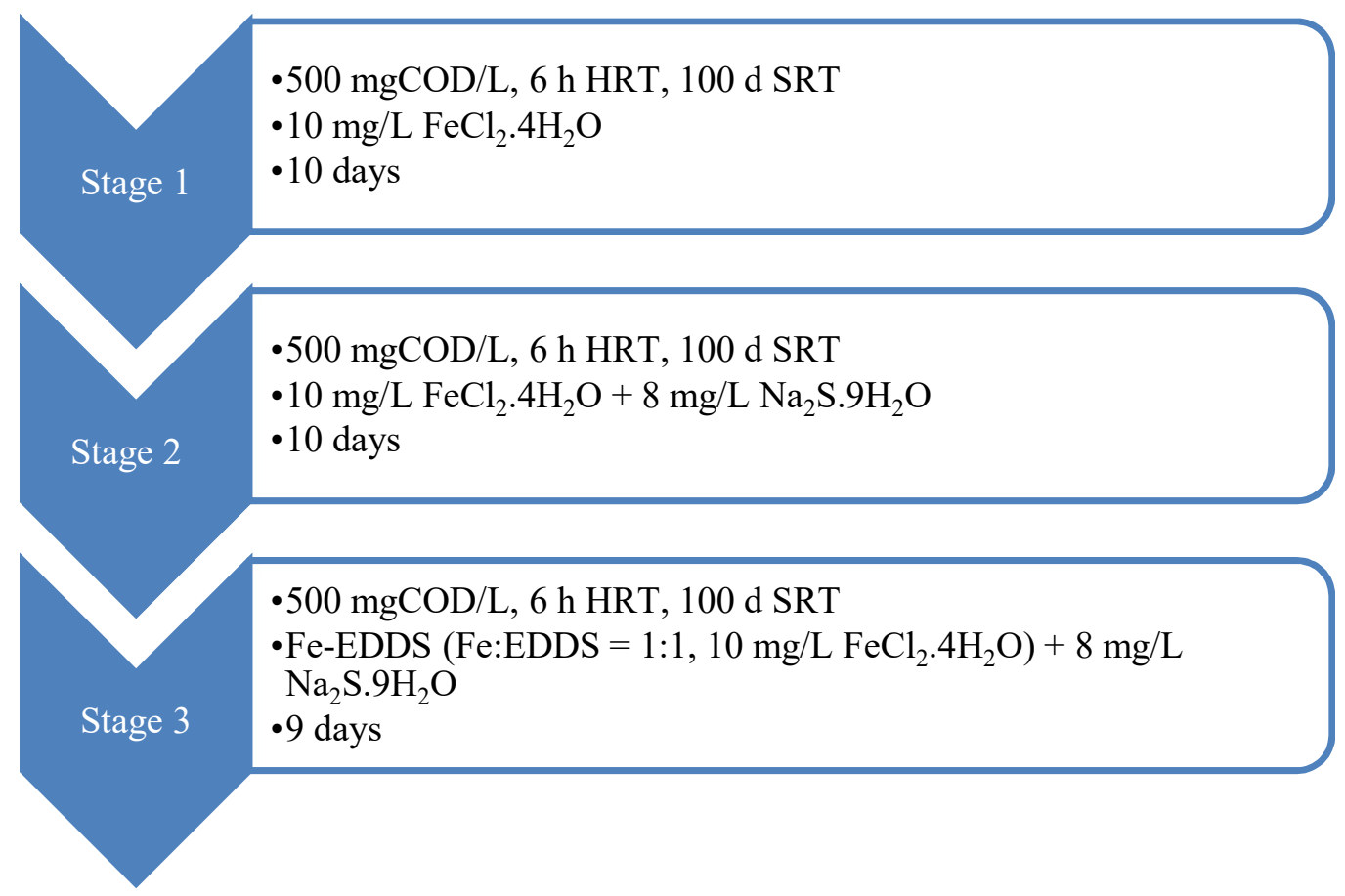

Figure 6.1 Schematic diagram of experimental design for each stage of the SAMBR.

\subsection{Results and Discussion}

\subsubsection{Dosing strategy for EDDS and $\mathrm{Fe}^{2+}$ in the presence of sulfide in a batch setup}

Figure 6.2 shows that the methane yields from the Control 1 set (substrate only) reached $114.3 \mathrm{mLCH}_{4} / \mathrm{gVSS}$, which was $65.3 \%$ of the theoretical 
Chapter 6: Dosing of Ethylenediamine-N,N'-disuccinic acid (EDDS) to improve the bioavailability of $\mathrm{Fe}^{2+}$ in the presence of sulfide in a submerged anaerobic membrane bioreactor

methane production, and the remaining substrate was probably used for biomass generation. In comparison, there was no statistical difference in the methane yields between the other two control sets i.e. Control 2 (substrate and EDDS) (114.3 $\mathrm{mLCH}_{4} / \mathrm{gVSS}$ ) and Control 3 (substrate and $\mathrm{Fe}$ ) (116.3 $\left.\mathrm{mLCH}_{4} / \mathrm{gVSS}\right)$ to Control 1 ( $\left.\mathrm{p}>0.05\right)$. These findings have two implications; firstly, the addition of EDDS to the Control 2 set did not result in any significant improvement in the methane yields compared with those without EDDS. Hence, any increase in methane yields will be undoubtedly from the positive effect of EDDS on the bioavailability of $\mathrm{Fe}^{2+}$, and not from its degradation within the 8 day test. Secondly, the addition of $\mathrm{Fe}^{2+}$ to the Control 3 set did not significantly increase the methane yields compared to the Control 1 set $(p>0.05)$, which indicates that due to the presence of added sulfide in the test bottles, most of the $\mathrm{Fe}^{2+}$ probably precipitated as $\mathrm{FeS}$, and hence became less bioavailable for the microorganisms to take up.

The addition of $\mathrm{Fe}^{2+}$ and EDDS simultaneously (Fe+EDDS set) stimulated the methanogens as there was a significant increase in methane yields compared to the Control 3 set, i.e. $124.1 \mathrm{mLCH}_{4} / \mathrm{gVSS}$ v.s. 116.3 $\mathrm{mLCH}_{4} / \mathrm{gVSS}(\mathrm{p}<0.05)$. These results were in agreement with findings from a previous study of ours (Thanh et al., 2017), which was carried out under the same experimental conditions with the same seed sludge. However, compared to the Fe+EDDS set, the methane yields from the metal complex set Fe-EDDS was significant higher i.e. $136.5 \mathrm{mLCH}_{4} / \mathrm{gVSS}(\mathrm{p}<0.05)$. As a result, compared to the Control 3 set (without EDDS), the methane yields from the FeEDDS set also increased significantly by $17.3 \%(\mathrm{p}<0.05)$. The results suggested that the addition of EDDS was able to compete with the sulfide to maintain a certain level of $\mathrm{Fe}^{2+}$ solubility, and hence improve its bioavailability for microbial uptake. Clearly, the dosing of EDDS as a complex with $\mathrm{Fe}^{2+}$ showed a better improvement in methane yields than when it was supplemented simultaneously with $\mathrm{Fe}^{2+}$. 
Chapter 6: Dosing of Ethylenediamine-N,N'-disuccinic acid (EDDS) to improve the bioavailability of $\mathrm{Fe}^{2+}$ in the presence of sulfide in a submerged anaerobic membrane bioreactor

Hydrogen concentration is often an indicator of process stability in anaerobic digestion systems (Ketheesan \& Stuckey, 2015). The measurement of hydrogen in the gas phase (average of 3 samples) (Figure 6.3) showed that from time zero to 8.5 hours of the experiment, there was no hydrogen detected in the gas phase. However, after 8.5 hours, the hydrogen concentration was at the same level in all sets $(142.3 \mathrm{ppm}$ to $143.8 \mathrm{ppm})(\mathrm{p}>0.05)$. As time increased, the hydrogen concentration in the Fe-EDDS set reduced at a faster rate than the other sets $(p<0.05)$, and reached the lowest value at the end of the experiment $(17.0 \mathrm{ppm})$. This finding indicated that the Fe supplemented as a complex with EDDS was better at stimulating the growth and metabolism of the methanogens than when it was supplemented without EDDS or simultaneously with EDDS, and it effectively enhanced the removal rate of the hydrogen produced by substrate degradation by the fermentative bacteria.

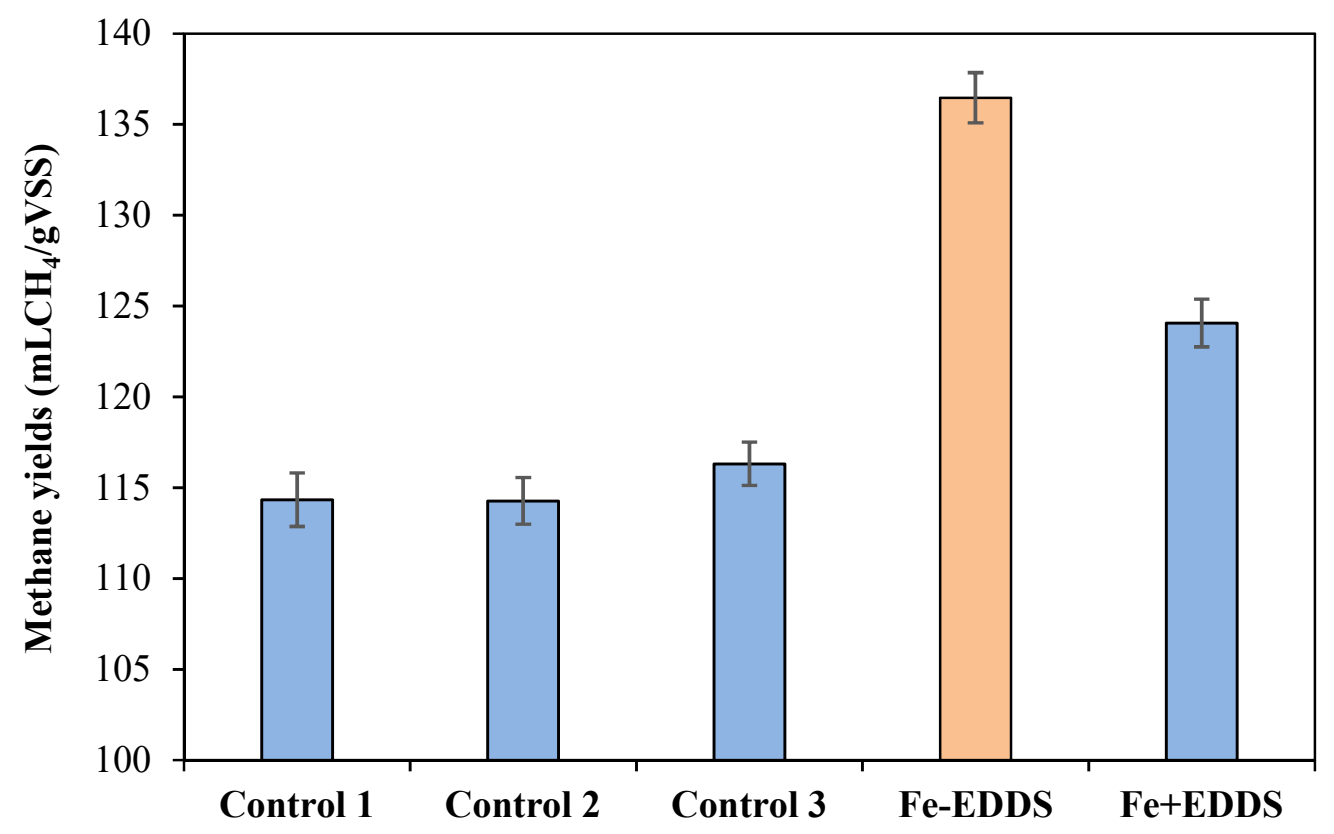

Control 1 - Substrate only, Control $2-$ Substrate + EDDS, Control $3-$ Substrate $+\mathrm{Fe}^{2+}$

Figure 6.2 Methane yields ( $\left.\mathrm{mLCH}_{4} / \mathrm{gVSS}\right)$ from different sets in the batch experiment after $8 d(n=3)$. 
Chapter 6: Dosing of Ethylenediamine-N,N'-disuccinic acid (EDDS) to

improve the bioavailability of $\mathrm{Fe}^{2+}$ in the presence of sulfide in a

submerged anaerobic membrane bioreactor

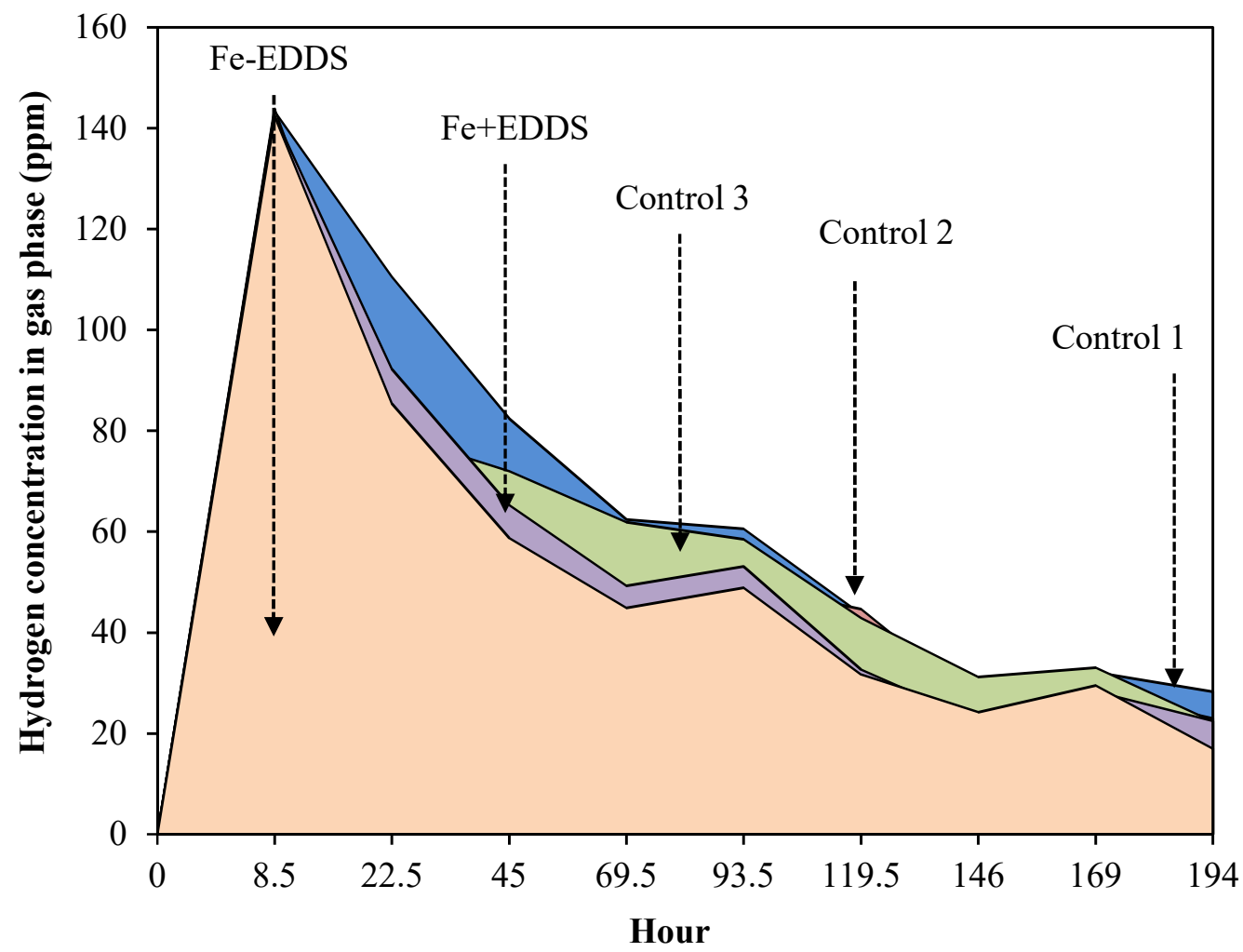

$\square$ Control $1 \quad \square$ Control $2 \quad \square$ Control $3 \quad \square$ Fe+EDDS $\quad \square$ Fe-EDDS

Control 1 - Substrate only, Control 2 - Substrate + EDDS, Control $3-$ Substrate $+\mathrm{Fe}^{2+}$

Figure 6.3 Hydrogen concentration in the gas phase (ppm) from the batch experiment over $8 d(n=3)$.

The measurement of metal content in each fraction from the BCR method at the end of the experiment is given in Table 6.1. The metal extraction showed good recovery for $\mathrm{Fe}^{2+}$ in all sets i.e. $95.6 \%$ to $104.6 \%$. The distribution of $\mathrm{Fe}^{2+}$ between different fractions is illustrated in Figure 6.4. $\mathrm{Fe}^{2+}$ was found to be present mainly in the Fe-Mn oxides fraction (F2) i.e. $43.9 \%$ to $48.5 \%$. The first fraction of the Control 1 set (substrate only), i.e. Soluble (Sol), was the lowest compared to that of the other sets, i.e. $0.03 \%$, as no $\mathrm{Fe}^{2+}$ was added to this set. The Sol fraction for the Control 2 set (substrate and EDDS) was higher than for the Control 3 set (substrate and Fe), i.e. 2.01\% and $0.28 \%(\mathrm{p}<0.05)$, 
Chapter 6: Dosing of Ethylenediamine-N,N'-disuccinic acid (EDDS) to improve the bioavailability of $\mathrm{Fe}^{2+}$ in the presence of sulfide in a submerged anaerobic membrane bioreactor

respectively. The reason for this difference is due to the complexation of EDDS with $\mathrm{Fe}^{2+}$ present in the seed sludge, which was found to be around 0.1 $\mathrm{mgFe} \mathrm{ge}^{2+} / \mathrm{gTSS}$, and hence there was still a fraction of $\mathrm{Fe}^{2+}$ left in the soluble form. The presence of $8 \mathrm{mg} / \mathrm{L}$ sulfide in Control 3 set resulted in the precipitation of $\mathrm{Fe}^{2+}$ as $\mathrm{FeS}$, and hence this reduced its solubility. The addition of EDDS to the Fe-EDDS and Fe+EDDS sets both increased the soluble fractions to $9.04 \%$ and $7.15 \%(\mathrm{p}<0.05)$, respectively, which shows that EDDS was able to compete with sulfide to keep the $\mathrm{Fe}^{2+}$ in a soluble form. The sum of the two most bioavailable fractions in the sequential chemical extraction method (BCR), i.e. Soluble and Exchangeable fraction (Sol+F1), was not statistically different for all the three Control sets, i.e. $29.7 \%, 29.9 \%$, and $28.7 \%$ $(p>0.05)$. However, the addition of EDDS to the Fe-EDDS and Fe+EDDS sets resulted in an increase in this sum, i.e. $38.6 \%$ and $34.3 \%(\mathrm{p}<0.05)$, respectively. In contrast, the sum of the last two fractions which are considered the least bioavailable, i.e. Organic matter/sulfide and Residual (F3+F4) was the lowest for the Fe-EDDS and Fe+EDDS, set i.e. $17.3 \%$ and $21.8 \%$, respectively.

These speciation results showed that the addition of EDDS was able to prevent the $\mathrm{Fe}^{2+}$ from precipitating with sulfide, and kept it in a highly bioavailable form, i.e. Sol and F1. Dosing of $\mathrm{Fe}^{2+}$ as a metal complex with EDDS also resulted in a better retention of $\mathrm{Fe}^{2+}$ in these highly bioavailable forms than when they were added simultaneously (Fe+EDDS). 
Chapter 6: Dosing of Ethylenediamine-N,N'-disuccinic acid (EDDS) to

improve the bioavailability of $\mathrm{Fe}^{2+}$ in the presence of sulfide in a

submerged anaerobic membrane bioreactor

Table 6.1 Fe content $\left(\mu \mathrm{gFe} \mathrm{F}^{2+} / \mathrm{gTSS}\right)$ from sequential extraction at the end of the batch experiment $(n=3)$.

\begin{tabular}{ccccccccc}
\hline & Sol & F1 & F2 & F3 & F4 & $\begin{array}{c}\text { Sum of } \\
\text { fractions }\end{array}$ & $\begin{array}{c}\text { Total by } \\
\text { acid } \\
\text { digestion }\end{array}$ & $\begin{array}{c}\text { Recovery } \\
\text { (\%) }\end{array}$ \\
\hline Control 1 & 4.2 & 4061.0 & 6610.6 & 1004.5 & 2025.7 & 13706.0 & 13101.7 & 104.6 \\
Control 2 & 276.2 & 3841.5 & 6594.2 & 964.8 & 2078.6 & 13755.3 & 14393.6 & 95.6 \\
Control 3 & 39.6 & 4088.0 & 6968.8 & 1011.2 & 2272.1 & 14379.7 & 14711.6 & 97.7 \\
Fe-EDDS & 1409.7 & 4613.1 & 6870.1 & 997.8 & 1706.2 & 15596.9 & 15836.7 & $98 . .5$ \\
Fe+EDDS & 1090.9 & 4133.6 & 6702.6 & 1001.9 & 2324.9 & 15253.9 & 14890.6 & 102.4 \\
\hline
\end{tabular}

Control 1 - Substrate only, Control 2 - Substrate + EDDS, Control $3-$ Substrate $+\mathrm{Fe}^{2+}$ Sol - Soluble, F1 - Exchangeable, F2 - Fe/Mn oxides, F3 - Organic matter, F4 - Residual

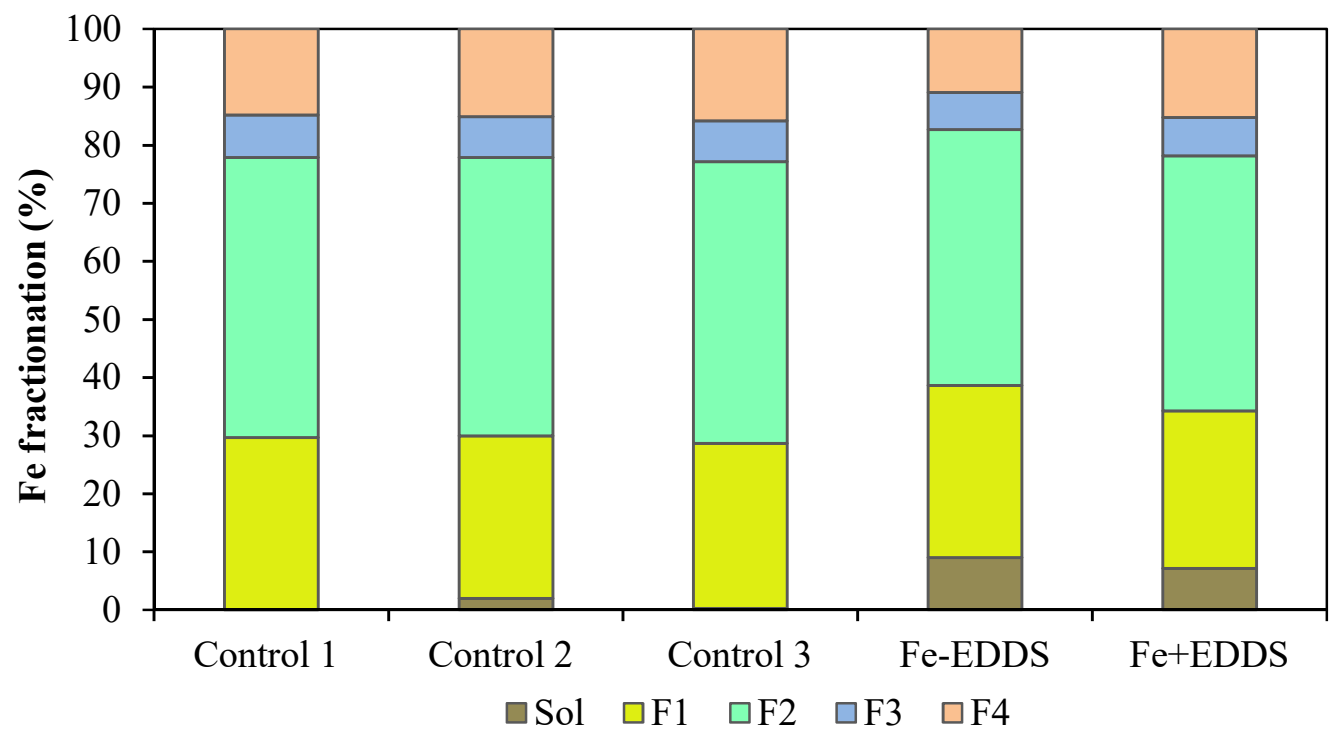

Sol - Soluble, F1 - Exchangeable, F2 - Fe/Mn oxides, F3 - Organic matter, F4 - Residual. Control 1 - Substrate only, Control $2-$ Substrate + EDDS, Control $3-$ Substrate $+\mathrm{Fe}^{2+}$

Figure 6.4 Fe fractionation using the BCR method at the end of the batch experiment $(8 d)(n=3)$. 
Chapter 6: Dosing of Ethylenediamine-N,N'-disuccinic acid (EDDS) to improve the bioavailability of $\mathrm{Fe}^{2+}$ in the presence of sulfide in a submerged anaerobic membrane bioreactor

The measurement of free EDDS and EDDS in the metal complex using UHPLC (Table 6.2) showed that the concentrations of these two EDDS forms in the Fe-EDDS set were statistically higher than those in the Fe+EDDS set i.e. $4.78 \%$ and $36.47 \%$ compared to $3.96 \%$ and $33.58 \%(\mathrm{p}<0.05)$, respectively. As the result, the total concentration of EDDS remaining in the soluble form for the Fe-EDDS set was higher, i.e. $78.8 \%$ compared to $71.7 \%$ for the Fe+EDDS set $(p<0.05)$. This result supports the findings on the increase in methane yields, and the increase in highly bioavailable fractions when the EDDS was added. This was due to the increase in the amount of $\mathrm{Fe}^{2+}$ present in the Fe-EDDS complex which was (probably) bioavailable for microbial uptake. Furthermore, the amount of EDDS in a free and complex form for the Fe-EDDS set was higher than for the Fe+EDDS set, which explains why $\mathrm{Fe}^{2+}$ is better to dose as a complex with EDDS than separately. The result from this experiment was in agreement with previous studies carried out in batch systems (Bartacek et al., 2012; Vintiloiu et al., 2013) that the bioavailability of the TM was increased when it was dosed as a metal complex with a chelating agent. However, these studies were carried out with conventional chelating agents such as EDTA, which has very low biodegradability compared to the biodegradable chelating agent EDDS used in this work. Furthermore, without the analytical technique to determine the fate of the added chelating agent, these studies were not able to explain the mechanisms behind the improvement in trace metal bioavailability. Therefore, the dosing of a novel biodegradable chelating agent EDDS in this experiment showed that it can be an excellent alternative to the conventional chelating agents as it was effective competing with sulfide, and kept the $\mathrm{Fe}^{2+}$ soluble so it could be taken up more easily by the microorganisms. It should be noted that the biodegradability of EDDS in an anaerobic system requires further study in order to optimise the dosage frequency as it would be undesirable to discharge effluent containing significant amounts of EDDS into the environment. 
Chapter 6: Dosing of Ethylenediamine-N,N'-disuccinic acid (EDDS) to

improve the bioavailability of $\mathrm{Fe}^{2+}$ in the presence of sulfide in a

submerged anaerobic membrane bioreactor

Table 6.2 Measurement of free EDDS and Fe-EDDS complex (mg/L) using UHPLC in the batch experiment $(n=3)$.

\begin{tabular}{ccc}
\hline & Fe-EDDS & Fe+EDDS \\
\hline Free EDDS & 4.78 & 3.96 \\
Fe-EDDS complex & 36.4 & 33.6 \\
Total EDDS & 41.3 & 37.5 \\
\% of added mass EDDS & 78.8 & 71.7 \\
\hline
\end{tabular}

\subsubsection{Effect of sulfide on the speciation and bioavailability of $\mathrm{Fe}^{2+}$ in a SAMBR}

Before starting this experiment, the SAMBR was operated with a mixture of TMs (Fe, $\mathrm{Co}, \mathrm{Ni}, \mathrm{Zn}, \mathrm{Mn}$, and Mo) for about 3 months, therefore, there were high levels of these TMs, especially $\mathrm{Fe}^{2+}$, in the sludge of the SAMBR (10004 $\mu \mathrm{gFe} / \mathrm{gTSS}, 837.1 \mu \mathrm{gCo} / \mathrm{gTSS}, 658.5 \mu \mathrm{gNi} / \mathrm{gTSS}, 1202 \mu \mathrm{gZn} / \mathrm{gTSS}, 148.7$ $\mu \mathrm{gMn} / \mathrm{gTSS}$, and $124.4 \mu \mathrm{gMo} / \mathrm{gTSS})$. The accumulation of these TMs could explain why when $\mathrm{Fe}^{2+}$ was supplemented as the only metal nutrient to the SAMBR (Stage 1), the reactor was still capable of operating at very high treatment efficiencies for 10 days as the accumulated TMs were still sufficient to support the growth of the anaerobes. The average soluble COD levels inside the reactor and in the effluent (Figure 6.5) were $50.1 \mathrm{mg} / \mathrm{L}$ and $8.2 \mathrm{mg} / \mathrm{L}$, respectively, and thus the average COD removal was remarkably high, i.e. 98.4\%; the average daily methane yields reached $58.3 \mathrm{mLCH}_{4} / \mathrm{gVSS}$.d (Figure 6.6). However, when sulfide was added to the feed (day 11 - Stage 2), the SAMBR performance dropped slightly, and the average soluble COD inside the reactor and in the effluent (Figure 6.5) increased to $64.8 \mathrm{mg} / \mathrm{L}$ and $17.2 \mathrm{mg} / \mathrm{L} \mathrm{(p}$ $<0.05)$, respectively. Hence, the corresponding average COD removal in this 
Chapter 6: Dosing of Ethylenediamine-N,N'-disuccinic acid (EDDS) to improve the bioavailability of $\mathrm{Fe}^{2+}$ in the presence of sulfide in a submerged anaerobic membrane bioreactor

stage decreased to $96.6 \%(\mathrm{p}<0.05)$. The addition of sulfide also showed a negative effect on the average daily methane yield which was reduced by $14.6 \%$ to $49.8 \mathrm{mLCH}_{4} / \mathrm{gVSS} . \mathrm{d}(\mathrm{p}<0.05$ ) (Figure 6.6 ); since sulfide was added below its toxic level, it should have not inhibited the anaerobic microorganisms. VFAs (formate and acetate) were found to increase from $1.62 \mathrm{mgCOD} / \mathrm{L}$ at Stage 1 to $3.98 \mathrm{mgCOD} / \mathrm{L}(\mathrm{p}<0.05)$. Therefore, the decrease in SAMBR performance during Stage 2 was almost certainly due to the indirect limiting effects of sulfide on the growth rate of methanogens by reducing the bioavailability of the metals for microbial uptake.

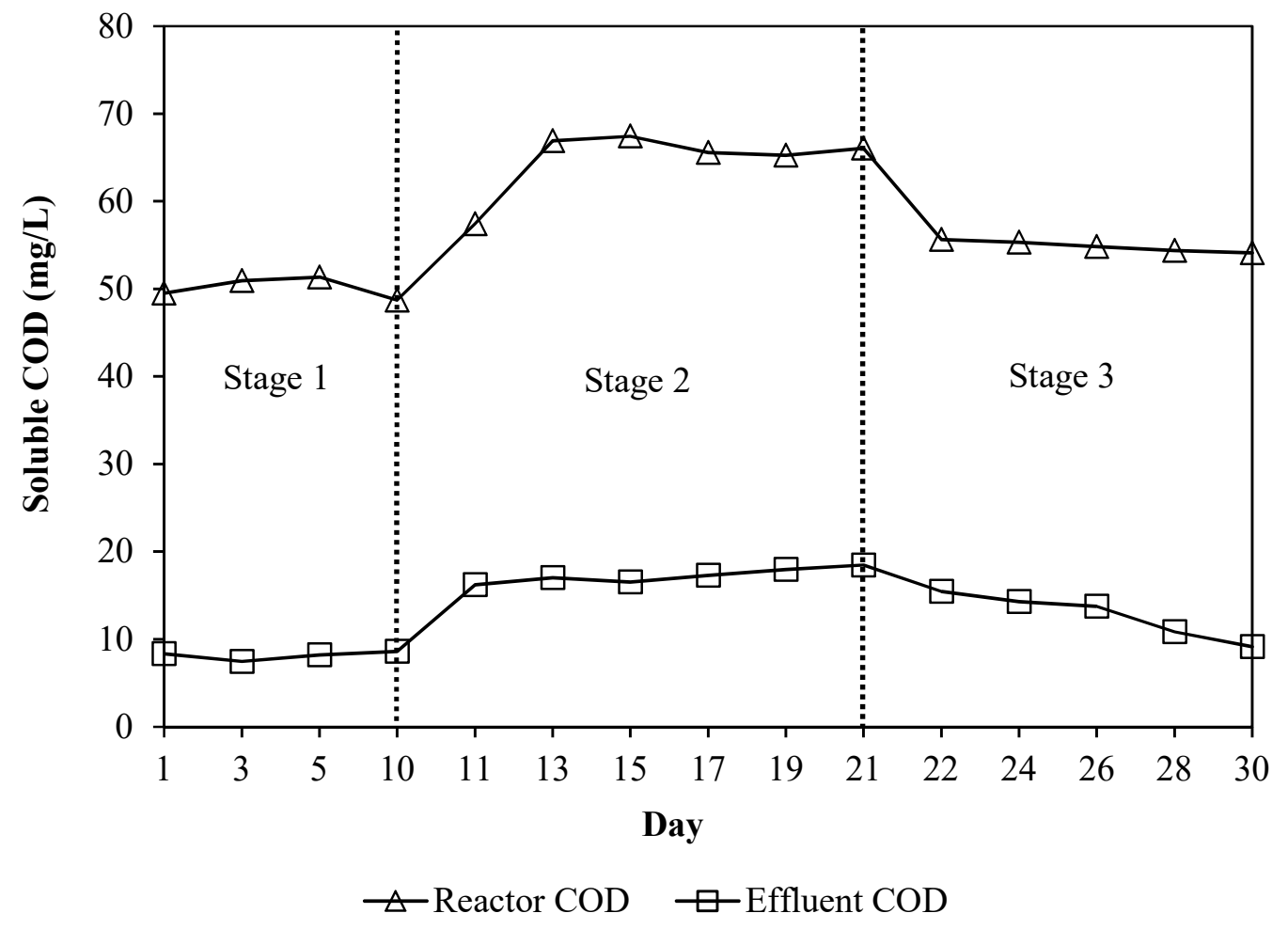

Stage $1-\mathrm{Fe}$ only, Stage $2-\mathrm{Fe}$ and $\mathrm{S}$, Stage $3-\mathrm{Fe}$, EDDS and S

Figure 6.5 Soluble COD in the SAMBR reactor and effluent at different stages $(n=3)$. 
Chapter 6: Dosing of Ethylenediamine-N,N'-disuccinic acid (EDDS) to improve the bioavailability of $\mathrm{Fe}^{2+}$ in the presence of sulfide in a submerged anaerobic membrane bioreactor

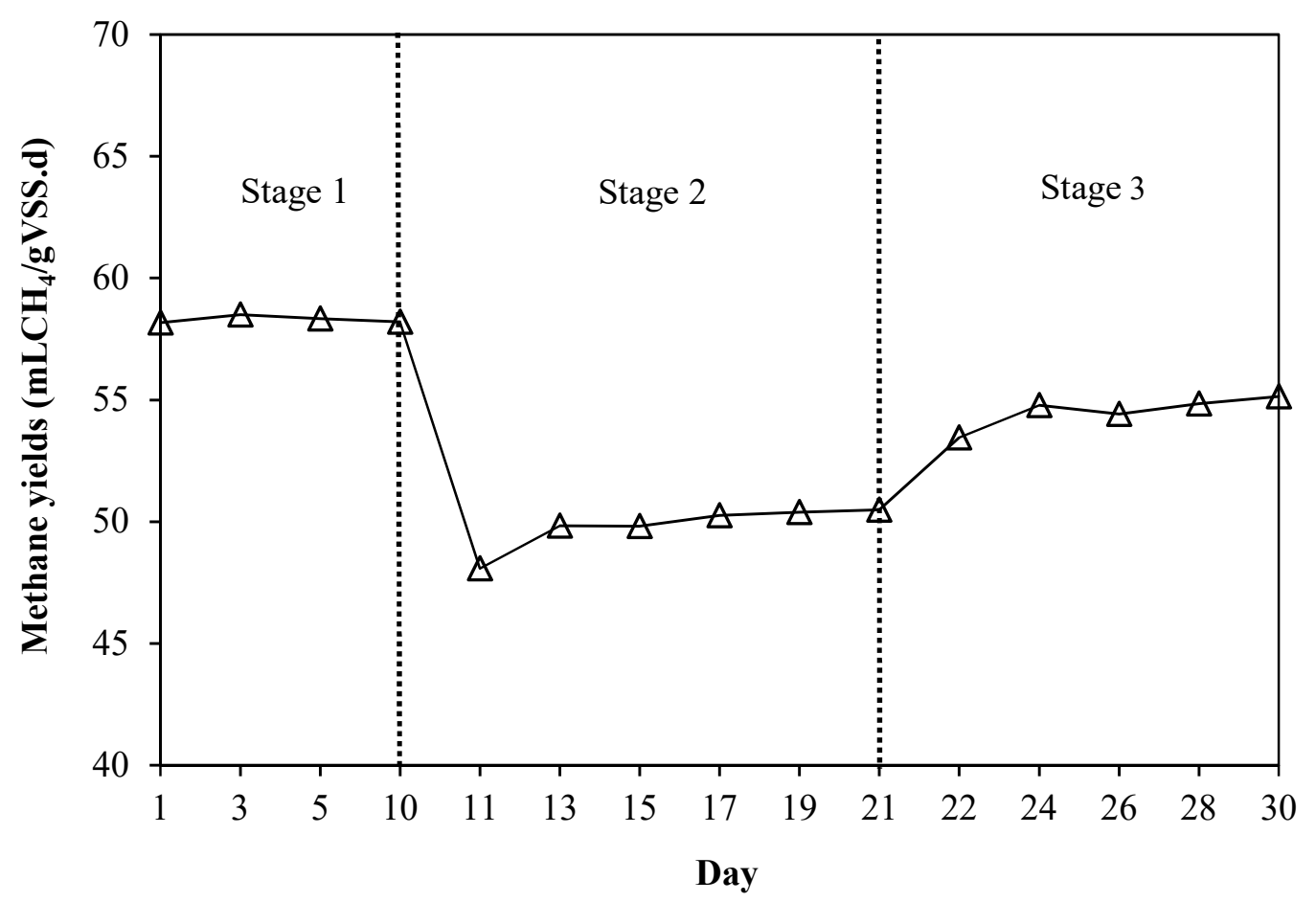

Stage 1 - Fe only, Stage 2 - Fe and S, Stage 3 - Fe, EDDS and S

Figure 6.6 Methane yields of the SAMBR at different stages.

The soluble concentration of $\mathrm{Fe}^{2+}$ was measured in the influent and effluent during each stage of the experiment (Figure 6.7). It can be clearly seen that there was difference between the level of $\mathrm{Fe}^{2+}$ in the influent and in the effluent, which indicated that $\mathrm{Fe}^{2+}$ accumulated in the reactor. The significance of $\mathrm{Fe}^{2+}$ accumulation in a SAMBR which is important for the metal dosing, has been discussed in Section 4.3.1. The solids retention time (SRT) therefore needs to be maintained in order to control the level of $\mathrm{Fe}^{2+}$ associating with the biomass in the reactor. In addition, the level of $\mathrm{Fe}^{2+}$ in the effluent cannot be negligible compared to the level of $\mathrm{Fe}^{2+}$ in the influent, hence, dosing optimization is essential to make sure the effluent quality is within the discharge standards. 
Chapter 6: Dosing of Ethylenediamine-N,N'-disuccinic acid (EDDS) to improve the bioavailability of $\mathrm{Fe}^{2+}$ in the presence of sulfide in a submerged anaerobic membrane bioreactor

The average concentration of soluble $\mathrm{Fe}^{2+}$ in the influent in Stage 1 was $29.1 \mu \mathrm{gFe}^{2+} / \mathrm{gTSS}$. When sulfide was introduced into the feed in Stage 2, the level of soluble $\mathrm{Fe}^{2+}$ dropped to an average of $11.4 \mu \mathrm{gFe}^{2+} / \mathrm{gTSS}(\mathrm{p}<0.05)$, which means $60.9 \%$ of the added $\mathrm{Fe}^{2+}$ may precipitate with sulfide as $\mathrm{FeS}$. The average level of soluble $\mathrm{Fe}^{2+}$ in the effluent was $25.4 \mu \mathrm{gFe}^{2+} / \mathrm{gTSS}$ in Stage 1, which was then reduced by $72.9 \%$ to only $6.9 \mu \mathrm{gFe}^{2+} / \mathrm{gTSS}$ in Stage 2 ( $\mathrm{p}<$ $0.05)$. This finding clearly shows the effect of sulfide on the solubility of $\mathrm{Fe}^{2+}$ as it had already precipitated the Fe in the feed before entering the SAMBR, hence reducing the level of soluble $\mathrm{Fe}^{2+}$ in the reactor and also in the effluent.

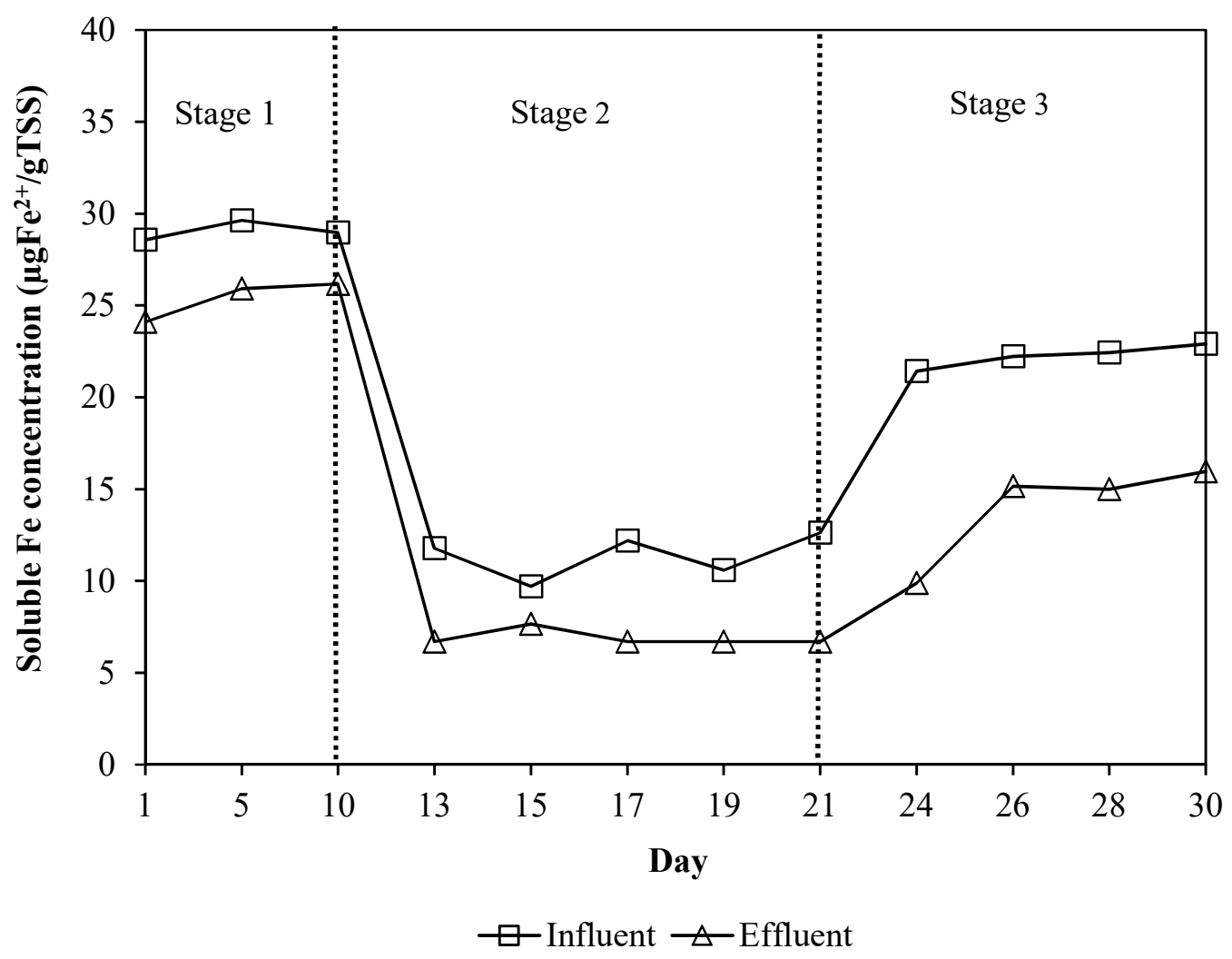

Stage 1 - Fe only, Stage 2 - Fe and S, Stage 3 - Fe, EDDS and S

Figure 6.7 Soluble Fe concentration in the SAMBR influent and effluent at different stages. 
Chapter 6: Dosing of Ethylenediamine-N,N'-disuccinic acid (EDDS) to improve the bioavailability of $\mathrm{Fe}^{2+}$ in the presence of sulfide in a submerged anaerobic membrane bioreactor

Table A.1 (Appendix) gives the content of $\mathrm{Fe}^{2+}$ in each fraction from the BCR extraction, while Figure 6.8 documents the distribution of $\mathrm{Fe}^{2+}$ during each stage of the experiment. These results show that without sulfide (Stage 1), $\mathrm{Fe}^{2+}$ was mainly present in Fe-Mn oxides fraction (F2) in the SAMBR, i.e. $49.8 \%$ of the total $\mathrm{Fe}^{2+}$ content. The Exchangeable (F1) and Residual fractions (F4) were the second highest fractions, i.e. $19.8 \%$ and $20.6 \%$, respectively. The Soluble (Sol) and Organic matter/sulfide (F3) fractions were the lowest at $0.26 \%$ and $9.53 \%$, respectively. During Stage 2, with the addition of sulfide to the feed, there was a significant decrease in the first two fractions which have the highest bioavailability (Sol and F1) to $0.09 \%$ and $5.02 \%(\mathrm{p}<0.05$ ). In contrast, the last two fractions (F3 and F4) which are considered to be the least bioavailable fractions, increased to $15.0 \%$ and $39.8 \%(\mathrm{p}<0.05)$.

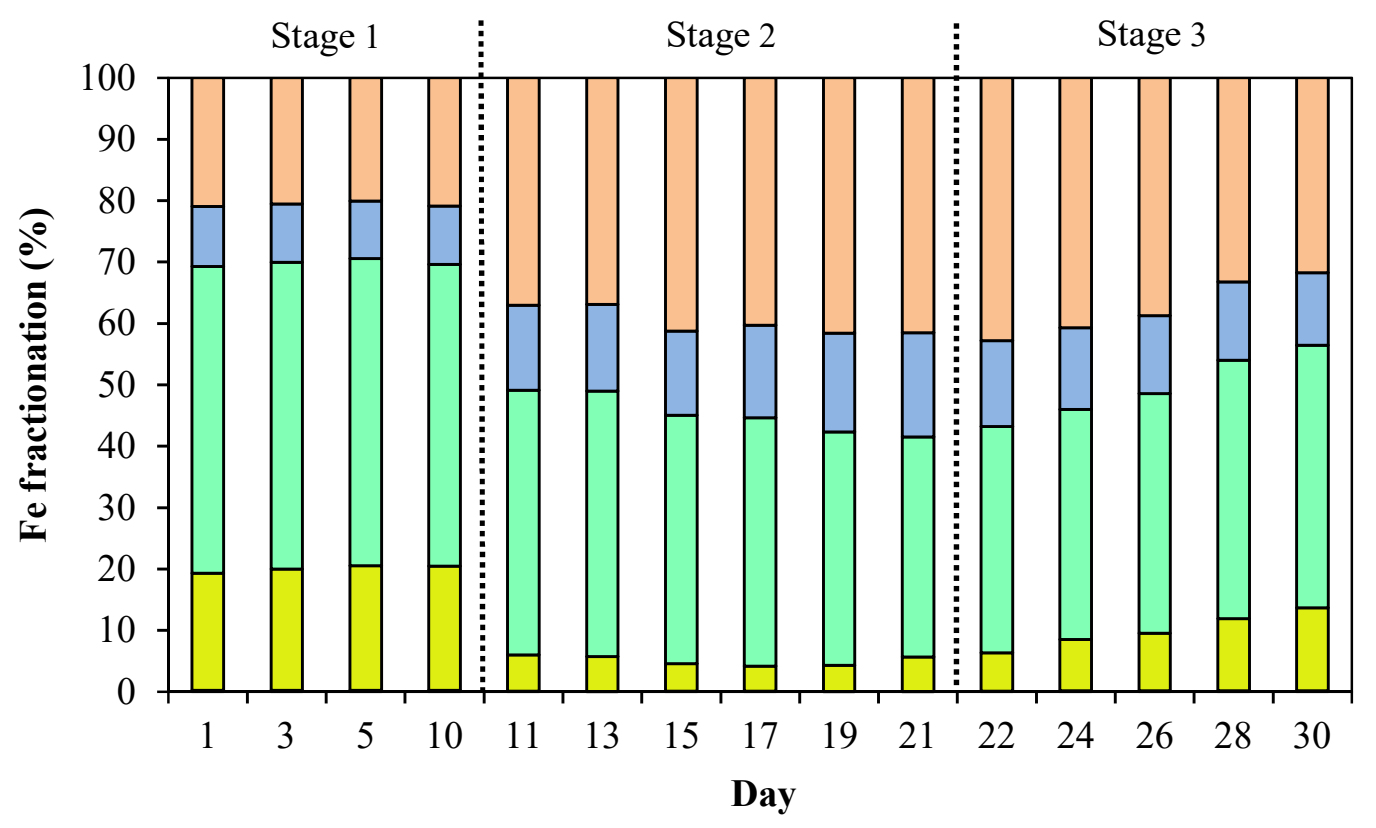

$\square$ Sol $\square \mathrm{F} 1 \quad \square \mathrm{F} 2 \quad \square \mathrm{F} 3 \quad \square \mathrm{F} 4$

Sol - Soluble, F1 - Exchangeable, F2 - Fe/Mn oxides, F3 - Organic matter, F4 - Residual

Figure 6.8 Speciation of Fe in the SAMBR at different stages. 
Chapter 6: Dosing of Ethylenediamine-N,N'-disuccinic acid (EDDS) to improve the bioavailability of $\mathrm{Fe}^{2+}$ in the presence of sulfide in a submerged anaerobic membrane bioreactor

The results from this experiment show that in the absence of sulfide, with $\mathrm{Fe}^{2+}$ as the only TM, the SAMBR was still able to achieve very high treatment efficiencies. However, in the presence of sulfide in the feed, the precipitation of $\mathrm{Fe}^{2+}$ as $\mathrm{FeS}$ resulted in a shift in $\mathrm{Fe}$ speciation towards less bioavailable fractions, which in turn reduced the performance of the SAMBR.

\subsubsection{Dosage of EDDS to improve the bioavailability of $\mathrm{Fe}^{2+}$ in the presence of sulfide in a SAMBR}

The dosing strategy for $\mathrm{Fe}^{2+}$ and EDDS determined from experiment 6.3.1 was applied in Stage 3 of this study, as $\mathrm{Fe}^{2+}$ was pre-complexed with EDDS before adding it to the feed for the SAMBR. The introduction of EDDS clearly helped improve the performance of the SAMBR, as the average soluble COD in the reactor and effluent decreased from $64.8 \mathrm{mg} / \mathrm{L}$ and $17.2 \mathrm{mg} / \mathrm{L}$ (Stage 2) to $54.9 \mathrm{mg} / \mathrm{L}$ and $12.7 \mathrm{mg} / \mathrm{L}$ (Stage 3) ( $<$ 0.05), respectively (Figure 6.5). Accordingly, the average COD removal of the SAMBR increased from 96.6\% (Stage 2) to $97.5 \%$ (Stage 3$)(\mathrm{p}<0.05)$. The average daily methane yields also increased by $9.46 \%$ from $49.8 \mathrm{mLCH}_{4} / \mathrm{gVSS} \mathrm{d}$ (Stage 2) to 54.5 $\mathrm{mLCH}_{4} / \mathrm{gVSS}$.d (Stage 3$)(\mathrm{p}<0.05)$, however, this was still slightly below the level before the addition of sulfide and EDDS (Stage 1) i.e. 58.3 $\mathrm{mLCH}_{4} / \mathrm{gVSS}$.d (Figure 6.6). The VFA level was also slightly reduced from $3.98 \mathrm{mgCOD} / \mathrm{L}$ to $1.92 \mathrm{mgCOD} / \mathrm{L}(\mathrm{p}<0.05)$.

The measurement of soluble $\mathrm{Fe}^{2+}$ concentrations in the feed and effluent during Stage 3 showed the positive effect of EDDS on $\mathrm{Fe}^{2+}$ bioavailability when it was added to the feed as an Fe-EDDS complex. From Figure 6.7, it can be seen that the average soluble $\mathrm{Fe}^{2+}$ level in the feed and effluent increased from $11.4 \mu \mathrm{gFe}^{2+} / \mathrm{gTSS}$ and $6.9 \mu \mathrm{gFe}^{2+} / \mathrm{gTSS}$ (Stage 2) to $22.2 \mu \mathrm{gFe}^{2+} / \mathrm{gTSS}$ and $14.0 \mu \mathrm{gFe}^{2+} / \mathrm{gTSS}$ (Stage 3$)(\mathrm{p}<0.05)$, respectively. However, these levels of $\mathrm{Fe}^{2+}$ in Stage 3 are still below those at Stage 1 i.e. $29.1 \mu \mathrm{gFe}^{2+} / \mathrm{gTSS}$ (influent) and $25.4 \mu \mathrm{gFe}^{2+} / \mathrm{gTSS}$ (effluent). These findings show that the 
Chapter 6: Dosing of Ethylenediamine-N,N'-disuccinic acid (EDDS) to improve the bioavailability of $\mathrm{Fe}^{2+}$ in the presence of sulfide in a submerged anaerobic membrane bioreactor

complexation of $\mathrm{Fe}^{2+}$ and EDDS in the feed was able to prevent $\mathrm{Fe}^{2+}$ from precipitating with the sulfide, hence improving $\mathrm{Fe}^{2+}$ solubility.

Results from $\mathrm{BCR}$ extraction showed a reverse trend in $\mathrm{Fe}^{2+}$ speciation when the $\mathrm{Fe}^{2+}$ was added to the feed as a complex with EDDS (Figure 6.8). The most bioavailable fractions of $\mathrm{Fe}^{2+}$, i.e. Soluble (Sol) and Exchangeable (F2), increased slightly from $0.09 \%$ and $5.0 \%$ in Stage 2 to $0.2 \%$ and $9.9 \%$ in Stage 3 $(\mathrm{p}<0.05)$, respectively, while the dominant fraction of Fe-Mn oxides (F2) was relatively stable, i.e. $40.2 \%$ (Stage 2) and 39.6\% (Stage 3) (p >0.05). The last two fractions which are considered to be the least bioavailable, i.e. Organic matters/sulfides (F3) and Residual (F4), reduced from 15.0\% and 39.8\% (Stage 2) to $12.9 \%$ and $37.5 \%$ (Stage 3$)(p<0.05)$, respectively. The extraction results show that when complexed with EDDS, the speciation of $\mathrm{Fe}^{2+}$ was shifted towards more bioavailable fractions, i.e. Soluble and Exchangeable, and hence the bioavailability of $\mathrm{Fe}^{2+}$ for microbial uptake was improved. Other TMs (Co, $\mathrm{Ni}, \mathrm{Zn}, \mathrm{Mn}$ and Mo), although not added to the reactor, had accumulated in the seed sludge, and their speciation results showed that the addition of EDDS also slightly increased their soluble fraction, however, there was no statistically significant difference in other fractions from the BCR extraction (data not shown).

A mass balance of soluble EDDS in the reactor determined using UHPLC is shown in Table 6.3. It can be seen that the sum of free EDDS and EDDS in the Fe-EDDS complex was up to about $84 \%$ of the total soluble EDDS measured in the reactor. The concentration of free EDDS and Fe-EDDS complex in the influent, reactor, and effluent of the SAMBR is shown in Tables 6.4 and 6.5. Since EDDS was added as a complex to the feed (Fe-EDDS), it was expected that there would be very low concentrations of free EDDS detected. Table 6.4 shows that the concentration of free EDDS in the influent was very low, i.e. $0.04-0.07 \mathrm{mg} / \mathrm{L}$, which is about $5 \%$ of the total EDDS added to complex with $\mathrm{Fe}^{2+}$. The concentration of free EDDS in the reactor and 
Chapter 6: Dosing of Ethylenediamine-N,N'-disuccinic acid (EDDS) to improve the bioavailability of $\mathrm{Fe}^{2+}$ in the presence of sulfide in a submerged anaerobic membrane bioreactor

effluent, therefore, was also not significant, i.e. $0-0.02 \mathrm{mg} / \mathrm{L}$. The average concentration of EDDS as the Fe-EDDS complex in the influent was 1.13 $\mathrm{mg} / \mathrm{L}$, which was $86.2 \%$ of the total added EDDS (Table 6.5). The average equivalent concentration of $\mathrm{Fe}^{2+}$ in the Fe-EDDS complex in the feed was 0.15 $\mathrm{mg} / \mathrm{L}(9.52 \mu \mathrm{g} / \mathrm{TSS})$, which is $85.6 \%$ of the total soluble $\mathrm{Fe}^{2+}$ measured in the feed. In addition, this level of $\mathrm{Fe}^{2+}$ present in the complex $(0.15 \mathrm{mg} / \mathrm{L}=0.05$ $\mathrm{mg} / \mathrm{gTSS}$.d) was about $25.4 \%$ of the total amount of $\mathrm{Fe}^{2+}$ added to the feed (10 $\mathrm{mg} / \mathrm{L}=0.22 \mathrm{mg} / \mathrm{gTSS} . \mathrm{d})$. These results could explain why the average soluble concentration of $\mathrm{Fe}^{2+}$ in the influent increased in Stage 3 as greater amounts of $\mathrm{Fe}^{2+}$ were kept in solution. From the previous studies carried out in a continuous system (Fermoso et al., 2008c), it was expected that the retention of the Fe-EDDS complex by the SAMBR was not very high due to its high solubility, i.e. up to $83 \%$ of the complex in the reactor left in the effluent. However, the results of this experiment showed that the effect of complexation on the bioavailability of $\mathrm{Fe}^{2+}$ was still significant, as the majority of added EDDS was able to compete with sulfide and keep $\mathrm{Fe}^{2+}$ in a soluble form for microbial uptake.

Table 6.3 Mass balance of soluble EDDS in the reactor $(\mathrm{mg} / \mathrm{L})$ using UHPLC in the SAMBR at Stage 3 (Fe, EDDS, and S) $(n=3)$.

\begin{tabular}{cccccc}
\hline Day & $\mathbf{2 2}$ & $\mathbf{2 4}$ & $\mathbf{2 6}$ & $\mathbf{2 8}$ & $\mathbf{3 0}$ \\
\hline Free EDDS & 0.06 & 0.07 & 0.04 & 0.04 & 0.05 \\
EDDS as Fe-EDDS & 0.02 & 0.03 & 0.01 & 0.02 & 0.02 \\
Total EDDS & 0.01 & 0.02 & 0.00 & 0.01 & 0.01 \\
Recovery (\%) & 79.24 & 71.30 & 76.43 & 84.35 & 72.69 \\
\hline
\end{tabular}


Chapter 6: Dosing of Ethylenediamine-N,N'-disuccinic acid (EDDS) to improve the bioavailability of $\mathrm{Fe}^{2+}$ in the presence of sulfide in a submerged anaerobic membrane bioreactor

Table 6.4 Measurement of free EDDS (mg/L) using UHPLC in the SAMBR at Stage 3 (Fe, EDDS, and $\mathrm{S})(\mathrm{n}=3)$.

\begin{tabular}{cccccc}
\hline Day & $\mathbf{2 2}$ & $\mathbf{2 4}$ & $\mathbf{2 6}$ & $\mathbf{2 8}$ & $\mathbf{3 0}$ \\
\hline Influent & 0.06 & 0.07 & 0.04 & 0.04 & 0.05 \\
Reactor & 0.02 & 0.03 & 0.01 & 0.02 & 0.02 \\
Effluent & 0.01 & 0.02 & 0.00 & 0.01 & 0.01 \\
\hline
\end{tabular}

Table 6.5 Measurement of Fe-EDDS complex (mg/L) using UHPLC in the SAMBR (Fe, EDDS, and S) at Stage $3(n=3)$.

\begin{tabular}{cccccc}
\hline Day & $\mathbf{2 2}$ & $\mathbf{2 4}$ & $\mathbf{2 6}$ & $\mathbf{2 8}$ & $\mathbf{3 0}$ \\
\hline Influent & 0.84 & 1.13 & 1.19 & 1.17 & 1.31 \\
Reactor & 0.75 & 0.72 & 0.78 & 0.82 & 0.79 \\
Effluent & 0.61 & 0.59 & 0.63 & 0.68 & 0.65 \\
\hline
\end{tabular}

\subsection{Conclusions}

The results from this study showed that the presence of sulfide in the feed resulted in a decrease in $\mathrm{Fe}^{2+}$ bioavailability as $\mathrm{Fe}^{2+}$ speciation was shifted towards the less bioavailable fractions, i.e. organic matter/sulfide and residual, which in turn reduced the performance of the SAMBR. When EDDS and $\mathrm{Fe}^{2+}$ were dosed at a 1:1 molar ratio $\left(10 \mathrm{mg} / \mathrm{L} \mathrm{Fe}^{2+}\right)$ as a complex, the shift in $\mathrm{Fe}^{2+}$ speciation was reversed. When applied to the SAMBR, its performance was improved as both COD removal and daily methane yields increased significantly. 


\section{Chapter 7}

\section{Effects of trace metal deficiency and supplementary on a submerged anaerobic membrane bioreactor}

\section{Outline:}

7.1 Introduction

7.2 Experimental and analytical methods

7.3 Results and discussion

7.4 Conclusions

Note: this chapter was published in Bioresource Technology, 2017, volume 241, pages 161-170.

\subsection{Introduction}

The importance of trace metals (TMs) has been emphasized in the literature. In anaerobic treatment processes, some types of wastewater contain a sufficient level of these TMs, such as swine wastewater (Cestonaro do Amaral et al., 2014), whereas TM supplementation is required for other types of wastewater, eg. methanol wastewater (Fermoso et al., 2008a), maize silage (Evranos \& Demirel, 2014), and wheat stillage (Schmidt et al., 2014). When TMs are not supplemented for these wastewaters this will result in nutrient deficiency for the anaerobic microorganisms, and this is known to increase the minimum generation time of methanogens, decrease rates of substrate utilization, and can ultimately lead to process failure (Worm et al., 2011). 
In term of dosing strategies, TMs can be added to the reactor continuously (Zandvoort et al., 2002), pre-loaded (Zandvoort et al., 2004) or pulsed (Zandvoort et al., 2004; Fermoso et al., 2008c). A continuous addition of $\mathrm{CoCl}_{2}$ at low levels $(0.62 \mu \mathrm{mol} / \mathrm{L} . \mathrm{d})$ to a methanol-fed UASB reactor could only increase the specific methanogenic activity (SMA) up to $215 \mathrm{mgCOD}$ $\mathrm{CH}_{4} / \mathrm{gVSS} . d$ (Zandvoort et al., 2002). The pre-loading strategy involved contacting the inoculum for a UASB reactor with a $1 \mathrm{mM}$ cobalt solution $\left(\mathrm{CoCl}_{2} \cdot 6 \mathrm{H}_{2} \mathrm{O}\right)$ for $24 \mathrm{~h}$ at $30^{\circ} \mathrm{C}$ in a serum bottle in the absence of substrate, and was found to be able to control Co limitations in the methanol-fed UASB reactor, but it resulted in very high levels of Co being lost in the effluent (Zandvoort et al., 2004). Fermoso et al. (2008c) investigated the feasibility of pulse dosing of a low quantity of $\mathrm{CoCl}_{2}(5 \mu \mathrm{mol} / \mathrm{L})$ to a USAB reactor, a compromise strategy between continuous and pre-loading, to control metal limitations. They found that without having to supplement Co continuously, around $90 \%$ of the Co was retained in the granular sludge matrix.

The aim of this study was, therefore, to evaluate the effect of TM deficiency on the performance of a SAMBR by excluding the TMs from the influent. Consequently, rapid addition of a mixture of TMs as a pulse to the SAMBR was investigated to determine if this could be an effective dosing strategy to overcome nutrient deficiency. Changes in metal content, speciation and bioavailability over time during the nutrient deficiency and metal dosing period were monitored to evaluate their correlation with changes in SAMBR performance.

\subsection{Experimental and analytical methods}

\subsubsection{Trace metal deficiency}

Before starting the nutrient deficiency experiment, the SAMBR was operated at steady state (normal) conditions, i.e. 6 h HRT, $100 \mathrm{~d}$ SRT and 500 $\mathrm{mgCOD} / \mathrm{L}$ feed, with TMs supplemented at concentrations specified in Table 
Chapter 7: Effects of trace metal deficiency and supplementary on a submerged anaerobic membrane bioreactor

3.1 (Section 3.4) for $76 \mathrm{~d}$. From day 15 onwards, no TMs were added to the feed and the SAMBR was allowed to operate under nutrient deficient conditions for $24 \mathrm{~d}$ (day 17 to day 41). Samples were collected during each period to analyse for reactor performance and TM speciation.

\subsubsection{Trace metal dosing strategies}

The pulse dosing of TMs was carried out in three phases, with the metal concentrations given in Table 7.1. In Phase 1, on day 43 after the nutrient deficiency, TMs were dosed at 5 times of their daily dosing amounts at normal operating conditions to determine if the performance of the SAMBR can be restored. In Phase 2, on day 51, the same amount of TMs in Phase 1 was added again to confirm if a second pulse could have the same effect as the first. In Phase 3, on day 59, a third pulse was added at 10 times the daily loading of TMs to test the limit of anaerobic microorganisms to a high level of TMs. The TM solution was prepared in advance and added directly to the SAMBR; samples were collected regularly during each pulse to analyse for reactor performance and TM speciation.

Table 7.1 Concentrations of TMs for each pulse $(\mathrm{mg} / \mathrm{L})$.

\begin{tabular}{cccc}
\hline Day & $\mathbf{4 3}-\mathbf{5 0}$ & $\mathbf{5 1}-\mathbf{5 8}$ & $\mathbf{5 9}-\mathbf{7 2}$ \\
\hline $\mathbf{F e}$ & $\mathbf{1}^{\text {st }}$ pulse (5x) & $\mathbf{2}^{\text {nd }}$ pulse (5x) & $\mathbf{3}^{\text {rd }}$ pulse (10x) \\
$\mathbf{C o}$ & 2.75 & 2.75 & 5.51 \\
$\mathbf{N i}$ & 0.44 & 0.44 & 0.88 \\
$\mathbf{Z n}$ & 0.08 & 0.08 & 0.17 \\
$\mathbf{M n}$ & 0.06 & 0.06 & 0.13 \\
$\mathbf{M o}$ & 0.13 & 0.13 & 0.26 \\
\hline
\end{tabular}

$5 \mathrm{x}$ (5 time) and 10x (10 time) the daily metal mass loading at steady state conditions 


\section{and supplementary on a submerged anaerobic membrane bioreactor}

\subsection{Results and Discussion}

\subsubsection{Trace metal deficiency}

\subsubsection{The performance of the SAMBR}

During normal conditions, the continuous addition of TMs for more than 2 months (76 d) clearly resulted in a positive effect on the performance of the SAMBR. Within the sampling period (last $16 \mathrm{~d}$ ), the SAMBR was able to achieve very high treatment efficiency, i.e. 96.8\% COD removal, with the soluble COD concentration in the reactor (supernatant) and effluent being relatively stable with an average value of $59.0 \mathrm{mg} / \mathrm{L}$ and $16.0 \mathrm{mg} / \mathrm{L}$, respectively, as shown in Figure 7.1. The difference between the soluble COD level in the reactor and in the effluent was due to the membrane which retained a large amount of dissolved COD by the thin polarisation layer, or cake, on the membrane surface. The flux of the membrane in the SAMBR was kept at $15 \mathrm{~L}$ per square meter per hour (LMH) throughout the experiment which was much below the critical flux (24 LMH). The transmembrane pressure (TMP) was measured continuously during the whole experiment and its value was fairly constant ranging from $3.52 \mathrm{kPa}$ to $3.69 \mathrm{kPa}$, hence, the cake layer formation was relatively stable. Therefore, the changes in COD level and its difference in the reactor and effluent was only due to the effects of different metal dosing stages (deficiency or pulsing).

However, 9 days after the TMs were excluded from the feed (day 25), the soluble COD concentration in the reactor and effluent rose significantly to $79.32 \mathrm{mg} / \mathrm{L}$ and $36.28 \mathrm{mg} / \mathrm{L}(\mathrm{p}<0.05)$, respectively. On day 41 (25 days after $\mathrm{TM}$ exclusion), these concentrations increased further to $94.2 \mathrm{mg} / \mathrm{L}$ and 50.4 $\mathrm{mg} / \mathrm{L}(\mathrm{p}<0.05)$, which are equivalent to a $59.3 \%$ and $233 \%$ increase compared to these concentrations under "normal" conditions. As a result, the COD removal dropped, but still maintained a relatively acceptable level, i.e. 89.9\% (p $<0.05)$. 
The VFA profile in comparison to the soluble COD in the reactor and effluent is shown in Figures 7.2 and 7.3. Similar to the COD profile, there were concentration differences between the reactor VFAs (as COD), and the effluent VFAs (as COD) from the reactors. The cake gel layer, acting as a secondary dynamic membrane, appeared to have made a significant contribution to reducing the VFAs passing through the membrane. It can be seen that with the supplementation of TMs, only very low concentrations of VFAs were detected in the reactor (up to $2 \mathrm{mg} \mathrm{COD} / \mathrm{L}$ ), and none were found in the effluent. This indicates that the amount of TMs added was sufficient to support the growth of the anaerobic microorganisms to convert all the incoming substrate COD into biomass, $\mathrm{CH}_{4}$ and $\mathrm{CO}_{2}$.

However, the absence of TMs had a significant effect on the performance of the SAMBR as the soluble COD concentration in the reactor and effluent increased, and the VFAs also increased accordingly. A VFA peak was measured on day 41 in both the reactor and effluent, i.e. $25.5 \mathrm{mg} / \mathrm{L}$ as COD $(27.0 \%$ of reactor COD) $(\mathrm{p}<0.05)$ and $4.9 \mathrm{mg} / \mathrm{L}$ as COD $(9.7 \%$ of effluent COD) $(\mathrm{p}<0.05)$, respectively. The accumulation of VFAs due to TM deficiency in anaerobic systems has been reported in several studies (Worm et al., 2009; Banks et al., 2012; Schmidt et al., 2014). It is clear from the literature that there are kinetic differences between different groups of anaerobic bacteria, and since the methanogens have very slow growth rates, and strict growth requirements, the fast growing acidogenic and acetogenic bacteria compete more efficiently for the available metal nutrients (White \& Stuckey, 2000). Ketheesan et al. (2016) observed the accumulation of VFAs in Fe-deficient anaerobic reactors, and postulated that the competition for TMs by those groups of bacteria can create a temporary nutrient imbalance, which is bound to affect the methanogens primarily, compounding the problem of the accumulation of intermediates, i.e. VFAs.

Figures 7.2 and 7.3 also show that the soluble COD in the reactor and the effluent, respectively, was considerably higher than the VFAs concentration as 
Chapter 7: Effects of trace metal deficiency and supplementary on a submerged anaerobic membrane bioreactor

COD. This implies that VFAs were not the only contributors to the soluble COD, but also other organic compounds such as soluble microbial products (SMPs). Bacteria are known to excrete SMPs into solution due to biomass decay and substrate metabolism (Barker \& Stuckey, 1999), and it has been confirmed that metal nutrient deficiency is one of the factors that result in increased SMP production in anaerobic reactors (Barber \& Stuckey, 2000; Aquino \& Stuckey, 2003).

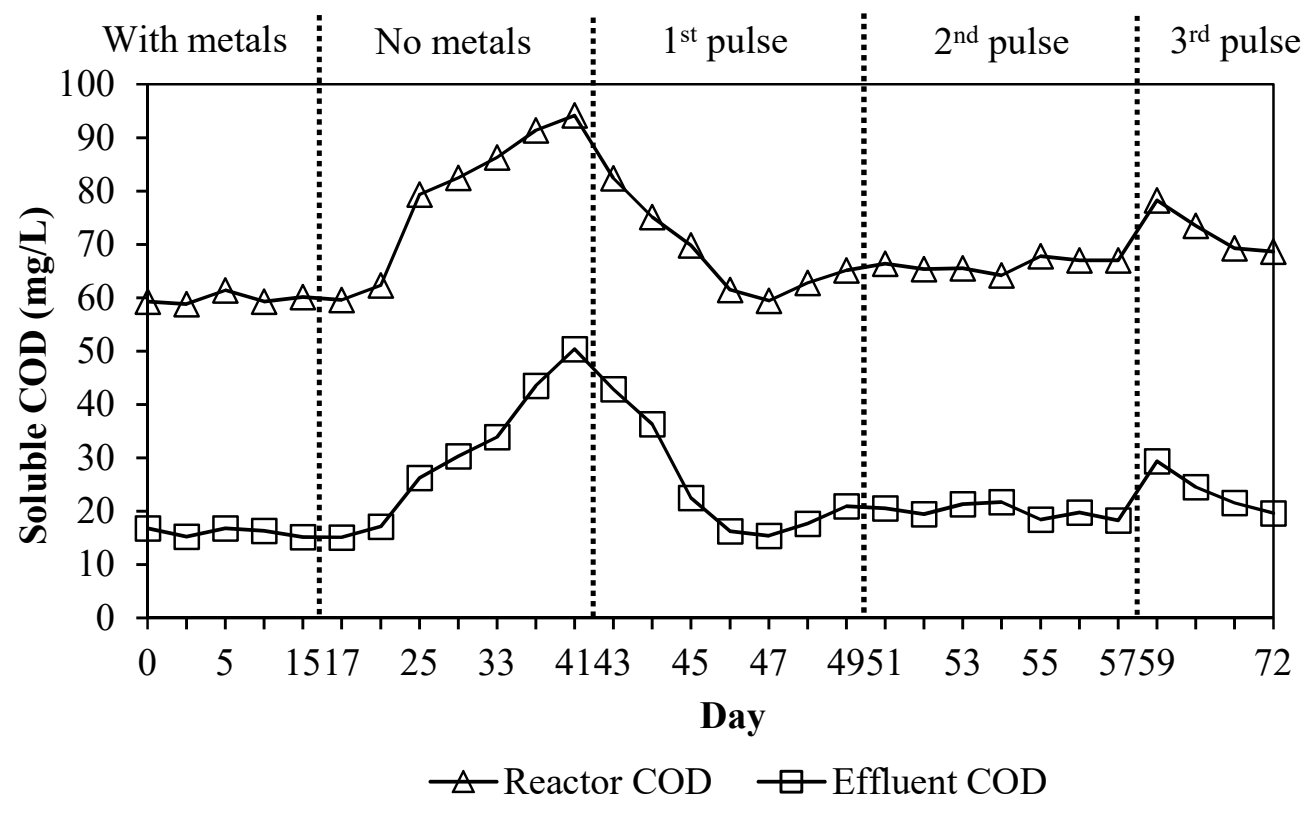

Figure 7.1 Profile of soluble COD in reactor and effluent and the methane yields from the SAMBR $(\mathrm{n}=3)$. 


\section{and supplementary on a submerged anaerobic membrane bioreactor}

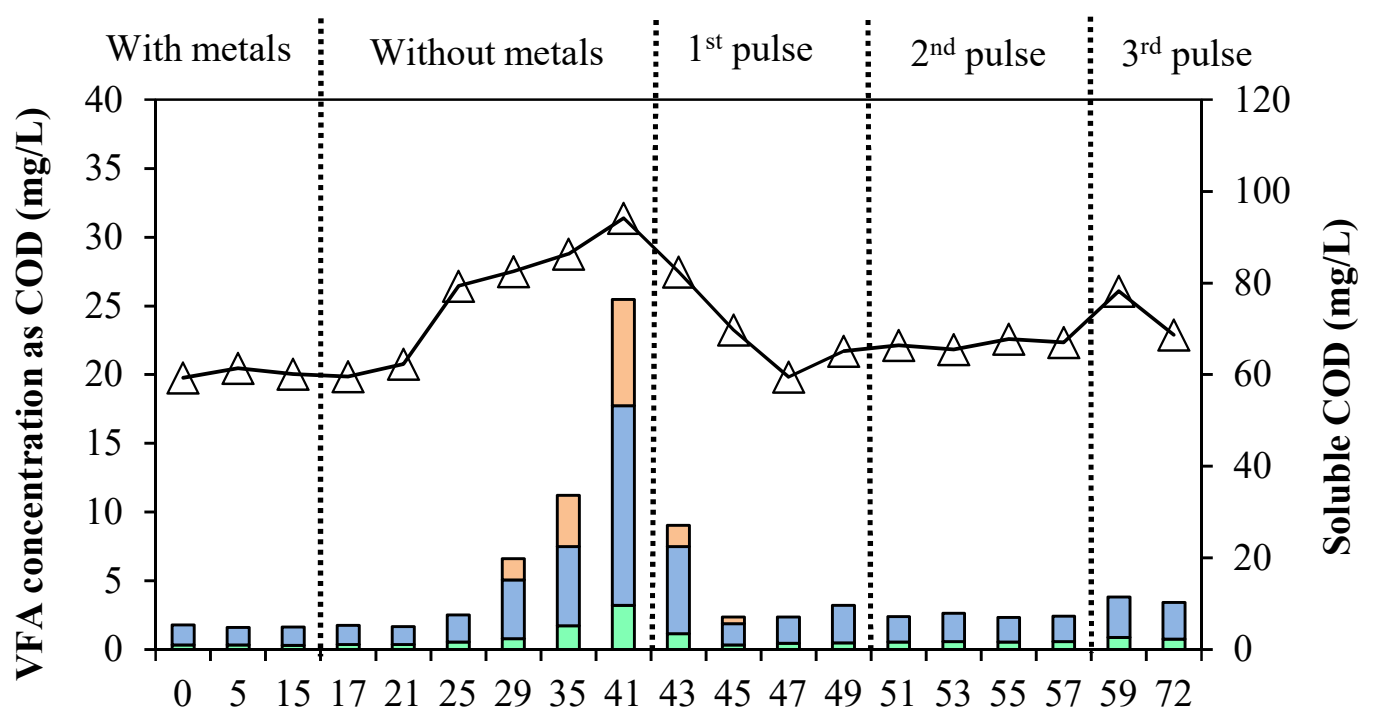

Day

$\square$ Formic acid $\square$ Acetic acid $\square$ Propionic acid $\triangle$ Reactor COD

Figure 7.2 VFA concentrations as COD (left), and Reactor COD (right) of the $\operatorname{SAMBR}(\mathrm{n}=3)$.

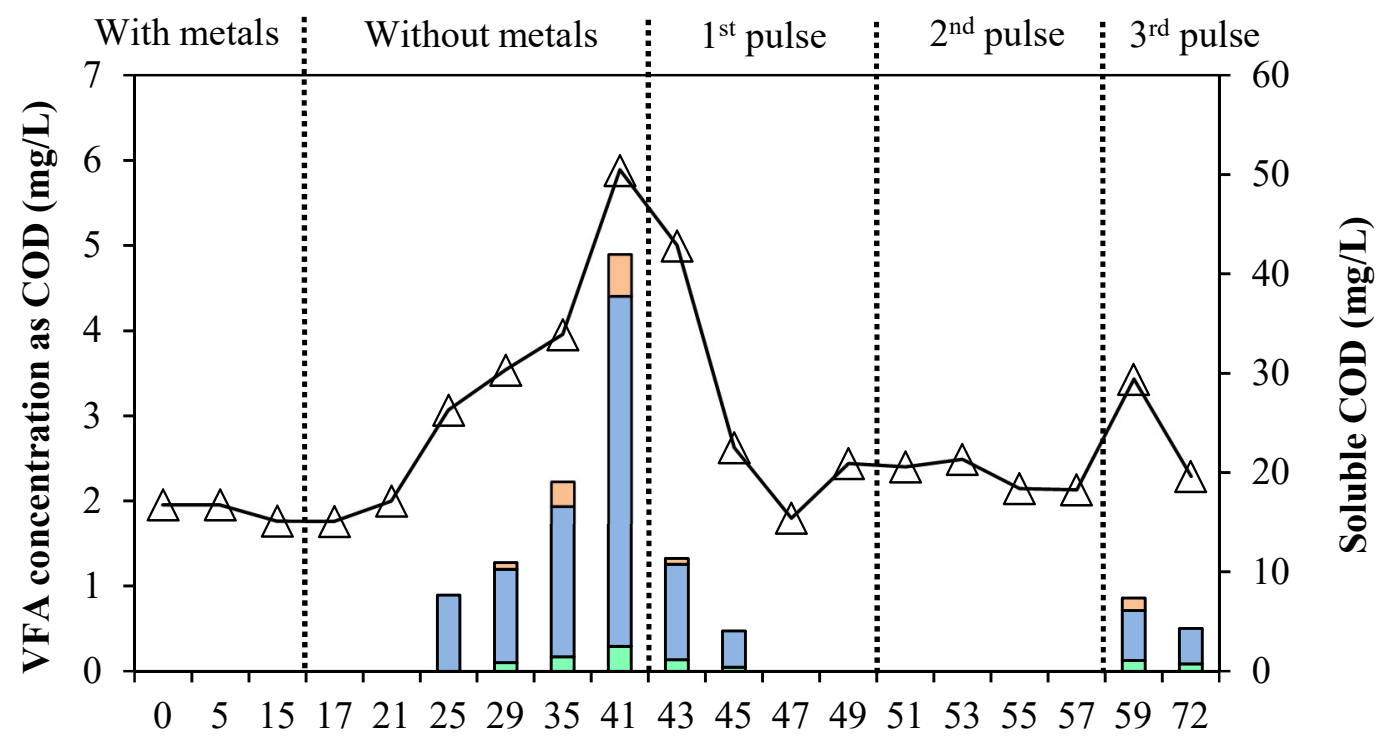

Day

$\varpi$ Formic acid $\square$ Acetic acid $\square$ Propionic acid $\triangle$ Effluent COD

Figure 7.3 VFA concentrations as COD (left), and Effluent COD (right) of the SAMBR at different phases $(n=3)$. 
Figure 7.4 shows the profile of methane yield during normal TM deficiency and system recovery periods. With the supplementation of TMs, the methane yield from the SAMBR were relative stable at an average of 80.4 $\mathrm{mLCH}_{4} / \mathrm{gVSS} . \mathrm{d}$ ( $\mathrm{p}>0.05$ ); around $87 \%$ of the theoretical yield (92.4 $\mathrm{mLCH}_{4} / \mathrm{gVSS} . \mathrm{d}$ at $35^{\circ} \mathrm{C}$ ) was achieved, with the balance due to cell growth, accumulation of biomass in the reactor, and loss of methane in the effluent which can be up to $17 \%$ (Kunacheva et al, 2017). However, the methane yields dropped abruptly by around $38 \%$ to $50.5 \mathrm{mLCH}_{4} / \mathrm{gVSS} . \mathrm{d}(\mathrm{p}<0.05)$ on day 41 due to the absence of TMs in the influent. This result clearly reflected the negative influence of TM deficiency on the methanogens as it limited their growth, and hence reduced their ability to convert the influent COD into biomass, $\mathrm{CH}_{4}$ and $\mathrm{CO}_{2}$.

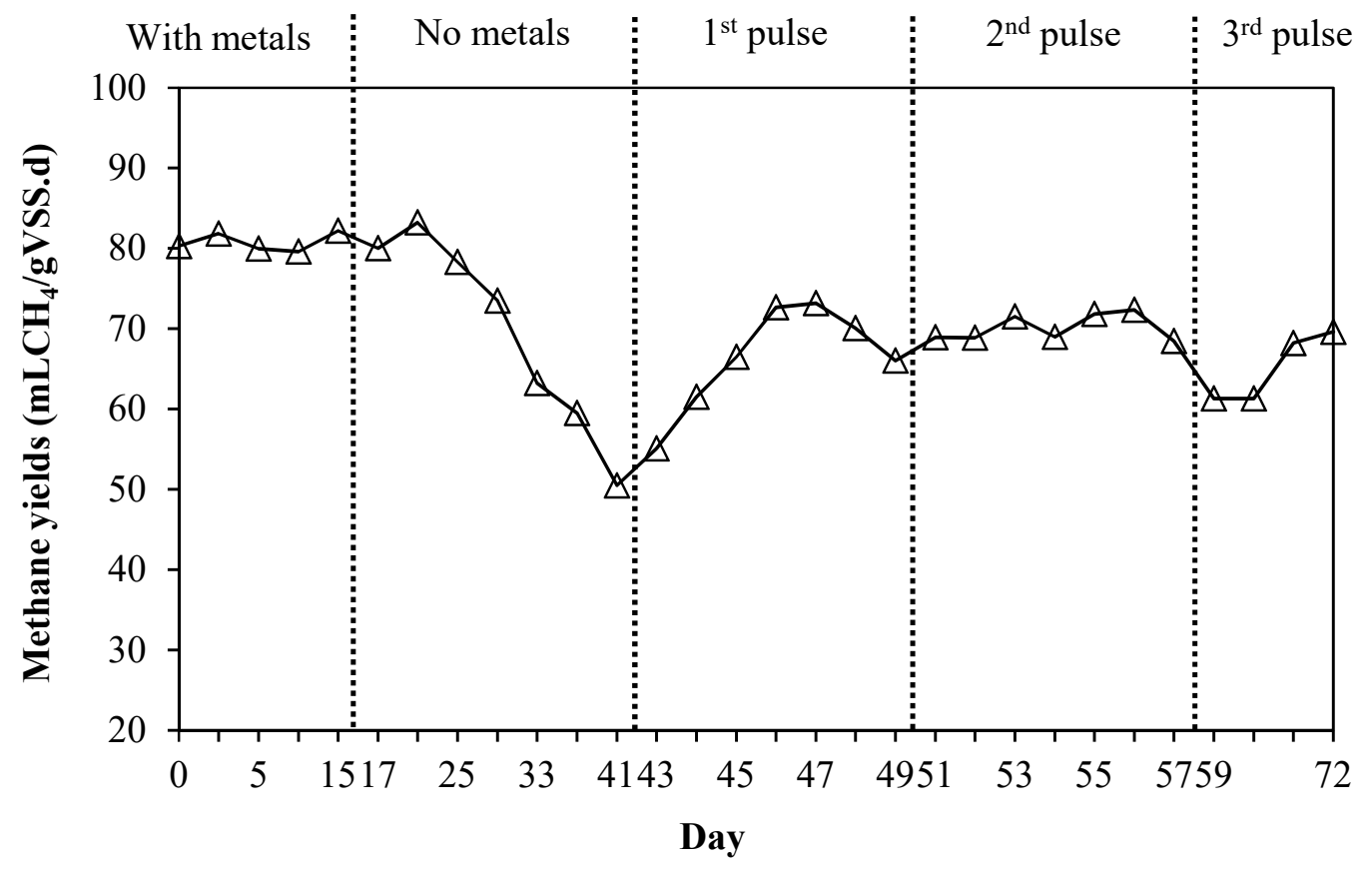

Figure 7.4 Methane yields of the SAMBR at different phases $(\mathrm{n}=3)$. 
Chapter 7: Effects of trace metal deficiency and supplementary on a submerged anaerobic membrane bioreactor

\subsubsection{The speciation of trace metals}

Table 7.2 shows the content of TMs in the influent, reactor, and effluent during different phases of the study. During the first phase (with metals), the average total metal content (sum of all BCR fractions) in the reactor ( $\mu \mathrm{g} / \mathrm{gTSS}$ ) (in comparison with the metal content in the feed $(\mu \mathrm{g} / \mathrm{gTSS})$ ) was in the following order: $\mathrm{Fe}(0.9 \%)>\mathrm{Co}(0.6 \%)>\mathrm{Zn}(0.1 \%)>\mathrm{Ni}(0.4 \%)>\mathrm{Mo}(0.7 \%)$ $>\mathrm{Mn}(1.7 \%)$. These results showed that the level of metal content in the reactor varied between metals, and this was almost certainly due to the different physicochemical properties of the metals, and also their supplemented concentrations in the feed. Since the reactor had been operated with the continuous supplementation of TMs for a long period of time (5 months in total and steady state for 76 days), and with long retention of biomass in the reactor (100 d SRT), this could have resulted in the substantial accumulation of TMs in the reactor in both the cells and as precipitates. The initial content of these metals in the seed sludge at the beginning of this experiment was quite high; the highest was for Fe $(6387 \mu \mathrm{g} / \mathrm{gTSS}$ or $114.4 \mu \mathrm{mol} / \mathrm{gTSS})$ while the lowest was for Mn $(157.8 \mu \mathrm{g} / \mathrm{gTSS}$ or $2.9 \mu \mathrm{mol} / \mathrm{gTSS})$. Compared to the metal content in the sludge, the level of metals added to the feed was very low i.e. from $0.1 \%$ for $\mathrm{Zn}$ up to $1.7 \%$ for $\mathrm{Mn}$, but due to the complexity of anaerobic sludge and its environment, the total metal content in the sludge is not a good indicator of metal bioavailability and mobility (Zandvoort et al., 2006a).

Table 7.2 also shows that the effluent concentration of all TMs was always lower than the influent, which explains the increase in total metal content in the reactor based on a mass balance. The accumulation rate of metals ( $\mu \mathrm{g} / \mathrm{gTSS} . \mathrm{d})$ is given in Table 7.3, and occurs in the following order: Fe (2.5\%) $>\operatorname{Zn}(25.4 \%)>\operatorname{Co}(2.4 \%)=\operatorname{Mn}(8.1 \%)>\operatorname{Mo}(11.9 \%)>\mathrm{Ni}(4.2 \%)$. The percentage is the ratio between the average metal accumulation rate in the reactor $(\mu \mathrm{g} / \mathrm{gTSS} . \mathrm{d})$, and the average metal content added in the feed ( $\mu \mathrm{g} / \mathrm{gTSS} . \mathrm{d})$, and this indicates that $\mathrm{Zn}$ and Fe/Co had the highest and lowest affinity towards the biomass in the reactor, respectively. 


\section{Chapter 7: Effects of trace metal deficiency and supplementary on a submerged anaerobic}

membrane bioreactor

Table 7.2 Metal content $(\mu \mathrm{g} / \mathrm{gTSS})$ in the influent, reactor, and effluent from the SAMBR at different phases $(\mathrm{n}=3)$.

\begin{tabular}{|c|c|c|c|c|c|c|c|c|c|c|c|c|c|c|c|c|}
\hline \multirow{2}{*}{$\begin{array}{c}\text { Fe } \\
\text { Day }\end{array}$} & \multicolumn{3}{|c|}{ With metals } & \multicolumn{4}{|c|}{ No metals } & \multicolumn{3}{|c|}{$1^{\text {st }}$ pulse } & \multicolumn{3}{|c|}{$2^{\text {nd }}$ pulse } & \multicolumn{3}{|c|}{$3^{\text {rd }}$ pulse } \\
\hline & $\mathbf{0}$ & 5 & 15 & 17 & 25 & 33 & 41 & 43 & 45 & 49 & 51 & 53 & 57 & 59 & 65 & 72 \\
\hline Influent & 57.1 & 59.2 & 60.5 & 0.0 & 0.0 & 0.0 & 0.0 & 290.0 & 0.0 & 0.0 & 285.4 & 0.0 & 0.0 & 570.9 & 0.0 & 0.0 \\
\hline Reactor & 6386.8 & 6425.4 & 6477.3 & 6401.6 & 6314.9 & 6196.4 & 6072.5 & 6192.6 & 6114.8 & 6080.7 & 6265.2 & 6215.9 & 6192.2 & 6687.3 & 6470.8 & 6266.5 \\
\hline Effluent & 25.9 & 26.2 & 26.3 & 26.9 & 27.3 & 27.5 & 29.2 & 41.3 & 32.9 & 29.4 & 46.8 & 28.4 & 24.9 & 61.8 & 42.1 & 28.4 \\
\hline
\end{tabular}

\begin{tabular}{|c|c|c|c|c|c|c|c|c|c|c|c|c|c|c|c|c|}
\hline \multirow{2}{*}{$\begin{array}{l}\text { Co } \\
\text { Day }\end{array}$} & \multicolumn{3}{|c|}{ With metals } & \multicolumn{4}{|c|}{ No metals } & \multicolumn{3}{|c|}{$1^{\text {st }}$ pulse } & \multicolumn{3}{|c|}{$2^{\text {nd }}$ pulse } & \multicolumn{3}{|c|}{$3^{\text {rd }}$ pulse } \\
\hline & $\mathbf{0}$ & 5 & 15 & 17 & 25 & 33 & 41 & 43 & 45 & 49 & 51 & 53 & 57 & 59 & 65 & 72 \\
\hline Influent & 9.1 & 9.5 & 9.7 & 0.0 & 0.0 & 0.0 & 0.0 & 46.4 & 0.0 & 0.0 & 45.7 & 0.0 & 0.0 & 91.4 & 0.0 & 0.0 \\
\hline Reactor & 1568.5 & 1572.6 & 1582.7 & 1557.0 & 1504.6 & 1407.1 & 1239.1 & 1262.4 & 1244.5 & 1177.1 & 1215.5 & 1189.9 & 1170.0 & 1249.9 & 1184.0 & 1140.8 \\
\hline Effluent & 2.4 & 2.4 & 2.6 & 2.7 & 2.9 & 3.3 & 3.8 & 5.5 & 4.3 & 3.2 & 5.6 & 4.1 & 2.8 & 6.4 & 4.6 & 3.4 \\
\hline
\end{tabular}


Chapter 7: Effects of trace metal deficiency and supplementary on a submerged anaerobic membrane bioreactor

\begin{tabular}{|c|c|c|c|c|c|c|c|c|c|c|c|c|c|c|c|c|}
\hline \multirow{2}{*}{$\begin{array}{l}\mathbf{N i} \\
\text { Day }\end{array}$} & \multicolumn{3}{|c|}{ With metals } & \multicolumn{4}{|c|}{ No metals } & \multicolumn{3}{|c|}{$1^{\text {st }}$ pulse } & \multicolumn{3}{|c|}{$2^{\text {nd }}$ pulse } & \multicolumn{3}{|c|}{$3^{\text {rd }}$ pulse } \\
\hline & $\mathbf{0}$ & 5 & 15 & 17 & 25 & 33 & 41 & 43 & 45 & 49 & 51 & 53 & 57 & 59 & 65 & 72 \\
\hline Influent & 1.7 & 1.8 & 1.8 & 0.0 & 0.0 & 0.0 & 0.0 & 8.7 & 0.0 & 0.0 & 8.6 & 0.0 & 0.0 & 17.2 & 0.0 & 0.0 \\
\hline Reactor & 429.8 & 431.6 & 434.8 & 414.6 & 391.1 & 351.9 & 295.2 & 301.3 & 296.4 & 289.9 & 296.0 & 291.4 & 288.9 & 301.7 & 289.1 & 273.7 \\
\hline Effluent & 0.3 & 0.4 & 0.6 & 0.6 & 0.8 & 0.9 & 0.6 & 1.4 & 1.1 & 0.8 & 1.4 & 0.9 & 0.6 & 2.7 & 2.1 & 1.2 \\
\hline
\end{tabular}

\begin{tabular}{|c|c|c|c|c|c|c|c|c|c|c|c|c|c|c|c|c|}
\hline \multirow{2}{*}{$\begin{array}{l}\mathbf{Z n} \\
\text { Day }\end{array}$} & \multicolumn{3}{|c|}{ With metals } & \multicolumn{4}{|c|}{ No metals } & \multicolumn{3}{|c|}{$1^{\text {st }}$ pulse } & \multicolumn{3}{|c|}{$2^{\text {nd }}$ pulse } & \multicolumn{3}{|c|}{$3^{\text {rd }}$ pulse } \\
\hline & $\mathbf{0}$ & 5 & 15 & 17 & 25 & 33 & 41 & 43 & 45 & 49 & 51 & 53 & 57 & 59 & 65 & 72 \\
\hline Influent & 1.3 & 1.4 & 1.4 & 0.0 & 0.0 & 0.0 & 0.0 & 6.7 & 0.0 & 0.0 & 6.6 & 0.0 & 0.0 & 13.2 & 0.0 & 0.0 \\
\hline Reactor & 1273.1 & 1286.4 & 1296.1 & 1288.6 & 1254.9 & 1219.3 & 1123.8 & 1129.2 & 1128.1 & 1115.5 & 1121.6 & 1113.8 & 1100.9 & 1111.7 & 1099.8 & 1068.2 \\
\hline Effluent & 0.2 & 0.2 & 0.3 & 0.4 & 0.5 & 0.7 & 0.8 & 1.2 & 0.7 & 0.5 & 0.9 & 0.6 & 0.4 & 1.8 & 1.2 & 0.5 \\
\hline
\end{tabular}


Chapter 7: Effects of trace metal deficiency and supplementary on a submerged anaerobic

membrane bioreactor

\begin{tabular}{ccccccccccccccccccc}
\hline Mn & \multicolumn{3}{c}{ With metals } & \multicolumn{4}{c}{ No metals } & \multicolumn{3}{c}{$1^{\text {st }}$ pulse } & \multicolumn{3}{c}{$2^{\text {nd }}$ pulse } \\
\hline Day & $\mathbf{0}$ & $\mathbf{5}$ & $\mathbf{1 5}$ & 17 & 25 & 33 & 41 & $\mathbf{4 3}$ & $\mathbf{4 5}$ & $\mathbf{4 9}$ & 51 & 53 & 57 & $\mathbf{5 9}$ & $\mathbf{6 5}$ & $\mathbf{7 2}$ \\
\hline Influent & 2.7 & 2.8 & 2.8 & 0.0 & 0.0 & 0.0 & 0.0 & 13.6 & 0.0 & 0.0 & 13.4 & 0.0 & 0.0 & 26.8 & 0.0 & 0.0 \\
\hline Reactor & 157.8 & 160.8 & 171.4 & 165.7 & 146.2 & 123.1 & 103.6 & 107.9 & 97.9 & 91.5 & 101.0 & 100.5 & 95.2 & 103.8 & 93.8 & 86.7 \\
\hline Effluent & 0.7 & 0.8 & 0.8 & 0.9 & 1.1 & 1.2 & 1.4 & 2.5 & 1.8 & 1.3 & 2.6 & 2.1 & 1.4 & 3.6 & 2.8 & 1.6 \\
\hline
\end{tabular}

\begin{tabular}{cccccccccccccccccc}
\hline Mo & \multicolumn{3}{c}{ With metals } & \multicolumn{3}{c}{ No metals } & \multicolumn{3}{c}{$1^{\text {st }}$ pulse } & \multicolumn{3}{c}{$2^{\text {nd }}$ pulse } \\
\hline Day & $\mathbf{0}$ & $\mathbf{5}$ & $\mathbf{1 5}$ & 17 & 25 & 33 & 41 & $\mathbf{4 3}$ & $\mathbf{4 5}$ & $\mathbf{4 9}$ & 51 & 53 & 57 & $\mathbf{5 9}$ & $\mathbf{6 5}$ & $\mathbf{7 2}$ \\
\hline Influent & 1.4 & 1.5 & 1.5 & 0.0 & 0.0 & 0.0 & 0.0 & 7.3 & 0.0 & 0.0 & 7.2 & 0.0 & 0.0 & 14.3 & 0.0 & 0.0 \\
\hline Reactor & 216.5 & 219.2 & 226.3 & 219.7 & 199.6 & 180.7 & 141.5 & 143.7 & 138.9 & 132.8 & 136.6 & 131.3 & 129.4 & 142.0 & 136.6 & 130.8 \\
\hline Effluent & 0.4 & 0.5 & 0.7 & 0.7 & 0.9 & 1.2 & 1.4 & 2.3 & 1.5 & 1.1 & 1.5 & 1.3 & 0.9 & 2.9 & 2.1 & 1.5 \\
\hline
\end{tabular}


Chapter 7: Effects of trace metal deficiency and supplementary on a submerged anaerobic membrane bioreactor

Table 7.3 The accumulation and leaching rate of TMs ( $\mu \mathrm{g} / \mathrm{gTSS} . \mathrm{d})$ compared to the loading rate of TMs $(\mu \mathrm{g} / \mathrm{gTSS} . \mathrm{d})$ at different phases $(\mathrm{n}=3)$

\begin{tabular}{|c|c|c|c|c|c|}
\hline \multirow{2}{*}{ Metal } & $\begin{array}{l}\text { Accumulation } \\
\text { rate/loading rate }\end{array}$ & \multicolumn{4}{|c|}{ Leaching rate/loading rate $(\mu \mathrm{g} / \mathrm{gTSS} . \mathrm{d})$} \\
\hline & With metals & No metals & $1^{\text {st }}$ pulse & $2^{\text {nd }}$ pulse & $3^{\text {rd }}$ pulse \\
\hline $\mathbf{F e}$ & $6.0 / 235.8(2.5 \%)$ & $13.2 / 0.0$ & $\begin{array}{c}16.0 / 41.0 \\
(39 \%)\end{array}$ & $\begin{array}{c}10.4 / 41.3 \\
(25 \%)\end{array}$ & $\begin{array}{c}30.1 / 39.9 \\
(75 \%)\end{array}$ \\
\hline Co & $0.9 / 37.7(2.4 \%)$ & $12.7 / 0.0$ & $\begin{array}{l}12.2 / 6.6 \\
(185 \%)\end{array}$ & $\begin{array}{l}6.5 / 6.6 \\
(98 \%)\end{array}$ & $\begin{array}{l}7.8 / 6.4 \\
(122 \%)\end{array}$ \\
\hline $\mathbf{N i}$ & $0.3 / 7.1(4.2 \%)$ & $4.8 / 0.0$ & $\begin{array}{l}1.6 / 1.2 \\
(133 \%)\end{array}$ & $\begin{array}{l}1.0 / 1.2 \\
(83 \%)\end{array}$ & $\begin{array}{l}2.0 / 1.2 \\
(167 \%)\end{array}$ \\
\hline Zn & $1.5 / 5.9(25.4 \%)$ & $6.6 / 0.0$ & $\begin{array}{l}2.0 / 0.9 \\
(222 \%)\end{array}$ & $\begin{array}{l}3.0 / 0.9 \\
(333 \%)\end{array}$ & $\begin{array}{l}3.1 / 0.9 \\
(344 \%)\end{array}$ \\
\hline Mn & $0.9 / 11.1(8.1 \%)$ & $2.5 / 0.0$ & $\begin{array}{l}2.3 / 1.9 \\
(121 \%)\end{array}$ & $\begin{array}{l}0.8 / 2.0 \\
(40 \%)\end{array}$ & $\begin{array}{l}1.2 / 1.9 \\
(63 \%)\end{array}$ \\
\hline Mo & $0.7 / 5.9(11.9 \%)$ & $3.1 / 0.0$ & $\begin{array}{l}1.6 / 1.0 \\
(160 \%)\end{array}$ & $\begin{array}{l}1.0 / 1.1 \\
(91 \%)\end{array}$ & $\begin{array}{l}0.8 / 1.0 \\
(80 \%)\end{array}$ \\
\hline
\end{tabular}

The accumulation of TMs, or the metal retention capacity, in an anaerobic reactor depends on their reactions in anaerobic sludge, which involves several mechanisms, namely, complex formation, chelation of metals, ion exchange, adsorption, inorganic micro-precipitation and translocation of TMs into the cells (Zandvoort et al., 2006a). Therefore, it is very difficult to determine the ultimate fate of metals in anaerobic reactors as these mechanisms are complex and compete with each other, and often exhibit non ideal behaviour; hence, theoretical modelling of equilibrium concentrations often fail to correlate well with actual measurements (Ortner et al., 2014). There has been a limited number of studies carried out to determine the adsorption capacity and kinetics of metal precipitation, and these are only for a few TMs such as $\mathrm{Co}, \mathrm{Ni}$, and $\mathrm{Zn}$ 
Chapter 7: Effects of trace metal deficiency and supplementary on a submerged anaerobic membrane bioreactor

(van Hullebusch et al., 2004; van Hullebusch et al., 2005a; Hawari \& Mulligan, 2006). Between $\mathrm{Co}$ and $\mathrm{Ni}$, there was no significant difference in the adsorption capacity of granular sludge (van Hullebusch et al., 2004), while Ni and Zn were found to have a very low affinity for anaerobic sludge sites (Leighton \& Forster, 1997; Artola et al., 2000; Wang et al., 2007).

When all TMs were excluded from the feed, the SAMBR was operating under nutrient deficient conditions. The results show that the metal content in the reactor reduced immediately, which was probably due to the leaching of metals from the sludge, but also as a result of some "dilution" due to bacterial growth which has to be supported by the metals available in the inoculum sludge (Zandvoort et al., 2003). In this study, there was no increase in biomass concentration in the reactor during the metal deficient period $(p>0.05)$, and hence TM washout was the only cause of the reduction in the total metal content in the reactor, which increases the metal content in the effluent. The leaching rate of the metal content ( $\mu \mathrm{g} / \mathrm{gTSS} . \mathrm{d})$ is also presented in Table 7.3, and was found to be of the same order as for the total metal content in the reactor, i.e. $\mathrm{Fe}>\mathrm{Co}>\mathrm{Zn}>\mathrm{Ni}>\mathrm{Mo}>\mathrm{Mn}$. However, the leaching rate as a percentage of the metal loading rate $(\mu \mathrm{g} / \mathrm{gTSS} . \mathrm{d})$ was ordered differently, i.e. $\mathrm{Zn}>\mathrm{Co}>\mathrm{Mo}>\mathrm{Ni}>\mathrm{Mn}>\mathrm{Fe}$, which was due to the different reactions (complexation, precipitation, adsorption, absorption) of different trace metals in anaerobic digesters.

It can also be seen that the order of the leaching rate ( $\mu \mathrm{g} / \mathrm{gTSS} . \mathrm{d})$ for all metals was the same as for their total content in the reactor. Zandvoort et al. (2006a) also found that metal leaching from the reactor/biomass (Fe, Co, and $\mathrm{Ni}$ ) was proportional to their initial concentrations in the sludge when their supplementation was stopped. In another study, Fe and Ni loss was found to greatly exceed the "dilution" effect resulting from biomass growth, despite increases in sludge bed volume (Zandvoort et al., 2003).

Most of the previous studies on the deficiency of TMs were carried in upflow anaerobic sludge blanket (UASB) reactors. Fermoso et al. (2008a) found 
that, in the same period in their study (around 30 days), Co, Ni, Zn, and Fe were lost from the granular sludge in UASB reactors through the effluent at a rate of around 2, 2.8, 17 and $184 \mu \mathrm{g} / \mathrm{gTSS}$.d, respectively. The leaching rate of these metals in this study was $12.7(\mathrm{Co}), 4.8(\mathrm{Ni}), 6.6(\mathrm{Zn})$, and $13.2(\mathrm{Fe}) \mu \mathrm{g} / \mathrm{gTSS} . \mathrm{d}$, which showed that $\mathrm{Zn}$ and Fe were better retained in the SAMBRs.

Table A.2 (Appendix) gives the metal content ( $\mu \mathrm{g} / \mathrm{gTSS})$ in each fraction from the BCR extraction, while Figure 7.5 show the speciation of TMs in both the liquid and solid phases in the reactor. Generally, during normal operating conditions, TMs were present in a soluble form in extremely low concentrations $(<0.18 \%$ of the total metal content) in all cases, except for Mn and Mo as their soluble concentrations reached to $18.7 \%$ and $5.01 \%$, respectively. However, when the reactor was in a nutrient deficient mode, a reduction in soluble concentration was observed for several TMs i.e. $12.84 \%$ to $10.64 \%(\mathrm{Mn})$ (p < 0.05 ), and $5.01 \%$ to $3.19 \%(\mathrm{Mo})(\mathrm{p}<0.05)$, and clearly the cells were abstracting as much of the TMs in solution as they ran out internally.

In the solid phase, most of the TMs were present mainly in the organic matter/sulfide fraction (F3) of around 74\% (Co), 57\% (Ni), 59\% (Zn), 25\% $(\mathrm{Mn})$, and $61 \%(\mathrm{Mo})$. This fraction contributes significantly to the accumulation of TMs in the reactor, as metals are known to be better retained in the sludge due to sulfide precipitation (Gonzalez-Gil et al., 2003). Callander and Barford (1983b) showed that metals such as Co and Ni can be precipitated in their sulfide form as long as the total concentration of these metals does not exceed the total sulfide $\left(\mathrm{H}_{2} \mathrm{~S}+\mathrm{HS}^{-}+\mathrm{S}^{2-}\right)$ level. Hydrogen sulfide and organic matter including thiol functionalities are known to have a high affinity for $\mathrm{Co}$ and $\mathrm{Ni}$ (Smith et al., 2002) The exception was for Fe as its Fe-Mn oxide fraction (F2) accounted for around $70 \%$ of its total content; van Hullebusch et al. (2005b) also found the highest amount of Fe present in this fraction (up to 34\%). One hypothesis is that the formation of ferrous phosphate or ferrous-hydroxylphosphate compounds (possible amorphous; as suggested by (Smith \& Carliell- 
Marquet, 2009)) that would then be readily dissolved by the low $\mathrm{pH}$ (2) of the extracting reagent used in the $2^{\text {nd }} \mathrm{BCR}$ step.

The BCR method (Table 3.2) was developed to categorize metals into different extraction fractions according to their level of bioavailability; therefore, the first two fractions, i.e. Soluble (Sol) and Exchangeable (F1) are considered as the most bioavailable, while the last two fractions, i.e. Organic matter/sulfide (F3) and Residual (F4), are the least bioavailable. For all the metals, the sum of Sol and F1 was always lower than the sum of F3 and F4 (p < $0.05)$, indicating that under all conditions, most of the TMs in the reactor had a low bioavailability for microbial uptake. The high metal content in the last two fractions was possibly due to the inevitable presence of inorganic ligands in the reactor such as sulfide, phosphate, or carbonate which encourages the precipitation of metals, hence making them become less soluble (Speece, 1996). Since they have low solubility products, this results in their precipitation and hence reduces their free ion concentration (Thanh et al., 2016).

As the total content of TMs in the reactor decreased during nutrient deficiency, their speciation shifted as most of the metals were mobilized from the relatively bioavailable fractions, i.e. Sol and F1, towards less bioavailable fractions i.e. F3 and F4. The increase in the sum of the F3 and F4 fractions was in the following order: $\mathrm{Mo}(4.23 \%)>\mathrm{Ni}(3.96 \%)>\mathrm{Fe}(2.79 \%)>\operatorname{Mn}(2.16 \%)>$ $\mathrm{Zn}(1.85 \%)>\mathrm{Co}(1.29 \%)$, however, only the increases in $\mathrm{Mo}, \mathrm{Ni}, \mathrm{Fe}$, and $\mathrm{Mn}$ were statistically significant $(\mathrm{p}<0.05)$. These results indicate that the loss in total metal content in the reactor was coming from the fractions that were highly soluble and easy to wash out from the sludge, i.e. Soluble and Exchangeable, and also because metals were better retained in the last two fractions.

The results from this experiment showed that the omission of TMs from the feed to the SAMBR resulted in a reduction in reactor performance, i.e. a decrease in COD removal and methane yields, and an increase in VFA concentrations. Previous studies on the effect of trace metal deficiency in 
Chapter 7: Effects of trace metal deficiency and supplementary on a submerged anaerobic membrane bioreactor

anaerobic reactors also showed similar findings, however, they all focussed on individual TMs such as Co (Zandvoort et al., 2002; Zandvoort et al., 2006b), Ni (Fermoso et al., 2008d), and Zn (Fermoso et al., 2008a). In addition, these studies were carried out in UASB reactors, which might not have the same TM retention capacity as the SAMBR used in this study as the presence of a membrane helps to prevent the loss of solids from the reactor. The fate of TMs when they leached out from the reactor was also monitored constantly throughout this study.

The speciation results from BCR extraction showed that the total TMs accumulated in the reactor were depleted during the metal deficiency, and their leaching rates varied due to their different degrees of affinity/reactions in the anaerobic sludge, while their speciation shifted towards less bioavailable fractions. Therefore, a quick dosing strategy was assessed to determine whether this could help the reactor overcome its nutritionally deficient conditions.

\section{Iron $(\mathrm{Fe})$}

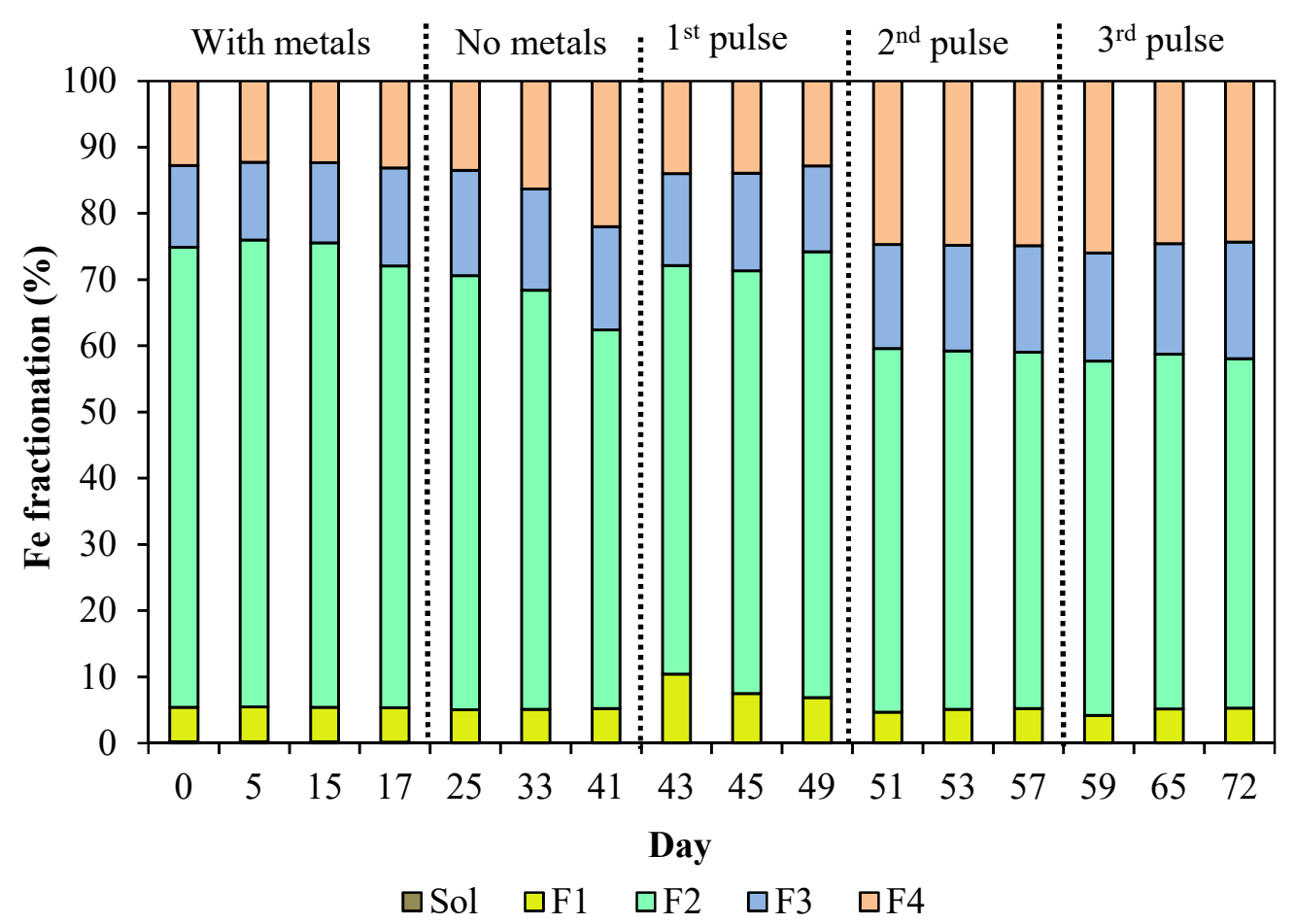


Chapter 7: Effects of trace metal deficiency

and supplementary on a submerged anaerobic membrane bioreactor

Cobalt (Co)

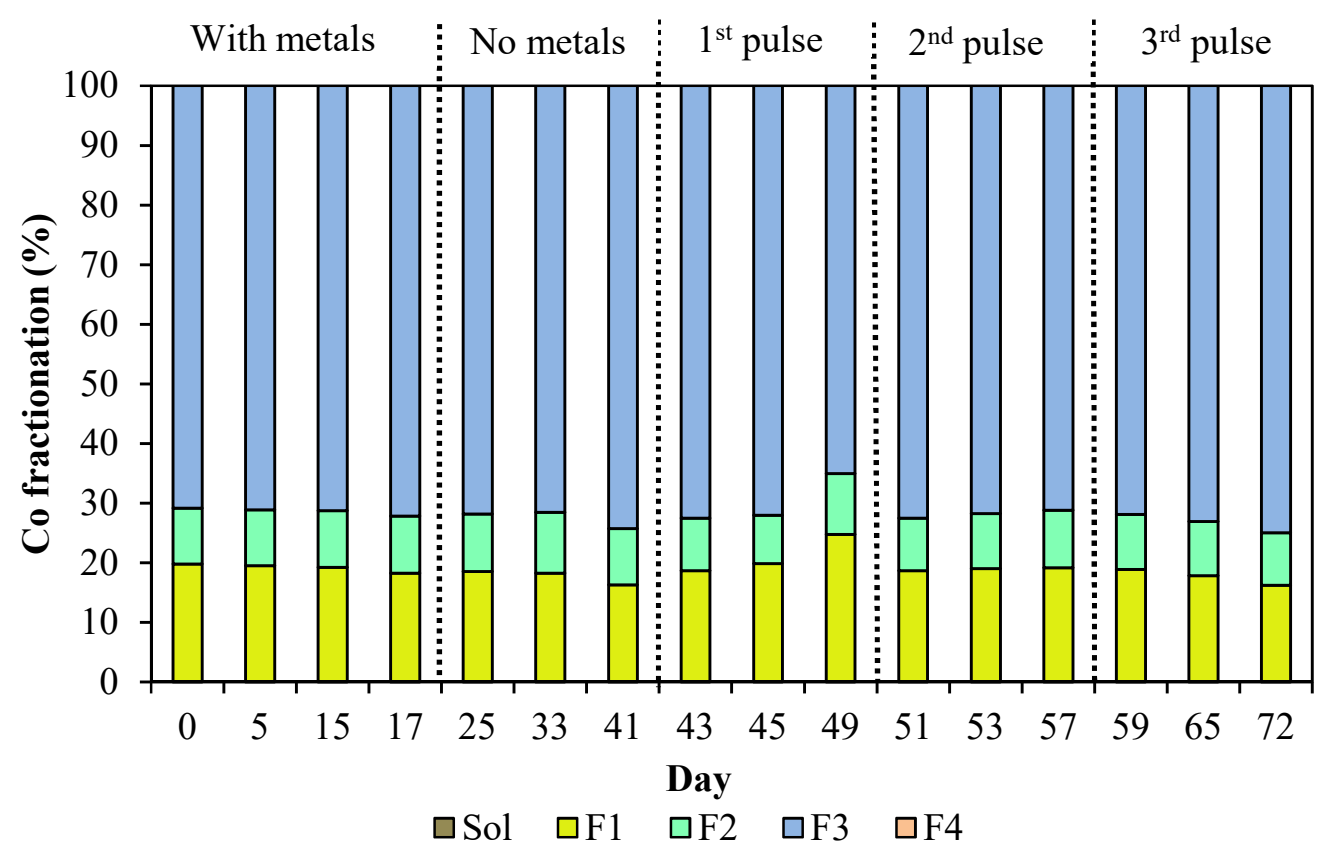

Nickel (Ni)

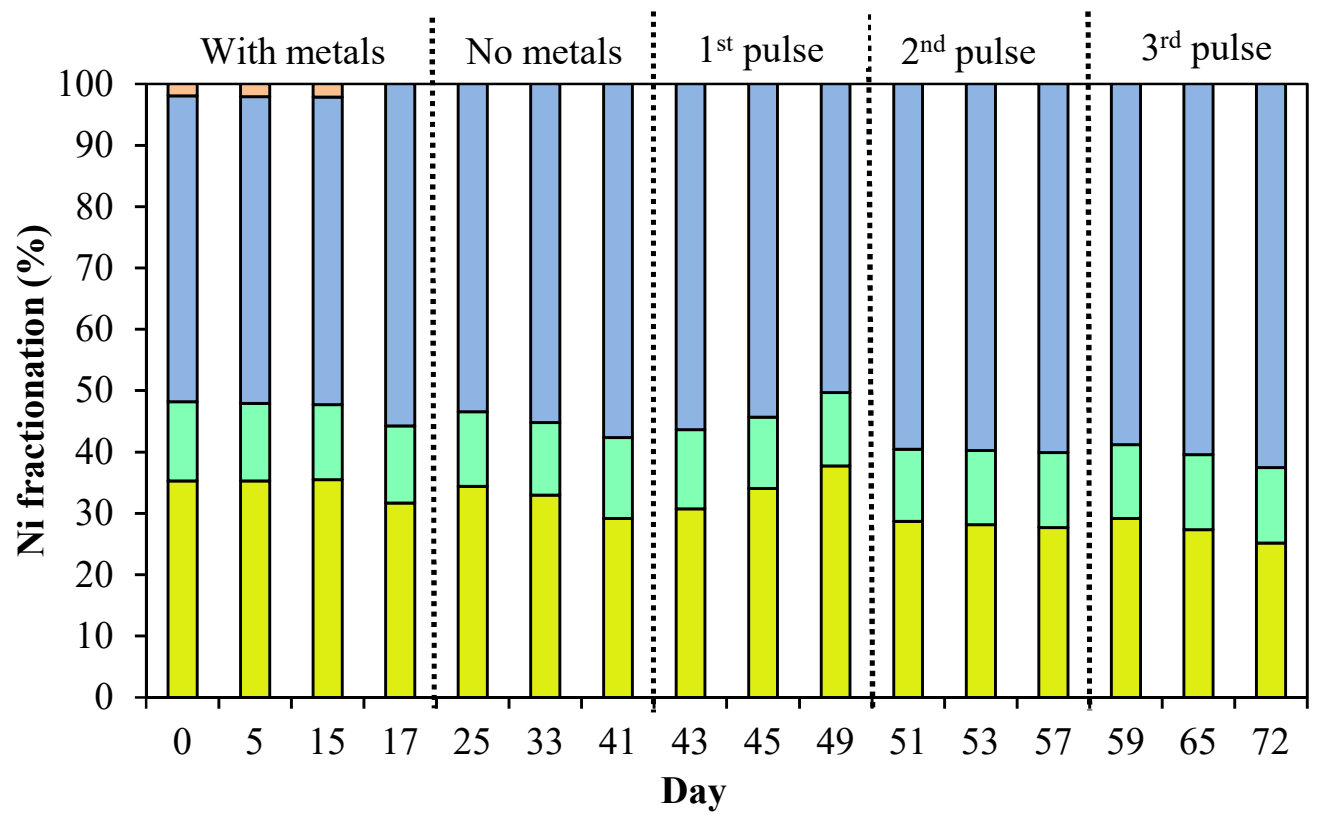

$\square$ Sol $\quad \square \mathrm{F} 1 \quad \square \mathrm{F} 2 \quad \square \mathrm{F} 3 \quad \square \mathrm{F} 4$ 
Chapter 7: Effects of trace metal deficiency

\section{and supplementary on a submerged anaerobic membrane bioreactor}

Zinc (Zn)

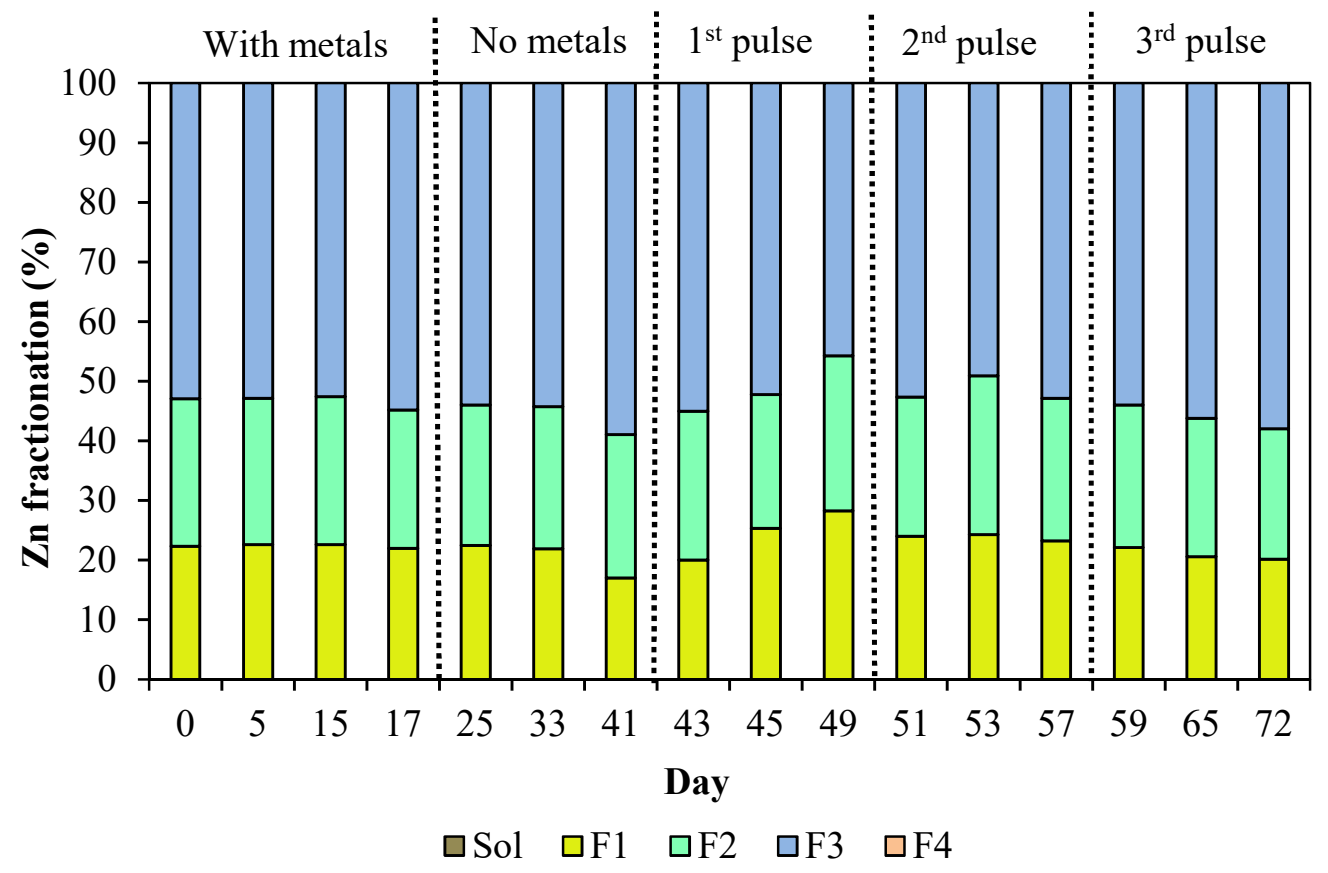

Manganese (Mn)

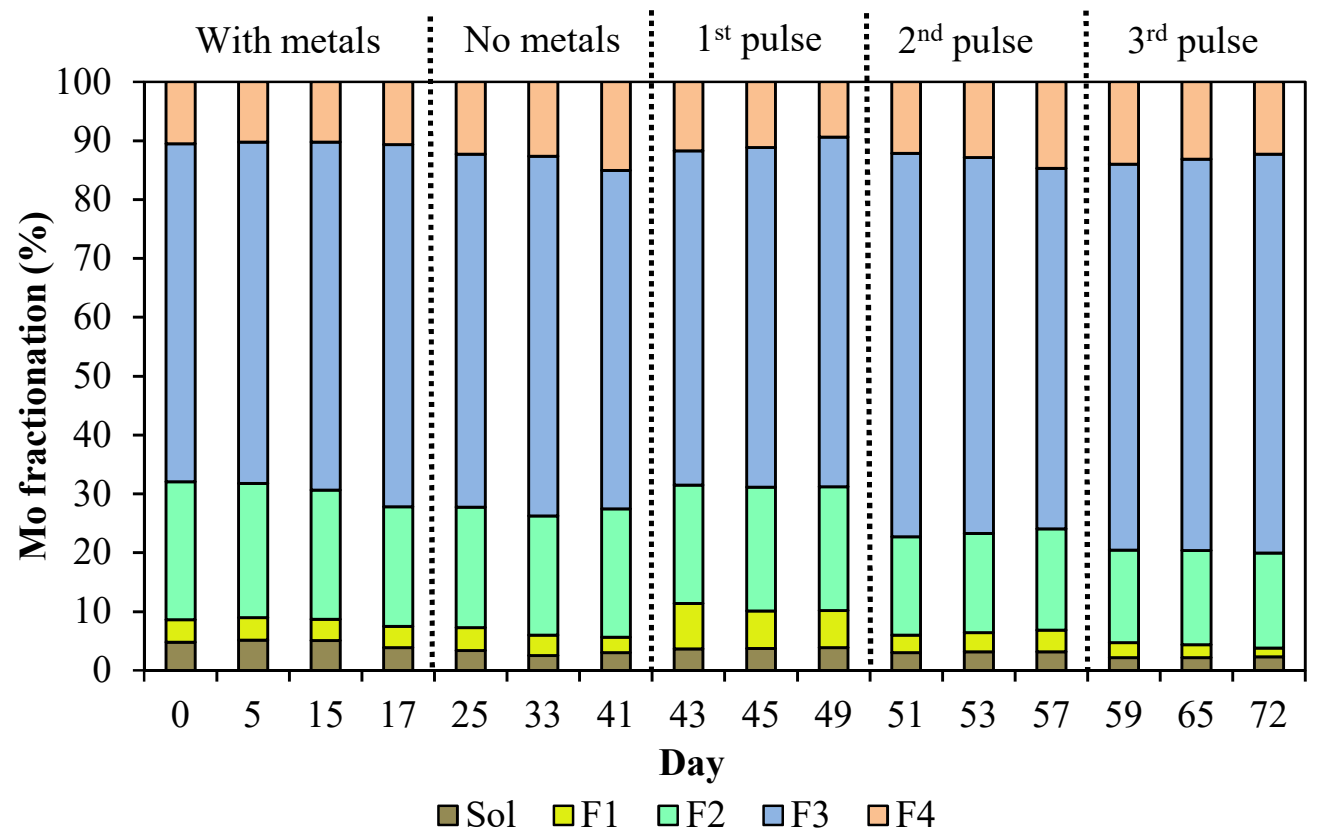


Chapter 7: Effects of trace metal deficiency and supplementary on a submerged anaerobic membrane bioreactor

Molybdenum (Mo)

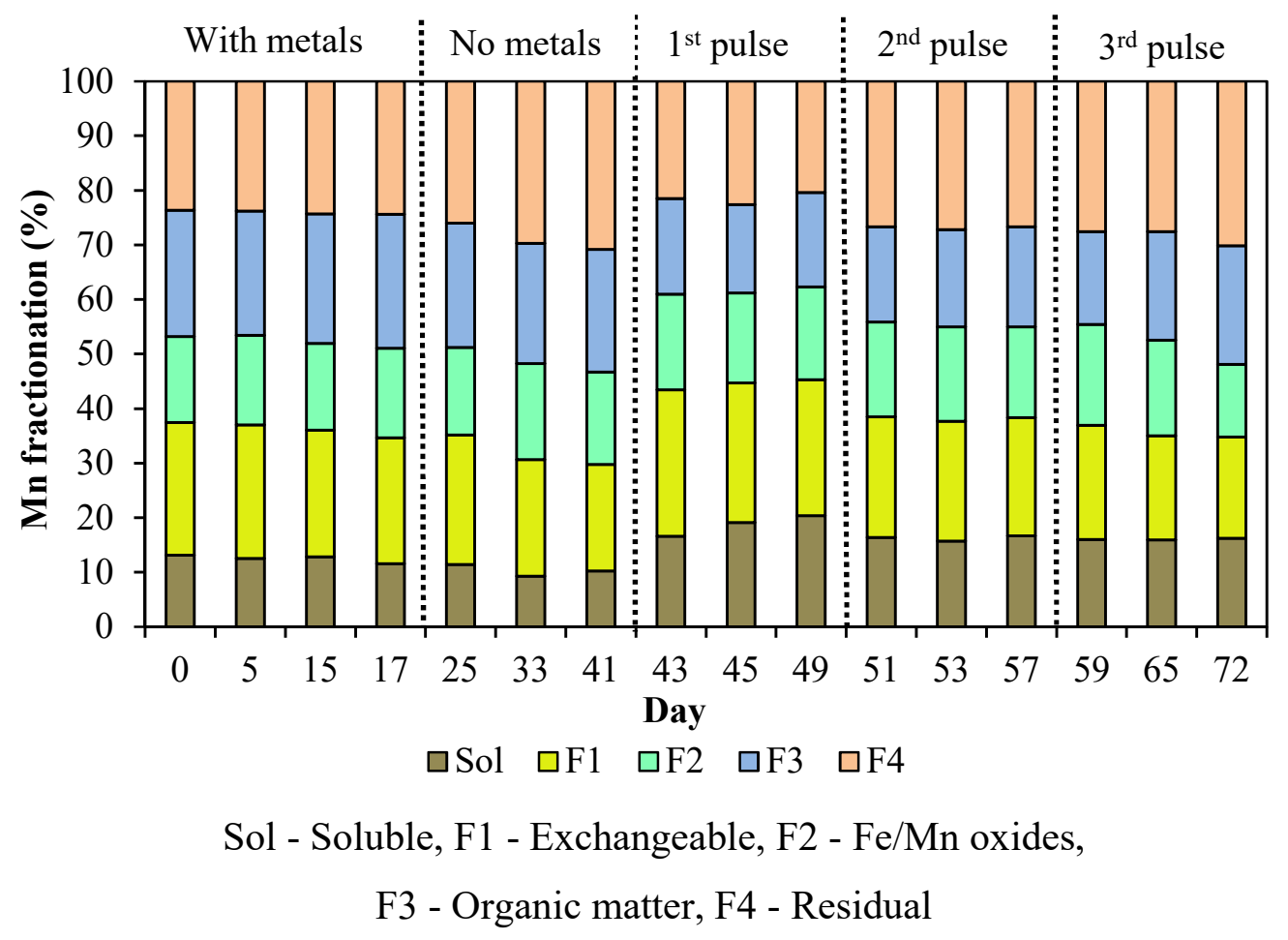

Figure 7.5 Speciation of TMs in the SAMBR at different phases $(n=3)$.

\subsubsection{Trace metal dosing strategies}

\subsubsection{The performance of the SAMBR}

Following the first pulse of TMs (from day 43 to 49) after their exclusion from the feed, the performance of the SAMBR improved within 4 days as the COD removal increased substantially from $89.9 \%$ to $96.9 \%$ ( $p<0.05$ ) on day 47. The corresponding soluble COD concentrations in the reactor and effluent also reduced to similar levels as normal conditions, i.e. $59.5 \mathrm{mg} / \mathrm{L}$ and 15.4 $\mathrm{mg} / \mathrm{L}(\mathrm{p}<0.05)$, respectively (Figure 7.1). The VFA levels in the reactor and effluent also reduced to below $2 \mathrm{mgCOD} / \mathrm{L}$ and $0 \mathrm{mgCOD} / \mathrm{L}(\mathrm{p}<0.05) 4$ days after the pulse (Figures 7.2 and 7.3), indicating that the added TMs enhanced the degradation of the accumulated VFAs during metal deficiency. Ketheesan et al. (2016) also found the addition of Fe to a Fe-deficient reactor helped to 
Chapter 7: Effects of trace metal deficiency and supplementary on a submerged anaerobic membrane bioreactor

degrade acetate which was added as a substrate, and resulted in a 2.1-3.9-fold increase in the rate of methane production. The methane yields also increased by around $45 \%$ from $50.5 \mathrm{mLCH}_{4} / \mathrm{gVSS}$.d (day 41 - end of no metal phase) to $73.2 \mathrm{mLCH}_{4} / \mathrm{gVSS} . \mathrm{d}(\mathrm{p}<0.05$ ) (day 47) (Figure 7.4). However, from day 49 the SAMBR performance reduced slightly as the soluble COD increased slightly to $65.2 \mathrm{mg} / \mathrm{L}$ and $20.9 \mathrm{mg} / \mathrm{L}(\mathrm{p}<0.05)$, which led to a decrease in COD removal to $95.8 \%$ (Figure 7.1 ), and the methane yield also reduced slightly to 66.0 $\mathrm{mLCH}_{4} / \mathrm{gVSS} . \mathrm{d}(\mathrm{p}<0.05)$ (Figure 7.4). These results indicated that although the improvement in SAMBR performance was substantial after the pulse addition, the effect of TMs was only temporary as after $9 \mathrm{~d}$ the pulsed TMs should have been completely washed out from the reactor, and the reactor returned to the previous metal deficient condition.

A second pulse with the same TM loading was then applied on day 51 . However, there was no significant improvement in the SAMBR performance after the first pulse as the average COD removal remained at around 96\% ( $p>$ 0.05 ) and the methane yield did not change significantly i.e. $68 \mathrm{mLCH}_{4} / \mathrm{gVSS} . \mathrm{d}$ (day 57) $(\mathrm{p}>0.05)$ (Figure 7.4). The main difference between the first and second pulse was the accumulated COD level in the reactor prior to the pulse: in the first pulse $94.16 \mathrm{mgCOD} / \mathrm{L}$ accumulated, however, only $65.18 \mathrm{mgCOD} / \mathrm{L}$ accumulated in the second pulse. Therefore, the improvement on the SAMBR performance was more significant after the first pulse. This finding was not in agreement with Fermoso et al. (2008c) as they found that the specific methanogenic activity (SMA) of a Co deficient USAB increased even after the second pulse of $\mathrm{CoCl}_{2}$.

The third pulse with 10 times TM loading was applied on day 59. One day after the pulse, the methane yields dropped to only $61.3 \mathrm{mLCH}_{4} / \mathrm{gVSS}$.d (p $<0.05$ ) (Figure 7.4 ), which was $24 \%$ below the level under "normal conditions" with TMs in the feed. Due to this low methane yield, the soluble COD in the reactor and effluent increased from $67.1 \mathrm{mg} / \mathrm{L}$ and $18.3 \mathrm{mg} / \mathrm{L}$ (day $57-2^{\text {nd }}$ pulse) to $78.3 \mathrm{mg} / \mathrm{L}$ and $29.4 \mathrm{mg} / \mathrm{L}$ (day $59-3^{\text {rd }}$ pulse) $(\mathrm{p}<0.05)$, respectively 
Chapter 7: Effects of trace metal deficiency and supplementary on a submerged anaerobic membrane bioreactor

(Figure 7.1). This led to a reduction in COD removal efficiency from $96.2 \%$ (day $57-2^{\text {nd }}$ pulse) to $94.1 \%$ (day $59-3^{\text {rd }}$ pulse) $(\mathrm{p}<0.05)$. The VFA concentrations in the reactor and effluent rose slightly to $3.4 \mathrm{mgCOD} / \mathrm{L}$ and 0.9 $\operatorname{mgCOD} / \mathrm{L}$ on day $59(\mathrm{p}<0.05)$, respectively (Figure 7.2 and 7.3). These results indicate that the high concentration of the TMs added in the third pulse might have resulted in some inhibitory effects as the direct instant loading of those metals into the bioreactor caused some immediate stress to the methanogenic bacteria, and hence reduced the performance of the SAMBR.

\subsubsection{The speciation of trace metals}

When TM addition to the feed was stopped, there were no TMs in the feed stream to the SAMBR, and hence it was certain that there was no interference with the metals being dosed. Measurements of TM concentrations in the reactor and effluent after each pulse are shown in Table 7.2. Due to the instant dose, there was a significant increase in the metal content in the reactor and effluent within $24 \mathrm{~h}$ after each pulse of TMs $(\mathrm{p}<0.05)$. The retention capacity of the TMs in the reactor over $24 \mathrm{~h}$ following each pulse varied between each metal, with Co having the highest retention, i.e. $7.0 \%-12.3 \%$ of the added Co lost in the effluent, while Mn had the lowest, i.e. $20.2 \%-31.6 \%$ of the added Mn lost in the effluent. Table 7.3 shows the leaching rate of TMs ( $\mu \mathrm{g} / \mathrm{gTSS} . \mathrm{d}$ and $\mu \mathrm{mol} / \mathrm{gTSS} . \mathrm{d}$ ) after each pulse. Similar to the results from experiment 3.1, Fe was not well retained in the reactor and had the highest leaching rate i.e. $10.4-30.1 \mu \mathrm{g} / \mathrm{gTSS} . \mathrm{d}$ or $18.7-53.8 \mathrm{mmol} / \mathrm{gTSS} . \mathrm{d}$, whereas Mo had the lowest rate i.e. $0.8-1.6 \mu \mathrm{g} / \mathrm{gTSS} . \mathrm{d}$ or $1.5-2.2 \mathrm{mmol} / \mathrm{gTSS}$.d.

Table A.2 (Appendix) gives the metal content ( $\mu \mathrm{g} / \mathrm{gTSS})$ in each fraction from the BCR extraction, while Figure 7.5 shows the speciation of TMs in both the liquid and solid phases in the reactor for each pulse. The data indicates that following the first pulse there was a shift in metal speciation as the TMs were mobilized from the last two fractions F3 and F4 towards the "relatively bioavailable fractions" (Sol and F1) $(\mathrm{p}<0.05)$. This increase in the bioavailable 
fractions could be due to the complexation of the added TMs with the increased amount of SMPs produced during nutrient deficiency. SMPs are natural chelating agents which are known to play an important role in making metal ions available for microbial uptake by maintaining higher soluble concentrations of TMs through complexation (Patidar \& Tare, 2008). On the other hand, the interaction between different types of TMs due to chemical equilibria when they are supplemented together to an anaerobic system also needs to be taken into account in evaluating metal speciation. For example, it was suggest that $\mathrm{Co}$ and $\mathrm{Ni}$ are able to exchange with $\mathrm{Fe}^{2+}$, preferably with $\mathrm{Fe}$ sulfide, as FeS has the highest solubility $\left(\mathrm{Ksp}=10^{-18}\right)$ compared to NiS (Ksp= $\left.10^{-27}\right)$ and $\operatorname{CoS}\left(\mathrm{Ksp}=10^{-20}\right)($ Oleszkiewicz \& Sharma, 1990). Osuna et al. (2003) found that the addition of Co to a metal depleted UASB reactor resulted in not only a reduction in the total amount of Fe, but also shifted its speciation from the exchangeable fraction towards the organic fraction. In contrast, following the second pulse of TMs speciation was shifted slightly towards less bioavailable fractions, i.e. F3 and F4 $(\mathrm{p}<0.05)$. A more significant shift was observed after the third pulse as a higher percentage of the metal content in the F3 and F4 fractions was observed $(\mathrm{p}<0.05)$, as shown in Table A.2 (Appendix).

The speciation results seem to correlate well with the changes in SAMBR performance, as the increase in metal content in the bioavailable fractions (Sol and F1) following the first pulse was able to enhance reactor recover from the nutrient deficit. On the other hand, the reduction in these bioavailable fractions after the second and third pulses seemed to limit the bioavailability of the TMs, and hence did not result in any improvements in SAMBR performance. For the third pulse, the concentration of TMs supplemented was considerably higher, and the increase in less bioavailable forms, i.e. organic matter/sulfide and residuals, could be attributed to the inhibition by TMs as these fractions can also be bioavailable to anaerobic microorganisms, although there has been some argument about whether metal sulfides are bioavailable in AD. Zehnder et al. 
Chapter 7: Effects of trace metal deficiency and supplementary on a submerged anaerobic membrane bioreactor

(1982) suggested that the presence of sulfide could restrict the availability of Fe to methanogens. However, Gustavsson et al. (2013b) found that the precipitation of $\mathrm{Co}$ and $\mathrm{Ni}$ with sulfide did not limit the microbial uptake of $\mathrm{Co}$ and Ni. Ketheesan et al. (2016) also found that the toxicity of Fe supplemented at 50,70 , and $100 \mathrm{mg} / \mathrm{L}$ could be due to the availability of $\mathrm{Fe}$ in the dominant sulfide and residual forms.

\subsection{Conclusions}

This study showed that temporary nutrient limitations caused by the exclusion of TMs from the feed to a SAMBR quite quickly resulted in a significant reduction in the metal content of the sludge, shifting the speciation of TMs towards less bioavailable fractions, i.e. organic matter/sulfide and residual, which resulted in reduced COD removal and methane yields. A dosing strategy by pulsing a mixture of TMs at 5 times of the normal daily metal loading seemed to be effective in controlling the metal deficiency by increasing the metal content of the more bioavailable fractions, i.e. soluble and exchangeable, and hence help the reactor recover to optimal performance within 4 days. However, with higher doses (10x), TM addition was not helpful because the TMs might have inhibited the methanogenic bacteria due to the instant loading of high amounts of TMs into the reactor. 


\section{Chapter 8}

\section{Effect of operating conditions on speciation and bioavailability of trace metals in submerged anaerobic membrane bioreactors}

\section{Outline:}

8.1 Introduction

8.2 Experimental and analytical methods

8.3 Results and discussion

8.4 Conclusions

Note: this chapter was published in Bioresource Technology, 2017, volume 243, pages $810-819$.

\subsection{Introduction}

The bioavailability of TMs for microbial uptake and growth in anaerobic bioreactors is strongly dependent on metal speciation, and this in turn can be affected by some of the reactor operating parameters such as $\mathrm{pH}$, hydraulic retention time (HRT), and possibly solids retention time (SRT) (Thanh et al., 2016). Changes in $\mathrm{pH}$ can not only affect the performance of the anaerobic microorganisms, it can also dramatically influence the fate of TMs in anaerobic digestion, and these effects can be interrelated. A number of studies have been carried out in Up-flow Anaerobic Sludge Bed (UASB) reactors to determine the correlation between TM speciation and changes in $\mathrm{pH}$ (van Hullebusch et al., 2005b; Zandvoort et al., 2005; Lopes et al., 2008; Gonzalez-Gil et al., 2012; 


\section{Chapter 8: Effect of operating conditions on speciation and bioavailability}

\section{of trace metals in submerged anaerobic membrane bioreactors}

Dong et al., 2013). Generally, these studies showed that an increase in $\mathrm{pH}$ led to the transformation of TMs from available mobile fractions like their "exchangeable" component, to stable organic or residue forms which reduced their bioavailability. In contrast, a reduction in $\mathrm{pH}$ resulted in the dissolution of TMs into solution, shifting them from non-bioavailable fractions (residual and organic/sulfide) towards more bioavailable fractions (exchangeable and carbonates).

Understanding the relationship between HRT and TM speciation in anaerobic processes is very limited. Cestonaro do Amaral et al. (2014) studied the distribution of $\mathrm{Cu}$ and $\mathrm{Zn}$ in swine wastewater in an up-flow bio-digester; they found that when the HRT was reduced from $17.86 \mathrm{~d}$ to $7.57 \mathrm{~d}$, the metal retention capacity of the bioreactors decreased. While other metal fractions remained the same or decreased, the less bioavailable oxidizable fraction comprised of the metals associated with organic matter/sulfide increased, indicating that the metals became less bioavailable to anaerobic microorganisms.

Finally, SRT is another important operating parameter for anaerobic bioreactors, as the SRT needs to be maintained at a certain level so that there is a sufficient active population present in the reactors to enable anaerobic digestion to proceed efficiently. At long SRTs, it is expected that TMs will accumulate, and are present in high levels in the bioreactor, and also that the majority of the metals are associated with the biomass, either on the surface or inside the biomass. Therefore, at short SRTs it is possible that the high daily biomass removal rate will alter the total content of TMs and change their speciation. There has been no study in the literature carried out to determine how the SRT could influence TM speciation in anaerobic bioreactors.

Reactor configuration also plays an important role in the dynamics of TMs as it affects the metal retention capacity of anaerobic bioreactors (Thanh et al., 2016). Most of the studies in metal speciation and bioavailability have been carried out in UASB or conventional CSTR reactors. The anaerobic membrane bioreactor (AnMBR) is one of the most advanced anaerobic reactor designs 
Chapter 8: Effect of operating conditions on speciation and bioavailability of trace metals in submerged anaerobic membrane bioreactors

available as it offers independent control of the SRT and HRT, which then allows larger volumes of wastewater to be treated on a smaller footprint, and also prevents any loss of biomass into the effluent (Kunacheva et al., 2017).

Based on these considerations, this study was aimed at exploring how the changes in operating parameters in a SAMBR, i.e. pH, HRT, and SRT, can influence the bioavailability of TMs, i.e. Fe, Co, Ni, Zn, Mn, and Mo, by monitoring their speciation over time under a variety of reactor operating conditions.

\subsection{Experimental and analytical methods}

\subsubsection{SAMBRs}

Three independent experiments with changes in $\mathrm{pH}, \mathrm{HRT}$, and SRT were carried out in three SAMBRs with the same configuration as described in Chapter 3, i.e. SAMBR1, SAMBR2, and SAMBR3, respectively. The steady state (control) conditions for these SAMBRs were defined as $500 \mathrm{mg} / \mathrm{L} \mathrm{COD}$, $\mathrm{pH}$ 7, $6 \mathrm{~h} \mathrm{HRT}$ and $100 \mathrm{~d}$ SRT.

\subsubsection{Changes in $\mathbf{p H}$}

SAMBR1 was operated at steady state conditions at neutral $\mathrm{pH} 7$ for $36 \mathrm{~d}$. The $\mathrm{pH}$ was subsequently reduced to 6.5 and then 6 by adding diluted $\mathrm{HCl}$ to adjust the $\mathrm{pH}$. The reactor was operated at each $\mathrm{pH}$ for about $8 \mathrm{~d}$, which constitutes 32 HRTs, and previous work in this lab has showed that steady state occurs in this time (Kunacheva et al., 2017). At the end of the pH 6 run, no further $\mathrm{pH}$ adjustment was carried out on the feed, and the SAMBR was allowed to recover until the $\mathrm{pH}$ was back to neutral.

\subsubsection{Changes in HRT}

SAMBR2 was operated under steady state conditions at $6 \mathrm{~h}$ HRT for $53 \mathrm{~d}$. The HRT was subsequently reduced from $6 \mathrm{~h}$ to $4 \mathrm{~h}$, and then to $2 \mathrm{~h}$ by 
Chapter 8: Effect of operating conditions on speciation and bioavailability of trace metals in submerged anaerobic membrane bioreactors

increasing the speed of the influent pumps, i.e. double and triple, respectively. The membrane flux was also increased accordingly in order to maintain a constant liquid level in the SAMBR, and the reactor was operated at each HRT for $5 \mathrm{~d}$. SRT was maintained at $100 \mathrm{~d}$, whereas, VSS was $10.2 \mathrm{~g} / \mathrm{L}$ at the start of $6 \mathrm{~h} \mathrm{HRT}$. At the end of the $2 \mathrm{~h}$ HRT run, the membrane was removed and the cake layer on the membrane surface was carefully collected by rinsing with deionized water, and the physical parameters and TM composition in the cake layer were analysed.

\subsubsection{Changes in SRT}

SAMBR3 was operated under steady state conditions at an SRT of $100 \mathrm{~d}$ with the daily removal of $32 \mathrm{~mL}$ of sludge for almost 3 months; during this time samples were collected several times to establish baseline conditions. Before the SRT was reduced to $25 \mathrm{~d}$, it was temporarily reduced to $75 \mathrm{~d}$ and $50 \mathrm{~d}$ for 1 week each to ensure a smooth transition. To maintain $25 \mathrm{~d} \mathrm{SRT,} 128 \mathrm{~mL}$ of sludge was removed every day from the reactor for $27 \mathrm{~d}$. This SRT is considered as the optimal operating SRT to achieve minimum normalized production of soluble microbial products (SMPs) in an anaerobic CSTR (Kuo et al., 1996).

\subsection{Results and Discussion}

\subsubsection{Changes in $\mathrm{pH}$}

\subsubsection{Performance of the SAMBR1 at different pHs}

As expected, since low pHs of 6.5 and 6 are outside the favoured $\mathrm{pH}$ range for anaerobic microorganisms of 6.8 - 7.2 (Rittmann \& McCarty, 2001), they caused an upset, especially to the methanogens, and hence destabilized the performance of the SAMBR. As a result, there was a significant increase in the average soluble COD in the reactor and effluent from $65.6 \mathrm{mg} / \mathrm{L}$ and 12.6 
Chapter 8: Effect of operating conditions on speciation and bioavailability of trace metals in submerged anaerobic membrane bioreactors

$\mathrm{mg} / \mathrm{L}(\mathrm{pH} 7)$ to $251.3 \mathrm{mg} / \mathrm{L}$ and $145.2 \mathrm{mg} / \mathrm{L}(\mathrm{pH} 6.5)(\mathrm{p}<0.05)$ and then to $390.7 \mathrm{mg} / \mathrm{L}$ and $237.4 \mathrm{mg} / \mathrm{L}(\mathrm{pH} 6)(\mathrm{p}<0.05)$, respectively (Figure 8.1). The difference between the soluble COD level in the reactor and in the effluent was due to the membrane which retained a large amount of dissolved COD by the thin polarisation layer, or cake, on the membrane surface. The corresponding average COD removal dropped from 97.6\% (pH 7) to 74.3\% (pH 6.5) (p< $0.05)$ and then to $52.5 \%(\mathrm{pH} 6)(\mathrm{p}<0.05)$.

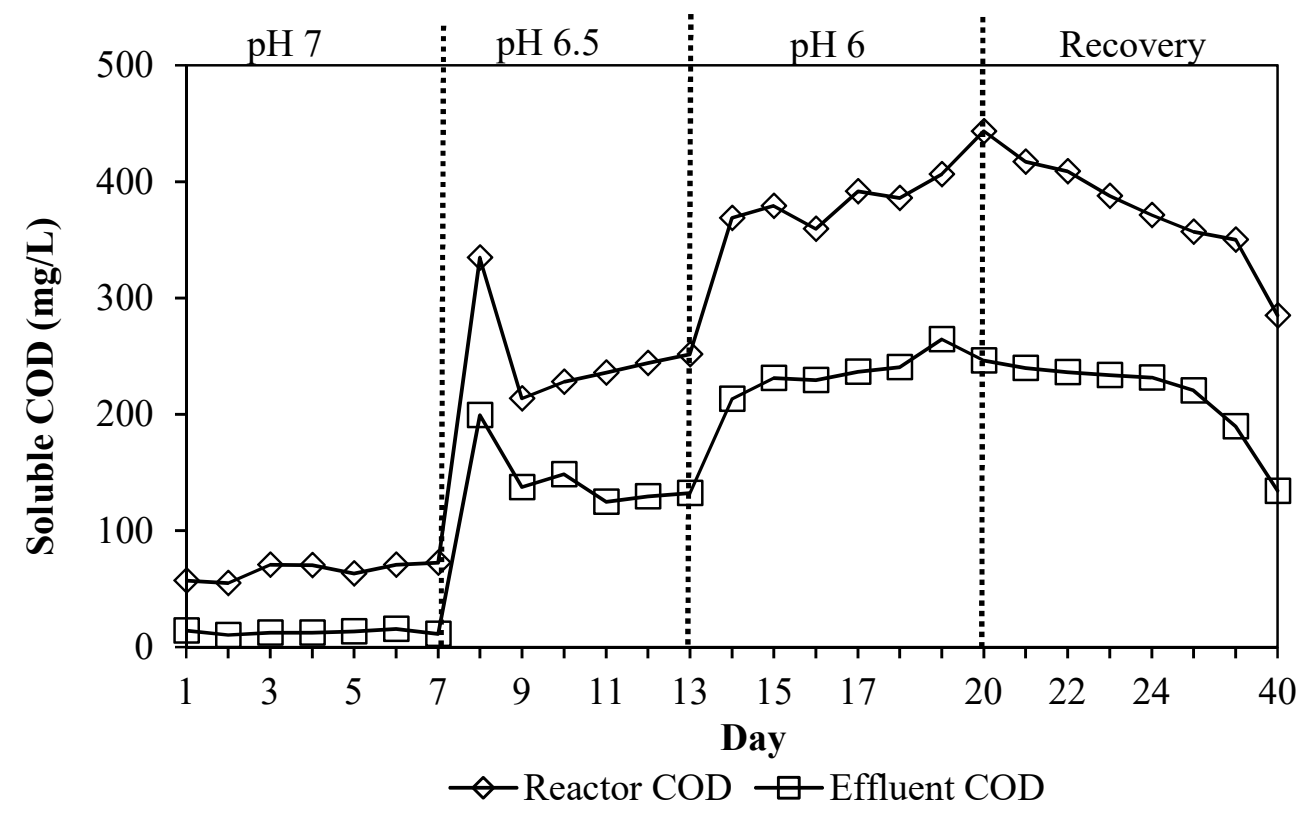

Figure 8.1 Soluble COD in the reactor and effluent of the SAMBR1 at different $\mathrm{pHs}(\mathrm{n}=3)$.

The $\mathrm{pH}$ reduction also resulted in a proportional increase in VFA concentrations in the reactor and effluent, with acetate as the main VFA accumulated (Figures 8.2 and 8.3). As can be seen that the total VFA concentrations (as COD) in the reactor were considerably lower than the soluble reactor COD. This implies that VFAs are not the only contributor to the soluble COD in the reactor, but there are also SMPs which are released by the bacteria under stressed conditions. 


\section{of trace metals in submerged anaerobic membrane bioreactors}

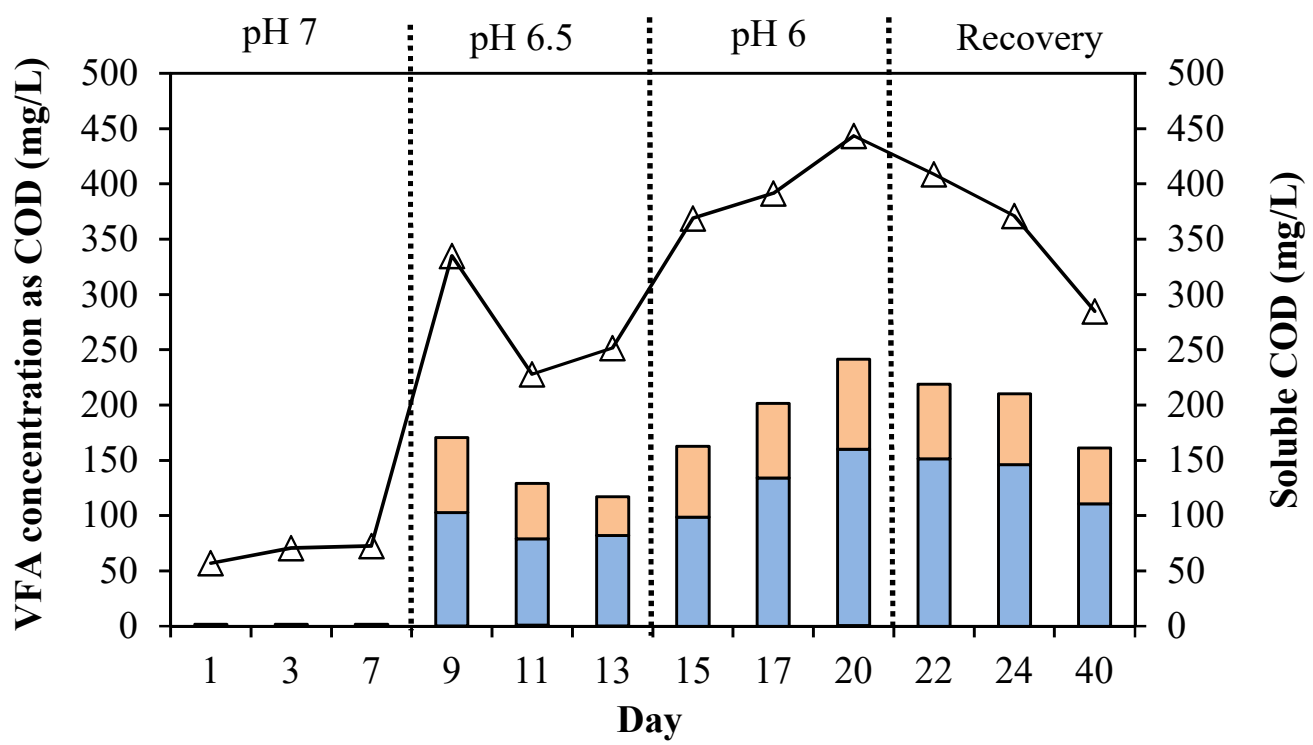

$\square$ Formic acid $\square$ Acetic acid $\square$ Propionic acid $\triangle$ Reactor COD

Figure 8.2 VFA concentration as COD with Reactor COD of the SAMBR1 at different $\mathrm{pHs}(\mathrm{n}=3)$.

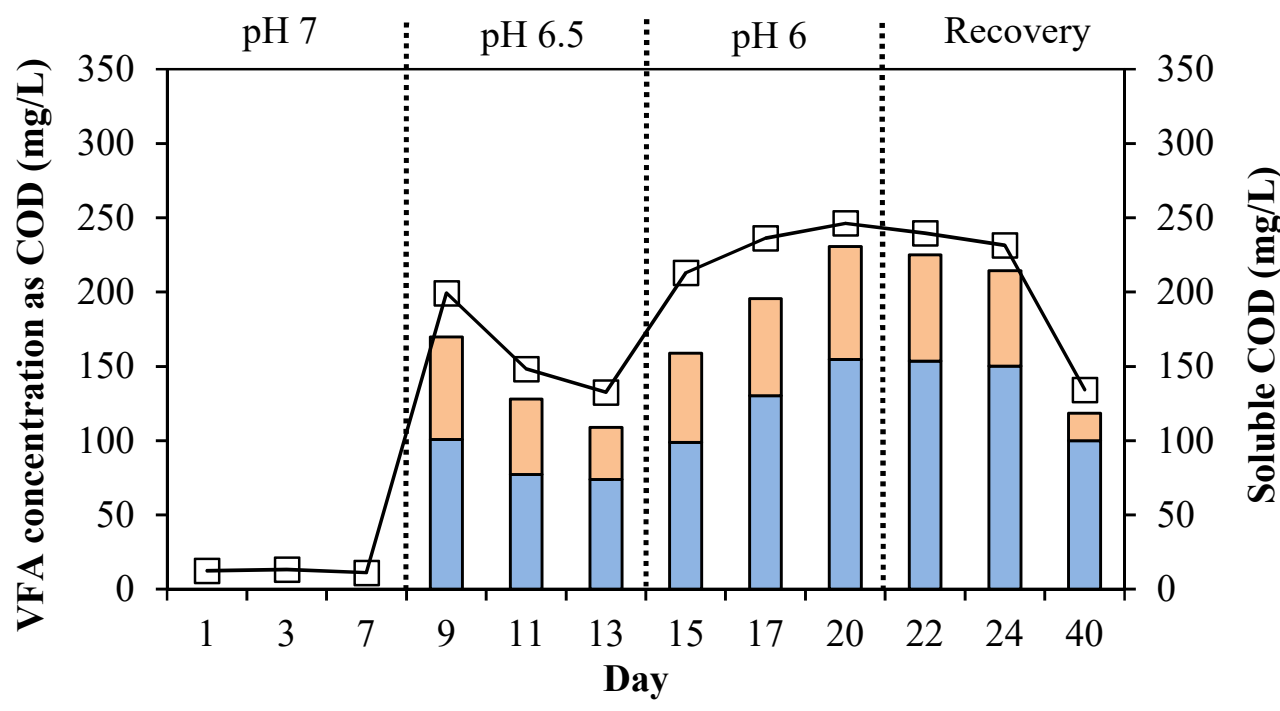

$\varpi$ Formic acid $\square$ Acetic acid $\square$ Propionic acid $\square$ Effluent COD

Figure 8.3 VFA concentration as COD with Effluent COD of the SAMBR1 at different $\mathrm{pHs}(\mathrm{n}=3)$. 
The methanogens were seriously affected by the low pHs, but there was no sign of complete inhibition as the average methane yields declined from 59.6 $\mathrm{mLCH}_{4} / \mathrm{gVSS} . \mathrm{d}(\mathrm{pH} 7)$ to $41.7 \mathrm{mLCH}_{4} / \mathrm{gVSS} . d(\mathrm{pH} 6.5)(\mathrm{p}<0.05)$ and then to $30.9 \mathrm{mLCH}_{4} / \mathrm{gVSS} . \mathrm{d}(\mathrm{pH} 6)(\mathrm{p}<0.05)$ (Figure 8.4).

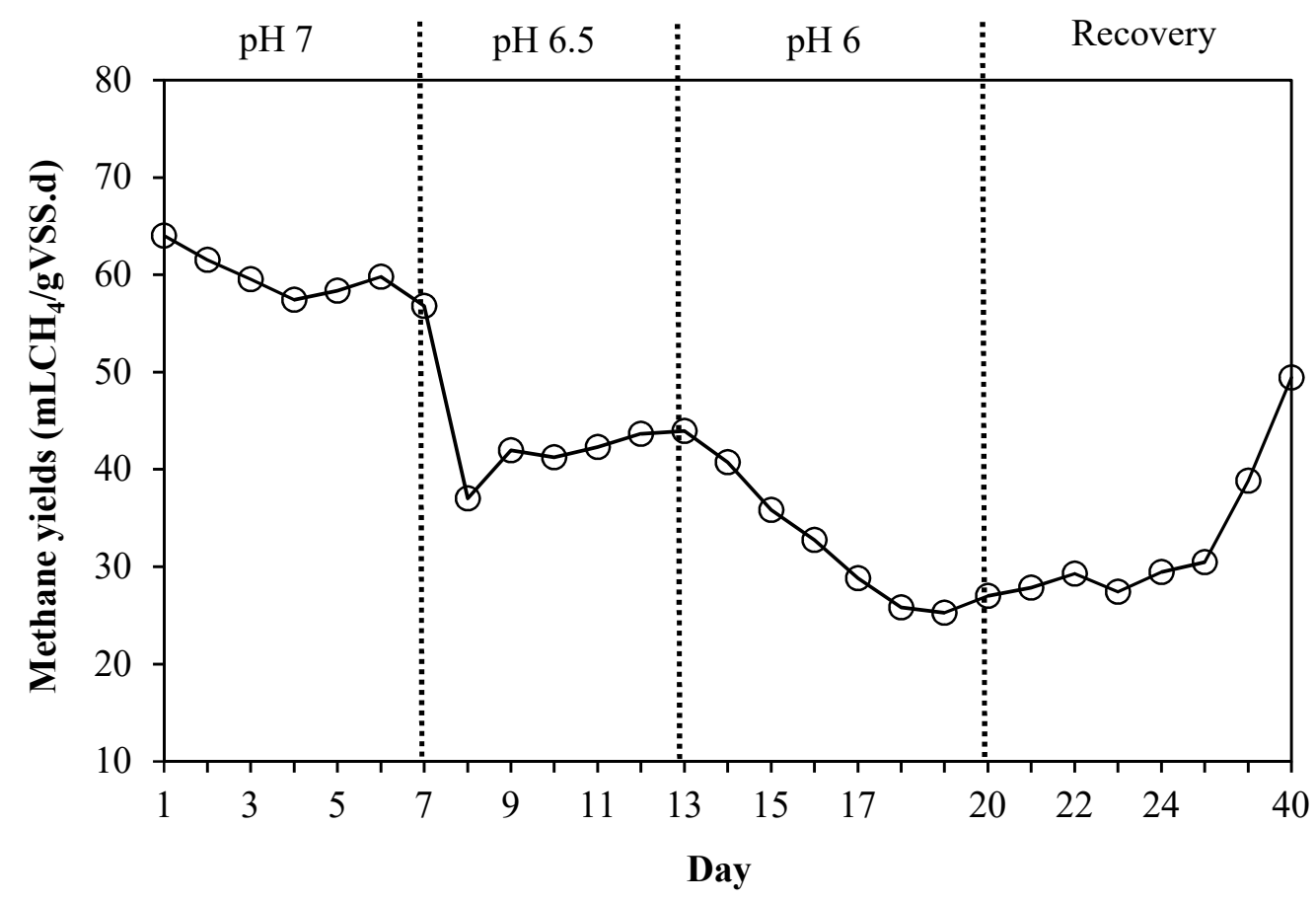

Figure 8.4 Methane yields of the SAMBR1 at different $\mathrm{pHs}$.

The reactor took only $2 \mathrm{~d}$ for the $\mathrm{pH}$ to return to its favoured $\mathrm{pH}$ for methanogens, i.e. $\mathrm{pH}$ 6.8, but much longer to return to neutral $(\mathrm{pH} 7)$ i.e. $12 \mathrm{~d}$. Accordingly, recovery in SAMBR COD removal was very slow (Figure 8.1), and the methane yield only increased to $73.2 \%$ and $49.4 \mathrm{mLCH}_{4} / \mathrm{gVSS} \mathrm{d}$ ( $\mathrm{p}<$ 0.05), respectively, $20 \mathrm{~d}$ after the end of $\mathrm{pH} 6$ (Figure 8.4). In methanol fed granular sludge bioreactors, Zandvoort et al. (2005) also found that the $\mathrm{pH}$ shock ( 7 to 5 ) significantly affected reactor performance as after $2 \mathrm{~d}$ the methanol and VFA concentrations in the effluent increased to $1418 \mathrm{mgCOD} / \mathrm{L}$ and $186 \mathrm{mgCOD} / \mathrm{L}$, respectively. However, the shock was performed for a 
Chapter 8: Effect of operating conditions on speciation and bioavailability of trace metals in submerged anaerobic membrane bioreactors

much shorter period $(30 \mathrm{~h})$, and hence the bioreactors were able to recover very quickly, i.e. no methanol or VFAs were present in the effluent $3 \mathrm{~d}$ after the $\mathrm{pH}$ was restored to 7 .

\subsubsection{Dynamic changes in trace metal speciation at different $\mathrm{pHs}$}

Total content of trace metals - The total content ( $\mu \mathrm{g} / \mathrm{gTSS})$ of each TM in the SAMBR at $\mathrm{pH} 7$ is shown in Table 8.1. Due to the long period of operation with the continuous supplementation of TMs, the total metal content in the reactor was high, i.e. from $147.9 \mu \mathrm{g} / \mathrm{gTSS}$ for Mo up to $11256.1 \mu \mathrm{g} / \mathrm{gTSS}$ for $\mathrm{Fe}$, and was in the following order: $\mathrm{Fe}>\mathrm{Zn}>\mathrm{Co}>\mathrm{Ni}>\mathrm{Mn}>\mathrm{Mo}$. The reduction in $\mathrm{pH}$ from 7 to 6.5 and then to 6 caused TMs to be washed out from the sludge, and hence a reduction in the retention capacity of TMs over time in the SAMBR was observed. The order of the leaching rate $(\mu \mathrm{g} / \mathrm{gTSS} . \mathrm{d})$ in metal content (Table 1) was slightly different at each $\mathrm{pH}$, i.e. $\mathrm{Fe}>\mathrm{Ni}>\mathrm{Co}>\mathrm{Zn}>\mathrm{Mn}$ $>\mathrm{Mo}(\mathrm{pH}$ 6.5) and $\mathrm{Fe}>\mathrm{Zn}>\mathrm{Ni}>\mathrm{Co}>\mathrm{Mn}>\mathrm{Mo}(\mathrm{pH}$ 6). Lopes et al. (2008) also found a high degree of leaching for $\mathrm{Fe}, \mathrm{Ni}$, and $\mathrm{Co}$ from acidifying sulfate reducing granular sludge at low $\mathrm{pHs}(6,5$, and 4$)$. When the $\mathrm{pH}$ returned to neutral (7), there was a significant increase in metal content for all TMs ( $p<$ 0.05 ) compared to the level at the end of $\mathrm{pH} 6$ i.e. from $2.2 \%(\mathrm{Mn})$ to $14.28 \%$ (Co). This was due to the increase in $\mathrm{pH}$ which stopped the leaching of TMs from the sludge. Zandvoort et al. (2005) also found that immediately following the $\mathrm{pH}$ shock ( $\mathrm{pH} 7$ to 5 for $30 \mathrm{~h}$ ) the effluent concentration of $\mathrm{Fe}, \mathrm{Co}$, and $\mathrm{Ni}$ from UASB reactors quickly returned to values found prior to the shock. 
Chapter 8: Effect of operating conditions on speciation and bioavailability of trace metals in submerged anaerobic membrane bioreactors

Table 8.1 Total content $(\mu \mathrm{g} / \mathrm{gTSS})$ of TMs as an average of samples collected at each $\mathrm{pH}$ and leaching rate ( $\mu \mathrm{g} / \mathrm{gTSS} . \mathrm{d})$ of TMs determined from total content $(\mu \mathrm{g} / \mathrm{gTSS})$ at the beginning and the end of each $\mathrm{pH}$ in the SAMBR1.

\begin{tabular}{|c|c|c|c|c|c|c|c|c|}
\hline \multirow[b]{3}{*}{ Metal } & \multicolumn{8}{|c|}{$\mathrm{pH}$} \\
\hline & \multicolumn{2}{|c|}{7} & \multicolumn{2}{|c|}{6.5} & \multicolumn{2}{|c|}{6} & \multicolumn{2}{|c|}{ Recovery } \\
\hline & $\begin{array}{c}\text { Metal } \\
\text { content } \\
(\mu \mathrm{g} / \mathrm{g})\end{array}$ & $\begin{array}{c}\text { Metal } \\
\text { leaching } \\
\text { rate } \\
(\mu \mathrm{g} / \mathrm{g} . \mathrm{d})\end{array}$ & $\begin{array}{l}\text { Metal } \\
\text { content } \\
(\mu \mathrm{g} / \mathrm{g})\end{array}$ & $\begin{array}{c}\text { Metal } \\
\text { leaching } \\
\text { rate } \\
(\mu \mathrm{g} / \mathrm{g} . \mathrm{d})\end{array}$ & $\begin{array}{l}\text { Metal } \\
\text { content } \\
(\mu \mathrm{g} / \mathrm{g})\end{array}$ & $\begin{array}{c}\text { Metal } \\
\text { leaching } \\
\text { rate } \\
(\mu \mathrm{g} / \mathrm{g} . \mathrm{d})\end{array}$ & $\begin{array}{l}\text { Metal } \\
\text { content } \\
(\mu \mathrm{g} / \mathrm{g})\end{array}$ & $\begin{array}{c}\text { Metal } \\
\text { leaching } \\
\text { rate } \\
(\mu \mathrm{g} / \mathrm{g} . \mathrm{d})\end{array}$ \\
\hline $\mathbf{F e}$ & 11256.1 & 21.7 & 8825.0 & 486.2 & 6895.9 & 385.8 & 7062.3 & -33.3 \\
\hline Co & 902.8 & -0.2 & 806.7 & 19.2 & 760.5 & 9.2 & 869.1 & -21.7 \\
\hline $\mathbf{N i}$ & 686.9 & -0.7 & 588.5 & 19.7 & 528.1 & 12.1 & 544.2 & -3.2 \\
\hline Zn & 1226.6 & 0.6 & 1144.0 & 16.5 & 1057.9 & 17.2 & 1108.1 & -10.0 \\
\hline Mn & 161.9 & 0.5 & 155.5 & 1.3 & 139.8 & 3.1 & 142.9 & -0.6 \\
\hline Mo & 147.9 & 0.4 & 142.3 & 1.1 & 127.0 & 3.1 & 144.6 & -3.5 \\
\hline
\end{tabular}

Speciation of trace metals - Table A.3 (Appendix) shows the measurements, and Figure 8.5 shows the distribution of each TM in different fractions from the BCR extraction method. In the liquid phase, generally, soluble TMs were relatively low (from $0.0 \%$ up to $2.64 \%$ ), which was also reported by Oleszkiewicz and Sharma (1990) and Roussel and Carliell-Marquet (2016), except for $\mathrm{Mn}$ which reached as high as $17.2 \%$. As expected, the lower $\mathrm{pH}$ caused a higher leaching rate of TMs from the sludge, and a higher metal solubility (Zandvoort et al., 2005; Lopes et al., 2008; Gonzalez-Gil et al., 2012). This resulted in an increase in the average soluble fraction as the $\mathrm{pH}$ was reduced from 7 to 6.5 then to 6 i.e. $\mathrm{Fe}(0.15 \%-0.77 \%-2.09 \%)(\mathrm{p}<0.05), \mathrm{Ni}$ $(1.39 \%-1.95 \%-2.64 \%)(\mathrm{p}<0.05), \operatorname{Mn}(12.05 \%-14.4 \%-17.17 \%)(\mathrm{p}<$ $0.05)$, Mo $(1.34 \%-2.02 \%-2.44 \%)(\mathrm{p}<0.05)$, except for Co and $\mathrm{Zn}$ which 
Chapter 8: Effect of operating conditions on speciation and bioavailability of trace metals in submerged anaerobic membrane bioreactors

was not found in the soluble fraction at any $\mathrm{pH}$ value, and this finding was in agreement with Marcato et al. (2009).

\section{Iron $(\mathbf{F e})$}

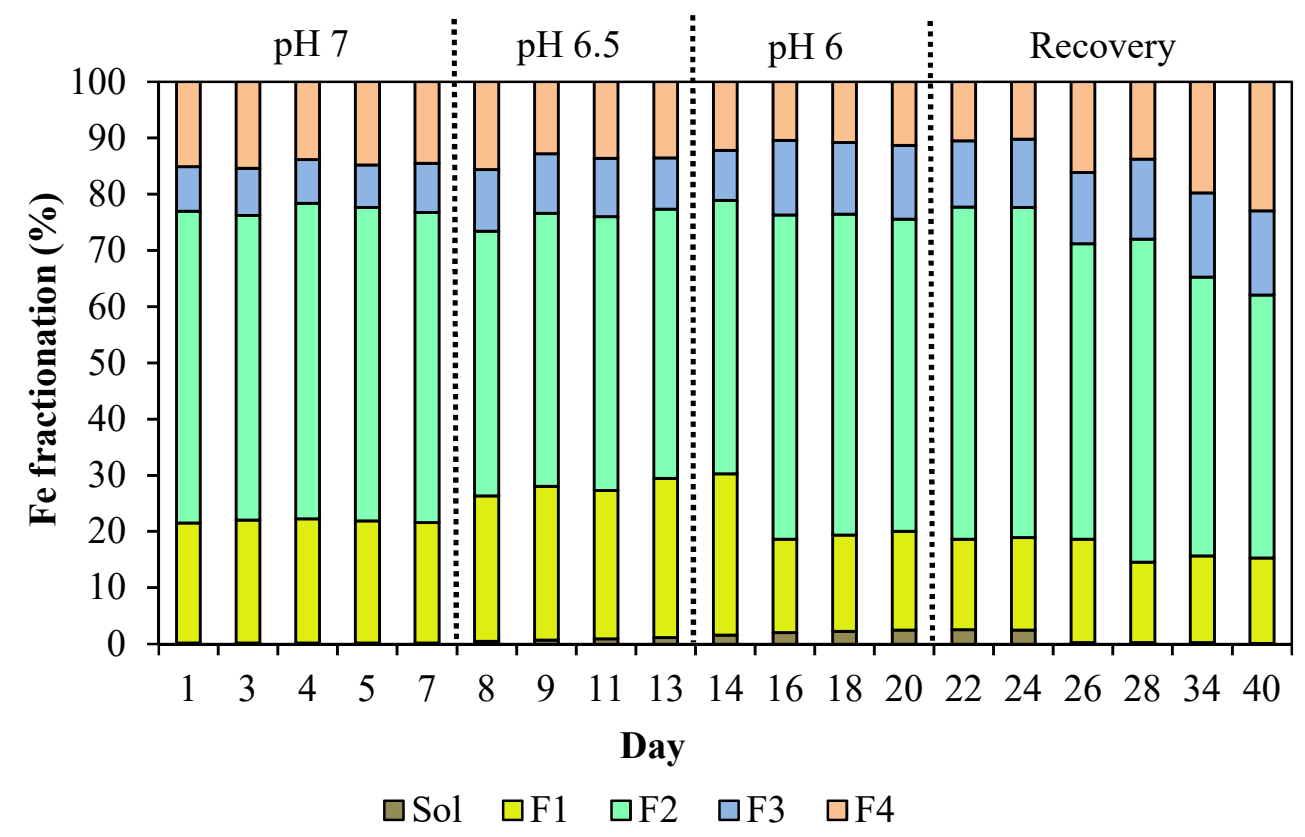

\section{Cobalt (Co)}

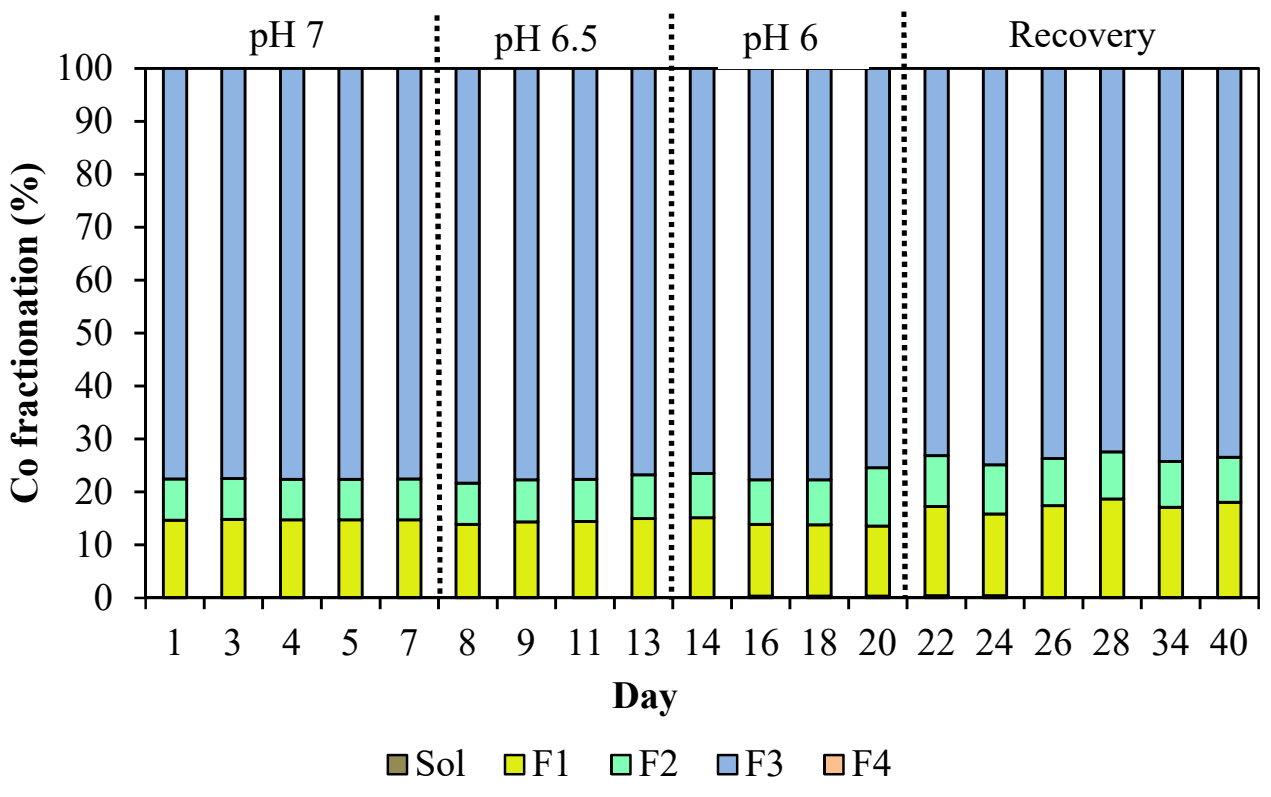


Chapter 8: Effect of operating conditions on speciation and bioavailability of trace metals in submerged anaerobic membrane bioreactors

Nickel (Ni)

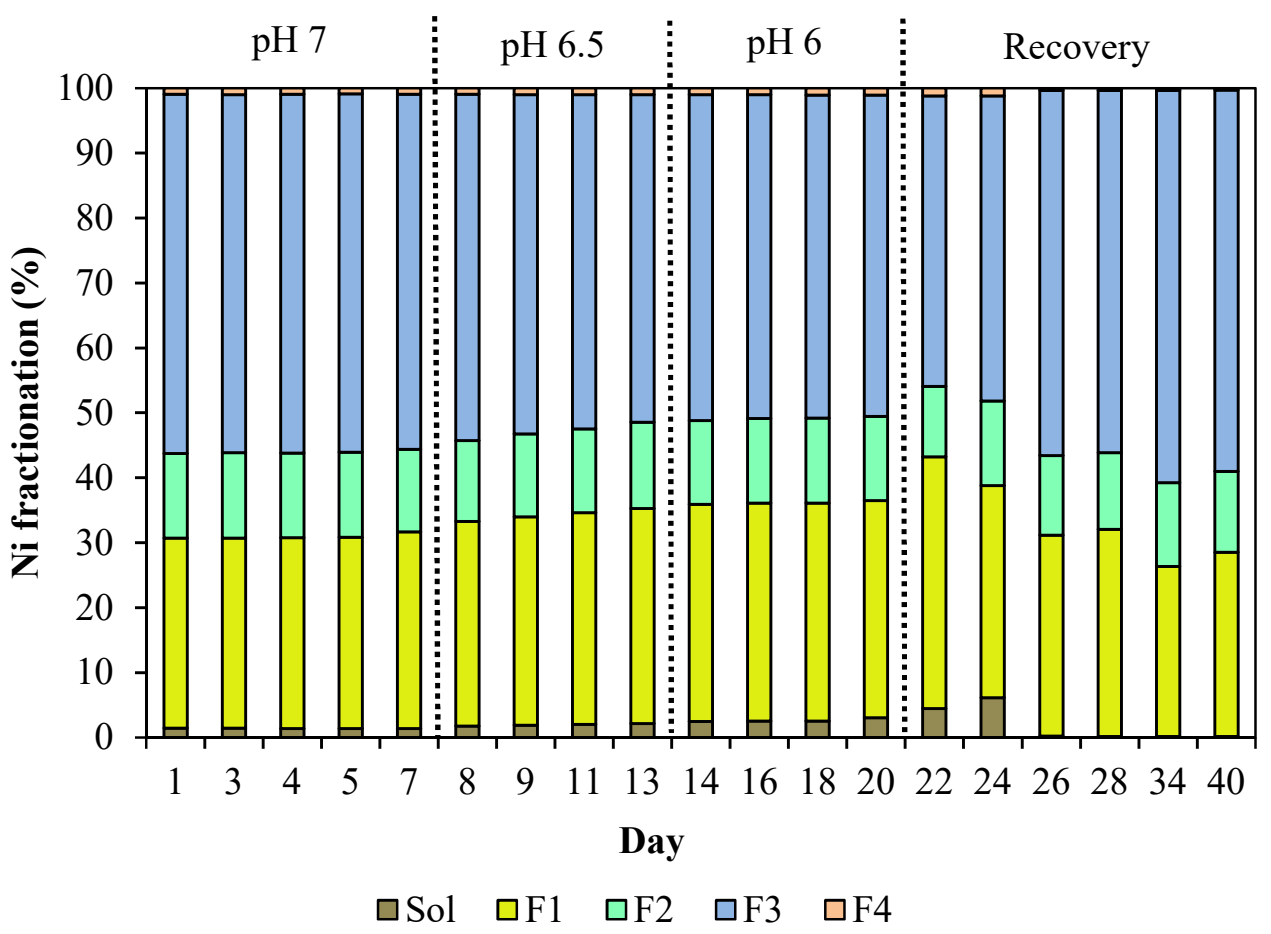

Zinc (Zn)

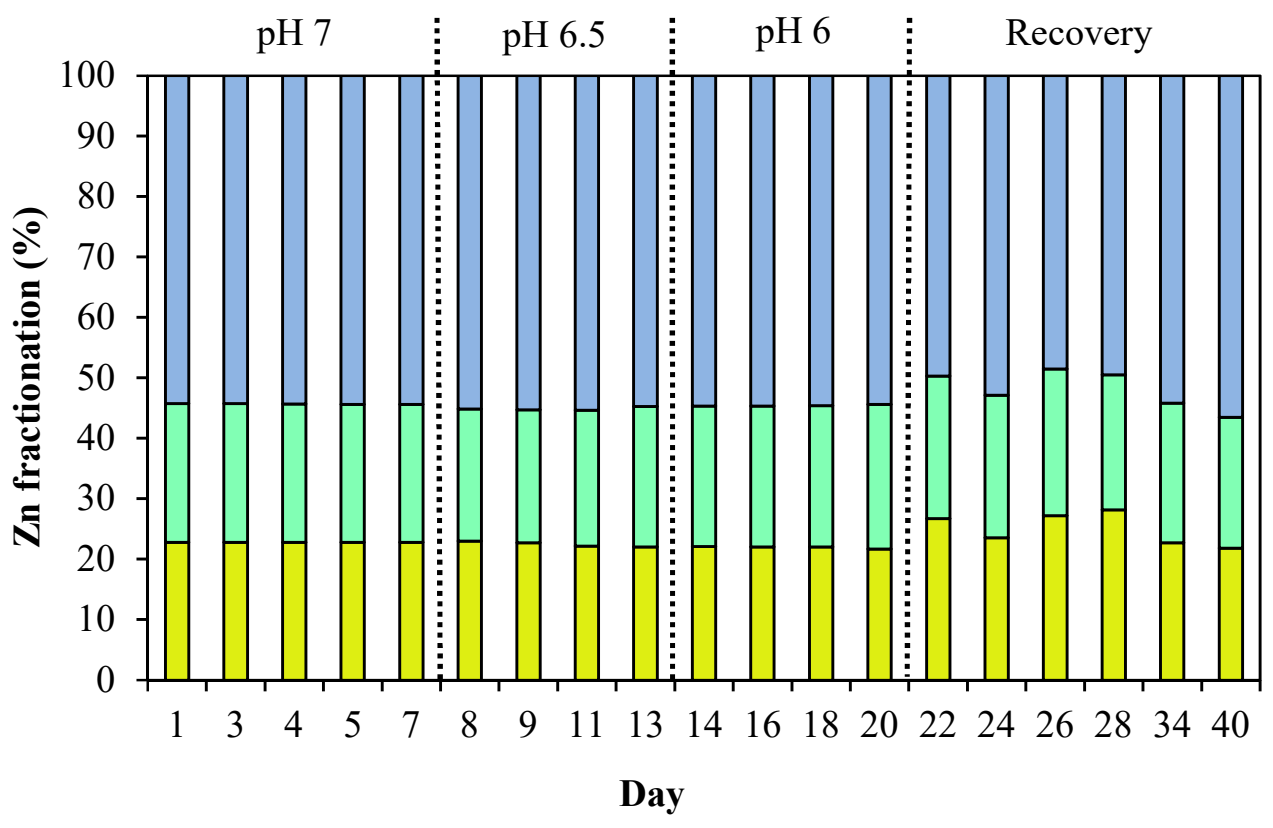

$\square$ Sol $\quad \square \mathrm{F} 1 \quad \square \mathrm{F} 2 \quad \square \mathrm{F} 3 \quad \square \mathrm{F} 4$ 
Chapter 8: Effect of operating conditions on speciation and bioavailability of trace metals in submerged anaerobic membrane bioreactors

Manganese (Mn)

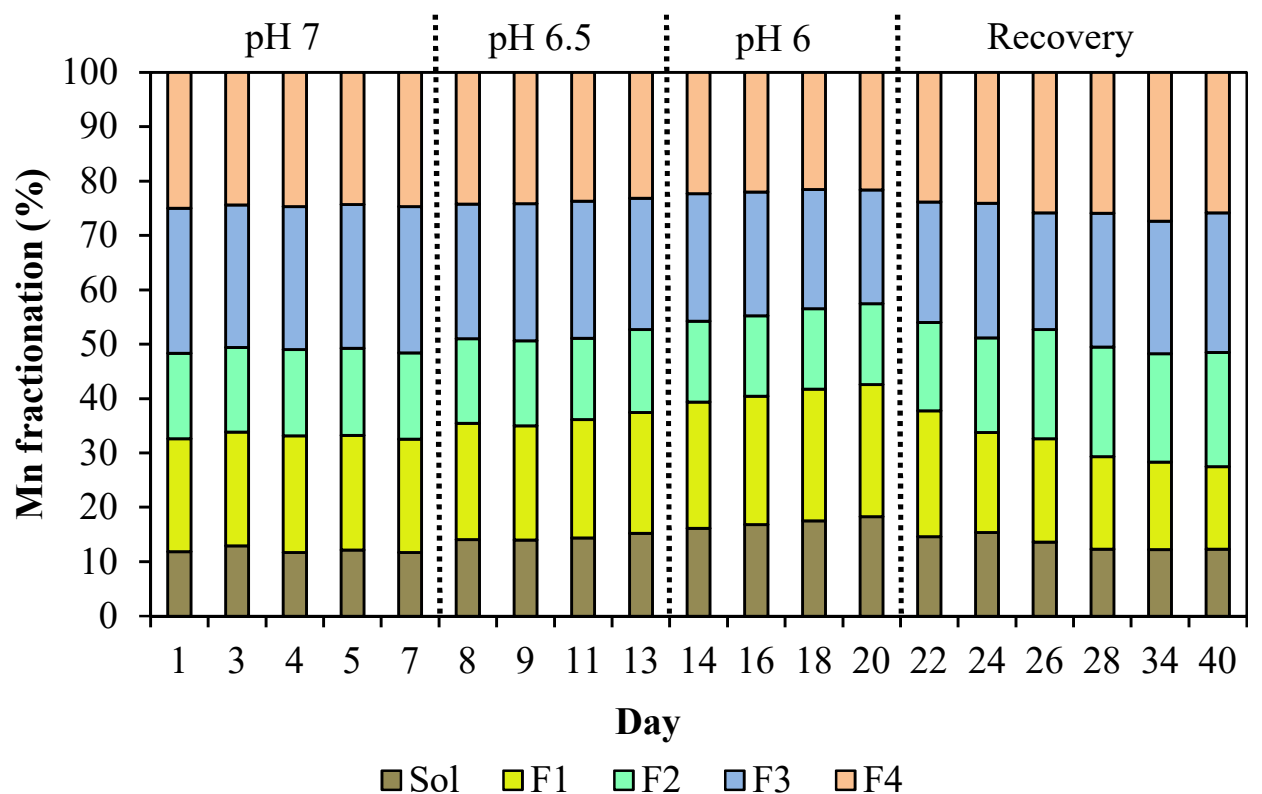

Molybdenum (Mo)

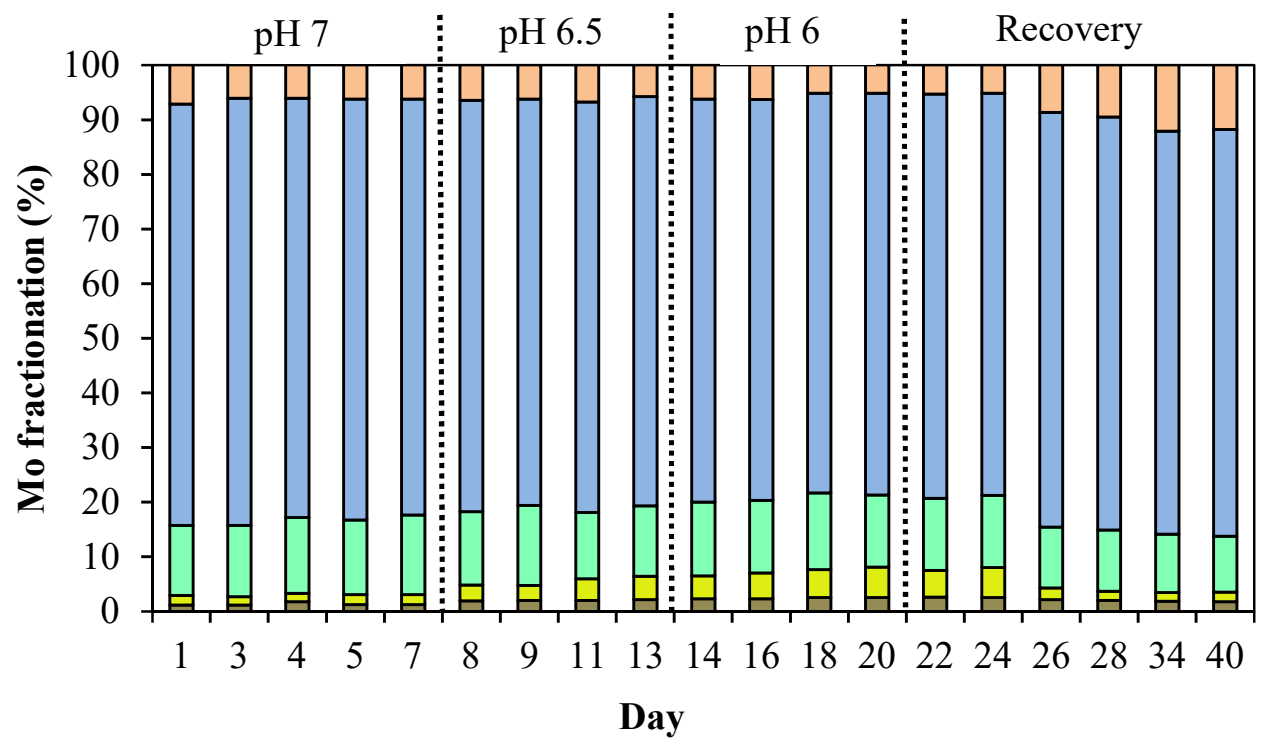

$\square$ Sol $\quad \square F 1 \quad \square F 2 \quad \square F 3 \quad \square F 4$

Sol - Soluble, F1 - Exchangeable, F2 - Fe/Mn oxides,

F3 - Organic matter, F4 - Residual

Figure 8.5 Speciation of TMs in SAMBR1 at different $\mathrm{pHs}(\mathrm{n}=3)$. 
In the solid phase, most of the TMs were found to exist mainly in the organic matter/sulfide fraction (F3), which is considered to have low bioavailability, except for Fe where its dominant fraction was the Fe-Mn oxides fraction (F2). These results were similar to the findings from Chapter 7 as precipitation of metals such as $\mathrm{Co}$ and $\mathrm{Ni}$ with sulfide was the reason for the dominance of the F3 fraction, and dissolution of amorphous Fe by the BCR extracting reagent possibly resulted in the accumulation of $\mathrm{Fe}$ in the $\mathrm{F} 2$ fraction. The changes in TM speciation at different $\mathrm{pH}$ values varied for different TMs, as shown in Figure 8.5.

There was a significant shift in the speciation of $\mathrm{Fe}$ as the average for the F1 fraction (Exchangeable) increased from 21.7\% $(\mathrm{pH} 7)$ to $26.6 \%(\mathrm{pH} 6.5)(\mathrm{p}$ $=0.028)$ but then reduced to $19.4 \%(\mathrm{pH} 6)(\mathrm{p}=0.021)$, while the F3 fraction (Organic matter/sulfide) also increased from $8.08 \%(\mathrm{pH} 7)$ to $10.1 \%(\mathrm{pH} \mathrm{6.5)}$ $(\mathrm{p}=0.482)$ then to $11.76 \%(\mathrm{pH} 6)(\mathrm{p}=0.478)$, respectively. In contrast, the F2 fraction (Fe-Mn oxides) reduced from 55.3\% (pH 7) to 47.4\% $(\mathrm{pH} 6.5)(\mathrm{p}=$ $0.034)$ but then increased to $53.5 \%(\mathrm{pH} 6)(\mathrm{p}=0.044)$, and the F4 fraction (Residual) also reduced from $14.7 \%(\mathrm{pH} 7)$ to $13.9 \%(\mathrm{pH} 6.5)$ and further reduced to $11.2 \%(\mathrm{pH}$ 6), respectively. As the $\mathrm{F} 1$ and $\mathrm{F} 2$ fractions are considered more bioavailable (total 76.0\% $\mathrm{pH} 7,75.0 \% \mathrm{pH} 6.5$, and $74.7 \% \mathrm{pH}$ 6) than the F3 and F4 fractions (total 22.8\% pH 7, 24.1\% pH 6.5, and 23.2\% $\mathrm{pH}$ 6), these results did not indicate that the speciation of Fe shifted towards higher or lower bioavailability.

In contrast, the change in Co speciation at lower pHs was much less significant. The average F1 fraction was relatively stable at $\mathrm{pH} 7$ and $\mathrm{pH} 6.5$, i.e. $14.8 \%$ and $14.4 \%(p=0.144)$, respectively, and only slightly reduced to $13.8 \%$ at $\mathrm{pH} 6.5(\mathrm{p}=0.042)$. The average $\mathrm{F} 2$ fraction also did not vary significantly at $\mathrm{pH} 7$ and $\mathrm{pH} 6.5$, i.e. $7.7 \%$ and $8 \%(\mathrm{p}=0.185)$, respectively, then it slightly increased to $9.05 \%$ at $\mathrm{pH} 6(\mathrm{p}=0.032)$. At all $\mathrm{pH}$ values, the F3 fraction was relatively stable i.e. $77.6 \%, 77.6 \%$ and $76.8 \%(p=0.203)$, while no Co was found in the F4 fraction. 
Ni showed a significant increase in its bioavailability as the average F1 fraction increased from $29.5 \%$ at $\mathrm{pH} 7$ to $32.3 \%$ at $\mathrm{pH} 6.5(\mathrm{p}=0.041)$ and then it stayed relatively constant at $33.5 \%$ at $\mathrm{pH} 6(\mathrm{p}=0.138)$. On the other hand, the average F3 fraction, which is considered less bioavailable than the F1 fraction, reduced significantly from $55.1 \%$ at $\mathrm{pH} 7$ to $51.9 \%$ at $\mathrm{pH} 6.5 \mathrm{p}=$ $0.028)$ and then to $49.8 \%$ at $\mathrm{pH} 6(\mathrm{p}=0.043)$. However, the average of the remaining two fractions, F2 and F4, did not change significantly as they stayed at the same levels of around $13 \%$ and $1 \%(\mathrm{p}=0.073$ and $\mathrm{p}=0.09)$, respectively.

Although the total metal content in the reactor for $\mathrm{Zn}$ reduced, no pattern was established for $\mathrm{Zn}$ speciation at different $\mathrm{pHs}$ as the average $\mathrm{Zn}$ content in the F1, F2, and F3 fractions was approximately constant at around 23\%, 23\%, and $55 \%$, with $\mathrm{p}$ values of $0.193,0.238$, and 0.142 , respectively. Similar to Co, no $\mathrm{Zn}$ was found in the last fraction F4.

The bioavailability of $\mathrm{Mn}$ was slightly improved when the $\mathrm{pH}$ was reduced. The average of the $\mathrm{F} 1$ fraction was $21.0 \%$ at $\mathrm{pH} 7$, and it remained almost the same at $21.6 \%$ at $\mathrm{pH} 6.5(\mathrm{p}=0.181)$ before increasing to $23.9 \%$ at pH $6(\mathrm{p}=0.031)$. In contrast, at lower $\mathrm{pH}$ values, there was no significant difference in the F2 fraction i.e. $15.8 \%$ to $15.4 \%$ to $14.9 \%(p=0.394)$, whereas, the last two fractions (F3 and F4) showed a similar declining trend i.e. $26.5 \%$ to $24.8 \%$ to $22.3 \%(\mathrm{p}=0.028)$, and $24.6 \%$ to $23.8 \%$ to $21.9 \%$ ( $\mathrm{p}=$ $0.031)$ at $\mathrm{pH} 7,6.5$ and 6 , respectively.

Similar to Mn, the speciation of Mo shifted towards higher bioavailable fractions (F1), which slightly increased from $1.71 \%$ to $3.5 \%$ to $4.9 \%$ ( $p=$ 0.043 ), while the F2 fraction did not change significantly, i.e. $13.6 \%, 13.3 \%$ and $13.5 \%$ at $\mathrm{pH} 7,6.5$ and $6(\mathrm{p}=0.341)$, respectively. The average content of Mo in the last two fractions (F3 and F4) reduced as the $\mathrm{pH}$ reduced, i.e. $77.1 \%$ to $74.9 \%$ to $73.5 \%(\mathrm{p}=0.041)$ and $6.33 \%$ to $6.27 \%$ to $5.66 \%(\mathrm{p}=0.047)$, respectively. 
Chapter 8: Effect of operating conditions on speciation and bioavailability of trace metals in submerged anaerobic membrane bioreactors

The $\mathrm{pH}$ of the reactor was allowed to recover after the $\mathrm{pH}$ adjustment was stopped. For all TMs, when the $\mathrm{pH}$ increased their total content increased accordingly, showing that the metal solubility had been reduced, and the reactor was able to regain its metal retention capacity, i.e. up to $14.3 \%$ after $\mathrm{pH}$ 6 (Table 8.1). In addition, the speciation of the TMs was reversed towards less bioavailable fractions, i.e. decreasing Soluble and Exchangeable forms, and increasing Organic matter/sulfide and Residuals, as shown in Figure 8.5.

In summary, a reduction in $\mathrm{pH}$ resulted in a decrease in total metal content, but an increase in the soluble fraction for all TMs. $\mathrm{Fe}$ and $\mathrm{Ni}$ underwent the most significant changes in their BCR fractions, while changes in $\mathrm{Co}, \mathrm{Mn}$ and Mo were less significant. The speciation of Ni, Mn, and Mo shifted towards stable fractions, i.e. Soluble and Exchangeable, which are more bioavailable to the anaerobic microorganisms, whereas, Fe and Co showed no shifting pattern in their speciation. Zn was found not to be sensitive to $\mathrm{pH}$ changes, which is in agreement with Lopes et al. (2008). These results showed that the degree of change in metal speciation varied as some metal ions are more sensitive to $\mathrm{pH}$ changes than others, and also some metals have stronger affinity towards anaerobic sludge binding sites than others (Leighton \& Forster, 1997; Artola et al., 2000; Marcato et al., 2009).

\subsubsection{Changes in HRT}

\subsubsection{Performance of the SAMBR2 under different HRTs}

Figure 8.6 shows soluble COD concentrations in the reactor and effluent from SAMBR2 at different HRTs. It can be seen that the effluent COD in the SAMBR increased initially with decreasing HRT, but the reactor recovered rapidly from the hydraulic shock within a few days, and became stable again; a similar profile could be seen when the HRT was decreased from $6 \mathrm{~h}$ to $4 \mathrm{~h}$ and 2 h. It should be pointed out here that theoretically there should be no concentration difference between the reactor and effluent COD during 
Chapter 8: Effect of operating conditions on speciation and bioavailability of trace metals in submerged anaerobic membrane bioreactors

microfiltration with a pore size of $0.4 \mu \mathrm{m}$. However, Figure 8.6 shows that the reactor COD in the SAMBR2 was more than six times higher than the effluent COD at HRT $6 \mathrm{~h}$, five times at $4 \mathrm{~h}$, and 1.5 times at $2 \mathrm{~h}$. This difference in COD concentrations is similar to the findings from the $\mathrm{pH}$ experiment which is due to the rejection of soluble COD by the fouling layer on the membrane surface. In addition, Figure 8.7 shows that the state of the SAMBR2 membrane at the end of the HRT experiment as a cake was formed on the surface of the membrane. This cake formation might have occurred almost immediately in the SAMBR after the flux pump speed was increased to accommodate higher influent loading rates. Over the whole experiment, the effluent COD at various HRTs was the highest at $71.2 \mathrm{mg} / \mathrm{L}$ at the beginning of $2 \mathrm{~h} \mathrm{HRT} \mathrm{(day} \mathrm{10),} \mathrm{indicating}$ that good COD removal was achieved under virtually all conditions. The soluble COD removal efficiencies were consistent with previous studies in anaerobic membrane bioreactors (Hu, 2004; Kunacheva et al., 2017). From Figure 8.6 it can be seen that the removal efficiency decreased with decreasing HRT; it was nearly $99 \%$ at an HRT of $6 \mathrm{~h}$, then reduced slightly to $96 \%$ at the beginning of 4 h HRT (day 5) (p < 0.05), but returned to 99\% after 5 days (day 9) $(\mathrm{p}<0.05)$, dropped to $88 \%$ at the beginning of $2 \mathrm{~h}$ HRT (day 10) $(\mathrm{p}<0.05)$ but still achieved 93\% after 5 days (day 14) ( $<<0.05)$. Kunacheva et al. (2017) were also able to achieve 94\% COD removal when the HRT of a SAMBR was reduced from $4 \mathrm{~h}$ to $2 \mathrm{~h}$ for $6 \mathrm{~d}$. These results showed that the tolerance of the SAMBR to changes in HRT is very high as there was no washout of biomass, and the dynamic fouling layer on the membrane acts to reject many of the SMPs as well as solids.

The measurement of VFA concentrations at each HRT (Figure 8.8 and 8.9) showed that at steady state only $0.35 \mathrm{mgCOD} / \mathrm{L}$ of VFAs were present in the reactor, and no VFAs were detected in the effluent; this indicates that the incoming COD was almost all degraded to biomass, $\mathrm{CH}_{4}$ and $\mathrm{CO}_{2}$. Figures 8.8 and 8.9 also shows that the major VFAs present in the reactor and effluent were formate, acetate, and propionate. When the organic loading rate doubled at $4 \mathrm{~h}$ 
Chapter 8: Effect of operating conditions on speciation and bioavailability of trace metals in submerged anaerobic membrane bioreactors

HRT, VFA concentrations in the reactor increased rapidly to $11.5 \mathrm{mgCOD} / \mathrm{L}$ (day 5), but then decreased to $1.63 \mathrm{mgCOD} / \mathrm{L}(\mathrm{p}<0.05)$ after 5 days (day 9) showing quick recovery of the SAMBR. When the organic loading rate doubled again at $2 \mathrm{~h}$ HRT, a VFA peak of $62.9 \mathrm{mgCOD} / \mathrm{L}$ was found on the first day (day 10), but after 5 days it reduced to $20.3 \mathrm{mgCOD} / \mathrm{L}(\mathrm{p}<0.05)$ (day 14). The rapid accumulation of VFAs on the first day of HRT reduction was because the feed glucose was metabolized into acetate very quickly, leading to an accumulation of intermediate VFAs in the reactor. The VFAs in the effluent were only slightly less than those in the reactor, implying that VFA rejection by the membrane was not significant. As the soluble COD present in the reactor and effluent were considerably higher than the VFAs, this indicates that the COD in the reactor and effluent was not only VFAs, but also SMPs produced by the biomass.

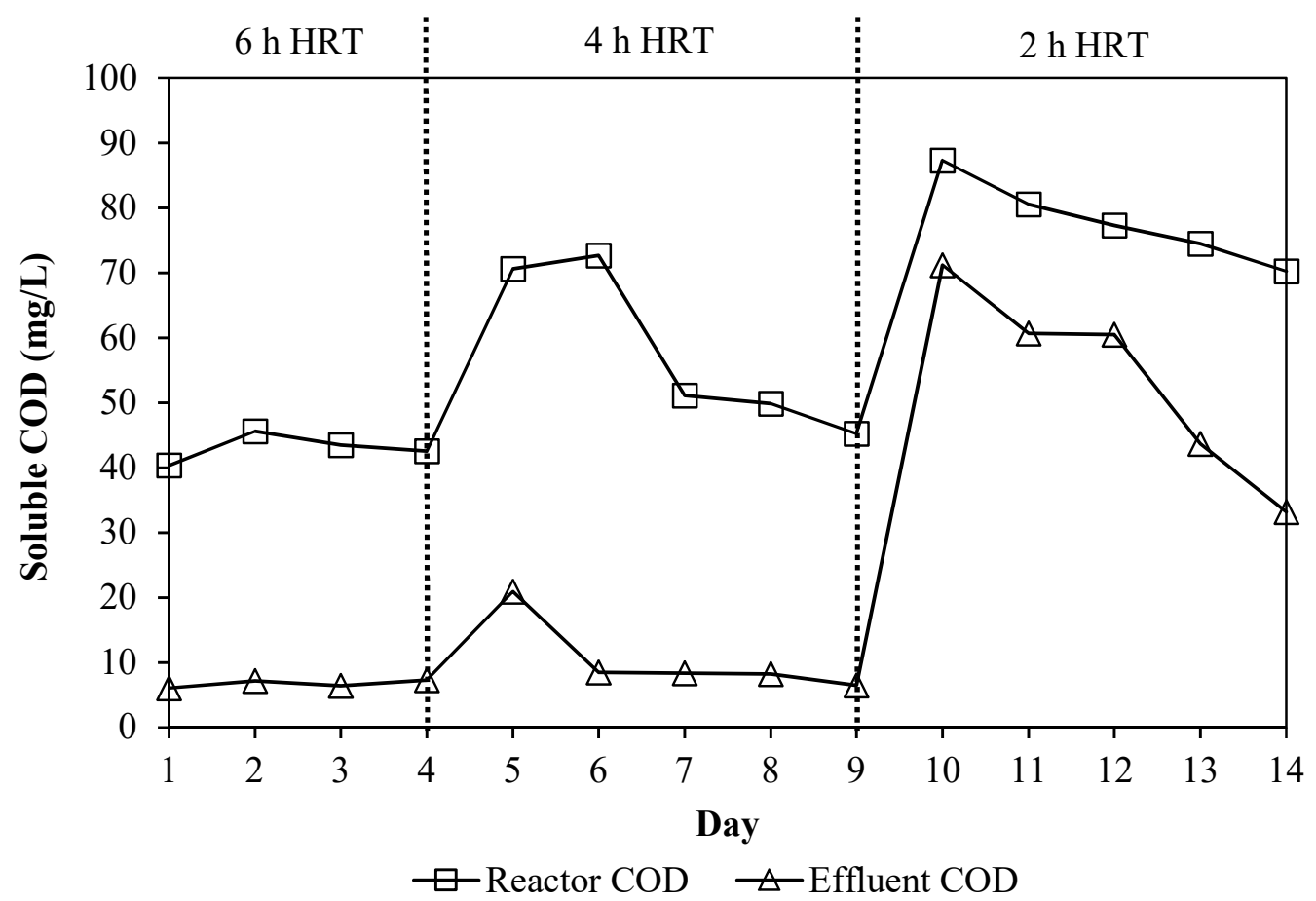

Figure 8.6 Soluble COD in SAMBR2 reactor and effluent at different HRTs $(n=3)$. 
Chapter 8: Effect of operating conditions on speciation and bioavailability of trace metals in submerged anaerobic membrane bioreactors

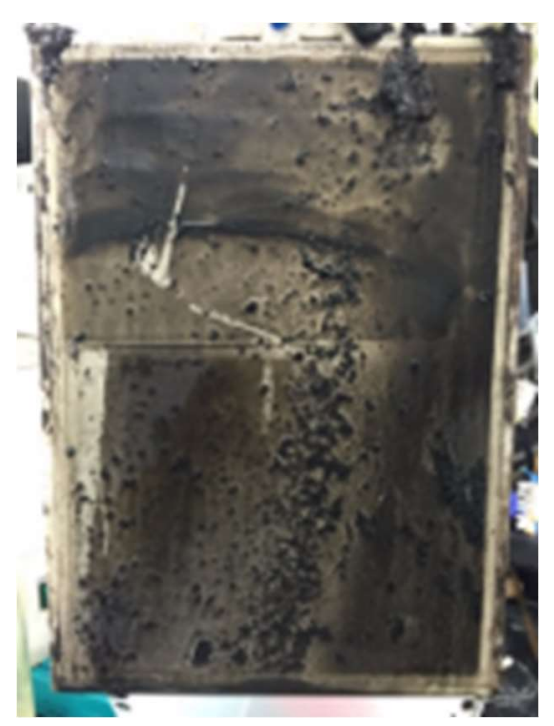

Figure 8.7 Cake layer on the membrane surface of the SAMBR2 at the end of 2 h HRT.

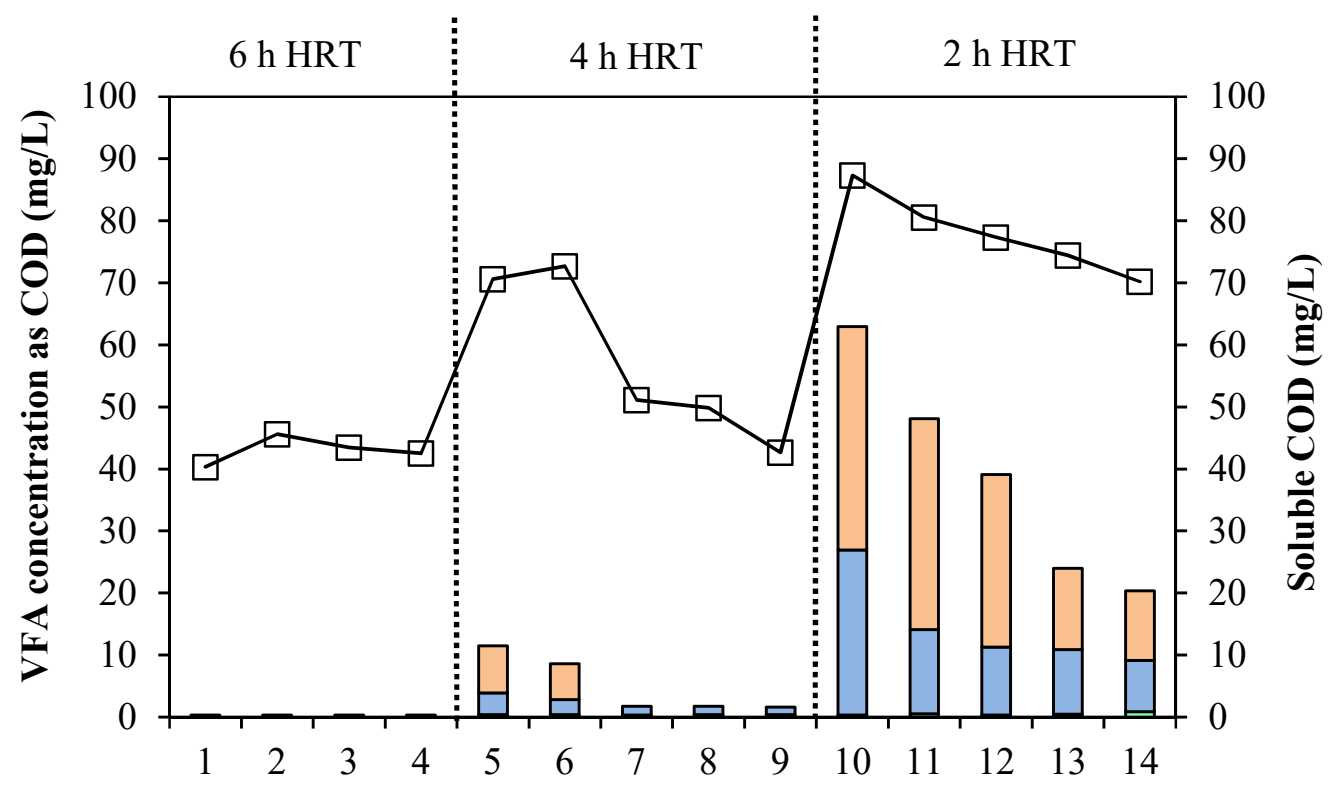

Day

$\varpi$ Formic acid $\square$ Acetic acid $\square$ Propionic acid $\square$ Reactor COD

Figure $8.8 \quad$ VFA concentration as COD with Reactor COD of SAMBR2 at different HRTs $(n=3)$. 


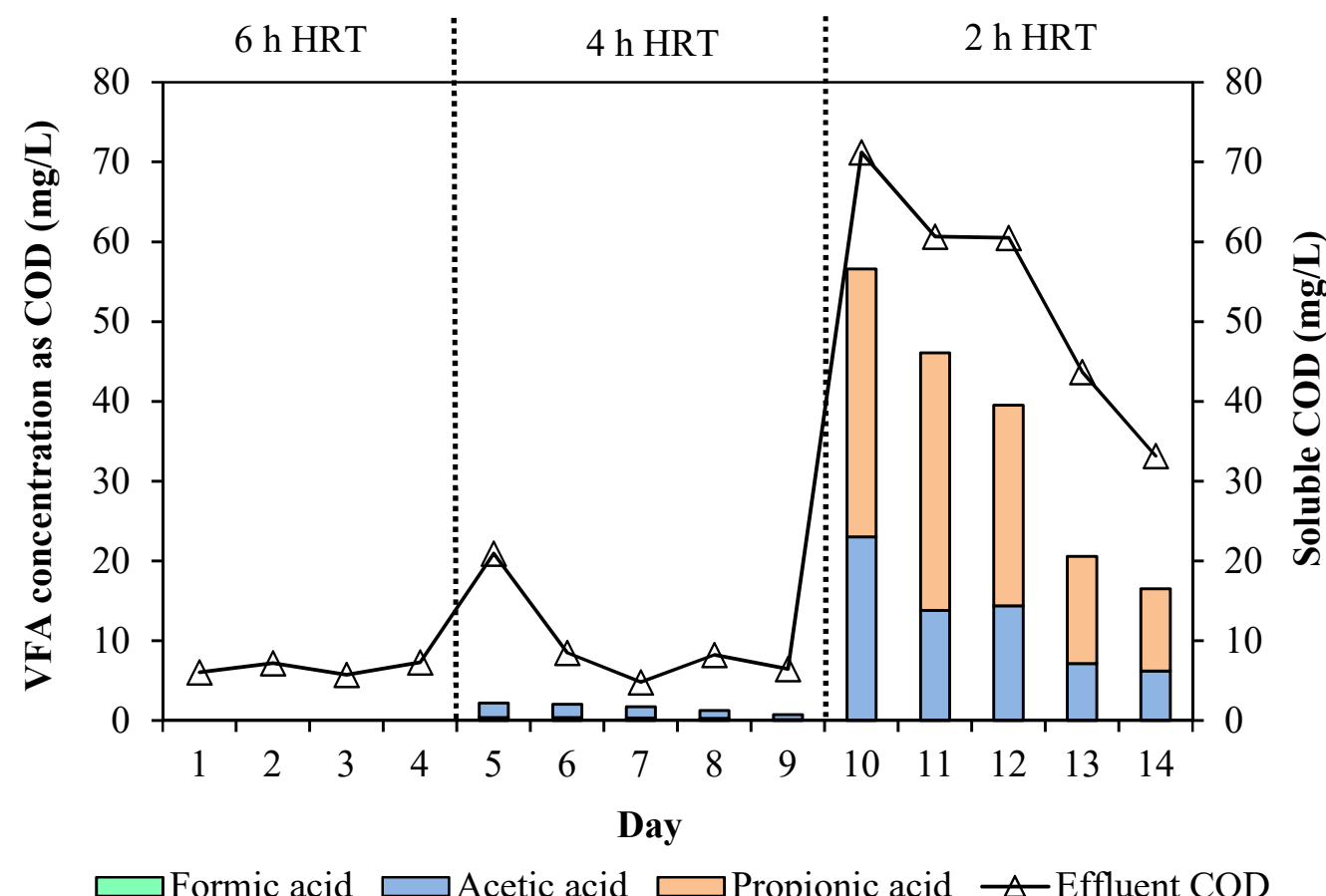

Figure 8.9 VFA concentration as COD with Effluent COD of SAMBR2 at different HRTs $(\mathrm{n}=3)$.

Due to the increase in organic loading rate (OLR) when the HRT was reduced, it was obvious that the methane yields in the SAMBR would increase from steady state (6 h HRT), i.e. $40.6 \mathrm{mLCH}_{4} / \mathrm{gVSS} \mathrm{d}$ to $48 \mathrm{mLCH}_{4} / \mathrm{gVSS}$.d $(\mathrm{p}<0.05)$ and it further increased to $85.39 \mathrm{mLCH}_{4} / \mathrm{gVSS} . \mathrm{d}(\mathrm{p}<0.05) 5$ days after $4 \mathrm{~h}$ and $2 \mathrm{~h}$ HRT, respectively. In order to accommodate the increase in OLR, the biomass concentration in the reactor also increased accordingly. At 6 $\mathrm{h}$ HRT the average TSS and VSS of the SAMBR were $11.69 \mathrm{~g} / \mathrm{L}$ and 10.56 $\mathrm{g} / \mathrm{L}$, respectively, and they increased to $13.47 \mathrm{~g} / \mathrm{L}$ and $12.37 \mathrm{~g} / \mathrm{L}$ at $4 \mathrm{~h}$ HRT ( $\mathrm{p}$ $<0.05)$, and increased further to $17.15 \mathrm{~g} / \mathrm{L}$ and $15.9 \mathrm{~g} / \mathrm{L}$ at $2 \mathrm{~h} \mathrm{HRT}(\mathrm{p}<0.05)$. These results indicate that when the OLR was tripled, the biomass content in the SAMBR almost doubled from its initial levels at $6 \mathrm{~h}$ HRT. The average transmembrane pressure (TMP) also increased from $4.12 \mathrm{kPa}$ at $6 \mathrm{~h}$ HRT to $9.86 \mathrm{kPa}$ at $4 \mathrm{~h}$ HRT $(\mathrm{p}<0.05)$ and then to $13.42 \mathrm{kPa}$ at the end of $2 \mathrm{~h}$ HRT (p 
Chapter 8: Effect of operating conditions on speciation and bioavailability of trace metals in submerged anaerobic membrane bioreactors

$<0.05)$. The flux of the membrane had to be increased from $20 \mathrm{~L}$ per square meter per hour $(\mathrm{LMH})$ at $6 \mathrm{~h} \mathrm{HRT}$ to $25(\mathrm{LMH})$ at $4 \mathrm{~h}$ and then to $37(\mathrm{LMH})$ to accommodate the increase in feed flowrate into the reactor.

\subsubsection{Dynamic changes in trace metal speciation under different HRTs}

Total content of trace metals - The total content of each TM in the SAMBR at steady state (6 h HRT) was determined, and it was in the following order: $\mathrm{Fe}>\mathrm{Ni}>\mathrm{Co}>\mathrm{Zn}>\mathrm{Mo}>\mathrm{Mn}$ (Table 8.3). The retention capacity of TMs in the SAMBR was reduced for all TMs when the HRT was reduced to $4 \mathrm{~h}$ and $2 \mathrm{~h}$. The reduction in total content of TMs after each HRT reduction was the same for both $4 \mathrm{~h}$ and $2 \mathrm{~h}$, i.e. $\mathrm{Fe}>\mathrm{Ni}>\mathrm{Co}>\mathrm{Zn}>\mathrm{Mn}>\mathrm{Mo}$. The $2 \mathrm{~h}$ HRT exhibited a higher level of reduction in total content than at $4 \mathrm{~h}$ HRT for all TMs, except for Ni and Mo in which the level was almost the same at both HRTs. Cestonaro do Amaral et al. (2014) also found that when the HRT of a digester was reduced from $17.86 \mathrm{~d}$ to $5.32 \mathrm{~d}$, the retention capacity of $\mathrm{Zn}$ and $\mathrm{Cu}$ decreased significantly, which was due to an increase in flow rate, generating greater internal agitation of biomass in the digester dragging solids, and associated TMs, into the effluent. However, in this study, due to the membrane, no solids were lost from the reactor. Nevertheless, the low $\mathrm{pH}$ resulting from the hydraulic shock loading $(\mathrm{pH} 6.78 \pm 0.05)$ at $2 \mathrm{~h}$ HRT might have caused the TMs to leach out from the SAMBR in the soluble phase. 
Chapter 8: Effect of operating conditions on speciation and bioavailability of trace metals in submerged anaerobic membrane bioreactors

Table 8.2 Total content $(\mu \mathrm{g} / \mathrm{gTSS})$ of TMs as an average of samples collected at each HRT and leaching rate ( $\mu \mathrm{g} / \mathrm{gTSS} . \mathrm{d})$ of TMs determined from total content ( $\mu \mathrm{g} / \mathrm{gTSS})$ at the beginning and the end of each HRT in the SAMBR2.

\begin{tabular}{ccccccc}
\hline & \multicolumn{5}{c}{ HRT (day) } \\
\cline { 2 - 7 } Metal & \multicolumn{2}{c}{$\mathbf{6}$} & \multicolumn{2}{c}{$\mathbf{4}$} & \multicolumn{2}{c}{$\mathbf{2}$} \\
\cline { 2 - 7 } & $\begin{array}{c}\text { Metal } \\
\text { content } \\
(\mu \mathrm{g} / \mathrm{g})\end{array}$ & $\begin{array}{c}\text { Metal } \\
\text { leaching } \\
\text { rate } \\
(\mu \mathrm{g} / \mathrm{g} . \mathrm{d})\end{array}$ & $\begin{array}{c}\text { Metal } \\
\text { content } \\
(\mu \mathrm{g} / \mathrm{g})\end{array}$ & $\begin{array}{c}\text { Metal } \\
\text { leaching } \\
\text { rate } \\
(\mu \mathrm{g} / \mathrm{g} . \mathrm{d})\end{array}$ & $\begin{array}{c}\text { Metal } \\
\text { content } \\
(\mu \mathrm{g} / \mathrm{g})\end{array}$ & $\begin{array}{c}\text { Metal } \\
\text { leaching } \\
\text { rate } \\
(\mu \mathrm{g} / \mathrm{g} . \mathrm{d})\end{array}$ \\
\hline $\mathbf{F e}$ & 8487.0 & 6.6 & 7487.5 & 199.9 & 5393.9 & 418.7 \\
\hline $\mathbf{C o}$ & 950.4 & -1.7 & 909.9 & 8.1 & 638.8 & 54.2 \\
\hline $\mathbf{N i}$ & 1010.1 & 1.2 & 728.3 & 56.4 & 443.7 & 56.9 \\
\hline $\mathbf{Z n}$ & 880.6 & 0.9 & 838.0 & 8.5 & 775.6 & 12.5 \\
\hline $\mathbf{M n}$ & 126.0 & 1.3 & 111.8 & 2.9 & 86.1 & 5.1 \\
\hline Mo & 152.1 & 0.8 & 146.0 & 1.2 & 137.2 & 1.8 \\
\hline
\end{tabular}

Speciation of trace metals - The measurement of TM content in each fraction from BCR extraction is given in Table A.4 (Appendix), and the speciation of TMs is shown in Figure 8.10. Similar to the results from the $\mathrm{pH}$ experiment, in the liquid phase the soluble concentration for most of the TMs was very low, i.e. up to $2.63 \%$, except for $\mathrm{Mn}$ and Mo which reached $16.0 \%$ and $28.2 \%$, respectively. When the HRT was reduced, the soluble fraction for $\mathrm{Fe}, \mathrm{Co}, \mathrm{Ni}$ and $\mathrm{Zn}$ remained relatively constant, whereas the $\mathrm{Mn}$ and $\mathrm{Mo}$ soluble levels decreased from $15.6 \%$ and $25.6 \%$ at $6 \mathrm{~h}$ HRT to $12.4 \%$ and $12.2 \%$ at 2 h HRT $(p<0.05)$, respectively. In the solid phase, again similar to the $\mathrm{pH}$ experiment, most of the TMs were found in the organic matter/sulfide 
Chapter 8: Effect of operating conditions on speciation and bioavailability of trace metals in submerged anaerobic membrane bioreactors

fraction, except for Fe and $\mathrm{Mn}$ where their dominant fraction was $\mathrm{Fe}-\mathrm{Mn}$ oxides and Exchangeable, respectively.

Iron (Fe)

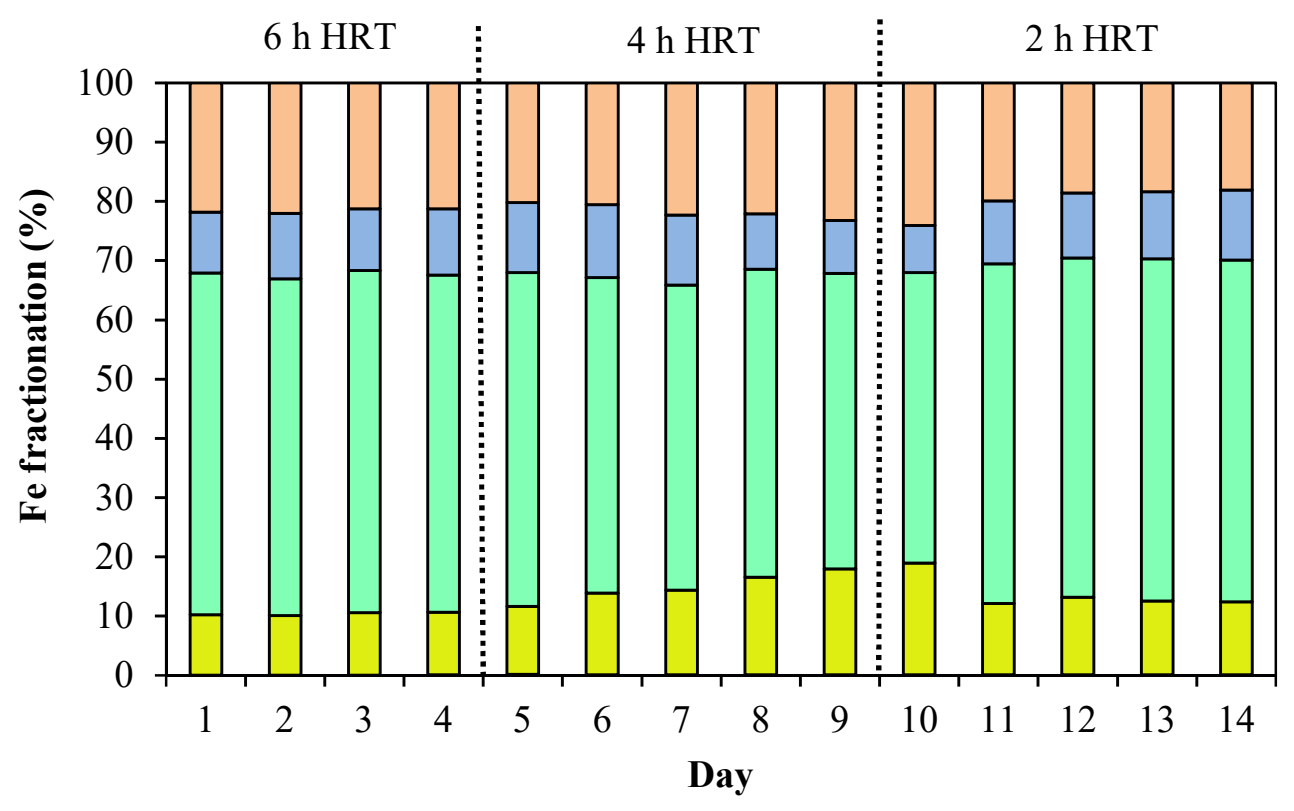

$\square$ Sol $\quad \square \mathrm{F} 1 \quad \square \mathrm{F} 2 \quad \square \mathrm{F} 3 \quad \square \mathrm{F} 4$

\section{Cobalt (Co)}

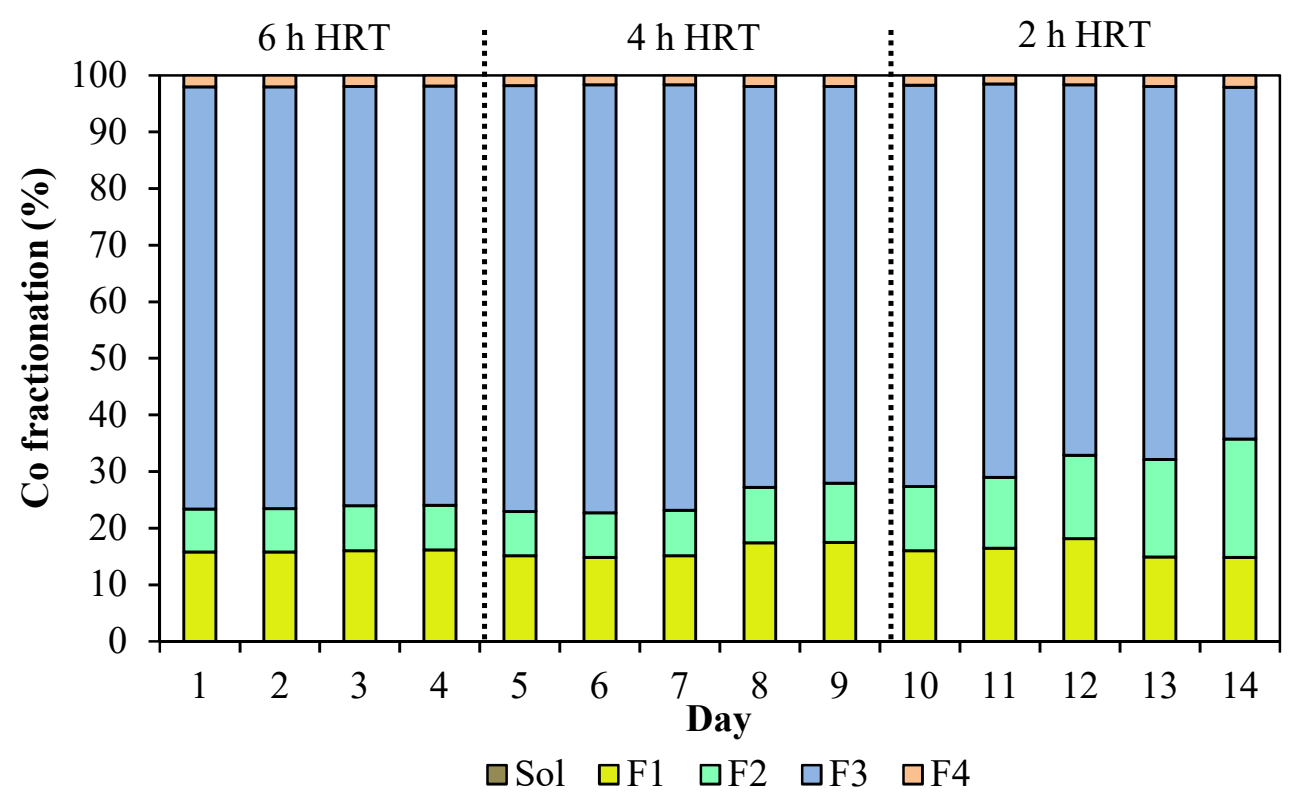


Chapter 8: Effect of operating conditions on speciation and bioavailability of trace metals in submerged anaerobic membrane bioreactors

Nickel (Ni)

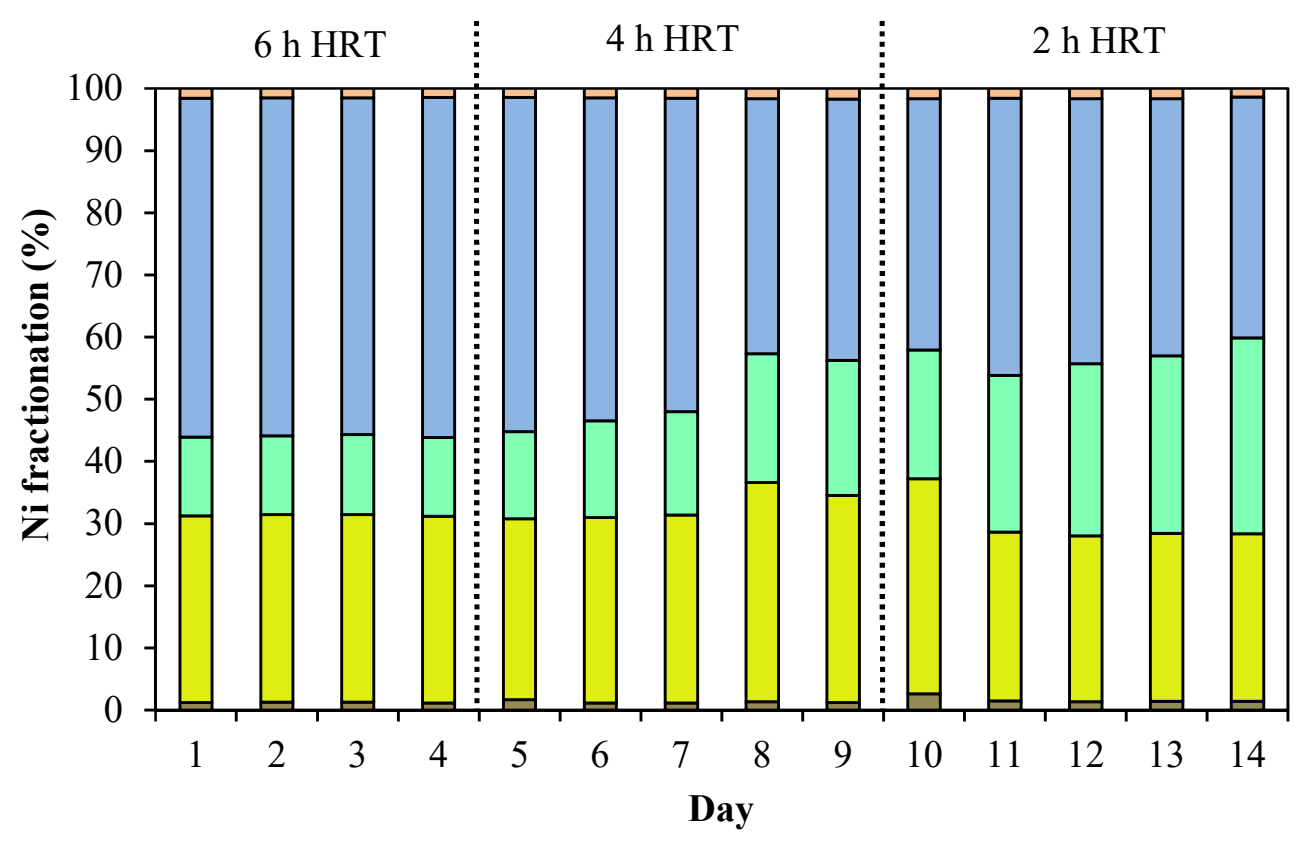

$\square$ Sol $\quad \square \mathrm{F} 1 \quad \square \mathrm{F} 2 \quad \square \mathrm{F} 3 \quad \square \mathrm{F} 4$

Zinc (Zn)

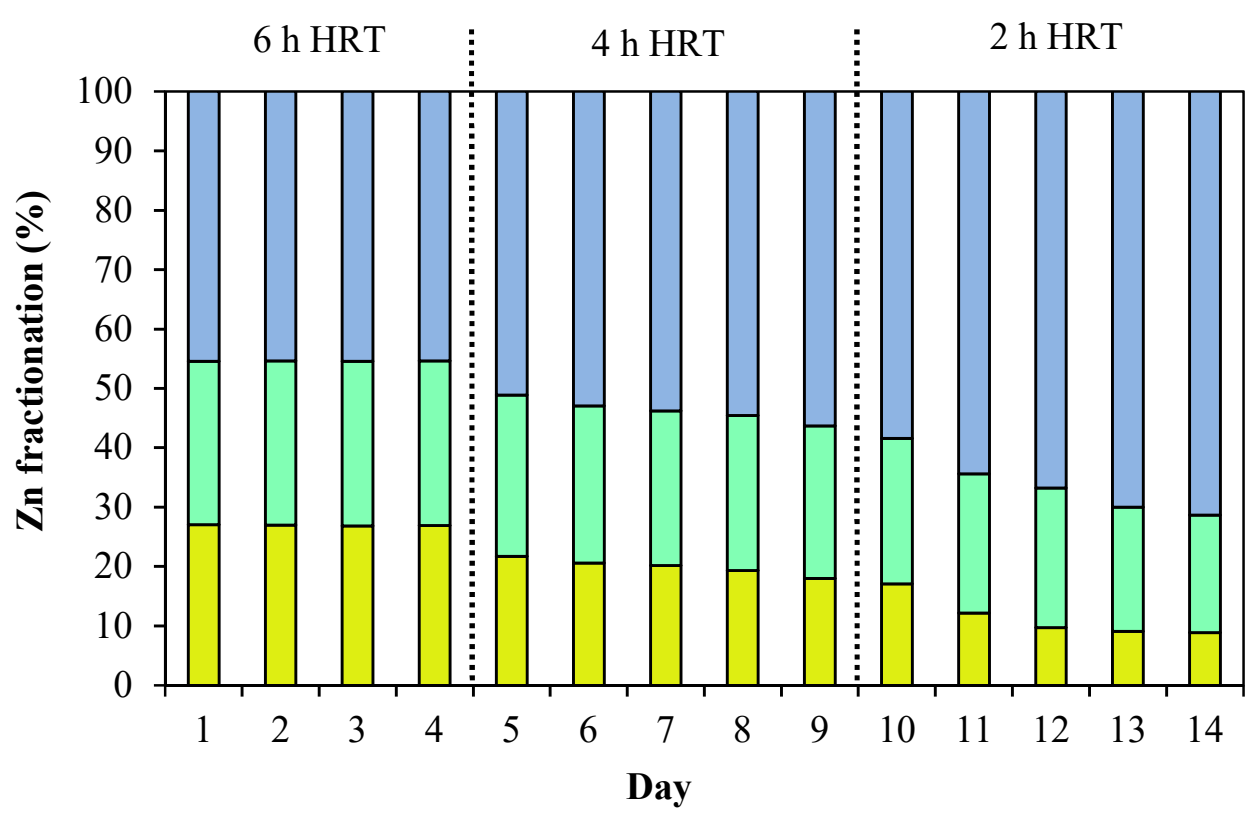

$\square$ Sol $\quad \square \mathrm{F} 1 \quad \square \mathrm{F} 2 \quad \square \mathrm{F} 3 \quad \square \mathrm{F} 4$ 
Chapter 8: Effect of operating conditions on speciation and bioavailability of trace metals in submerged anaerobic membrane bioreactors

Manganese (Mn)

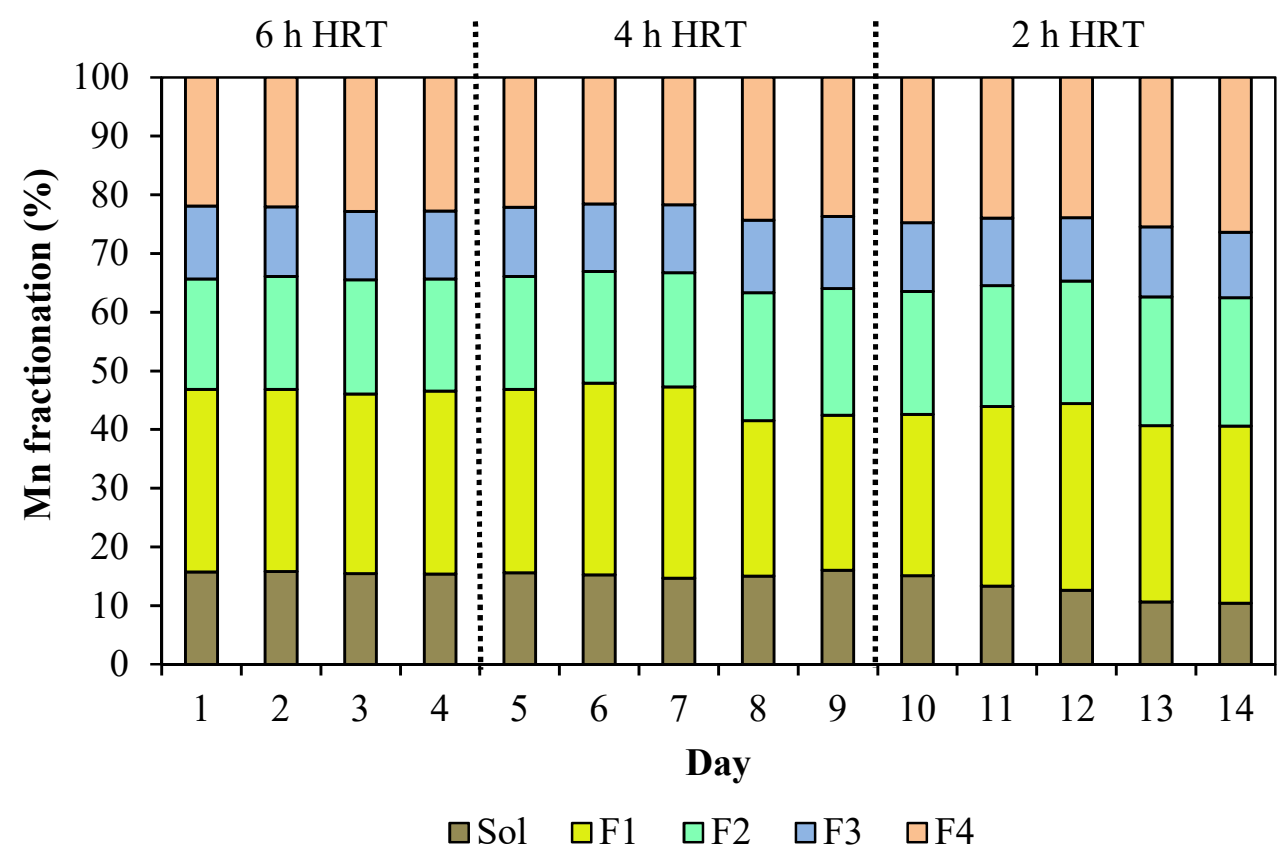

Molybdenum (Mo)

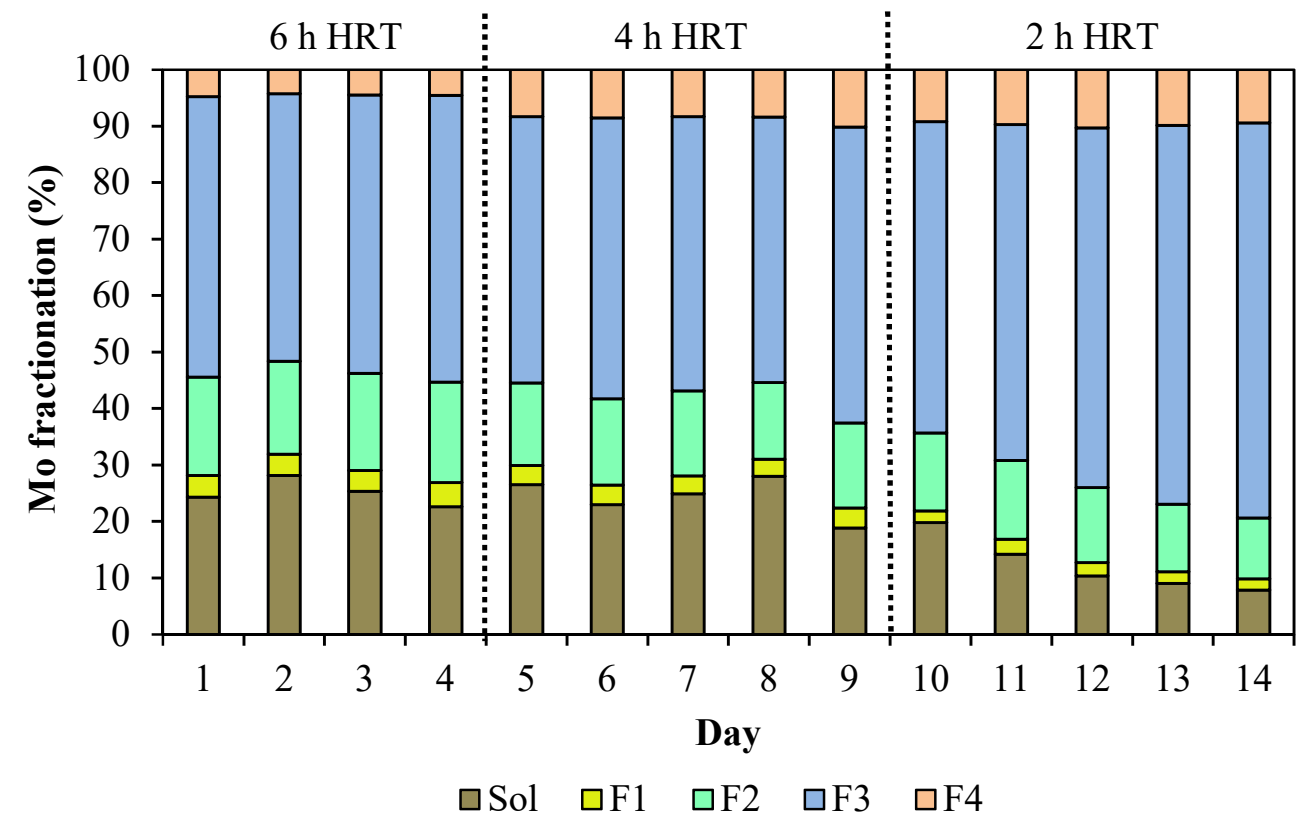

Sol - Soluble, F1 - Exchangeable, F2 - Fe/Mn oxides,

F3 - Organic matter, F4 - Residual

Figure 8.10 Speciation of TMs in the SAMBR2 at different HRTs $(n=3)$. 
Chapter 8: Effect of operating conditions on speciation and bioavailability of trace metals in submerged anaerobic membrane bioreactors

The bioavailability of Fe slightly increased as the average F1 fraction increased from $10.3 \%$ at $6 \mathrm{~h}$ HRT to $14.8 \%$ at $4 \mathrm{~h}$ HRT $(\mathrm{p}=0.038)$ and remained constant at $13.8 \%$ at $2 \mathrm{~h} \mathrm{HRT}(\mathrm{p}=0.067)$. Similarly, the average of F2 fraction also increased from $52.6 \%$ at $6 \mathrm{~h} \mathrm{HRT} \mathrm{to} 57.3 \%$ at $4 \mathrm{~h}$ HRT (p $=$ $0.035)$, but did not change significantly at 2 h HRT i.e. $55.8 \%(\mathrm{p}=0.083)$. On the other hand, the average F3 fraction was relatively stable at different HRTs i.e. $10.7 \%, 10.9 \%$ and $10.5 \%(\mathrm{p}=0.183)$, whereas, the last fraction $\mathrm{F} 4$ was also at the same level at $6 \mathrm{~h}$ and $4 \mathrm{~h}$ HRT i.e. $21.6 \%$ and $21.7 \%(\mathrm{p}=0.104)$, respectively, but then it reduced to $19.8 \%$ at $2 \mathrm{~h}$ HRT $(\mathrm{p}=0.035)$.

The change in Co speciation was more significant, although the first fraction F1 was the same at different HRTs, i.e. $15.9 \%, 16.0 \%$, and $16.1 \%(\mathrm{p}=$ 0.152 ), the second fraction F2 increased considerably from $7.8 \%$ at $6 \mathrm{~h} \mathrm{HRT} \mathrm{to}$ $15.3 \%$ at $2 \mathrm{~h}$ HRT $(\mathrm{p}=0.021)$. On the other hand, the less bioavailable fractions, i.e. F3, reduced from $74.3 \%$ at $6 \mathrm{~h} \mathrm{HRT} \mathrm{to} 66.8 \%$ at $2 \mathrm{~h} \mathrm{HRT}$, and the residual F4 was not statistically different when the HRT was reduced i.e. $2.0 \%$ and $1.8 \%(\mathrm{p}=0.092)$.

Just like Co, Ni bioavailability improved significantly; the Ni content in the first and the last fractions F1 and F4 stayed relatively constant at around 30\% and $1.5 \%(\mathrm{p}=0.063$ and 0.085$)$, respectively. However, the F2 fraction increased significantly from $12.7 \%$ at $6 \mathrm{~h}$ HRT to $26.7 \%$ at $2 \mathrm{~h}$ HRT (p $=$ 0.013), whereas, the F3 fraction reduced significantly from $54.5 \%$ at $6 \mathrm{~h} \mathrm{HRT}$ to $41.5 \%$ at $2 \mathrm{~h} \mathrm{HRT} \mathrm{(p=0.021).}$

In contrast to the TMs above, the bioavailability of $\mathrm{Zn}$ reduced as the $\mathrm{Zn}$ content in the first two fractions (F1 and F2) both decreased when the HRT was reduced i.e. from $27.0 \%$ and $27.6 \%$ at $6 \mathrm{~h}$ HRT to $11.4 \%$ and $22.4 \%$ at $2 \mathrm{~h}$ HRT ( $p=0.024$ and 0.041$)$, respectively. In contrast, the F3 fraction increased significantly from $45.4 \%$ at $6 \mathrm{~h} \mathrm{HRT} \mathrm{to} 66.2 \%$ at $2 \mathrm{~h} \mathrm{HRT}(\mathrm{p}=0.034)$ and no $\mathrm{Zn}$ was found in the last fraction F4.

The results from the BCR extraction showed no significant change in the Mn speciation as all of Mn fractions remained the same at all HRTs i.e. 
Chapter 8: Effect of operating conditions on speciation and bioavailability of trace metals in submerged anaerobic membrane bioreactors

around $30 \%, 20 \%, 12 \%$, and $25 \%(\mathrm{p}=0.059,0.091,0.121$, and 0.072$)$ for the F1, F2, F3, and F4 fractions, respectively.

Similar to $\mathrm{Zn}$, the first two fractions (F1 and F2) of Mo both reduced from $3.9 \%$ and $17.0 \%$ at $6 \mathrm{~h}$ HRT to $2.2 \%$ and $12.8 \%$ at $2 \mathrm{~h}$ HRT $(\mathrm{p}=0.028$ and 0.031), respectively. In contrast, the last two fractions F3 and F4 increased significantly from $49.2 \%$ and $4.4 \%$ at 6 h HRT to $63.0 \%$ and $9.7 \%$ at $2 \mathrm{~h} \mathrm{HRT}$ $(\mathrm{p}=0.013$ and 0.041$)$, respectively.

Analysis of TM speciation in the cake layer collected at the end of the 2 $\mathrm{h}$ HRT run showed that the dominant fraction for TMs was still organic matter/sulfide fraction (F3), except for Fe which was present mainly in the FeMn oxides fraction (F2). Compared to the speciation of TMs in the biomass from the reactor at steady state (6 h HRT), the TMs in the cake layer were found at higher levels in the last two fractions F3 and F4 (Figure 8.11). The distribution, immobilization, and remobilization of metals depend on the sorption properties of the biofilms, determined by many factors including $\mathrm{pH}$, and in this case, change in $\mathrm{pH}$ due to lower HRT might have affected the interaction of TMs with the biofilm in the cake layer (Thanh et al., 2016). This result indicates that the biomass attached to the membrane surface contains significant amounts of TMs in poorly bioavailable forms. These fractions have very low mobilities, and hence they have a higher resistance to the dissolution of TMs under low HRTs. It was found that TMs in the form of metal oxides/precipitates were often the origin of inorganic fouling (Gkotsis et al., 2014), and they coupled with organic foulants to enhance the formation of cake layer on the membrane surface (Gao et al., 2011; Zhou et al., 2015). 


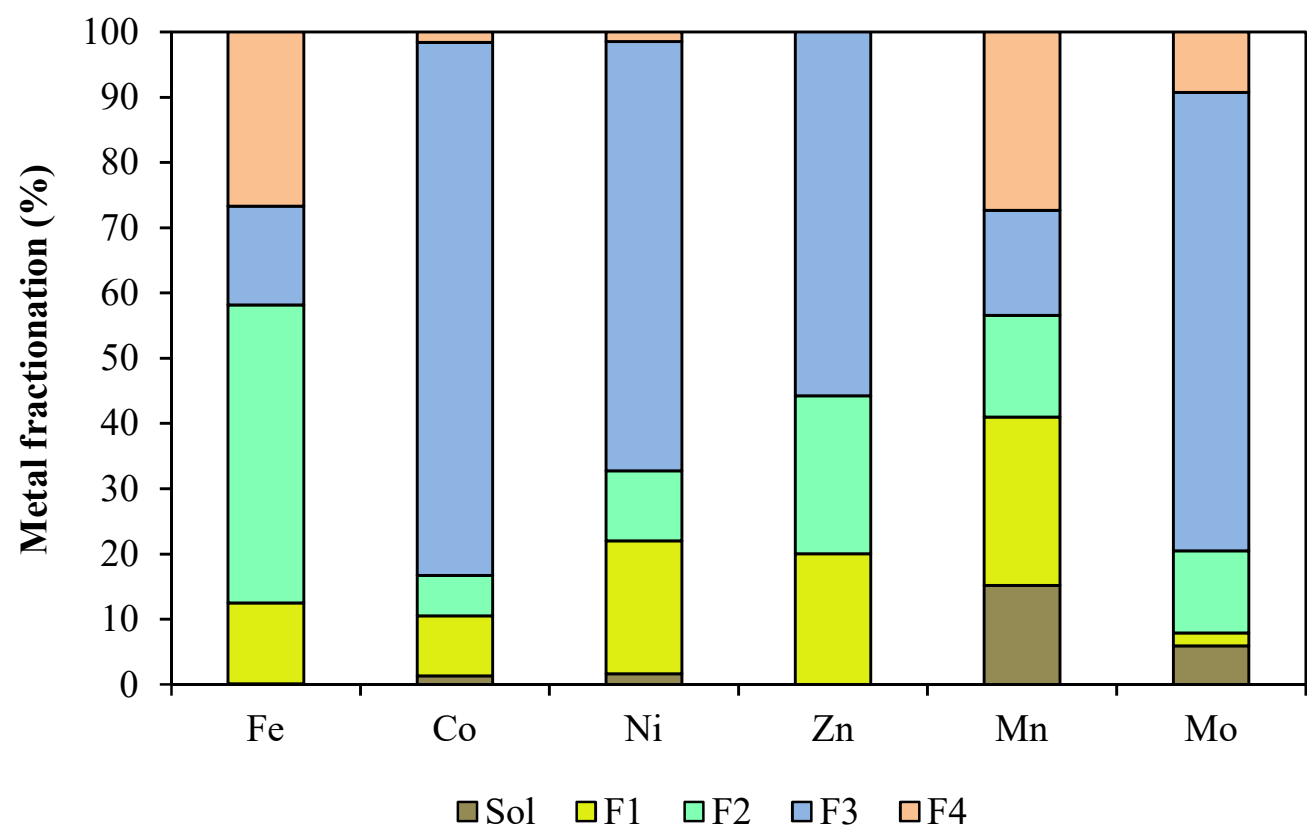

Sol - Soluble, F1 - Exchangeable, F2 - Fe/Mn oxides, F3 - Organic matter, F4 - Residual

Figure 8.11 Speciation of TMs in the cake layer of the SAMBR2 at the end of 2 h HRT experiment $(n=3)$.

In summary, the SAMBR was still able to achieve good treatment efficiencies when the HRT was reduced from $6 \mathrm{~h}$ to $2 \mathrm{~h}$. In terms of TM speciation, lowering the HRT resulted in the loss of TMs from the SAMBR, especially at $2 \mathrm{~h}$ HRT, although there was no significant increase in the soluble fraction. The speciation of $\mathrm{Fe}, \mathrm{Co}$, and $\mathrm{Ni}$ was shifted towards highly bioavailable fractions, whereas $\mathrm{Zn}, \mathrm{Mn}$, and Mo became less bioavailable at lower HRTs. Hence TM bioavailability changed in complex ways as the HRT decreased, and since $\mathrm{Fe}, \mathrm{Co}$ and $\mathrm{Ni}$ are essential for methanogens (Thanh et al., 2016), changes in their speciation may have had a positive impact on methanogenesis. 


\subsubsection{Changes in SRT}

\subsubsection{Performance of the SAMBR under different SRTs}

Figure 8.12 showed that the average effluent COD at different SRTs was fairly constant at around $13 \mathrm{mg} / \mathrm{L}$, and the COD removal was always more than $97 \%$. The average COD in the reactor was $76.3 \mathrm{mg} / \mathrm{L}$ at the "steady state" SRT of $100 \mathrm{~d}$, but reduced to $68.6 \mathrm{mg} / \mathrm{L}$ at $75 \mathrm{~d}$ SRT and $62.5 \mathrm{mg} / \mathrm{L}$ at $50 \mathrm{~d}$ SRT $(\mathrm{p}<$ $0.05)$, and then $53.5 \mathrm{mg} / \mathrm{L}$ at $25 \mathrm{~d} \mathrm{SRT}(\mathrm{p}<0.05)$.

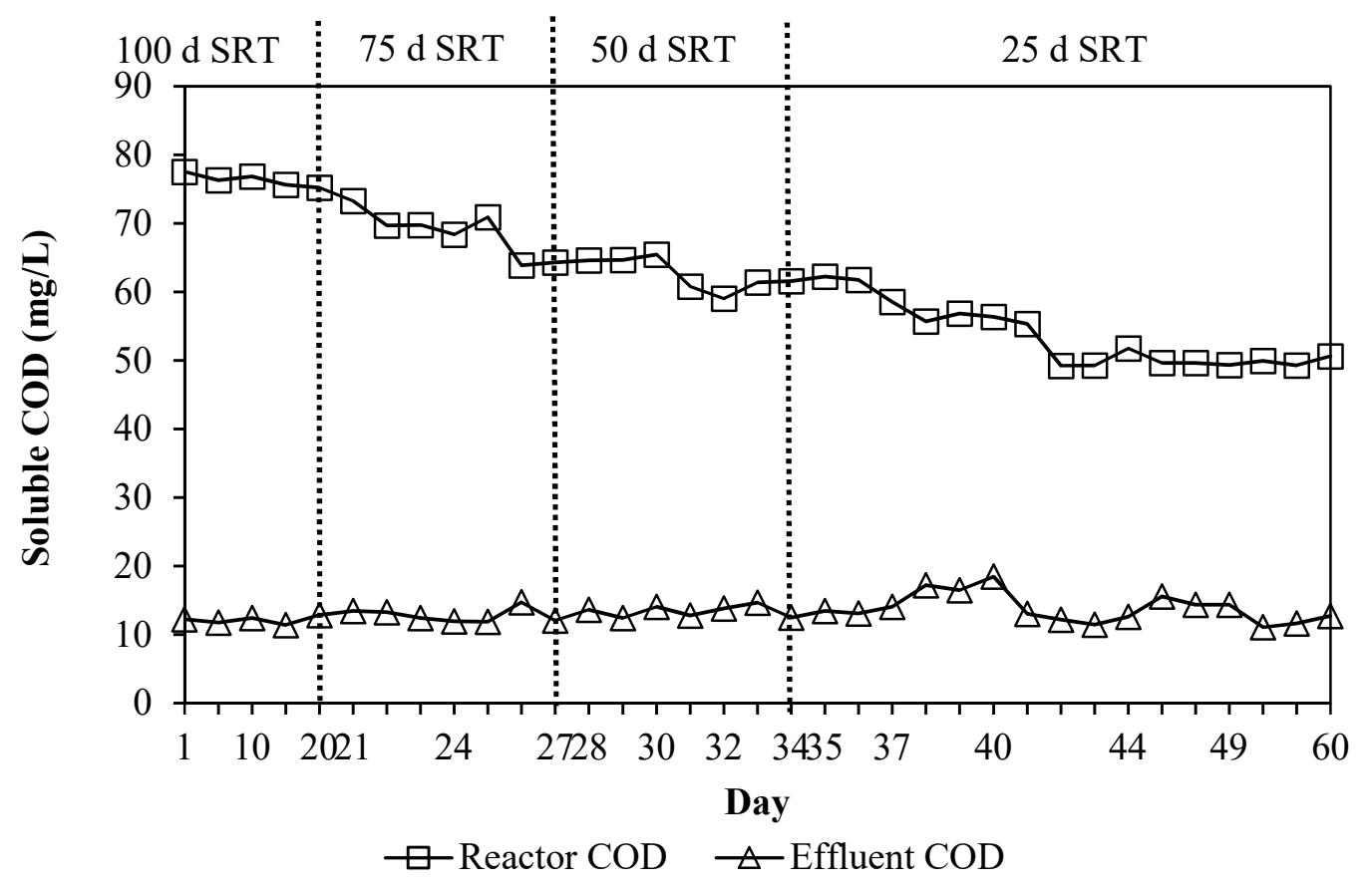

Figure 8.12 Soluble COD in the SAMBR3 reactor and effluent at different

$$
\text { SRTs }(n=3) \text {. }
$$

It is known that a long SRT will result in an accumulation of inactive biomass which does not contribute to the degradation of the substrate. On the other hand, at low SRTs microorganisms will be lost from the reactor. A rule of thumb for the design of anaerobic digestion systems is that the SRT should be at least twice the generation time of the methanogens (Dohányos \& Zábranská, 2001). In this study, although a significant amount of biomass was removed 
daily within 27 days (day 34 to day 60), $25 \mathrm{~d}$ was still above the minimum SRT (10 d) (Weimer, 1998). The maximum substrate utilization rate was calculated using the following equation:

$K_{\max }=\frac{-\mu_{\max } X}{Y}$

Where:

$\mathrm{K}_{\max }$ is the maximum substrate utilization rate (gCOD/L.d)

$\mu_{\max }$ is the maximum specific growth rate $(0.27 / \mathrm{d})$ (Wong et al., 2014)

$\mathrm{X}$ is the biomass concentration ( $5.95 \mathrm{gVSS} / \mathrm{d}$ at $25 \mathrm{~d}$ HRT)

$\mathrm{Y}$ is the yield coefficient (0.357 gCOD/gVSS) (Wong et al., 2014)

The calculated $\mathrm{K}_{\max }$ value was $4.42 \mathrm{gCOD} / \mathrm{L} . \mathrm{d}$, which is more than double the substrate load in the influent i.e. 2 gCOD/L.d. In addition, the maximum OLR on the reactor is $0.75 \mathrm{gCOD} / \mathrm{gVSS}$.d, which is also much higher than the applied OLR at $25 \mathrm{~d}$ HRT. These calculations show that the amount of substrate loaded into the SAMBR at the lowest SRT, i.e. $25 \mathrm{~d}$ was still below its maximum capacity. As the SRT decreased, the growth rate of anaerobic microorganisms increased due to the increase in OLR, hence, there was still a sufficient amount of active microorganisms in the reactor to consume the same amount of substrate, and hence to maintain the high level of treatment efficiency.

Reducing the SRT resulted in a reduction in the average biogas production rate from $100.7 \mathrm{~mL} / \mathrm{gVSS} . \mathrm{d}$ at $100 \mathrm{~d}$ SRT to $81.3 \mathrm{~mL} / \mathrm{gVSS} . \mathrm{d}$ (p < 0.05). The methane yields were also found to reduce from $65.2 \mathrm{mLCH}_{4} / \mathrm{gVSS}$.d at $100 \mathrm{~d}$ SRT to $60.8 \mathrm{mLCH}_{4} / \mathrm{gVSS} \mathrm{d}$ at $75 \mathrm{~d}$ SRT and to $57.6 \mathrm{mLCH}_{4} / \mathrm{gVSS} \mathrm{d}$ at $50 \mathrm{~d}$ SRT $(\mathrm{p}<0.05)$, then finally to $56.6 \mathrm{mLCH}_{4} / \mathrm{gVSS} . \mathrm{d}$ at $25 \mathrm{~d}$ SRT $(\mathrm{p}<$ 0.05 ) (Figure 8.13). Therefore, the methane yields dropped by $13.3 \%$ when the SRT reduced from $100 \mathrm{~d}$ to $25 \mathrm{~d}$. This was possible due to the reduction in biomass content in the reactor, as reflected by the decrease in VSS values from 
Chapter 8: Effect of operating conditions on speciation and bioavailability of trace metals in submerged anaerobic membrane bioreactors

$9.3 \mathrm{~g} / \mathrm{L}$ at $100 \mathrm{~d}$ SRT to $6.8 \mathrm{~g} / \mathrm{L}$ at $25 \mathrm{~d} \mathrm{SRT}(\mathrm{p}<0.05)$. SRT is known to significantly affect the substrate-utilization rate (the utilization rate for acetate or dissolved hydrogen gas for methanogens) in an anaerobic MBR (AnMBR) since the endogenous decay term become less significant with decreasing SRT (Yeo \& Lee, 2013). At shorter SRT, the amount of substrate for hydrolyzing/fermenting bacteria could be higher than for methanogens, which could possibly result in a decrease in methane production rate.

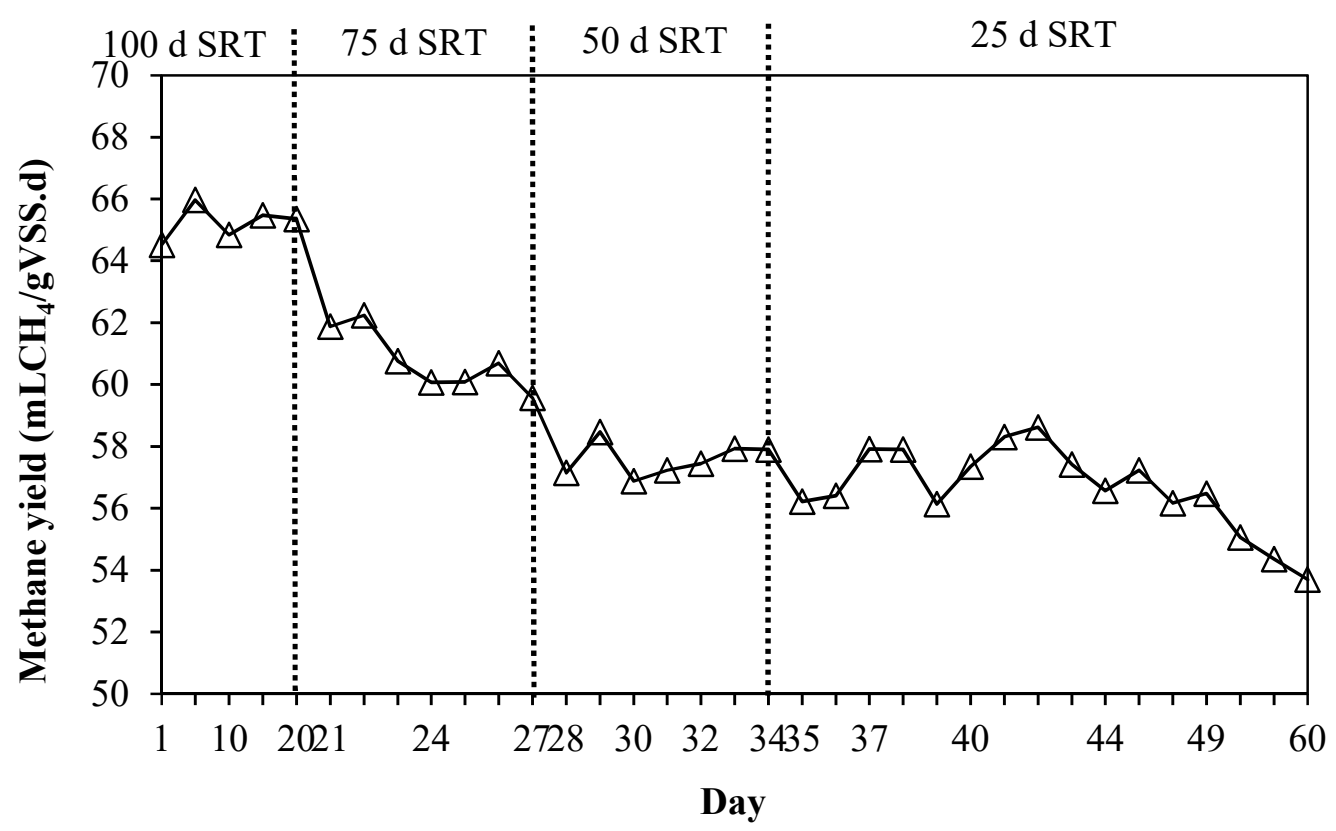

Figure 8.13 Methane yields in the SAMBR3 at different SRTs.

\subsubsection{Dynamic changes in trace metal speciation under different SRTs}

Total content of trace metals - The total content of TMs at all SRTs was found to be in the following order: $\mathrm{Fe}>\mathrm{Co}>\mathrm{Zn}>\mathrm{Ni}>\mathrm{Mo}>\mathrm{Mn}$ (Table 8.5). As the SRT was reduced, a greater amount of biomass was removed daily, and if the biomass removal rate is higher than the biomass growth rate, it will result in a decrease in biomass content in the SAMBR. With the same daily TM loading, as the SRT reduces it is expected that the total content of TMs in the SAMBR will also reduce due their adsorption onto the solids; hence, the TM 
Chapter 8: Effect of operating conditions on speciation and bioavailability of trace metals in submerged anaerobic membrane bioreactors

content will be depleted. The depletion rate was different for each TM and was in the following order: $\mathrm{Fe}>\mathrm{Ni}>\mathrm{Co}>\mathrm{Zn}>\mathrm{Mn}>$ Mo (Table 8.5). This difference could be attributed to the level of accumulation and affinity of a TM for the biomass in the SAMBR, as discussed in the above experiments. Among the TMs, the depletion rate was the highest for Fe, i.e. $32.3 \%$ and the lowest for Mn i.e. $0.2 \%$ when the SRT was reduced to $25 \mathrm{~d}$.

Table 8.3 Total content ( $\mu \mathrm{g} / \mathrm{gTSS})$ of TMs as an average of samples collected at each SRT and leaching rate ( $\mu \mathrm{g} / \mathrm{gTSS} . \mathrm{d})$ of TMs determined from total content ( $\mu \mathrm{g} / \mathrm{gTSS})$ at the beginning and the end of each SRT in the SAMBR3.

\begin{tabular}{cccccccccc}
\hline & \multicolumn{9}{c}{ SRT (day) } \\
\cline { 2 - 9 } Metal & \multicolumn{2}{c}{$\mathbf{1 0 0}$} & \multicolumn{2}{c}{$\mathbf{7 5}$} & $\mathbf{5 0}$ & \multicolumn{2}{c}{$\mathbf{2 5}$} \\
\cline { 2 - 9 } & $\begin{array}{c}\text { Metal } \\
\text { content } \\
(\mu \mathrm{g} / \mathrm{g})\end{array}$ & $\begin{array}{c}\text { Metal } \\
\text { leaching } \\
\text { rate } \\
(\mu \mathrm{g} / \mathrm{g} . \mathrm{d})\end{array}$ & $\begin{array}{c}\text { Metal } \\
\text { content } \\
(\mu \mathrm{g} / \mathrm{g})\end{array}$ & $\begin{array}{c}\text { Metal } \\
\text { leaching } \\
\text { rate } \\
(\mu \mathrm{g} / \mathrm{g} . \mathrm{d})\end{array}$ & $\begin{array}{c}\text { Metal } \\
\text { content } \\
(\mu \mathrm{g} / \mathrm{g})\end{array}$ & $\begin{array}{c}\text { Metal } \\
\text { leaching } \\
\text { rate } \\
(\mu \mathrm{g} / \mathrm{g} . \mathrm{d})\end{array}$ & $\begin{array}{c}\text { Metal } \\
\text { content } \\
(\mu \mathrm{g} / \mathrm{g})\end{array}$ & $\begin{array}{c}\text { Metal } \\
\text { leaching } \\
\text { rate } \\
(\mu \mathrm{g} / \mathrm{g} . \mathrm{d})\end{array}$ \\
\hline $\mathbf{F e}$ & 7048.2 & 28.8 & 6652.7 & 56.5 & 6298.9 & 50.5 & 5491.1 & 32.3 \\
\hline $\mathbf{C o}$ & 1124.3 & 0.7 & 1088.3 & 5.1 & 1031.8 & 8.1 & 1018.5 & 0.5 \\
\hline $\mathbf{N i}$ & 873.5 & 1.8 & 824.1 & 7.1 & 772.2 & 7.4 & 640.3 & 5.3 \\
\hline Zn & 911.6 & 0.1 & 892.1 & 2.8 & 887.1 & 0.7 & 832.8 & 2.2 \\
\hline Mn & 139.4 & 0.0 & 134.0 & 0.8 & 125.6 & 1.2 & 120.5 & 0.2 \\
\hline Mo & 194.5 & -0.7 & 192.5 & 0.3 & 186.2 & 0.9 & 174.8 & 0.5 \\
\hline
\end{tabular}

Speciation of trace metals - The measurement of TMs in each fraction using BCR extraction is given in Table A.5 (Appendix), and the speciation of TMs at different SRTs is shown in Figure 8.14. In the liquid phase, similar to the previous experiments on $\mathrm{pH}$ and HRT, very low levels of TMs were present in the soluble fraction, i.e. up to $2.2 \%$, except for $\mathrm{Mn}$ and Mo which 
Chapter 8: Effect of operating conditions on speciation and bioavailability of trace metals in submerged anaerobic membrane bioreactors

were up to $14.7 \%$. This fraction showed a decreasing trend as the SRT reduced to $25 \mathrm{~d}$ for all TMs.

\section{$\underline{\operatorname{Iron}(\mathbf{F e})}$}

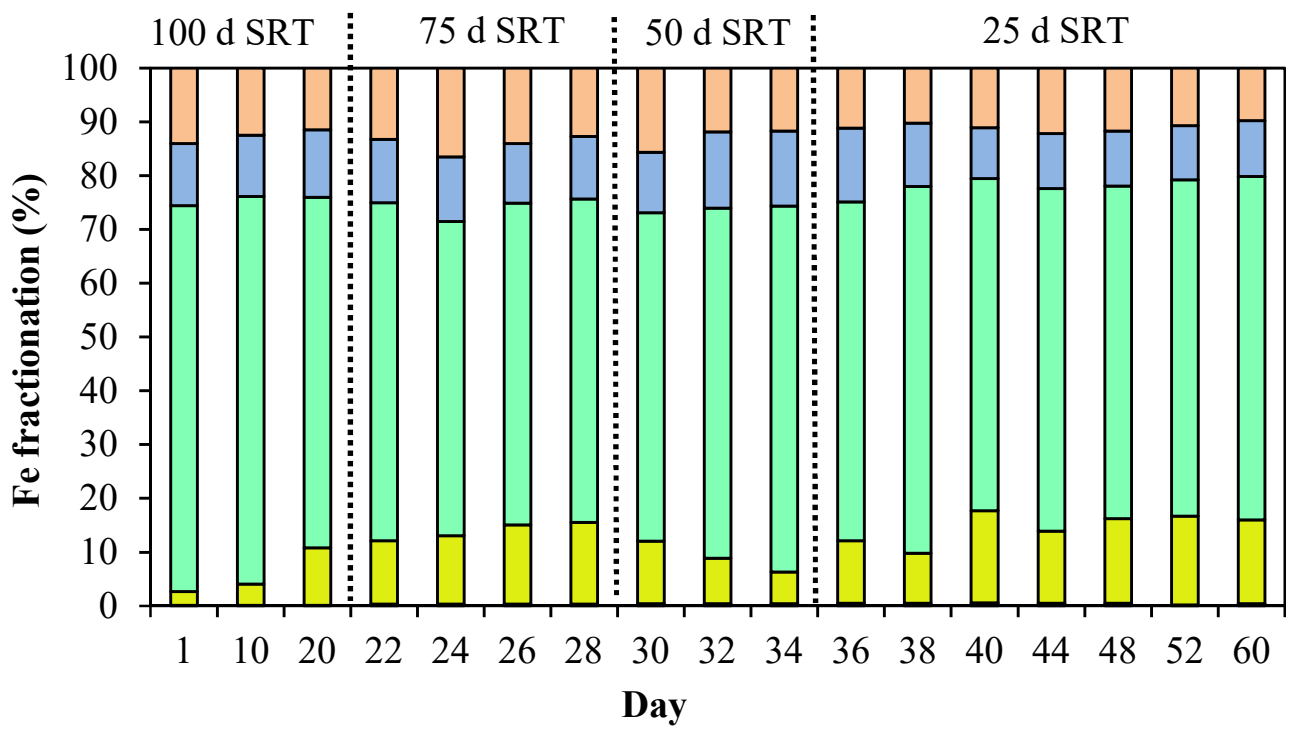

$\square$ Sol $\quad \square \mathrm{F} 1 \quad \square \mathrm{F} 2 \quad \square \mathrm{F} 3 \quad \square \mathrm{F} 4$

\section{Cobalt (Co)}

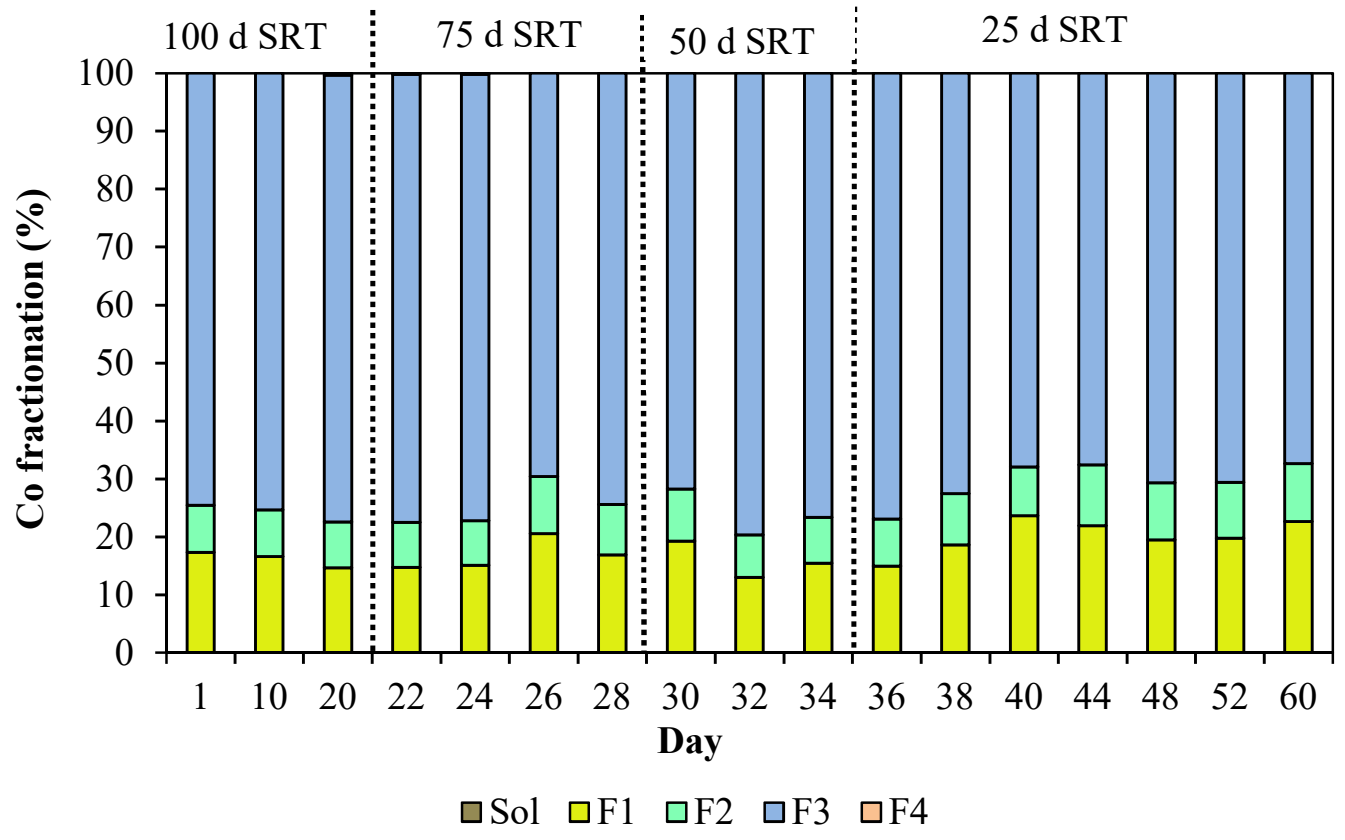


Chapter 8: Effect of operating conditions on speciation and bioavailability of trace metals in submerged anaerobic membrane bioreactors

$\underline{\text { Nickel (Ni) }}$

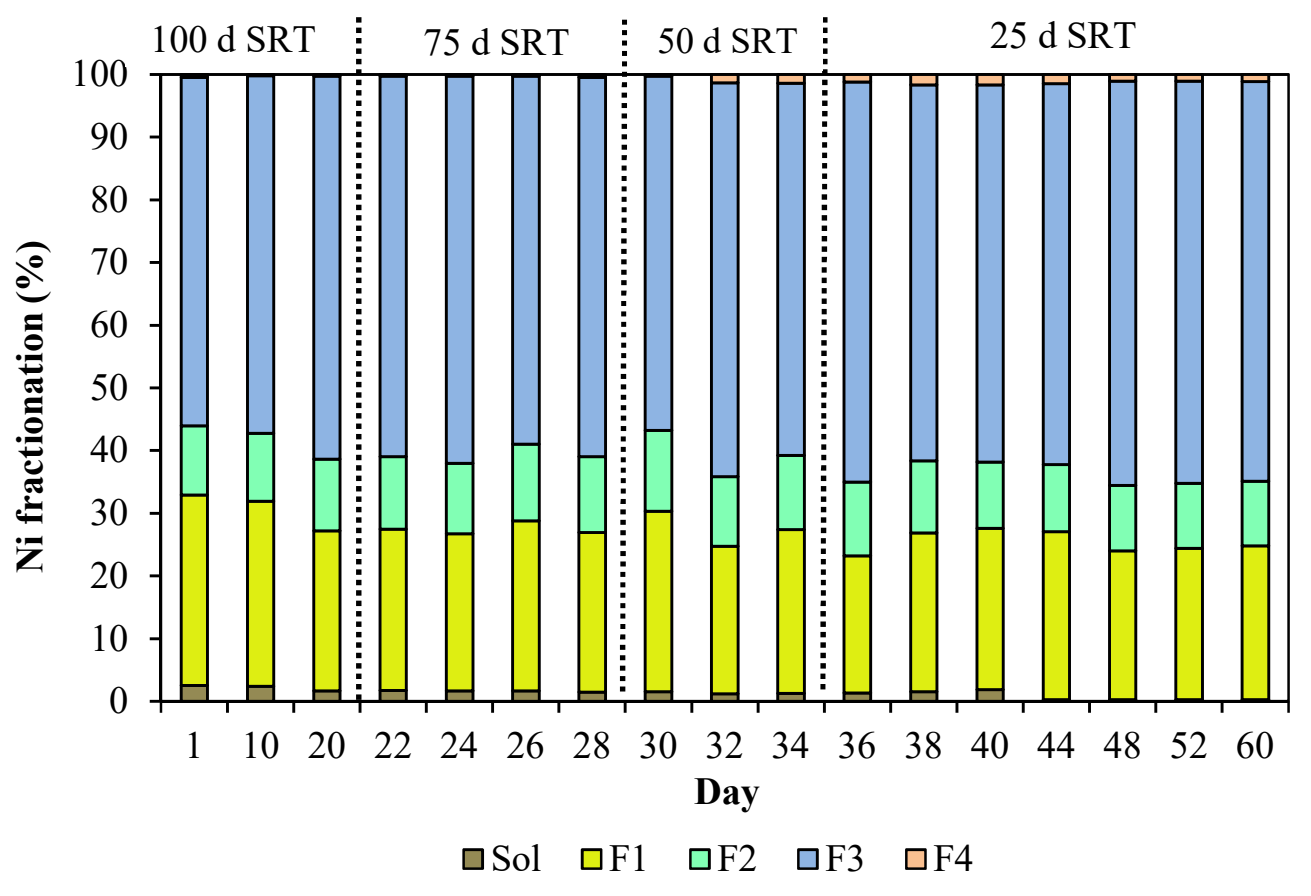

$\underline{\text { Zinc (Zn) }}$

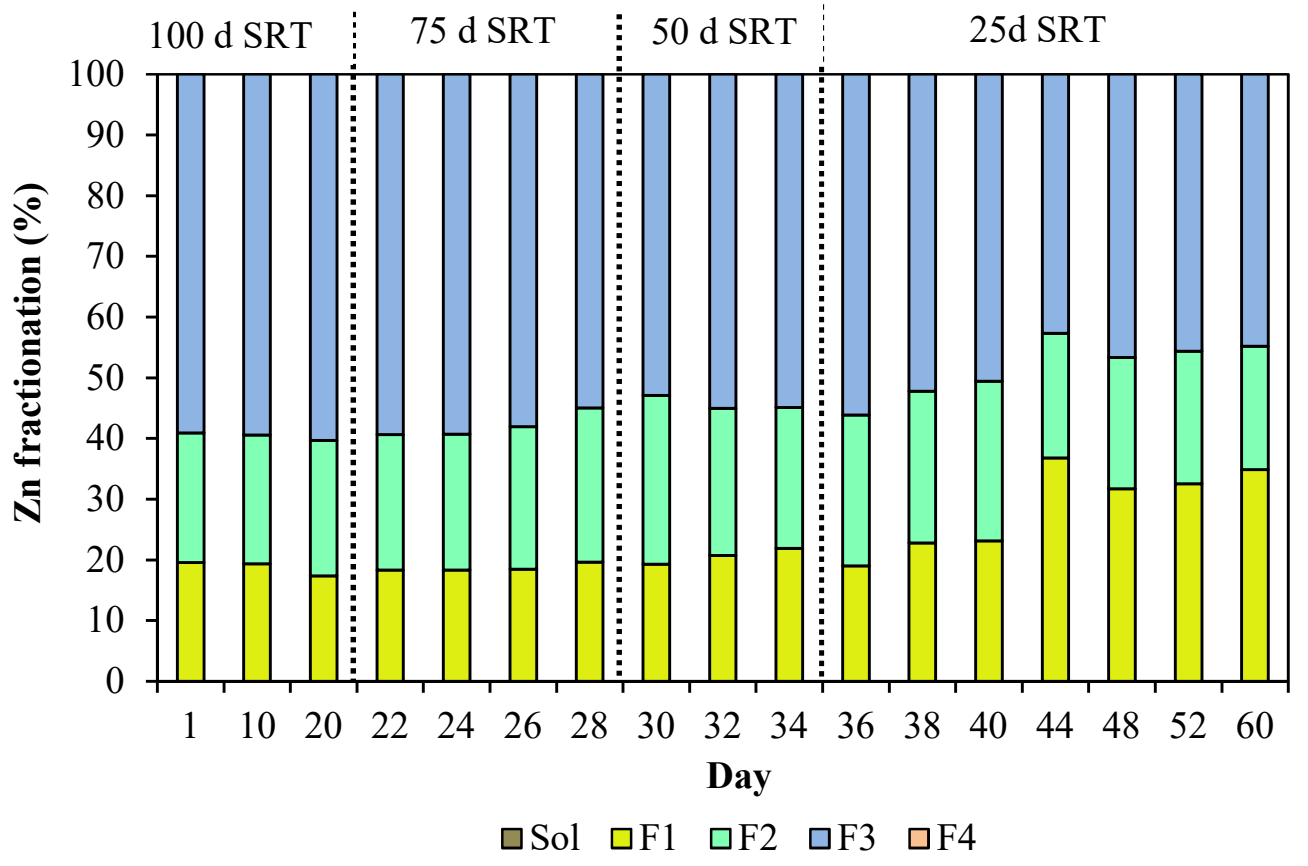


Chapter 8: Effect of operating conditions on speciation and bioavailability of trace metals in submerged anaerobic membrane bioreactors

Manganese (Mn)

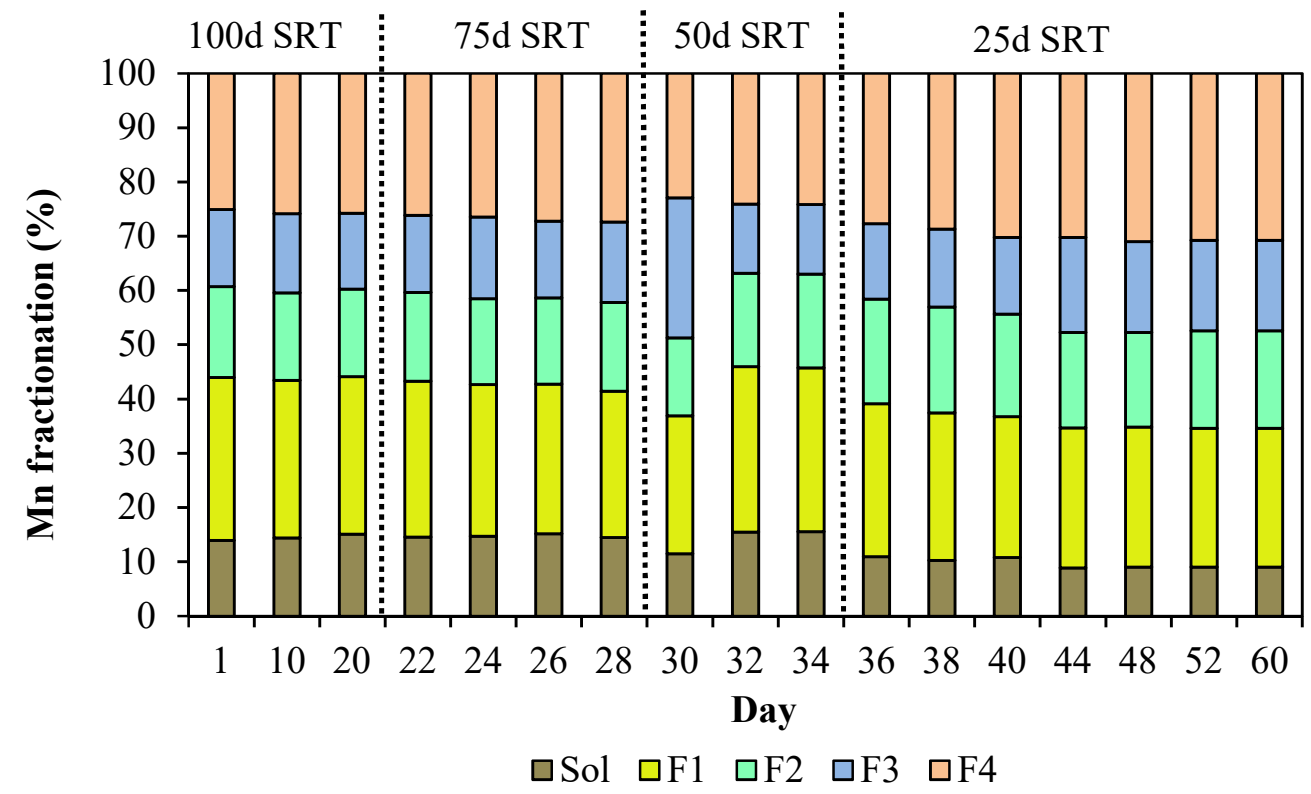

Molybdenum (Mo)

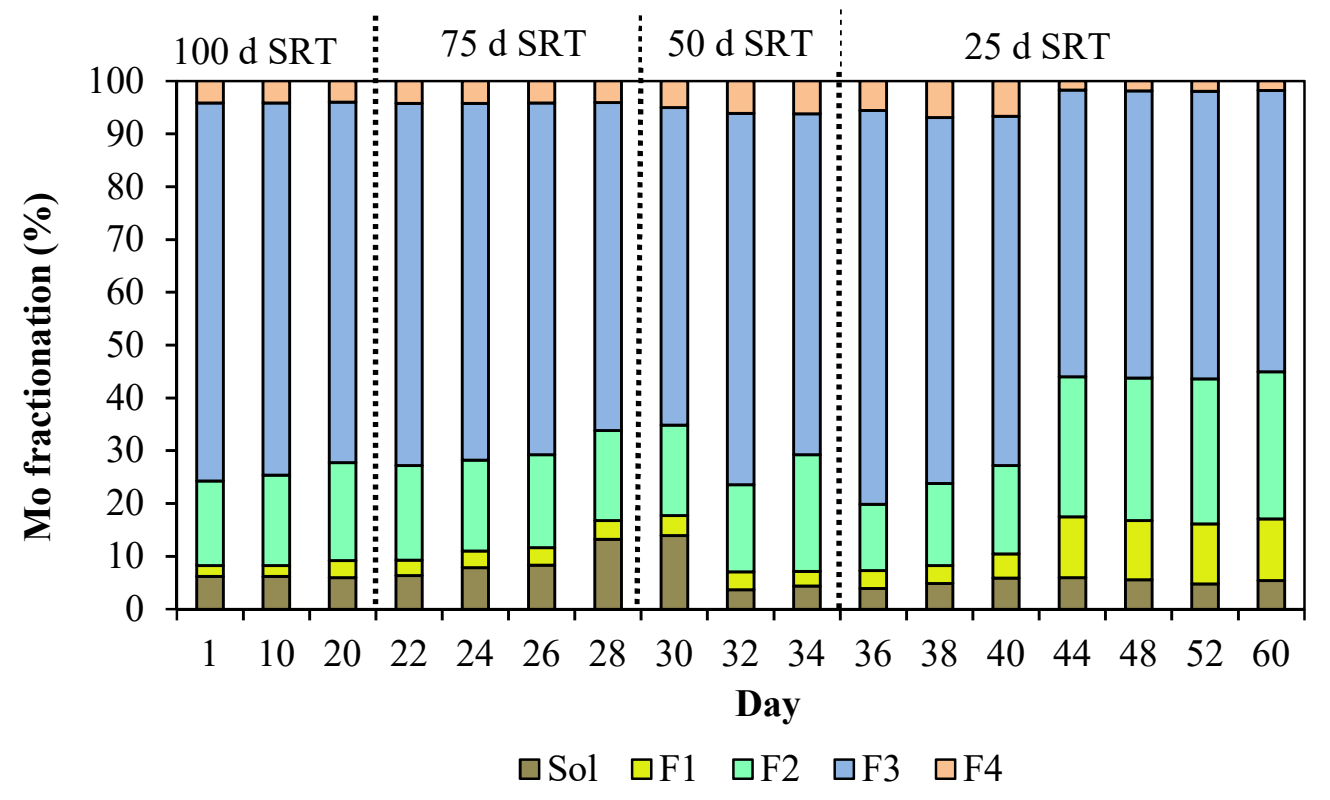

Sol - Soluble, F1 - Exchangeable, F2 - Fe/Mn oxides, F3 - Organic matter, F4 - Residual

Figure 8.14 Soluble COD in the SAMBR3 reactor and effluent at different SRTs $(n=3)$. 
Chapter 8: Effect of operating conditions on speciation and bioavailability of trace metals in submerged anaerobic membrane bioreactors

In the solid phase, generally the dominant fraction for most of the TMs was still organic matter/sulfide, except for $\mathrm{Fe}$ as up to $69.7 \%$ was found in the Fe-Mn oxides fraction, which was the same as the above experiments. The first fraction (Exchangeable F1), the second most bioavailable fraction, was found to increase significantly $(\mathrm{p}<0.05)$ for all TMs, i.e. up to around $10 \%(\mathrm{Zn})$, except for $\mathrm{Ni}$ and $\mathrm{Mn}$. The second fraction Fe-Mn oxides (F2) was relatively stable during the changes in SRT $(\mathrm{p}>0.05)$, except for Fe which reduced from $69.7 \%$ to $63.6 \%(\mathrm{p}<0.05)$. In contrast to the first fraction, the level of TMs presented in the last two fractions with the lowest bioavailability, i.e. organic matter/sulfide and residual, reduced significantly $(\mathrm{p}<0.05)$, except for $\mathrm{Ni}$ and Mn.

Therefore, it can be concluded that the reduction in SRT from $100 \mathrm{~d}$ to $25 \mathrm{~d}$ reduced the total content of TMs due to the high removal of biomass. However, the speciation results showed that TMs were mobilized towards more bioavailable fractions, except for $\mathrm{Ni}$ and $\mathrm{Mn}$. These results could be used to explain the findings on the performance of the SAMBR as the TMs became more bioavailable to support the growth of anaerobic microorganisms which had to consume a higher substrate loading.

\subsection{Conclusions}

The results clearly showed the strong effect of low $\mathrm{pH}$, HRT, and SRT values on TM leaching/accumulation dynamics and speciation in SAMBRs. There were two similar trends when these operating parameters changed. Firstly, the total content in the SAMBRs of all TMs was reduced significantly. Secondly, their speciation tended to shift towards highly bioavailable fractions, i.e. Soluble and Exchangeable, except for Fe, Co, and $\mathrm{Zn}$ ( $\mathrm{pH}$ reduced from 7 to 6.5 to 6); except for $\mathrm{Zn}, \mathrm{Mn}$, and Mo (HRT reduced from $6 \mathrm{~h}$ to $4 \mathrm{~h}$ to $2 \mathrm{~h}$ ); and except for $\mathrm{Ni}$ and $\mathrm{Mn}$ (SRT reduced from $100 \mathrm{~d}$ to $25 \mathrm{~d}$ ). Knowing which metals are retained in the reactor or lost in the effluent, and whether their speciation is shifted towards higher or lower bioavailability under each applied 
Chapter 8: Effect of operating conditions on speciation and bioavailability of trace metals in submerged anaerobic membrane bioreactors

condition, a specific dosing strategy can be developed to make sure that there is a sufficient amount of TMs present in the bioavailable fraction in the SAMBR for microbial uptake. 


\section{Chapter 9}

\section{Conclusions and Future Work}

\section{Outline:}

9.1 Introduction

9.2 Concluding discussion

9.3 Conclusions

9.4 Recommendations for future work

\subsection{Introduction}

The extent to which this work has accomplished the initial objectives outlined in Section 2.11 is analyzed in this chapter. In addition, the importance of the findings, and the conclusions which can be drawn from this study, are presented. Finally, the areas of research that could be further explored, and the knowledge gaps that need to be investigated in more detail are highlighted in Future Work.

\subsection{Concluding discussion}

The main aims of this study were:

- to investigate the effect of $\mathrm{Fe}^{2+}$ supplementation on the degradation of accumulated VFAs during organic shock loads in the SAMBR;

- to understand the influence of the addition of biodegradable chelating agent EDDS, and determining its dosing strategy to improve the bioavailability of $\mathrm{Fe}^{2+}$ in the presence of sulfide in the SAMBR; 
- to observe the changes in $\mathrm{pH}, \mathrm{HRT}$, and SRT on the speciation of trace metals in the SAMBR; and, to investigate the pulse doing of trace metals to improve the performance of the SAMBR during trace metal deficiency.

Based on the experimental findings, the following points can be made:

\subsubsection{Iron deficiency and bioavailability in anaerobic batch and} submerged membrane bioreactors during organic shock loads

- When the batch reactors were subjected to a glucose spike of $1 \mathrm{gCOD} / \mathrm{L}$, a rapid accumulation of VFAs and a subsequent $\mathrm{pH}$ drop resulted in the mobilization of $\mathrm{Fe}^{2+}$ from their sulfide forms to "relatively bioavailable forms" such as soluble and organically bound Fe. With the $3 \mathrm{gCOD} / \mathrm{L}$ shock, $\mathrm{pH} 5$ in the reactor resulted in almost $9 \%$ of $\mathrm{Fe}^{2+}$ in the residual form leaching out to soluble and organically bound forms, although no external $\mathrm{Fe}^{2+}$ was dosed initially;

- With the $3 \mathrm{gCOD} / \mathrm{L}$ shock, kinetic differences and thermodynamic considerations resulted in an almost 15 -fold increase in total VFAs, irrespective of Fe supplementation. A lower rate of methane production in Fe deficient reactors signify the synergetic effects of Fe limitations with 3 $\mathrm{gCOD} / \mathrm{L}$. The competition for TMs amongst fermentative bacteria, acetogens and methanogens seemed to create temporary nutrient limitations, which retarded the degradation of acetate and propionate during shock loading;

- The addition of $10 \mathrm{mg} / \mathrm{L} \mathrm{Fe}^{2+}$ (equivalent to $3.34 \mathrm{mgFe}^{2+} / \mathrm{gTSS}$ ) was found to be the optimal concentration for $\mathrm{Fe}^{2+}$ to improve the kinetics of propionate to methane conversion. The inhibition of $\mathrm{Fe}^{2+}$ concentrations above $50 \mathrm{mg} / \mathrm{L}$ was attributable to the availability of $\mathrm{Fe}^{2+}$ in less mobile forms as they can also be bioavailable to microorganisms. Among the VFAs, the stimulatory effect of $\mathrm{Fe}^{2+}$ was statistically significant for the 
degradation of acetate, as the methane production rate increased by 2.1-3.9 fold within the first $60 \mathrm{~h}$ compared to the non-Fe supplemented reactors;

- The effects of $10 \mathrm{mg} / \mathrm{L} \mathrm{Fe} \mathrm{Fe}^{2+}$ (equivalent to $3.34 \mathrm{mgFe}^{2+} / \mathrm{gTSS}$ ) supplementation to a SAMBR were statistically significant in the case of the $1 \mathrm{gCOD}$ glucose shock compared to $2 \mathrm{gCOD}$ for the rapid removal of VFAs as almost $50 \%$ of the acetic acid was reduced in the first hour, and completely removed within $2 \mathrm{~h}$. Propionic acid was removed at slower rate as only $60 \%$ of the accumulated propionic acid was eliminated within in 2 h.

\subsubsection{Effect of Ethylenediamine-N,N'-disuccinic acid (EDDS) on the speciation and bioavailability of $\mathrm{Fe}^{2+}$ in the presence of sulfide}

- The BCR extraction method exhibits good recovery for most of the metals for both dried and wet samples i.e. $89.0 \%$ to $113.5 \%$. However, the extraction of metals from wet samples not only produced comparable results, but also better extraction efficiencies than a dried sample. The use of wet samples for metal extraction reduced the time required for sample preparation, and it also eliminated the possibility of artificial altering the metal speciation;

- At their optimal concentrations, macronutrients $\mathrm{Ca}$ and $\mathrm{Mg}$ exhibited the highest increase in methane production rate i.e. $64.8 \mathrm{mLCH}_{4} / \mathrm{d}$, whereas trace metals $\mathrm{Fe}, \mathrm{Co}$, and $\mathrm{Ni}$ came second with up to $41.7 \mathrm{mLCH}_{4} / \mathrm{d}$, and the methane production rate was the lowest for $\mathrm{Cu}, \mathrm{Zn}$, and $\mathrm{Mn}$ i.e. 38.3 $\mathrm{mLCH}_{4} / \mathrm{d}$;

- In a model media (no biomass), in the presence of $8 \mathrm{mg} / \mathrm{L}$ sulfide, the remaining soluble concentration of $10 \mathrm{mg} / \mathrm{L} \mathrm{Fe}{ }^{2+}$ (equivalent to 3.34 $\mathrm{mgFe} \mathrm{FiSS}^{2+}$ ) was reduced to zero within the first 2 hours as the $\mathrm{Fe}^{2+}$ was precipitated as FeS. When EDDS was added at 1:1 molar ratio to $\mathrm{Fe}^{2+}$, the soluble $\mathrm{Fe}^{2+}$ concentration increased to $3.32 \mathrm{mg} / \mathrm{L}$ (33.6\% increase). With biomass, there was no significant difference in methane yields when the 
same amount of sulfide was added. However, in the presence of EDDS at 1:1 molar ratio to $\mathrm{Fe}^{2+}$, the methane yields increased by $13.3 \%$ and the methane production rate also increased by $11.2 \%$. The speciation of $\mathrm{Fe}^{2+}$ was shifted towards higher bioavailable fractions, which indicates that EDDS was able to complex with the $\mathrm{Fe}^{2+}$ and preventing it from precipitating with sulfide;

- Determining the concentration of free EDDS and Fe-EDDS complex using HPLC was able to confirm the increase in soluble concentration of $\mathrm{Fe}^{2+}$ as high amount of Fe-EDDS complex was present in the solution, which was then bioavailable for microbial uptake.

\subsubsection{Dosing of Ethylenediamine-N,N'-disuccinic acid (EDDS) to improve} the bioavailability of $\mathrm{Fe}^{2+}$ in the presence of sulfide in a submerged anaerobic membrane bioreactor

- In the presence of sulfide, the dosing of EDDS as a complex with $\mathrm{Fe}^{2+}$ resulted in greater improvement in the bioavailability of $\mathrm{Fe}^{2+}$ than when it was supplemented simultaneously with $\mathrm{Fe}^{2+}$ as it prevented the precipitation of $\mathrm{Fe}^{2+}$ with sulfide. As the result, the methane yields and production rate from the Fe-EDDS increased significantly by $17.3 \%$ and $9.9 \%$, respectively. It also effectively removed the hydrogen produced by substrate degradation by the fermentative bacteria;

- The addition of EDDS as a metal complex (Fe-EDDS) or simultaneously (Fe+EDDS) both increased the soluble $\mathrm{Fe}$ fraction to $9.0 \%$ and $7.2 \%$, respectively. However, the Fe-EDDS addition resulted in a better retention of $\mathrm{Fe}^{2+}$ in the highly bioavailable forms (soluble and exchangeable) than Fe+EDDS;

- The measurement of free EDDS and Fe-EDDS complex by UHPLC showed that these two EDDS forms in the Fe-EDDS set were statistically higher than those in the Fe+EDDS set, i.e. $4.8 \%$ and $36.5 \%$ compared to $4.0 \%$ and $33.6 \%$, respectively; 
- There was a significant amount of trace metals, including $\mathrm{Fe}^{2+}$, accumulated in the seed sludge of the SAMBR prior to the experiment. These accumulated metals seemed to be sufficient to support the growth of anaerobic microorganisms as the reactor was still capable of achieving very high treatment efficiencies for $10 \mathrm{~d}$ when only $\mathrm{Fe}^{2+}$ was added to the feed;

- The presence of $8 \mathrm{mg} / \mathrm{L}$ of sulfide clearly reduced the solubility of $\mathrm{Fe}^{2+}$ as it had already precipitated the $\mathrm{Fe}^{2+}$ in the feed before entering the SAMBR, thereby reducing the level of soluble $\mathrm{Fe}^{2+}$ in the reactor for microbial uptake;

- The precipitation of $\mathrm{Fe}^{2+}$ as $\mathrm{FeS}$ resulted in a shift in $\mathrm{Fe}^{2+}$ speciation towards less bioavailable fractions, which in turn reduced the performance of the SAMBR as the average soluble COD inside the reactor and in the effluent increased to $64.8 \mathrm{mg} / \mathrm{L}$ and $17.2 \mathrm{mg} / \mathrm{L}$, respectively. The corresponding average COD removal reduced to $96.6 \%$, and the average daily methane yields were reduced by $14.6 \%$ to $49.8 \mathrm{mLCH}_{4} / \mathrm{gVSS}$.d;

- The dosing of EDDS as a metal complex to the SAMBR clearly helped to improve the performance of the SAMBR as the COD removal increased to $97.5 \%$, and the methane yields also increased to $54.5 \mathrm{mLCH}_{4} / \mathrm{gVSS}$.d;

- Measurements from UHPLC showed that when pre-complexed with EDDS, $86.2 \%$ of $\mathrm{Fe}$ was retained in solution as an Fe-EDDS complex. The speciation of $\mathrm{Fe}^{2+}$ in the SAMBR was then shifted towards more bioavailable fractions, i.e. Soluble and Exchangeable, showing that the addition of EDDS was able to improve the bioavailability of $\mathrm{Fe}^{2+}$ for microbial uptake.

\subsubsection{Trace metal deficiency and dosing strategies in a submerged anaerobic membrane bioreactor}

- When trace metals were excluded from the feed, significant accumulation of VFAs in the SAMBR was observed due to the kinetic differences 
between different groups of anaerobic bacteria which might have created temporary nutrient imbalances;

- Organic compounds such as soluble microbial products (SMPs) might have contributed to the increase in soluble COD in the reactor and the effluent as they were released by the bacteria to scavenge the available metal nutrients in solution;

- A continuous supply of trace metals to the SAMBR resulted in substantial metal accumulation in the following order: $\mathrm{Fe}>\mathrm{Zn}>\mathrm{Co}=\mathrm{Mn}>\mathrm{Mo}>\mathrm{Ni}$. Most of the trace metals accumulated in the low bioavailable form, i.e. Organic matter/sulfide, as they were better retained in the reactor as sulfide precipitates;

- During metal deficient conditions, the metal content in the reactor was reduced due to the leaching of metals in the following order: $\mathrm{Fe}>\mathrm{Co}>\mathrm{Zn}>$ $\mathrm{Ni}>\mathrm{Mo}>\mathrm{Mn}$. The distribution of metals was shifted from relatively bioavailable fractions, i.e. Soluble and Exchangeable, towards less bioavailable fractions i.e. Organic matter/sulfide and residual;

- A pulse of trace metals at the five-times daily loading into the SAMBR improved reactor performance temporarily within $9 \mathrm{~d}$ by removing the VFAs accumulated from the metal deficient period. The trace metals added were mobilized towards bioavailable fractions. Pulses of the ten-times daily loading did not result in any improvement in the reactor performance, and the bioavailability of trace metals, but also might have inhibited the methanogenic microorganisms.

\subsubsection{Effect of operating conditions on speciation and bioavailability of} trace metals in submerged anaerobic membrane bioreactors

- Low pHs of 6.5 and 6 reduced the SAMBR performance significantly as they seriously affected the methanogens. It took $12 \mathrm{~d}$ for the $\mathrm{pH}$ to return to neutral, but the COD removal increased only very slowly i.e. to $73.2 \%$ after $20 \mathrm{~d}$; 
- The reduction in $\mathrm{pH}$ resulted in an increase in soluble metal concentration and leaching of metals from the reactor in the following order: $\mathrm{Fe}>\mathrm{Ni}>$ $\mathrm{Co}>\mathrm{Zn}>\mathrm{Mn}>\mathrm{Mo}(\mathrm{pH}$ 6.5) and $\mathrm{Fe}>\mathrm{Zn}>\mathrm{Ni}>\mathrm{Co}>\mathrm{Mn}>\mathrm{Mo}(\mathrm{pH}$ 6). $\mathrm{Fe}$ and Ni underwent the most significant changes in each BCR fraction;

- On the other hand, changes in Co, Mn and Mo contents were less significant. The speciation of $\mathrm{Ni}, \mathrm{Mn}$, and Mo shifted towards bioavailable fractions, i.e. Soluble and Exchangeable, whereas, Fe and Co showed no patterns in their speciation, and $\mathrm{Zn}$ was found not to be sensitive to the $\mathrm{pH}$ changes;

- Higher organic loading rates (OLR) at low HRTs of $4 \mathrm{~h}$ and $2 \mathrm{~h}$ resulted in the rapid accumulation of VFAs, but the SAMBR was able to recover very quickly. However, higher methane yields were obtained due to the increase in biomass content in the reactor;

- High leaching rates of trace metals from the SAMBR occurred when the HRT was reduced in the following order: $\mathrm{Fe}>\mathrm{Ni}>\mathrm{Co}>\mathrm{Zn}>\mathrm{Mn}>\mathrm{Mo}$, due to the low $\mathrm{pH}$ effect which increased the solubility of trace metals. The speciation of $\mathrm{Fe}, \mathrm{Co}$, and $\mathrm{Ni}$ was shifted towards highly bioavailable fractions, whereas $\mathrm{Zn}, \mathrm{Mn}$, and Mo became less bioavailable at lower HRTs;

- A reduction in SRT from $100 \mathrm{~d}$ to $25 \mathrm{~d}$ did not affect the performance of the SAMBR as COD removal was still more than $97 \%$, although the methane yields were reduced by $13.3 \%$. This was possibly due to the reduction of substrate utilization rate for methanogens at shorter SRT;

- A reduction in SRT from $100 \mathrm{~d}$ to $25 \mathrm{~d}$ resulted in a higher biomass removal rate than biomass growth rate, which consequently reduced the biomass content in the SAMBR in the following order: $\mathrm{Fe}>\mathrm{Ni}>\mathrm{Co}>\mathrm{Zn}>$ Mn $>$ Mo. However, the speciation results showed that trace metals were mobilized towards more bioavailable fractions, except for $\mathrm{Ni}$ and $\mathrm{Mn}$. 


\subsection{Conclusions}

Based on the results obtained from this study, the following conclusions can be drawn:

1) The accumulation of trace metals in the seed sludge was very significant due to the prolong continuous supply of trace metals, hence, it needs to be taken into account for an effective metal dosing strategy;

2) Acetoclastic methanogens were more constrained by $\mathrm{Fe}^{2+}$ limitations compared to the other trophic groups. An organic shock resulted in leaching of $\mathrm{Fe}^{2+}$ from the residual to organically bound and soluble forms while the precipitation of $\mathrm{Fe}^{2+}$ as sulfide seemed to reduce its bioavailability to acetoclastic methanogens;

3) Supplementation of $10 \mathrm{mg} / \mathrm{L} \mathrm{Fe}^{2+}$ (equivalent to $3.34 \mathrm{mgFe}{ }^{2+} / \mathrm{gTSS}$ ) helped to reduce significantly and quickly the accumulation of VFAs during organic shocks ( 1 and 2 gCOD glucose spike) in the SAMBR;

4) The presence of $8 \mathrm{mg} / \mathrm{L}$ sulfide indirectly limited the growth of methanogens as it precipitated the $\mathrm{Fe}^{2+}$ hence reduced the $\mathrm{Fe}^{2+}$ bioavailability for microbial uptake;

5) Biodegradable chelating agent EDDS when dosed at 1:1 molar ratio to $\mathrm{Fe}^{2+}$ at $10 \mathrm{mg} / \mathrm{L}$ (equivalent to $3.34 \mathrm{mgFe}^{2+} / \mathrm{gTSS}$ ) was able to compete with sulfide at $8 \mathrm{mg} / \mathrm{L}$ and to keep the $\mathrm{Fe}^{2+}$ in a soluble form as Fe-EDDS complex, which was bioavailable for the microorganism, hence resulting in a higher methane yields;

6) When EDDS and $\mathrm{Fe}^{2+}$ were dosed at a 1:1 molar ratio $\left(10 \mathrm{mg} / \mathrm{L} \mathrm{Fe}^{2+}\right.$ or $0.22 \mathrm{mg} / \mathrm{gTSS} . \mathrm{d}$ ) as a metal complex into the SAMBR, the $\mathrm{Fe}^{2+}$ speciation was reversed to highly bioavailable fractions, and hence the SAMBR performance was improved as the both COD removal and methane yields increased;

7) The performance of the SAMBR was significantly affected by the reduction in $\mathrm{pH}$ (from 7 to 6.5 and 6) as the low $\mathrm{pHs}$ were out of favoured range for the methanogens and the reduction in HRT (from $6 \mathrm{~h}$ to $4 \mathrm{~h}$ and 2 
h) due to the hydraulic shock loads; however, the SAMBR was able to sustain a low SRT $25 \mathrm{~d}$ as the corresponding OLR was still below the maximum OLR of the SAMBR;

8) The degrees of accumulation and leaching of trace metals in the SAMBR at different operating conditions ( $\mathrm{pH}, \mathrm{HRT}$, and SRT) varied between metals as they depend on the sensitivity of the trace metals towards the changes and also their affinity to anaerobic sludge sites;

9) The reduction of $\mathrm{pH}$ resulted in a decrease in total metal content in the SAMBR, but an increase in the soluble fraction for all TMs. Trace metal speciation was shifted towards highly bioavailable fractions for $\mathrm{Ni}, \mathrm{Mn}$, and Mo;

10) Lowering the HRT also resulted in the loss of metals from the SAMBR, but no significant increase in the soluble fraction. The bioavailability of essential trace metals i.e. $\mathrm{Fe}, \mathrm{Co}, \mathrm{Ni}$ was improved as their speciation was shifted towards highly bioavailable fractions, and hence the changes in HRT in the short term may have had a positive impact on methanogenesis;

11) The high removal of biomass in the SAMBR at low SRT $25 \mathrm{~d}$ also reduced the metal content in the reactor, and trace metals became more bioavailable except for $\mathrm{Ni}$ and $\mathrm{Mn}$.

\subsection{Recommendations for future work}

Based on the findings of this research and issues raised during the conduct of this research, the following recommendations for future study are suggested:

1) Trace metals such as $\mathrm{Fe}, \mathrm{Ni}$, and $\mathrm{Co}$ have been studied extensively in the literature; however, other metals such as the macro-nutrients i.e. $\mathrm{Ca}$ and $\mathrm{Mg}$ and other trace metals i.e. $\mathrm{W}$ and Se are also essential to the optimal operation of anaerobic digestion. Hence, further research is required in order to determine the relationship between their speciation and bioavailability in anaerobic digestion. In addition, the effects of one trace 
metal on the speciation and bioavailability of another during coprecipitation and adsorption are also important to understand;

2) EDDS has shown that due to its superior biodegradability, it can be an excellent replacement for the conventional chelating agents EDTA and NTA to improve the bioavailability of Fe. However, the biodegradability of EDDS during anaerobic digestion needs to be carefully evaluated. The application of EDDS should also be extended to other trace metals i.e. Co and $\mathrm{Ni}$, although competition between different trace metals for complexation with EDDS needs to be investigated as it might reduce the influence of EDDS dosing on the improvement of anaerobic reactor performance. Other new generation biodegradable chelating agents with higher complexing ability such as Glutamic acid diacetic acid (GLDA) and Iminodisuccinic acid (IDS) could be investigated to compare with the results with EDDS;

3) Better characterization and quantification of natural chelating agents SMPs, and further development of the EPS extraction procedure should be carried out in order to determine how important their roles are in trace metal complexing and binding properties in anaerobic reactors;

4) Metal sulfides such as NiS have been shown to become a storage of and source for trace metals. To further understand which factors influence the bioavailability of metal sulfides inside the bioreactor, it is necessary to determine their speciation in terms of organic/inorganic sulfides, possible interaction with other metal sulfides, and the degree of crystallinity of the metal-sulfide precipitates using Extended X-ray absorption fine structure (EXAFS) and XRD (X-ray diffraction);

5) Methanogens including acetoclastic methanogens and hydrogenotrophic methanogens are thought to be the most sensitive microbial group in anaerobic digestion processes to changes in trace metal speciation and bioavailability. The use of microbial community analysis such as DNA extraction, pyrosequencing, and terminal restriction fragment length 
polymorphism (T-RFLP) fingerprint (Wintsche et al., 2016) to monitor the dynamics of bacterial and methanogenic communities will be useful to explain the changes in trace metal speciation and bioavailability on anaerobic trophic groups. Much greater insight, and more data, on the microbial ecophysiology of trace metals will be needed to support this goal;

6) It would be useful to harmonize sequential extraction schemes for data comparability, and the design of new and simple schemes based on the existing ones with shorter extraction times. Advanced techniques include XANES, DGT, and DMT need to be further developed and adapted to better classify metal speciation, and hence to predict metal bioavailability in anaerobic reactors. The use of analytical techniques with higher accuracy such as ICP-MS and optical microfiber sensor (Ji et al., 2016) to detect trace metals at ppb level will help to better observe the changes in metal concentration in the effluent from the reactor. 
Chapter 9: Conclusion and future work 


\section{Publications}

Chapter 2 Literature review

Thanh, P.M., Ketheesan, B., Yan, Z., Stuckey, D. 2016. Trace metal speciation and bioavailability in anaerobic digestion: A review. Biotechnology Advances 34, 122-136.

Chapter 4 Iron deficiency and bioavailability in anaerobic batch and submerged membrane bioreactors during organic shock loads

Ketheesan, B., Thanh, P.M., Stuckey, D.C. 2016. Iron deficiency and bioavailability in anaerobic batch and submerged membrane bioreactors (SAMBR) during organic shock loads. Bioresource Technology 211, 136-145.

Chapter 5 Effect of Ethylenediamine-N,N'-disuccinic acid (EDDS) on the speciation and bioavailability of $\mathrm{Fe}^{2+}$ in the presence of sulfide

Thanh, P.M., Ketheesan, B., Yan, Z., Stuckey, D. 2017. Effect of Ethylenediamine- $N, N^{\prime}$-disuccinic acid (EDDS) on the speciation and bioavailability of $\mathrm{Fe}^{2+}$ in the presence of sulfide in anaerobic digestion. Bioresource Technology 229, 169-179.

Chapter 6 Dosing of Ethylenediamine-N,N'-disuccinic acid (EDDS) to improve the bioavailability of $\mathrm{Fe}^{2+}$ in the presence of sulfide in a submerged anaerobic membrane bioreactor

Thanh, P.M., Ketheesan, B., Stuckey, D.C., Zhou, Y. 2017. Dosing of Ethylenediamine- $N, N^{\prime}$-disuccinic acid (EDDS) to improve the bioavailability of $\mathrm{Fe}^{2+}$ in the presence of sulfide in a submerged anaerobic membrane bioreactor. Chemical Engineering Journal 330, 175-182. 
Chapter 7 Effects of trace metal deficiency and supplementary on a submerged anaerobic membrane bioreactor

Thanh, P.M., Ketheesan, B., Stuckey, D.C., Zhou, Y. 2017. Effects of trace metal deficiency and supplementation on a submerged anaerobic membrane bioreactor. Bioresource Technology 241, 161-170.

Chapter 8 Effect of operating conditions on speciation and bioavailability of trace metals in submerged anaerobic membrane bioreactors

Thanh, P.M., Ketheesan, B., Zhou, Y., Stuckey, D.C. 2017. Effect of operating conditions on speciation and bioavailability of trace metals in submerged anaerobic membrane bioreactors. Bioresource Technology 243, 810-819. 


\section{References}

Akram, A., Stuckey, D.C. 2008. Flux and performance improvement in a submerged anaerobic membrane bioreactor (SAMBR) using powdered activated carbon (PAC). Process Biochemistry 43, 93-102.

Alonso, E., Villar, P., Santos, A., Aparicio, I. 2006. Fractionation of heavy metals in sludge from anaerobic wastewater stabilization ponds in southern Spain. Waste Management 26, 1270-1276.

Amir, S., Hafidi, M., Merlina, G., Revel, J.C. 2005. Sequential extraction of heavy metals during composting of sewage sludge. Chemosphere 59, 801-10.

APHA. 1992. Standard Methods for the Examination of Water and Wastewater. American Public Health Association, Washington D.C.

Aquino, S., Stuckey, D. 2007. Bioavailability and Toxicity of Metal Nutrients during Anaerobic Digestion. Journal of Environmental Engineering 133, 28-35.

Aquino, S., Stuckey, D. 2003. Production of Soluble Microbial Products (SMP) in Anaerobic Chemostats Under Nutrient Deficiency. Journal of Environmental Engineering 129, 1007-1014.

Aquino, S.F., Stuckey, D.C. 2004. Soluble microbial products formation in anaerobic chemostats in the presence of toxic compounds. Water Research 38, 255-266.

Artola, A., Balaguer, M.D., Rigola, M. 1997. Heavy metal binding to anaerobic sludge. Water Research 31, 997-1004.

Artola, A., Martin, M., Balaguer, M., Rigola, M. 2000. Isotherm Model Analysis for the Adsorption of Cd (II), Cu (II), Ni (II), and Zn (II) on Anaerobically Digested Sludge. Journal of Colloid and Interface Science 232, 64-70.

Banks, C.J., Zhang, Y., Jiang, Y., Heaven, S. 2012. Trace element requirements for stable food waste digestion at elevated ammonia concentrations. Bioresource Technology 104, 127-135.

Barber, W., Stuckey, D. 2000. Metal Bioavailability and Trivalent Chromium Removal in ABR. Journal of Environmental Engineering 126, 649-656.

Barker, D.J., Stuckey, D.C. 1999. A review of soluble microbial products (SMP) in wastewater treatment systems. Water Research 33, 3063-3082.

Bartacek, J., Fermoso, F., Baldó Urrutia, A., van Hullebusch, E., Lens, P.N.L. 2008a. Cobalt toxicity in anaerobic granular sludge: influence of chemical speciation. Journal of industrial microbiology \& biotechnology 35, 1465-1474.

Bartacek, J., Fermoso, F., Catena, A., Lens, P.N.L. 2010. Effect of sorption kinetics on nickel toxicity in methanogenic granular sludge. Journal of hazardous materials 180, 289-296.

Bartacek, J., Fermoso, F., Vergeldt, F., Gerkema, E., Maca, J., van As, H., Lens, P.N.L. 2012. The impact of metal transport processes on bioavailability of free and complex metal ions in methanogenic granular sludge. Water science and technology 65, 1875. 
Bartacek, J., Fermoso, F.G., Baldo-Urrutia, A.M., van Hullebusch, E.D., Lens, P.N. 2008b. Cobalt toxicity in anaerobic granular sludge: influence of chemical speciation. $J$ Ind Microbiol Biotechnol 35, 1465-74.

Basiliko, N., Yavitt, J. 2001. Influence of Ni, Co, Fe, and $\mathrm{Na}$ additions on methane production in Sphagnum-dominated Northern American peatlands.

Biogeochemistry 52, 133-153.

Beiyuan, J., Tsang, D.C.W., Ok, Y.S., Zhang, W., Yang, X., Baek, K., Li, X.-D. 2016. Integrating EDDS-enhanced washing with low-cost stabilization of metalcontaminated soil from an e-waste recycling site. Chemosphere 159, 426-432.

Bourven, I., Simon, S., Bhatia, D., van Hullebusch, E.D., Guibaud, G. 2015. Effect of various size exclusion chromatography (SEC) columns on the fingerprints of extracellular polymeric substances (EPS) extracted from biological sludge. Journal of the Taiwan Institute of Chemical Engineers 49, 148-155.

Buzier, R., Tusseau-Vuillemin, M.-H., Mouchel, J.-M. 2006. Evaluation of DGT as a metal speciation tool in wastewater. Science of The Total Environment 358, 277-285.

Callander, I.J., Barford, J.P. 1983a. Precipitation, chelation, and the availability of metals as nutrients in anaerobic digestion. I. Methodology. Biotechnology and Bioengineering 25, 1947-1957.

Callander, I.J., Barford, J.P. 1983b. Precipitation, chelation, and the availability of metals as nutrients in anaerobic digestion. II. Applications. Biotechnol Bioeng 25, 1959-72.

Carliell, C.M., Wheatley, A.D. 1997. Metal and phosphate speciation during anaerobic digestion of phosphorus rich sludge. Water Science and Technology 36, 191200.

Carliell Marquet, C.M. 2002. Measuring metal and phosphorus speciation in P-rich anaerobic digesters. Water science and technology 45, 305-312.

Cestonaro do Amaral, A., Kunz, A., Radis Steinmetz, R.L., Justi, K.C. 2014. Zinc and copper distribution in swine wastewater treated by anaerobic digestion. Journal of Environmental Management 141, 132-137.

Chasteen, T.G., Bentley, R. 2003. Biomethylation of selenium and tellurium: microorganisms and plants. Chem Rev 103, 1-25.

Chen, H., Zhang, Y.-Y., Zhong, K.-L., Guo, L.-W., Gu, J.-L., Bo, L., Zhang, M.-H., Li, J.-R. 2014a. Selective sampling and measurement of $\mathrm{Cr}$ (VI) in water with polyquaternary ammonium salt as a binding agent in diffusive gradients in thin-films technique. Journal of Hazardous Materials 271, 160-165.

Chen, J.L., Ortiz, R., Steele, T.W.J., Stuckey, D.C. 2014b. Toxicants inhibiting anaerobic digestion: A review. Biotechnology Advances 32, 1523-1534.

Chen, Y., Cheng, J.J., Creamer, K.S. 2008. Inhibition of anaerobic digestion process: A review. Bioresource Technology 99, 4044-4064.

Cho, Y.T., Young, J.C., Jordan, J.A., Moon, H.M. 2005. Factors affecting measurement of specific methanogenic activity. Water Science and Technology 52, 435-440. 
d'Abzac, P., Bordas, F., van Hullebusch, E., Lens, P.N.L., Guibaud, G. 2010. Effects of extraction procedures on metal binding properties of extracellular polymeric substances (EPS) from anaerobic granular sludges. Colloids and Surfaces B: Biointerfaces 80, 161-168.

Dąbrowska, L., Rosińska, A. 2012. Change of PCBs and forms of heavy metals in sewage sludge during thermophilic anaerobic digestion. Chemosphere 88, 168173.

de Bok, F.A.M., Plugge, C.M., Stams, A.J.M. 2004. Interspecies electron transfer in methanogenic propionate degrading consortia. Water Research 38, 1368-1375.

Demirel, B., Scherer, P. 2011. Trace element requirements of agricultural biogas digesters during biological conversion of renewable biomass to methane. Biomass and Bioenergy 35, 992-998.

Diekert, G., Konheiser, U., Piechulla, K., Thauer, R.K. 1981. Nickel requirement and factor F430 content of methanogenic bacteria. Journal of Bacteriology 148, 459-464.

Dohányos, M., Zábranská, J. 2001. Sludge into biosolids: processing, disposal, and utilization. IWA Publishing, London.

Dong, B., Liu, X., Dai, L., Dai, X. 2013. Changes of heavy metal speciation during high-solid anaerobic digestion of sewage sludge. Bioresource Technology 131, 152-158.

Dong, X., Plugge, C.M., Stams, A.J.M. 1994. Anaerobic Degradation of Propionate by a Mesophilic Acetogenic Bacterium in Coculture and Triculture with Different Methanogens. Applied and Environmental Microbiology 60, 2834-2838.

EPA. 1994. Method 3051 - Microwave Assisted Acid Digestion of Sediments, Sludges, Soils, and Oils. Washington, DC.

Espinosa, A., Rosas, L., Ilangovan, K., Noyola, A. 1995. Effect of trace metals on the anaerobic degradation of volatile fatty acids in molasses stillage. Water Science and Technology 32, 121-129.

Evranos, B., Demirel, B. 2014. The impact of Ni, Co and Mo supplementation on methane yield from anaerobic mono-digestion of maize silage. Environmental Technology 1-7.

Facchin, V., Cavinato, C., Pavan, P., Bolzonella, D. 2013. Batch and Continuous Mesophilic Anaerobic Digestion of Food Waste: Effect of Trace Elements Supplementation Chemical Engineering Transaction 32, 457-462.

Fermoso, F., Collins, G., Bartacek, J., Lens, P.N.L. 2008a. Zinc deprivation of methanol fed anaerobic granular sludge bioreactors. Journal of industrial microbiology \& biotechnology 35, 543-557.

Fermoso, F., Collins, G., Bartacek, J., Oflaherty, V., Lens, P. 2008b. Role of nickel in high rate methanol degradation in anaerobic granular sludge bioreactors. Biodegradation 19, 725-737.

Fermoso, F.G., Bartacek, J., Chung, L.C., Lens, P. 2008c. Supplementation of cobalt to UASB reactors by pulse dosing: $\mathrm{CoCl} 2$ versus CoEDTA2- pulses. Biochemical Engineering Journal 42, 111-119. 
Fermoso, F.G., Bartacek, J., Jansen, S., Lens, P.N.L. 2009. Metal supplementation to UASB bioreactors: from cell-metal interactions to full-scale application. Science of The Total Environment 407, 3652-3667.

Fermoso, F.G., Bartacek, J., Manzano, R., van Leeuwen, H.P., Lens, P.N.L. 2010. Dosing of anaerobic granular sludge bioreactors with cobalt: Impact of cobalt retention on methanogenic activity. Bioresource Technology 101, 9429-9437.

Fermoso, F.G., Collins, G., Bartacek, J., O’Flaherty, V., Lens, P. 2008d. Role of nickel in high rate methanol degradation in anaerobic granular sludge bioreactors. Biodegradation 19, 725-737.

Ferraro, A., van Hullebusch, E.D., Huguenot, D., Fabbricino, M., Esposito, G. 2015. Application of an electrochemical treatment for EDDS soil washing solution regeneration and reuse in a multi-step soil washing process: Case of a $\mathrm{Cu}$ contaminated soil. Journal of Environmental Management 163, 62-69.

Filgueiras, A.V., Lavilla, I., Bendicho, C. 2002. Chemical sequential extraction for metal partitioning in environmental solid samples. J Environ Monit 4, 823-57.

Florian, D., Barnes, R.M., Knapp, G. 1998. Comparison of microwave-assisted acid leaching techniques for the determination of heavy metals in sediments, soils, and sludges. Fresenius' Journal of Analytical Chemistry 362, 558-565.

Förstner, U. 1993. Metal Speciation - General Concepts and Applications. International Journal of Environmental Analytical Chemistry 51, 5-23.

Friedmann, H.C., Klein, A., Thauer, R.K. 1990. Structure and function of the nickel porphinoid, coenzyme F430 and of its enzyme, methyl coenzyme M reductase. FEMS Microbiol Rev 7, 339-48.

Fuentes, A., Lloréns, M., Sáez, J., Isabel Aguilar, M., Ortuño, J.F., Meseguer, V.F. 2008. Comparative study of six different sludges by sequential speciation of heavy metals. Bioresource Technology 99, 517-525.

Gao, W.J., Lin, H.J., Leung, K.T., Schraft, H., Liao, B.Q. 2011. Structure of cake layer in a submerged anaerobic membrane bioreactor. Journal of Membrane Science 374, 110-120.

Gkotsis, P., Banti, D., Peleka, E., Zouboulis, A., Samaras, P. 2014. Fouling Issues in Membrane Bioreactors (MBRs) for Wastewater Treatment: Major Mechanisms, Prevention and Control Strategies. Processes 2, 795.

Glass, J.B., Orphan, V.J. 2012. Trace Metal Requirements for Microbial Enzymes Involved in the Production and Consumption of Methane and Nitrous Oxide. Frontiers in Microbiology 3, 61 .

Gleyzes, C., Tellier, S., Astruc, M. 2002. Fractionation studies of trace elements in contaminated soils and sediments: a review of sequential extraction procedures. TrAC Trends in Analytical Chemistry 21, 451-467.

Gonzalez-Gil, G., Jansen, S., Zandvoort, M.H., van Leeuwen, H.P. 2003. Effect of yeast extract on speciation and bioavailability of nickel and cobalt in anaerobic bioreactors. Biotechnol Bioeng 82, 134-42.

Gonzalez-Gil, G., Kleerebezem, R., Lettinga, G. 1999. Effects of Nickel and Cobalt on Kinetics of Methanol Conversion by Methanogenic Sludge as Assessed by On- 
Line $\mathrm{CH}(4)$ Monitoring. Applied and Environmental Microbiology 65, 17891793.

Gonzalez-Gil, G., Lopes, S.I.C., Saikaly, P.E., Lens, P.N.L. 2012. Leaching and accumulation of trace elements in sulfate reducing granular sludge under concomitant thermophilic and low pH conditions. Bioresource Technology 126, 238-246.

Goodwin, J.A.S., Wase, D.A.J., Forster, C.F. 1990. Effects of nutrient limitation on the anaerobic upflow sludge blanket reactor. Enzyme and Microbial Technology 12, 877-884.

Grčman, H., Velikonja-Bolta, Š., Vodnik, D., Kos, B., Leštan, D. 2001. EDTA enhanced heavy metal phytoextraction: metal accumulation, leaching and toxicity. Plant and Soil 235, 105-114.

Guiot, S.R., Safi, B., Frigon, J.C., Mercier, P., Mulligan, C., Tremblay, R., Samson, R. 1995. Performances of a full-scale novel multiplate anaerobic reactor treating cheese whey effluent. Biotechnol Bioeng 45, 398-405.

Gustavsson, J., Shakeri Yekta, S., Sundberg, C., Karlsson, A., Ejlertsson, J., Skyllberg, U., Svensson, B.H. 2013a. Bioavailability of cobalt and nickel during anaerobic digestion of sulfur-rich stillage for biogas formation. Applied Energy 112, 473-477.

Gustavsson, J., Yekta, S.S., Karlsson, A., Skyllberg, U., Svensson, B.H. 2013 b. Potential bioavailability and chemical forms of $\mathrm{Co}$ and $\mathrm{Ni}$ in the biogas process-An evaluation based on sequential and acid volatile sulfide extractions. Engineering in Life Sciences 13, 572-579.

Hawari, A.H., Mulligan, C.N. 2006. Biosorption of lead(II), cadmium(II), copper(II) and nickel(II) by anaerobic granular biomass. Bioresource Technology 97, 692-700.

Hawkes, F.R., Rozzi, A., Black, K., Guwy, A., Hawkes, D.L. 1992. The Stability of Anaerobic Digesters Operating on a Food-Processing Wastewater. Water Science \& Technology 25, 73-82.

He, M.M., Tian, G.M., Liang, X.Q. 2009. Phytotoxicity and speciation of copper, zinc and lead during the aerobic composting of sewage sludge. J Hazard Mater 163, 671-7.

Hoban, D.J., Van Den Berg, L. 1979. Effect of Iron on Conversion of Acetic Acid to Methane During Methanogenic Fermentations. Journal of Applied Bacteriology 47, 153-159.

Hochheimer, A., Schmitz, R.A., Thauer, R.K., Hedderich, R. 1995. The tungsten formylmethanofuran dehydrogenase from Methanobacterium thermoautotrophicum contains sequence motifs characteristic for enzymes containing molybdopterin dinucleotide. Eur J Biochem 234, 910-20.

Hsu, J.H., Lo, S.L. 2001. Effect of composting on characterization and leaching of copper, manganese, and zinc from swine manure. Environ Pollut 114, 119-27. 
Hsu, L.-C., Liu, Y.-T., Tzou, Y.-M. 2015. Comparison of the spectroscopic speciation and chemical fractionation of chromium in contaminated paddy soils. Journal of Hazardous Materials 296, 230-238.

Hu, A. 2004. Submerged Anaerobic Membrane Bioreactor (SAMBR) for Wastewater Treatment. Ph.D thesis, Chemical Engineering Dept., Imperial College London.

Hu, A., Stuckey, D. 2006. Treatment of Dilute Wastewaters Using a Novel Submerged Anaerobic Membrane Bioreactor. Journal of Environmental Engineering 132:2, 190-198

Hu, Q.-H., Li, X.-F., Du, G.-C., Chen, J. 2008a. Effect of nitrilotriacetic acid on bioavailability of nickel during methane fermentation. Chemical Engineering Journal 143, 111-116.

Hu, Q.-H., Li, X.-F., Liu, H., Du, G.-C., Chen, J. 2008b. Enhancement of methane fermentation in the presence of $\mathrm{Ni} 2+$ chelators. Biochemical Engineering Journal 38, 98-104.

Hursthouse, A.S. 2001. The relevance of speciation in the remediation of soils and sediments contaminated by metallic elements--an overview and examples from Central Scotland, UK. J Environ Monit 3, 49-60.

Hussain, A., Dubey, S.K. 2015. Specific methanogenic activity test for anaerobic degradation of influents. Applied Water Science 1-8.

Ilangovan, K. 1993. Availability of micronutrients during anaerobic digestion of molasses stillage using an upflow anaerobic sludge blanket (UASB) reactor. Environmental technology 14, 795-799.

Jansen, S., Gonzalez-Gil, G., van Leeuwen, H.P. 2007. The impact of Co and Ni speciation on methanogenesis in sulfidic media-Biouptake versus metal dissolution. Enzyme and Microbial Technology 40, 823-830.

Jarrell, K.F., Kalmokoff, M.L. 1988. Nutritional requirements of the methanogenic archaebacteria. in: Canadian Journal of Microbiology, Vol. 34, NRC Research Press, pp. 557-576.

Jarvis, Å., Nordberg, Å., Jarlsvik, T., Mathisen, B., Svensson, B.H. 1997. Improvement of a grass-clover silage-fed biogas process by the addition of cobalt. Biomass and Bioenergy 12, 453-460.

Ji, W.B., Yap, S.H.K., Panwar, N., Zhang, L.L., Lin, B., Yong, K.T., Tjin, S.C., Ng, W.J., Majid, M.B.A. 2016. Detection of low-concentration heavy metal ions using optical microfiber sensor. Sensors and Actuators B: Chemical 237, 142149.

Jones, J.B., Stadtman, T.C. 1977. Methanococcus vannielii: culture and effects of selenium and tungsten on growth. Journal of Bacteriology 130, 1404-1406.

Jong, T., Parry, D.L. 2004. Heavy metal speciation in solid-phase materials from a bacterial sulfate reducing bioreactor using sequential extraction procedure combined with acid volatile sulfide analysis. Journal of Environmental Monitoring 6, 278-285. 
Ketheesan, B., Stuckey, D.C. 2015. Effects of Hydraulic/Organic Shock/Transient Loads in Anaerobic Wastewater Treatment: A Review. Critical Reviews in Environmental Science and Technology 45, 2693-2727.

Ketheesan, B., Thanh, P.M., Stuckey, D.C. 2016. Iron deficiency and bioavailability in anaerobic batch and submerged membrane bioreactors (SAMBR) during organic shock loads. Bioresource Technology 211, 136-145.

Kida, K., Shigematsu, T., Kijima, J., Numaguchi, M., Mochinaga, Y., Abe, N., Morimura, S. 2001. Influence of $\mathrm{Ni} 2+$ and $\mathrm{Co} 2+$ on methanogenic activity and the amounts of coenzymes involved in methanogenesis. J Biosci Bioeng 91, 590-5.

Kim, M., Ahn, Y.-H., Speece, R.E. 2002. Comparative process stability and efficiency of anaerobic digestion; mesophilic vs. thermophilic. Water Research 36, 43694385 .

Koesnandar, Nishio, N., Nagai, S. 1991. Effects of trace metal ions on the growth, homoacetogenesis and corrinoid production by Clostridium thermoaceticum. Journal of Fermentation and Bioengineering 71, 181-185.

Kos, B., Leštan, D. 2003. Induced Phytoextraction/Soil Washing of Lead Using Biodegradable Chelate and Permeable Barriers. Environmental Science \& Technology 37, 624-629.

Krzycki, J., Zeikus, J.G. 1980. Quantification of corrinoids in methanogenic bacteria. Current Microbiology 3, 243-245.

Kunacheva, C., Soh, Y.N.A., Trzcinski, A.P., Stuckey, D.C. 2017. Soluble microbial products (SMPs) in the effluent from a submerged anaerobic membrane bioreactor (SAMBR) under different HRTs and transient loading conditions. Chemical Engineering Journal 311, 72-81.

Kuo, W.-C., Parkin, G.F. 1996. Characterization of soluble microbial products from anaerobic treatment by molecular weight distribution and nickel-chelating properties. Water Research 30, 915-922.

Kuo, W.-C., Sneve, M.A., Parkin, G.F. 1996. Formation of Soluble Microbial Products during Anaerobic Treatment. Water Environment Research 68, 279-285.

Lake, D.L., Kirk, P.W.W., Lester, J.N. 1985. The effects of anaerobic digestion on heavy metal distribution in sewage sludge. Water Pollut. Control 84, 549-558.

Langenhoff, A.A.M., Brouwers-Ceiler, D.L., Engelberting, J.H.L., Quist, J.J., Wolkenfelt, J.G.P.N., Zehnder, A.J.B., Schraa, G. 1997. Microbial reduction of manganese coupled to toluene oxidation. FEMS Microbiology Ecology 22, 119-127.

Lasheen, M.R., Ammar, N.S. 2009. Assessment of metals speciation in sewage sludge and stabilized sludge from different Wastewater Treatment Plants, Greater Cairo, Egypt. Journal of Hazardous Materials 164, 740-749.

Lebuhn, M., Liu, F., Heuwinkel, H., Gronauer, A. 2008. Biogas production from mono-digestion of maize silage-long-term process stability and requirements. Water Sci Technol 58, 1645-51. 
Legret, M. 1993. Speciation of Heavy Metals in Sewage Sludge and Sludge-Amended Soil. International Journal of Environmental Analytical Chemistry 51, 161165 .

Leighton, I.R., Forster, C.F. 1997. The adsorption of heavy metals in an acidogenic thermophilic anaerobic reactor. Water Research 31, 2969-2972.

Leitão, R.C., van Haandel, A.C., Zeeman, G., Lettinga, G. 2006. The effects of operational and environmental variations on anaerobic wastewater treatment systems: A review. Bioresource Technology 97, 1105-1118.

Lenz, M., Gmerek, A., Lens, P.N.L. 2006a. Selenium speciation in anaerobic granular sludge. International Journal of Environmental Analytical Chemistry 86, 615627.

Lenz, M., Gmerek, A., Lens, P.N.L. 2006b. Selenium Speciation in Biofilms from Granular Sludge Bed Reactors Used for Wastewater Treatment AIP Conference Proceedings;2007, Vol. 882 Issue 1, p229.

Lester, J.N., Sterritt, R.M., Kirk, P.W.W. 1983. Significance and behaviour of heavy metals in waste water treatment processes II. Sludge treatment and disposal. Science of the total environment 30, 45-83.

Lettinga, G., van Velsen, A.F.M., Hobma, S.W., de Zeeuw, W., Klapwijk, A. 1980. Use of the upflow sludge blanket (USB) reactor concept for biological wastewater treatment, especially for anaerobic treatment. Biotechnology and Bioengineering 22, 699-734.

Li, W., Zhao, H., Teasdale, P.R., John, R., Wang, F. 2005. Metal speciation measurement by diffusive gradients in thin films technique with different binding phases. Analytica Chimica Acta 533, 193-202.

Lin, C.Y., Chou, J., Lee, Y.S. 1998. Heavy metal-affected degradation of butyric acid in anaerobic digestion. Bioresource Technology 65, 159-161.

Liu, J.-y., Sun, S.-y. 2013. Total concentrations and different fractions of heavy metals in sewage sludge from Guangzhou, China. Transactions of Nonferrous Metals Society of China 23, 2397-2407.

Liu, R., Lead, J.R., Zhang, H. 2013. Combining cross flow ultrafiltration and diffusion gradients in thin-films approaches to determine trace metal speciation in freshwaters. Geochimica et Cosmochimica Acta 109, 14-26.

Liu, Y., Chang, S., Defersha, F.M. 2015. Characterization of the proton binding sites of extracellular polymeric substances in an anaerobic membrane bioreactor. Water Research 78, 133-143.

Long, Y.-Y., Hu, L.-F., Wang, J., Fang, C.-R., He, R., Hu, H., Shen, D.-S. 2009. Effect of sample pretreatment on speciation of copper and zinc in MSW. Journal of Hazardous Materials 168, 770-776.

Lopes, S.I.C., Capela, M.I., van Hullebusch, E.D., van der Veen, A., Lens, P.N.L. 2008. Influence of low pH (6, 5 and 4) on nutrient dynamics and characteristics of acidifying sulfate reducing granular sludge. Process Biochemistry 43, 1227-1238. 
Marcato, C.E., Pinelli, E., Cecchi, M., Winterton, P., Guiresse, M. 2009.

Bioavailability of $\mathrm{Cu}$ and $\mathrm{Zn}$ in raw and anaerobically digested pig slurry. Ecotoxicol Environ Saf 72, 1538-44.

Martell, A.E., Smith, R.M. 1989. Critical stability constants. New York: Plenum.

Matsushige, K., Inamori, Y., Mizuochi, M., Hosomi, M., Sudo, R. 1990. The effects of temperature on anaerobic filter treatment for low $\square$ strength organic wastewater. Environmental Technology 11, 899-910.

McGrath, S.P., Cegarra, J. 1992. Chemical extractability of heavy metals during and after long-term applications of sewage sludge to soil. Journal of Soil Science 43, 313-321.

McGrath, S.P., Cunliffe, C.H. 1985. A simplified method for the extraction of the metals $\mathrm{Fe}, \mathrm{Zn}, \mathrm{Cu}, \mathrm{Ni}, \mathrm{Cd}, \mathrm{Pb}, \mathrm{Cr}, \mathrm{Co}$ and $\mathrm{Mn}$ from soils and sewage sludges. Journal of the Science of Food and Agriculture 36, 794-798.

Merchant, S.S., Helmann, J.D. 2012. Chapter 2 - Elemental Economy: Microbial Strategies for Optimizing Growth in the Face of Nutrient Limitation. in: Advances in Microbial Physiology, (Ed.) K.P. Robert, Vol. Volume 60, Academic Press, pp. 91-210.

Meylan, S., Odzak, N., Behra, R., Sigg, L. 2004. Speciation of copper and zinc in natural freshwater: comparison of voltammetric measurements, diffusive gradients in thin films (DGT) and chemical equilibrium models. Analytica Chimica Acta 510, 91-100.

Moestedt, J., Nordell, E., Shakeri Yekta, S., Lundgren, J., Martí, M., Sundberg, C., Ejlertsson, J., Svensson, B.H., Björn, A. 2015. Effects of trace element addition on process stability during anaerobic co-digestion of OFMSW and slaughterhouse waste. Waste Management.

Mossop, K.F., Davidson, C.M. 2003. Comparison of original and modified BCR sequential extraction procedures for the fractionation of copper, iron, lead, manganese and zinc in soils and sediments. Analytica Chimica Acta 478, 111118.

Mountfort, D.O., Asher, R.A. 1979. Effect of inorganic sulfide on the growth and metabolism of Methanosarcina barkeri strain DM. Applied and Environmental Microbiology 37, 670-675.

Mulligan, C.N., Masaharu Fukue, M., Sato, Y. 2009. Sediments Contamination and Sustainable Remediation. CRC Press.

Nies, D.H. 1999. Microbial heavy-metal resistance. Appl Microbiol Biotechnol 51, 730-50.

Nomeda, S., Valdas, P., Chen, S.-Y., Lin, J.-G. 2008. Variations of metal distribution in sewage sludge composting. Waste Management 28, 1637-1644.

Okbah, M., Nasr, S., Kasem, S. 2008. Heavy metals availability (Fe, Mn, Zn, Cu and $\mathrm{Cr}$ ) in Aden Gulf sediments under aerobic and anaerobic conditions. Chemistry in ecology 24, 109-117.

Oleszkiewicz, J.A., Sharma, V.K. 1990. Stimulation and inhibition of anaerobic processes by heavy metals-A review. Biological Wastes 31, 45-67. 
Ortner, M., Rachbauer, L., Somitsch, W., Fuchs, W. 2014. Can bioavailability of trace nutrients be measured in anaerobic digestion? Applied Energy 126, 190-198.

Osuna, M.B., Iza, J., Zandvoort, M., Lens, P.N. 2003. Essential metal depletion in an anaerobic reactor. Water Sci Technol 48, 1-8.

Osuna, M.B., van Hullebusch, E.D., Zandvoort, M.H., Iza, J., Lens, P.N. 2004. Effect of cobalt sorption on metal fractionation in anaerobic granular sludge. $J$ Environ Qual 33, 1256-70.

Owen, W.F., Stuckey, D.C., Healy Jr, J.B., Young, L.Y., McCarty, P.L. 1979. Bioassay for monitoring biochemical methane potential and anaerobic toxicity. Water Research 13, 485-492.

Öztürk, M. 1991. Conversion of acetate, propionate and butyrate to methane under thermophilic conditions in batch reactors. Water Research 25, 1509-1513.

Pal, A., Paul, A.K. 2008. Microbial extracellular polymeric substances: Central elements in heavy metal bioremediation. Indian Journal of Microbiology $\mathbf{4 8}$, 49-64.

Parkin, G., Owen, W. 1986. Fundamentals of Anaerobic Digestion of Wastewater Sludges. Journal of Environmental Engineering 112, 867-920.

Patel, V., Patel, A., Patel, M., Madamwar, D. 1993. Effect of metals on anaerobic digestion of water hyacinth-cattle dung. Applied Biochemistry and Biotechnology 43, 45-50.

Patidar, S.K., Tare, V. 2008. Soluble microbial products formation and their effect on trace metal availability during anaerobic degradation of sulfate laden organics. Water science and technology 58, 749-755.

Paulo, P.L., Jiang, B., Cysneiros, D., Stams, A.J., Lettinga, G. 2004. Effect of cobalt on the anaerobic thermophilic conversion of methanol. Biotechnol Bioeng $\mathbf{8 5}$, 434-41.

Perez Cid, B., de Jesus Gonzalez, M., Fernandez Gomez, E. 2002. Comparison of single extraction procedures, using either conventional shaking or microwave heating, and the Tessier sequential extraction method for the fractionation of heavy metals from environmental samples. Analyst 127, 681-8.

Pichtel, J., Anderson, M. 1997. Trace metal bioavailability in municipal solid waste and sewage sludge composts. Bioresource Technology 60, 223-229.

Pobeheim, H., Munk, B., Lindorfer, H., Guebitz, G.M. 2011. Impact of nickel and cobalt on biogas production and process stability during semi-continuous anaerobic fermentation of a model substrate for maize silage. Water Research 45, 781-787.

Qiang, H., Lang, D.-L., Li, Y.-Y. 2012. High-solid mesophilic methane fermentation of food waste with an emphasis on Iron, Cobalt, and Nickel requirements. Bioresource Technology 103, 21-27.

Qiang, H., Niu, Q., Chi, Y., Li, Y. 2013. Trace metals requirements for continuous thermophilic methane fermentation of high-solid food waste. Chemical Engineering Journal 222, 330-336. 
Qiao, L., Ho, G. 1997. The effects of clay amendment and composting on metal speciation in digested sludge. Water Research 31, 951-964.

Quevauviller, P., Rauret, G., Muntau, H., Ure, A.M., Rubio, R., López-Sánchez, J.F., Fiedler, H.D., Griepink, B. 1994. Evaluation of a sequential extraction procedure for the determination of extractable trace metal contents in sediments. Fresenius' Journal of Analytical Chemistry 349, 808-814.

Rajeshwari, K.V., Balakrishnan, M., Kansal, A., Lata, K., Kishore, V.V.N. 2000. Stateof-the-art of anaerobic digestion technology for industrial wastewater treatment. Renewable and Sustainable Energy Reviews 4, 135-156.

Rauret, G., Lopez-Sanchez, J.F., Sahuquillo, A., Barahona, E., Lachica, M., Ure, A.M., Davidson, C.M., Gomez, A., Luck, D., Bacon, J., Yli-Halla, M., Muntau, H., Quevauviller, P. 2000. Application of a modified BCR sequential extraction (three-step) procedure for the determination of extractable trace metal contents in a sewage sludge amended soil reference material (CRM 483), complemented by a three-year stability study of acetic acid and EDTA extractable metal content. J Environ Monit 2, 228-33.

Ren, J., Williams, P., Luo, J., Ma, H., Wang, X. 2015. Sediment metal bioavailability in Lake Taihu, China: evaluation of sequential extraction, DGT, and PBET techniques. Environmental Science and Pollution Research 1-10.

Rensing, C., Maier, R.M. 2003. Issues underlying use of biosensors to measure metal bioavailability. Ecotoxicology and Environmental Safety 56, 140-147.

Rickard, D., Morse, J.W. 2005. Acid volatile sulfide (AVS). Marine Chemistry 97, 141-197.

Rittmann, B.E., McCarty, P.L. 2001. Environmental Biotechnology: Principles and Applications. McGraw-Hill, Boston, USA.

Romero-Güiza, M.S., Mata-Alvarez, J., Chimenos, J.M., Astals, S. 2016. The effect of magnesium as activator and inhibitor of anaerobic digestion. Waste Management.

Roussel, J., Carliell-Marquet, C. 2016. Significance of Vivianite Precipitation on the Mobility of Iron in Anaerobically Digested Sludge. Frontiers in Environmental Science 4.

Rudd, T., Lake, D.L., Mehrotra, I., Sterritt, R.M., Kirk, P.W.W., Campbell, J.A., Lester, J.N. 1988. Characterisation of metal forms in sewage sludge by chemical extraction and progressive acidification. Science of The Total Environment 74, 149-175.

Sahuquillo, A., López-Sánchez, J.F., Rubio, R., Rauret, G., Thomas, R.P., Davidson, C.M., Ure, A.M. 1999. Use of a certified reference material for extractable trace metals to assess sources of uncertainty in the BCR three-stage sequential extraction procedure. Analytica Chimica Acta 382, 317-327.

Sandrin, T.R., Maier, R.M. 2003. Impact of metals on the biodegradation of organic pollutants. Environmental Health Perspectives 111, 1093-1101.

Satyro, S., Race, M., Marotta, R., Dezotti, M., Spasiano, D., Mancini, G., Fabbricino, M. 2014. Simulated solar photocatalytic processes for the simultaneous 
removal of EDDS, $\mathrm{Cu}(\mathrm{II}), \mathrm{Fe}(\mathrm{III})$ and $\mathrm{Zn}(\mathrm{II})$ in synthetic and real contaminated soil washing solutions. Journal of Environmental Chemical Engineering 2 , 1969-1979.

Sauer, K., Thauer, R.K. 2000. Methyl-coenzyme M formation in methanogenic archaea. Involvement of zinc in coenzyme M activation. Eur J Biochem 267, 2498-504.

Schattauer, A., Abdoun, E., Weiland, P., Plöchl, M., Heiermann, M. 2011. Abundance of trace elements in demonstration biogas plants. Biosystems Engineering 108, 57-65.

Scherer, P., Lippert, H., Wolff, G. 1983. Composition of the major elements and trace elements of 10 methanogenic bacteria determined by inductively coupled plasma emission spectrometry. Biol Trace Elem Res 5, 149-63.

Schmidt, T., Nelles, M., Scholwin, F., Pröter, J. 2014. Trace element supplementation in the biogas production from wheat stillage - Optimization of metal dosing. Bioresource Technology 168, 80-85.

Schönheit, P., Moll, J., Thauer, R. 1979. Nickel, cobalt, and molybdenum requirement for growth of Methanobacterium thermoautotrophicum. Archives of Microbiology 123, 105-107.

Schonheit, P., Moll, J., Thauer, R.K. 1979. Nickel, cobalt, and molybdenum requirement for growth of Methanobacterium thermoautotrophicum. Arch Microbiol 123, 105-7.

Shakeri Yekta, S., Gustavsson, J., Svensson, B.H., Skyllberg, U. 2012. Sulfur K-edge XANES and acid volatile sulfide analyses of changes in chemical speciation of $\mathrm{S}$ and $\mathrm{Fe}$ during sequential extraction of trace metals in anoxic sludge from biogas reactors. Talanta 89, 470-477.

Shakeri Yekta, S., Lindmark, A., Skyllberg, U., Danielsson, Å., Svensson, B.H. 2014. Importance of reduced sulfur for the equilibrium chemistry and kinetics of $\mathrm{Fe}(\mathrm{II}), \mathrm{Co}(\mathrm{II})$ and $\mathrm{Ni}$ (II) supplemented to semi-continuous stirred tank biogas reactors fed with stillage. Journal of Hazardous Materials 269, 83-88.

Sharma, J., Singh, R. 2001. Effect of nutrients supplementation on anaerobic sludge development and activity for treating distillery effluent. Bioresource Technology 79, 203-206.

Sheng, X., Ting, Y.P., Pehkonen, S.O. 2008. The influence of ionic strength, nutrients and $\mathrm{pH}$ on bacterial adhesion to metals. Journal of Colloid and Interface Science 321, 256-264.

Smith, D.S., Bell, R.A., Kramer, J.R. 2002. Metal speciation in natural waters with emphasis on reduced sulfur groups as strong metal binding sites. Comparative Biochemistry and Physiology Part C: Toxicology \& Pharmacology 133, 65-74.

Smith, J.A., Carliell-Marquet, C.M. 2009. A novel laboratory method to determine the biogas potential of iron-dosed activated sludge. Bioresource Technology 100, 1767-1774.

Song, Q.J., Greenway, G.M. 2004. A study of the elemental leachability and retention capability of compost. J Environ Monit 6, 31-7. 
Souto, T.F., Aquino, S.F., Silva, S.Q., Chernicharo, C.A. 2010. Influence of incubation conditions on the specific methanogenic activity test. Biodegradation 21, 41124.

Speece, R.E. 1996. Anaerobic biotechnology for industrial wastewaters. Archae Press, Tennessee, USA.

Speece, R.E., Mc Carty,P.L. . 1962. Nutrient requirements and biological solids accumulation in anaerobic systems. In 1st Internat.conf. water.pollut. Res., London, UK 1-27.

Speece, R.E., Parkin, G.F., Gallagher, D. 1983. Nickel stimulation of anaerobic digestion. Water Research 17, 677-683.

Sposito, G., Lund, L.J., Chang, A.C. 1982. Trace Metal Chemistry in Arid-zone Field Soils Amended with Sewage Sludge: I. Fractionation of $\mathrm{Ni}, \mathrm{Cu}, \mathrm{Zn}, \mathrm{Cd}$, and $\mathrm{Pb}$ in Solid Phases1. Soil Sci. Soc. Am. J. 46, 260-264.

Standard, E. 2000. Characterization of Sludges - Determination of Trace Elements and Phosphorus - Aqua Regia Extraction Methods. European Committee for Standardization, EN 13346:2000, Brussels.

Stover, R.C., Sommers, L.E., Silveira, D.J. 1976. Evaluation of metals in wastewater sludge. J. Water Pollut. Control Fed. 48, 2165.

Stuckey, D.C. 2012. Recent developments in anaerobic membrane reactors. Bioresour Technol 122, 137-48.

Stylianou, M.A., Kollia, D., Haralambous, K.-J., Inglezakis, V.J., Moustakas, K.G., Loizidou, M.D. 2007. Effect of acid treatment on the removal of heavy metals from sewage sludge. Desalination 215, 73-81.

Tack, F.M., Callewaert, O.W., Verloo, M.G. 1996. Metal solubility as a function of pH in a contaminated, dredged sediment affected by oxidation. Environ Pollut 91, 199-208.

Takashima, M., Shimada, K., Speece, R.E. 2011. Minimum Requirements for Trace Metals (Iron, Nickel, Cobalt, and Zinc) in Thermophilic and Mesophilic Methane Fermentation from Glucose. Water Environment Research 83, 33946.

Takashima, M., Speece, R.E. 1989. Mineral nutrient requirements for high-rate methane fermentation of acetate at low SRT. Research Journal of the Water Pollution Control Federation 61, 1645-1650.

Tandy, S., Bossart, K., Mueller, R., Ritschel, J., Hauser, L., Schulin, R., Nowack, B. 2004. Extraction of Heavy Metals from Soils Using Biodegradable Chelating Agents. Environmental Science \& Technology 38, 937-944.

Tandy, S., Schulin, R., Suter, M.J., Nowack, B. 2005. Determination of [S,S']ethylenediamine disuccinic acid (EDDS) by high performance liquid chromatography after derivatization with FMOC. J Chromatogr A 1077, 37 43.

Temminghoff, E.J.M., Plette, A.C.C., Van Eck, R., Van Riemsdijk, W.H. 2000. Determination of the chemical speciation of trace metals in aqueous systems 
by the Wageningen Donnan Membrane Technique. Analytica Chimica Acta 417, 149-157.

Tessier, A., Campbell, P.G.C., Bisson, M. 1979. Sequential extraction procedure for the speciation of particulate trace metals. Analytical Chemistry 51, 844-851.

Thanh, P.M., Ketheesan, B., Yan, Z., Stuckey, D. 2017. Effect of Ethylenediamine$\mathrm{N}, \mathrm{N}^{\prime}$-disuccinic acid (EDDS) on the speciation and bioavailability of $\mathrm{Fe} 2+$ in the presence of sulfide in anaerobic digestion. Bioresource Technology 229, 169-179.

Thanh, P.M., Ketheesan, B., Yan, Z., Stuckey, D. 2016. Trace metal speciation and bioavailability in anaerobic digestion: A review. Biotechnology Advances 34, 122-136.

Thauer, R.K. 1998. Biochemistry of methanogenesis: a tribute to Marjory Stephenson: 1998 Marjory Stephenson Prize Lecture. Microbiology 144, 23772406.

Trzcinski, A.P., Ofoegbu, N., Stuckey, D.C. 2011. Post-treatment of the permeate of a submerged anaerobic membrane bioreactor (SAMBR) treating landfill leachate. J Environ Sci Health A Tox Hazard Subst Environ Eng 46, 1539-48.

Uemura, S. 2009. Mineral Requirements for Mesophilic and Thermophilic Anaerobic Digestion of Organic Solid Waste. International Journal of Environmental Research 4, 33-40.

Ure, A.M., Quevauviller, P., Muntau, H., Griepink, B. 1993. Speciation of Heavy Metals in Soils and Sediments. An Account of the Improvement and Harmonization of Extraction Techniques Undertaken Under the Auspices of the BCR of the Commission of the European Communities. International Journal of Environmental Analytical Chemistry 51, 135-151.

van der Veeken, P.L.R., Pinheiro, J.P., van Leeuwen, H.P. 2008. Metal Speciation by DGT/DET in Colloidal Complex Systems. Environmental Science \& Technology 42, 8835-8840.

van der Veen, A., Fermoso, F.G., Lens, P.N.L. 2007. Bonding Form Analysis of Metals and Sulfur Fractionation in Methanol-Grown Anaerobic Granular Sludge. Engineering in Life Sciences 7, 480-489.

van Hullebusch, E., Zandvoort, M., Lens, P.L. 2003. Metal immobilisation by biofilms: Mechanisms and analytical tools. Reviews in Environmental Science and Biotechnology 2, 9-33.

van Hullebusch, E.D., Gieteling, J., Zhang, M., Zandvoort, M.H., Daele, W.V., Defrancq, J., Lens, P.N.L. 2006. Cobalt sorption onto anaerobic granular sludge: Isotherm and spatial localization analysis. Journal of Biotechnology 121, 227-240.

van Hullebusch, E.D., Peerbolte, A., Zandvoort, M.H., Lens, P.N.L. 2005a. Sorption of cobalt and nickel on anaerobic granular sludges: isotherms and sequential extraction. Chemosphere 58, 493-505. 
van Hullebusch, E.D., Utomo, S., Zandvoort, M.H., L. Lens, P.N. 2005b. Comparison of three sequential extraction procedures to describe metal fractionation in anaerobic granular sludges. Talanta $\mathbf{6 5}, 549-558$.

van Hullebusch, E.D., Zandvoort, M.H., Lens, P.N.L. 2004. Nickel and cobalt sorption on anaerobic granular sludges: kinetic and equilibrium studies. Journal of Chemical Technology \& Biotechnology 79, 1219-1227.

Vintiloiu, A., Boxriker, M., Lemmer, A., Oechsner, H., Jungbluth, T., Mathies, E., Ramhold, D. 2013. Effect of ethylenediaminetetraacetic acid (EDTA) on the bioavailability of trace elements during anaerobic digestion. Chemical Engineering Journal 223, 436-441.

Virkutyte, J., van Hullebusch, E., Sillanpää, M., Lens, P. 2005. Copper and trace element fractionation in electrokinetically treated methanogenic anaerobic granular sludge. Environmental Pollution 138, 517-528.

Voolapalli, R.K., Stuckey, D.C. 1999. Relative importance of trophic group concentrations during anaerobic degradation of volatile fatty acids. Appl Environ Microbiol 65, 5009-16.

Voolapalli, R.K., Stuckey, D.C. 1998. Stability enhancement of anaerobic digestion through membrane gas extraction under organic shock loads. Journal of Chemical Technology \& Biotechnology 73, 153-161.

Vyrides, I., Conteras, P.A., Stuckey, D.C. 2010. Post-treatment of a submerged anaerobic membrane bioreactor (SAMBR) saline effluent using powdered activated carbon (PAC). J Hazard Mater 177, 836-41.

Wang, J., Huang, C.P., Allen, H.E. 2007. Effect of pH on Metal Uptake by Anaerobic Sludge. Environmental Engineering Science 24, 1095-1104.

Weimer, P.J. 1998. Manipulating ruminal fermentation: a microbial ecological perspective. J Anim Sci 76, 3114-22.

Westerholm, M., Hansson, M., Schnurer, A. 2012. Improved biogas production from whole stillage by co-digestion with cattle manure. Bioresour Technol 114, 3149.

White, C.J., Stuckey, D.C. 2000. The Influence of Metal Ion Addition on the Anaerobic Treatment of High Strength, Soluble Wastewaters. Environmental Technology 21, 1283-1292.

Williams, C.M., Shih, J.C., Spears, J.W. 1986. Effect of nickel on biological methane generation from a laboratory poultry waste digester. Biotechnol Bioeng $\mathbf{2 8}$, 1608-10.

Williams, R.J.P., Fraústo da Silva, J.J.R. 2000. The distribution of elements in cells. Coordination Chemistry Reviews 200-202, 247-348.

Wintsche, B., Glaser, K., Sträuber, H., Centler, F., Liebetrau, J., Harms, H., Kleinsteuber, S. 2016. Trace Elements Induce Predominance among Methanogenic Activity in Anaerobic Digestion. Frontiers in Microbiology 7.

Wisotzky, F., Cremer, N. 2003a. Sequential extraction procedure in columns. Part 1: Development and description of a new method. Environmental geology 44, 799-804. 
Wisotzky, F., Cremer, N. 2003b. Sequential extraction procedure in columns?part 2: application of a new method. Environmental geology 44, 805-810.

Wong, Y.-S., Teng, T.T., Ong, S.-A., Morad, N., Rafatullah, M. 2014. Suspended growth kinetic analysis on biogas generation from newly isolated anaerobic bacterial communities for palm oil mill effluent at mesophilic temperature. RSC Advances 4, 64659-64667.

Worm, P., Fermoso, F.G., Lens, P.N.L., Plugge, C.M. 2009. Decreased activity of a propionate degrading community in a UASB reactor fed with synthetic medium without molybdenum, tungsten and selenium. Enzyme and Microbial Technology 45, 139-145.

Worm, P., Fermoso, F.G., Stams, A.J.M., Lens, P.N.L., Plugge, C.M. 2011. Transcription of fdh and hyd in Syntrophobacter spp. and Methanospirillum spp. as a diagnostic tool for monitoring anaerobic sludge deprived of molybdenum, tungsten and selenium. Environmental Microbiology 13, 12281235.

Worms, I., Simon, D.F., Hassler, C.S., Wilkinson, K.J. 2006. Bioavailability of trace metals to aquatic microorganisms: importance of chemical, biological and physical processes on biouptake. Biochimie 88, 1721-1731.

Yeo, H., Lee, H.-S. 2013. The effect of solids retention time on dissolved methane concentration in anaerobic membrane bioreactors. Environmental Technology 34, 2105-2112.

Yezek, L.P., van der Veeken, P.L., van Leeuwen, H.P. 2008. Donnan effects in metal speciation analysis by DET/DGT. Environ Sci Technol 42, 9250-4.

Zandvoort, M.H., Geerts, R., Lettinga, G., Lens, P.N.L. 2002. Effect of Long-Term Cobalt Deprivation on Methanol Degradation in a Methanogenic Granular Sludge Bioreactor. Biotechnology Progress 18, 1233-1239.

Zandvoort, M.H., Geerts, R., Lettinga, G., Lens, P.N.L. 2003. Methanol degradation in granular sludge reactors at sub-optimal metal concentrations: role of iron, nickel and cobalt. Enzyme and Microbial Technology 33, 190-198.

Zandvoort, M.H., Gieteling, J., Lettinga, G., Lens, P.N.L. 2004. Stimulation of methanol degradation in UASB reactors: In situ versus pre-loading cobalt on anaerobic granular sludge. Biotechnology and Bioengineering 87, 897-904.

Zandvoort, M.H., van Hullebusch, E.D., Fermoso, F.G., Lens, P.N.L. 2006a. Trace Metals in Anaerobic Granular Sludge Reactors: Bioavailability and Dosing Strategies. Engineering in Life Sciences 6, 293-301.

Zandvoort, M.H., van Hullebusch, E.D., Golubnic, S., Gieteling, J., Lens, P.N.L. 2006b. Induction of cobalt limitation in methanol-fed UASB reactors. Journal of Chemical Technology \& Biotechnology 81, 1486-1495.

Zandvoort, M.H., van Hullebusch, E.D., Peerbolte, A., Golubnic, S., Lettinga, G., Lens, P.N. 2005. Influence of $\mathrm{pH}$ shocks on trace metal dynamics and performance of methanol fed granular sludge bioreactors. Biodegradation 16, $549-67$. 


\section{References}

Zehnder, A.J.B., Ingvorsen, K., Marti, T. 1982. Microbiology of methane bacteria. In Anaerobic Digestion 1981. Elsevier Biomedical Press, New York.

Zehnder, W.G.a.A.J.B. 1983. Conversion Processes in Anaerobic Digestion. Water Science \& Technology 15, 127-167.

Zhang, W., Wu, S., Guo, J., Zhou, J., Dong, R. 2015a. Performance and kinetic evaluation of semi-continuously fed anaerobic digesters treating food waste: Role of trace elements. Bioresource Technology 178, 297-305.

Zhang, W., Zhang, L., Li, A. 2015b. Enhanced anaerobic digestion of food waste by trace metal elements supplementation and reduced metals dosage by green chelating agent $[\mathrm{S}, \mathrm{S}]$-EDDS via improving metals bioavailability. Water Research 84, 266-277.

Zhao, Z., Xi, M., Jiang, G., Liu, X., Bai, Z., Huang, Y. 2010. Effects of IDSA, EDDS and EDTA on heavy metals accumulation in hydroponically grown maize (Zea mays, L.). Journal of Hazardous Materials 181, 455-459.

Zhou, L., Xia, S., Alvarez-Cohen, L. 2015. Structure and distribution of inorganic components in the cake layer of a membrane bioreactor treating municipal wastewater. Bioresource Technology 196, 586-591.

Zhou, Z., Tan, Y., Xiao, Y., Stuckey, D.C. 2016. Characterization and Significance of Sub-Visible Particles and Colloids in a Submerged Anaerobic Membrane Bioreactor (SAnMBR). Environmental Science \& Technology 50, 1275012758.

Zhu, N.-m., Qiang, L., Guo, X.-j., Hui, Z., Yu, D. 2014. Sequential extraction of anaerobic digestate sludge for the determination of partitioning of heavy metals. Ecotoxicology and Environmental Safety 102, 18-24.

Zitomer, D., Johnson, C., Speece, R. 2008. Metal Stimulation and Municipal Digester Thermophilic/Mesophilic Activity. Journal of environmental engineering 134, $42-47$. 
References 


\section{Appendix}

Table A.1 Fe content $(\mu \mathrm{g} / \mathrm{gTSS})$ from sequential extraction in the SAMBR $(\mathrm{n}=3)$.

\begin{tabular}{|c|c|c|c|c|c|c|c|}
\hline & Day & Sol & F1 & F2 & F3 & F4 & $\begin{array}{l}\text { Sum of } \\
\text { fractions }\end{array}$ \\
\hline \multirow{4}{*}{ Stage 1} & 1 & 25.9 & 1912.9 & 5016.5 & 977.8 & 2105.4 & 10038.5 \\
\hline & 3 & 25.9 & 2014.8 & 5081.5 & 971.1 & 2090.7 & 10184.0 \\
\hline & 5 & 28.0 & 2109.3 & 5195.3 & 971.7 & 2084.1 & 10388.6 \\
\hline & 10 & 27.6 & 2057.1 & 4994.9 & 966.6 & 2125.3 & 10171.7 \\
\hline \multirow{6}{*}{ Stage 2} & 11 & 9.7 & 594.2 & 4328.5 & 1382.9 & 3719.8 & 10035.0 \\
\hline & 13 & 8.8 & 564.8 & 4326.5 & 1415.3 & 3692.0 & 10007.4 \\
\hline & 15 & 9.3 & 462.1 & 4115.4 & 1398.2 & 4196.3 & 10181.4 \\
\hline & 17 & 9.6 & 419.1 & 4101.9 & 1530.5 & 4088.0 & 10149.2 \\
\hline & 19 & 8.7 & 437.0 & 3900.8 & 1651.1 & 4273.1 & 10270.6 \\
\hline & 21 & 8.7 & 592.2 & 3771.4 & 1792.4 & 4374.8 & 10539.4 \\
\hline
\end{tabular}


Appendix

\begin{tabular}{llllllll}
\hline & 22 & 11.7 & 649.6 & 3806.4 & 1444.4 & 4429.5 & 10341.5 \\
\cline { 2 - 7 } Stage 3 & 24 & 18.0 & 912.8 & 4083.4 & 1454.5 & 4439.8 & 10908.5 \\
\cline { 2 - 7 } & 26 & 16.8 & 965.1 & 4017.2 & 1309.8 & 3987.6 & 10296.6 \\
\cline { 2 - 7 } & 28 & 16.9 & 1222.1 & 4352.1 & 1326.3 & 3440.4 & 10357.7 \\
\hline 30 & 18.2 & 1379.1 & 4370.5 & 1202.4 & 3243.6 & 10213.8 \\
\hline
\end{tabular}


Table A.2 Metal content ( $\mu \mathrm{g} / \mathrm{gTSS})$ in each fraction from BCR extraction method $(\mathrm{n}=3)$.

\begin{tabular}{|c|c|c|c|c|c|c|c|}
\hline $\mathbf{F e}$ & Day & Sol & F1 & $\mathrm{F} 2$ & F3 & $\mathrm{F} 4$ & $\begin{array}{l}\text { Sum of } \\
\text { fractions }\end{array}$ \\
\hline \multirow{3}{*}{ With metals } & 0 & 11.4 & 332.1 & 4438.3 & 788.3 & 816.6 & 6386.8 \\
\hline & 5 & 11.2 & 337.6 & 4533.1 & 754.6 & 788.8 & 6425.4 \\
\hline & 15 & 11.6 & 339.3 & 4541.0 & 785.4 & 800.0 & 6477.3 \\
\hline \multirow{4}{*}{ No metals } & 17 & 10.4 & 329.3 & 4275.0 & 946.5 & 840.4 & 6401.6 \\
\hline & 25 & 0.0 & 317.9 & 4140.8 & 1002.7 & 853.6 & 6314.9 \\
\hline & 33 & 0.0 & 316.6 & 3921.1 & 946.1 & 1012.6 & 6196.4 \\
\hline & 41 & 0.0 & 317.0 & 3471.3 & 948.0 & 1336.2 & 6072.5 \\
\hline \multirow{3}{*}{$1^{\text {st }}$ pulse } & 43 & 0.0 & 643.7 & 3824.7 & 858.9 & 865.3 & 6192.6 \\
\hline & 45 & 0.0 & 458.9 & 3904.7 & 899.1 & 852.2 & 6114.8 \\
\hline & 49 & 0.0 & 418.7 & 4093.8 & 789.0 & 779.3 & 6080.7 \\
\hline \multirow{3}{*}{$2^{\text {nd }}$ pulse } & 51 & 0.0 & 293.3 & 3438.3 & 985.4 & 1548.2 & 6265.2 \\
\hline & 53 & 0.0 & 317.4 & 3365.3 & 992.2 & 1541.1 & 6215.9 \\
\hline & 57 & 0.0 & 323.8 & 3331.7 & 995.9 & 1540.7 & 6192.2 \\
\hline
\end{tabular}




\begin{tabular}{llllllll}
\hline \multirow{3}{*}{$3^{\text {rd }}$ pulse } & 59 & 0.0 & 278.8 & 3577.7 & 1095.6 & 1735.2 & 6687.3 \\
\cline { 2 - 8 } & 65 & 0.0 & 333.3 & 3465.2 & 1082.2 & 1590.0 & 6470.8 \\
\cline { 2 - 7 } & 72 & 0.0 & 329.1 & 3309.5 & 1104.1 & 1523.6 & 6266.5 \\
\hline
\end{tabular}

\begin{tabular}{cccccccc}
\hline Co & Day & Sol & F1 & F2 & F3 & F4 & $\begin{array}{c}\text { Sum of } \\
\text { fractions }\end{array}$ \\
\hline \multirow{3}{*}{ With metals } & 0 & 0.0 & 310.4 & 146.6 & 1111.5 & 0.0 & 1568.5 \\
\cline { 2 - 8 } & 5 & 0.0 & 306.7 & 147.2 & 1118.7 & 0.0 & 1572.6 \\
\cline { 2 - 8 } & 15 & 0.0 & 304.6 & 150.3 & 1127.7 & 0.0 & 1582.7 \\
\hline \multirow{3}{*}{ No metals } & 17 & 0.0 & 284.6 & 148.9 & 1123.5 & 0.0 & 1557.0 \\
\cline { 2 - 8 } & 25 & 0.0 & 278.8 & 145.3 & 1080.6 & 0.0 & 1504.6 \\
\cline { 2 - 8 } & 33 & 0.0 & 256.6 & 144.0 & 1006.6 & 0.0 & 1407.1 \\
\hline \multirow{2}{*}{$1^{\text {st }}$ pulse } & 41 & 0.0 & 202.1 & 116.5 & 920.5 & 0.0 & 1239.1 \\
\cline { 2 - 8 } & 43 & 0.0 & 235.3 & 111.6 & 915.5 & 0.0 & 1262.4 \\
\hline
\end{tabular}


Appendix

\begin{tabular}{cccccccc}
\hline & 49 & 0.0 & 291.7 & 119.7 & 765.7 & 0.0 & 1177.1 \\
\hline \multirow{3}{*}{$2^{\text {nd }}$ pulse } & 51 & 0.0 & 226.9 & 106.7 & 881.9 & 0.0 & 1215.5 \\
\cline { 2 - 7 } & 53 & 0.0 & 226.3 & 110.0 & 853.6 & 0.0 & 1189.9 \\
\cline { 2 - 7 } & 57 & 0.0 & 224.3 & 112.7 & 832.9 & 0.0 & 1170.0 \\
\hline 3 & 59 & 0.0 & 235.8 & 115.5 & 898.6 & 0.0 & 1249.9 \\
\cline { 2 - 8 } $3^{\text {rd }}$ pulse & 65 & 0.0 & 211.4 & 107.0 & 865.5 & 0.0 & 1184.0 \\
\cline { 2 - 8 } & 72 & 0.0 & 185.4 & 100.0 & 855.4 & 0.0 & 1140.8 \\
\hline
\end{tabular}

\begin{tabular}{cccccccc}
\hline Ni & Day & Sol & F1 & F2 & F3 & F4 & $\begin{array}{c}\text { Sum of } \\
\text { fractions }\end{array}$ \\
\hline \multirow{3}{*}{ With metals } & 0 & 0.0 & 151.8 & 55.4 & 214.2 & 8.3 & 429.8 \\
\cline { 2 - 8 } & 5 & 0.0 & 152.2 & 54.5 & 215.9 & 9.0 & 431.6 \\
\cline { 2 - 8 } & 15 & 0.0 & 154.3 & 53.2 & 218.1 & 9.2 & 434.8 \\
\hline
\end{tabular}


Appendix

\begin{tabular}{cccccccc}
\hline \multirow{3}{*}{ No metals } & 17 & 0.0 & 131.4 & 52.1 & 231.1 & 0 & 414.6 \\
\cline { 2 - 8 } & 25 & 0.0 & 134.6 & 47.5 & 208.9 & 0 & 391.1 \\
\cline { 2 - 8 } & 33 & 0.0 & 116.0 & 41.7 & 194.1 & 0 & 351.9 \\
\hline \multirow{3}{*}{$1^{\text {st }}$ pulse } & 41 & 0.0 & 86.2 & 38.8 & 170.2 & 0 & 295.2 \\
\cline { 2 - 8 } & 43 & 0.0 & 92.6 & 38.9 & 169.7 & 0 & 301.3 \\
\hline \multirow{3}{*}{$2^{\text {nd }}$ pulse } & 45 & 0.0 & 101.0 & 34.4 & 160.9 & 0 & 296.4 \\
\cline { 2 - 8 } & 51 & 0.0 & 109.3 & 34.7 & 145.9 & 0 & 289.9 \\
\hline \multirow{3}{*}{$3^{\text {rd }}$ pulse } & 53 & 0.0 & 82.1 & 35.3 & 174.1 & 0 & 291.4 \\
\cline { 2 - 8 } & 59 & 0.0 & 79.9 & 35.4 & 173.5 & 0 & 288.9 \\
\cline { 2 - 8 } & 65 & 0.0 & 88.1 & 36.3 & 177.3 & 0 & 301.7 \\
\hline & 72 & 0.0 & 68.8 & 33.7 & 171.2 & 0 & 273.7 \\
\hline
\end{tabular}


Appendix

\begin{tabular}{|c|c|c|c|c|c|c|c|}
\hline $\mathbf{Z n}$ & Day & Sol & $\mathrm{F} 1$ & $\mathrm{~F} 2$ & F3 & $\mathrm{F} 4$ & $\begin{array}{l}\text { Sum of } \\
\text { fractions }\end{array}$ \\
\hline \multirow{3}{*}{ With metals } & 0 & 0.0 & 284.5 & 314.5 & 674.1 & 0 & 1273.1 \\
\hline & 5 & 0.0 & 290.4 & 315.7 & 680.2 & 0 & 1286.4 \\
\hline & 15 & 0.0 & 293.1 & 321.4 & 681.6 & 0 & 1296.1 \\
\hline \multirow{4}{*}{ No metals } & 17 & 0.0 & 283.0 & 299.5 & 706.1 & 0 & 1288.6 \\
\hline & 25 & 0.0 & 282.1 & 295.5 & 677.2 & 0 & 1254.9 \\
\hline & 33 & 0.0 & 267.4 & 290.3 & 661.6 & 0 & 1219.3 \\
\hline & 41 & 0.0 & 191.0 & 270.7 & 662.1 & 0 & 1123.8 \\
\hline \multirow{3}{*}{$1^{\text {st }}$ pulse } & 43 & 0.0 & 225.8 & 282.1 & 621.3 & 0 & 1129.2 \\
\hline & 45 & 0.0 & 285.9 & 252.6 & 589.6 & 0 & 1128.1 \\
\hline & 49 & 0.0 & 315.5 & 289.6 & 510.4 & 0 & 1115.5 \\
\hline \multirow{3}{*}{$2^{\text {nd }}$ pulse } & 51 & 0.0 & 269.4 & 261.7 & 590.5 & 0 & 1121.6 \\
\hline & 53 & 0.0 & 270.5 & 296.8 & 546.4 & 0 & 1113.8 \\
\hline & 57 & 0.0 & 256.1 & 263.0 & 581.9 & 0 & 1100.9 \\
\hline $3^{\text {rd }}$ pulse & 59 & 0.0 & 245.6 & 265.8 & 600.3 & 0 & 1111.7 \\
\hline
\end{tabular}




\begin{tabular}{rrrrrrr}
\hline 65 & 0.0 & 225.9 & 255.2 & 618.7 & 0 & 1099.8 \\
\hline 72 & 0.0 & 215.6 & 233.7 & 619.0 & 0 & 1068.2 \\
\hline
\end{tabular}

\begin{tabular}{cccccccc}
\hline \multirow{3}{*}{ Mn } & Day & Sol & F1 & F2 & F3 & F4 & $\begin{array}{c}\text { Sum of } \\
\text { fractions }\end{array}$ \\
\hline \multirow{3}{*}{ With metals } & 0 & 20.7 & 38.3 & 24.9 & 36.5 & 37.3 & 157.8 \\
\cline { 2 - 8 } & 5 & 20.2 & 39.3 & 26.4 & 36.7 & 38.2 & 160.8 \\
\cline { 2 - 8 } & 15 & 22.0 & 39.9 & 27.2 & 40.8 & 41.6 & 171.4 \\
\hline \multirow{3}{*}{ No metals } & 17 & 19.1 & 38.3 & 27.1 & 40.7 & 40.4 & 165.7 \\
\cline { 2 - 8 } & 25 & 16.8 & 34.6 & 23.5 & 33.4 & 38.0 & 146.2 \\
\cline { 2 - 8 } & 43 & 11.4 & 26.3 & 21.7 & 27.1 & 36.6 & 123.1 \\
\hline \multirow{3}{*}{$1^{\text {st }}$ pulse } & 41 & 10.6 & 20.2 & 17.6 & 23.3 & 31.9 & 103.6 \\
\cline { 2 - 8 } & 45 & 17.9 & 28.9 & 18.9 & 18.9 & 23.2 & 107.9 \\
\cline { 2 - 8 } & 49 & 18.8 & 25.0 & 16.1 & 15.9 & 22.1 & 97.9 \\
\hline
\end{tabular}




\begin{tabular}{rccccccc}
\hline \multirow{2}{*}{$2^{\text {nd }}$ pulse } & 51 & 16.6 & 22.3 & 17.6 & 17.6 & 26.9 & 101.0 \\
\cline { 2 - 8 } & 53 & 15.8 & 22.1 & 17.4 & 17.9 & 27.4 & 100.5 \\
\cline { 2 - 8 } & 57 & 15.9 & 20.6 & 15.9 & 17.5 & 25.4 & 95.2 \\
\hline \multirow{3}{*}{$3^{\text {rd }}$ pulse } & 59 & 16.6 & 21.8 & 19.2 & 17.6 & 28.6 & 103.8 \\
\cline { 2 - 8 } & 65 & 14.9 & 17.9 & 16.4 & 18.7 & 25.9 & 93.8 \\
\cline { 2 - 8 } & 72 & 14.1 & 16.1 & 11.6 & 18.8 & 26.1 & 86.7 \\
\hline
\end{tabular}

\begin{tabular}{cccccccc}
\hline Mo & Day & Sol & F1 & F2 & F3 & F4 & $\begin{array}{c}\text { Sum of } \\
\text { fractions }\end{array}$ \\
\hline \multirow{3}{*}{ With metals } & 0 & 10.4 & 8.3 & 50.8 & 124.2 & 22.8 & 216.5 \\
\cline { 2 - 8 } & 5 & 11.2 & 8.4 & 50.0 & 127.1 & 22.5 & 219.2 \\
\cline { 2 - 8 } & 15 & 11.6 & 8.1 & 49.7 & 133.8 & 23.1 & 226.3 \\
\hline \multirow{3}{*}{ No metals } & 17 & 8.5 & 8.0 & 44.7 & 135.1 & 23.4 & 219.7 \\
\cline { 2 - 8 } & 25 & 6.7 & 7.8 & 40.8 & 119.7 & 24.6 & 199.6 \\
\cline { 2 - 8 } & 33 & 4.6 & 6.3 & 36.6 & 110.4 & 22.9 & 180.7
\end{tabular}


Appendix

\begin{tabular}{cccccccc}
\hline \multirow{3}{*}{$1^{\text {st }}$ pulse } & 41 & 4.3 & 3.7 & 30.9 & 81.4 & 21.3 & 141.5 \\
\cline { 2 - 8 } & 43 & 5.3 & 11.1 & 28.9 & 81.6 & 16.8 & 143.7 \\
\cline { 2 - 8 } & 45 & 5.2 & 8.9 & 29.2 & 80.2 & 15.5 & 138.9 \\
\hline \multirow{3}{*}{$2^{\text {nd }}$ pulse } & 49 & 5.2 & 8.3 & 28.0 & 78.9 & 12.4 & 132.8 \\
\cline { 2 - 8 } & 51 & 4.1 & 4.1 & 22.8 & 89.0 & 16.6 & 136.6 \\
\cline { 2 - 8 } & 57 & 4.2 & 4.2 & 22.1 & 83.9 & 16.8 & 131.3 \\
\hline 3 & 59 & 3.1 & 4.8 & 22.2 & 79.2 & 19.0 & 129.4 \\
\cline { 2 - 8 } rd pulse & 65 & 3.0 & 3.0 & 21.9 & 90.8 & 17.9 & 136.6 \\
\cline { 2 - 8 } & 72 & 3.0 & 2.0 & 21.1 & 88.6 & 16.1 & 130.8 \\
\hline
\end{tabular}


Table A.3 Metal content ( $\mu \mathrm{g} / \mathrm{gTSS})$ in each fraction from BCR extraction method at different $\mathrm{pHs}(\mathrm{n}=3)$.

\begin{tabular}{|c|c|c|c|c|c|c|c|}
\hline $\mathbf{F e}$ & Day & Sol & $\mathrm{F} 1$ & $\mathrm{~F} 2$ & $\mathrm{~F} 3$ & F4 & $\begin{array}{l}\text { Sum of } \\
\text { fractions }\end{array}$ \\
\hline \multirow{5}{*}{ pH 7} & 1 & 16.9 & 2407.0 & 6239.1 & 896.1 & 1696.8 & 11255.9 \\
\hline & 3 & 16.0 & 2445.6 & 6062.0 & 938.9 & 1722.2 & 11184.7 \\
\hline & 4 & 16.7 & 2560.2 & 6498.1 & 901.2 & 1602.1 & 11578.3 \\
\hline & 5 & 17.8 & 2428.2 & 6219.6 & 842.8 & 1649.2 & 11157.6 \\
\hline & 7 & 16.4 & 2384.4 & 6125.5 & 965.1 & 1612.5 & 11103.8 \\
\hline \multirow{4}{*}{ pH 6.5} & 8 & 38.1 & 2333.2 & 4237.2 & 987.1 & 1407.7 & 9003.2 \\
\hline & 9 & 57.5 & 2418.1 & 4294.5 & 937.2 & 1131.7 & 8839.0 \\
\hline & 11 & 79.2 & 2349.8 & 4333.3 & 922.1 & 1211.6 & 8896.0 \\
\hline & 13 & 96.5 & 2423.3 & 4105.0 & 777.1 & 1159.8 & 8561.7 \\
\hline \multirow{4}{*}{ pH 6} & 14 & 127.8 & 2356.2 & 3986.8 & 730.6 & 996.5 & 8197.9 \\
\hline & 16 & 137.5 & 1115.5 & 3878.1 & 893.2 & 701.8 & 6726.1 \\
\hline & 18 & 147.7 & 1110.7 & 3711.8 & 827.6 & 700.9 & 6498.7 \\
\hline & 20 & 152.9 & 1081.9 & 3419.4 & 810.3 & 696.3 & 6160.8 \\
\hline
\end{tabular}


Appendix

\begin{tabular}{cccccccc}
\hline & 22 & 161.1 & 1015.2 & 3726.1 & 740.5 & 663.3 & 6306.2 \\
\cline { 2 - 7 } $\mathrm{pH}$ & 24 & 157.0 & 1042.7 & 3719.9 & 775.2 & 643.6 & 6338.3 \\
\cline { 2 - 7 } Recovery & 26 & 17.4 & 1376.6 & 3922.8 & 948.9 & 1204.3 & 7470.1 \\
\cline { 2 - 7 } & 28 & 14.2 & 1022.8 & 4099.5 & 1014.2 & 978.7 & 7129.4 \\
\cline { 2 - 7 } & 34 & 18.3 & 1121.2 & 3613.9 & 1095.2 & 1436.4 & 7285.0 \\
\hline & 40 & 5.7 & 1192.4 & 3671.4 & 1173.5 & 1801.9 & 7844.9 \\
\hline
\end{tabular}

\begin{tabular}{cccccccc}
\hline Co & Day & Sol & F1 & F2 & F3 & F4 & $\begin{array}{c}\text { Sum of } \\
\text { fractions }\end{array}$ \\
\hline & 1 & 0.0 & 132.3 & 69.9 & 699.6 & 0.0 & 901.7 \\
\cline { 2 - 7 } $\mathrm{pH} 7$ & 0.0 & 133.9 & 69.4 & 699.9 & 0.0 & 903.2 \\
\cline { 2 - 7 } & 4 & 0.0 & 133.0 & 69.1 & 700.1 & 0.0 & 902.2 \\
\cline { 2 - 7 } & 5 & 0.0 & 133.3 & 69.2 & 701.2 & 0.0 & 903.7 \\
\hline & 0.0 & 133.3 & 69.3 & 700.7 & 0.0 & 903.3 \\
\hline
\end{tabular}


Appendix

\begin{tabular}{|c|c|c|c|c|c|c|c|}
\hline \multirow{4}{*}{ pH 6.5} & 8 & 0.0 & 116.6 & 65.4 & 658.5 & 0.0 & 840.5 \\
\hline & 9 & 0.0 & 116.1 & 64.3 & 628.1 & 0.0 & 808.5 \\
\hline & 11 & 0.0 & 115.9 & 64.3 & 624.8 & 0.0 & 805.0 \\
\hline & 13 & 0.0 & 115.5 & 63.9 & 593.4 & 0.0 & 772.8 \\
\hline \multirow{4}{*}{ pH 6} & 14 & 0.0 & 116.4 & 63.7 & 587.3 & 0.0 & 767.4 \\
\hline & 16 & 2.7 & 101.4 & 63.6 & 583.8 & 0.0 & 751.5 \\
\hline & 18 & 2.8 & 101.4 & 63.6 & 585.7 & 0.0 & 753.5 \\
\hline & 20 & 2.8 & 101.9 & 84.7 & 580.2 & 0.0 & 769.6 \\
\hline \multirow{6}{*}{$\begin{array}{c}\mathrm{pH} \\
\text { Recovery }\end{array}$} & 22 & 2.5 & 100.4 & 57.0 & 436.2 & 0.0 & 596.1 \\
\hline & 24 & 2.7 & 101.8 & 61.3 & 493.4 & 0.0 & 659.2 \\
\hline & 26 & 0.0 & 159.8 & 81.0 & 674.7 & 0.0 & 915.5 \\
\hline & 28 & 0.0 & 176.6 & 84.3 & 685.5 & 0.0 & 946.4 \\
\hline & 34 & 0.0 & 174.5 & 88.9 & 758.7 & 0.0 & 1022.1 \\
\hline & 40 & 0.0 & 194.3 & 91.4 & 789.4 & 0.0 & 1075.1 \\
\hline
\end{tabular}




\begin{tabular}{|c|c|c|c|c|c|c|c|}
\hline $\mathbf{N i}$ & Day & Sol & $\mathrm{F} 1$ & $\mathrm{~F} 2$ & F3 & $\mathrm{F} 4$ & $\begin{array}{l}\text { Sum of } \\
\text { fractions }\end{array}$ \\
\hline \multirow{5}{*}{ pH 7} & 1 & 9.7 & 201.1 & 89.8 & 379.8 & 6.5 & 686.8 \\
\hline & 3 & 10.0 & 201.1 & 90.6 & 379.0 & 6.7 & 687.4 \\
\hline & 4 & 9.4 & 201.0 & 89.5 & 378.4 & 6.3 & 684.7 \\
\hline & 5 & 9.2 & 201.5 & 89.2 & 377.2 & 6.2 & 683.3 \\
\hline & 7 & 9.4 & 209.9 & 88.0 & 378.5 & 6.3 & 692.1 \\
\hline \multirow{4}{*}{ pH 6.5} & 8 & 11.2 & 199.3 & 78.6 & 337.2 & 6.1 & 632.4 \\
\hline & 9 & 11.1 & 191.0 & 75.9 & 310.8 & 6.0 & 594.7 \\
\hline & 11 & 11.6 & 185.5 & 73.4 & 293.0 & 5.8 & 569.3 \\
\hline & 13 & 11.9 & 184.9 & 74.0 & 281.4 & 5.5 & 557.6 \\
\hline \multirow{4}{*}{ pH 6} & 14 & 13.3 & 181.0 & 69.5 & 271.6 & 5.3 & 540.6 \\
\hline & 16 & 13.6 & 179.1 & 69.5 & 266.3 & 5.5 & 534.0 \\
\hline & 18 & 13.1 & 175.2 & 68.2 & 259.5 & 5.6 & 521.6 \\
\hline & 20 & 15.7 & 172.7 & 66.7 & 255.6 & 5.6 & 516.2 \\
\hline
\end{tabular}




\begin{tabular}{cccccccc}
\hline & 22 & 18.6 & 161.2 & 45.1 & 185.8 & 5.1 & 415.7 \\
\cline { 2 - 8 } $\mathrm{pH}$ & 24 & 26.7 & 143.1 & 56.9 & 205.6 & 5.3 & 437.6 \\
\cline { 2 - 7 } Recovery & 26 & 1.1 & 180.4 & 71.7 & 327.6 & 2.2 & 583.0 \\
\cline { 2 - 7 } & 28 & 1.0 & 184.3 & 68.0 & 322.5 & 2.0 & 577.8 \\
\cline { 2 - 7 } & 34 & 1.0 & 156.7 & 76.9 & 361.5 & 2.0 & 598.2 \\
\hline & 40 & 1.0 & 185.2 & 81.4 & 383.3 & 1.9 & 652.9 \\
\hline
\end{tabular}

\begin{tabular}{cccccccc}
\hline \multirow{2}{*}{ Zn } & Day & Sol & F1 & F2 & F3 & F4 & $\begin{array}{c}\text { Sum of } \\
\text { fractions }\end{array}$ \\
\hline & 1 & 0.00 & 279.6 & 281.7 & 666.5 & 0.0 & 1227.8 \\
\cline { 2 - 7 } pH 7 & 3 & 0.00 & 280.0 & 282.2 & 667.4 & 0.0 & 1229.6 \\
\cline { 2 - 7 } & 4 & 0.00 & 279.6 & 281.2 & 666.2 & 0.0 & 1227.0 \\
\cline { 2 - 7 } & 5 & 0.00 & 279.0 & 280.0 & 665.8 & 0.0 & 1224.7 \\
\hline pH 6.5 & 8 & 0.00 & 279.2 & 279.2 & 665.5 & 0.0 & 1223.8 \\
\hline
\end{tabular}


Appendix

\begin{tabular}{|c|c|c|c|c|c|c|c|}
\hline & 9 & 0.00 & 265.3 & 257.3 & 646.2 & 0.0 & 1168.8 \\
\hline & 11 & 0.00 & 250.7 & 254.1 & 626.2 & 0.0 & 1131.0 \\
\hline & 13 & 0.00 & 240.2 & 253.9 & 598.1 & 0.0 & 1092.1 \\
\hline \multirow{4}{*}{ pH 6} & 14 & 0.00 & 237.2 & 249.6 & 586.9 & 0.0 & 1073.7 \\
\hline & 16 & 0.00 & 235.0 & 248.6 & 583.6 & 0.0 & 1067.3 \\
\hline & 18 & 0.00 & 233.2 & 247.7 & 578.9 & 0.0 & 1059.7 \\
\hline & 20 & 0.00 & 223.6 & 246.3 & 560.9 & 0.0 & 1030.8 \\
\hline \multirow{6}{*}{$\begin{array}{c}\mathrm{pH} \\
\text { Recovery }\end{array}$} & 22 & 0.00 & 221.5 & 195.8 & 412.0 & 0.0 & 829.3 \\
\hline & 24 & 0.00 & 233.8 & 233.8 & 524.3 & 0.0 & 991.9 \\
\hline & 26 & 0.00 & 326.6 & 291.8 & 582.7 & 0.0 & 1201.2 \\
\hline & 28 & 0.00 & 334.5 & 265.0 & 587.6 & 0.0 & 1187.1 \\
\hline & 34 & 0.00 & 273.6 & 278.8 & 653.0 & 0.0 & 1205.4 \\
\hline & 40 & 0.00 & 269.5 & 266.7 & 697.4 & 0.0 & 1233.6 \\
\hline
\end{tabular}




\begin{tabular}{|c|c|c|c|c|c|c|c|}
\hline Mn & Day & Sol & $\mathrm{F} 1$ & $\mathrm{~F} 2$ & F3 & F4 & $\begin{array}{l}\text { Sum of } \\
\text { fractions }\end{array}$ \\
\hline \multirow{5}{*}{ pH 7} & 1 & 19.4 & 33.9 & 25.8 & 43.5 & 40.9 & 163.4 \\
\hline & 3 & 21.1 & 34.4 & 25.6 & 43.1 & 40.0 & 164.2 \\
\hline & 4 & 18.8 & 34.6 & 25.7 & 42.4 & 39.8 & 161.3 \\
\hline & 5 & 19.5 & 33.8 & 25.6 & 42.4 & 39.0 & 160.4 \\
\hline & 7 & 18.8 & 33.3 & 25.5 & 43.1 & 39.6 & 160.3 \\
\hline \multirow{4}{*}{ pH 6.5} & 8 & 22.3 & 34.0 & 24.8 & 39.3 & 38.5 & 159.0 \\
\hline & 9 & 22.1 & 33.2 & 24.6 & 39.8 & 38.2 & 157.9 \\
\hline & 11 & 22.2 & 33.8 & 23.2 & 39.1 & 36.7 & 155.1 \\
\hline & 13 & 22.8 & 33.3 & 22.8 & 36.2 & 34.7 & 149.9 \\
\hline \multirow{4}{*}{ pH 6} & 14 & 23.0 & 33.2 & 21.2 & 33.5 & 31.9 & 142.8 \\
\hline & 16 & 23.6 & 33.2 & 20.9 & 32.0 & 30.9 & 140.7 \\
\hline & 18 & 24.3 & 33.6 & 20.6 & 30.5 & 29.9 & 138.9 \\
\hline & 20 & 25.0 & 33.3 & 20.4 & 28.6 & 29.6 & 136.9 \\
\hline
\end{tabular}




\begin{tabular}{cccccccc}
\hline & 22 & 18.6 & 29.5 & 20.7 & 28.3 & 30.4 & 127.4 \\
\cline { 2 - 7 } $\mathrm{pH}$ & 24 & 20.4 & 24.4 & 23.1 & 32.9 & 32.0 & 132.9 \\
\cline { 2 - 7 } Recovery & 26 & 20.7 & 28.8 & 30.4 & 32.6 & 39.1 & 151.6 \\
\cline { 2 - 7 } & 28 & 18.3 & 25.4 & 29.9 & 36.7 & 38.6 & 148.9 \\
\cline { 2 - 7 } & 34 & 18.3 & 24.0 & 29.8 & 36.4 & 40.9 & 149.4 \\
\hline & 40 & 18.1 & 22.4 & 31.0 & 37.7 & 38.1 & 147.3 \\
\hline
\end{tabular}

\begin{tabular}{cccccccc}
\hline Mo & Day & Sol & F1 & F2 & F3 & F4 & $\begin{array}{c}\text { Sum of } \\
\text { fractions }\end{array}$ \\
\hline & 1 & 1.8 & 2.7 & 19.1 & 115.3 & 10.7 & 149.6 \\
\cline { 2 - 7 } & 3 & 1.7 & 2.1 & 18.1 & 108.8 & 8.4 & 139.1 \\
\cline { 2 - 7 } $\mathrm{pH} 7$ & 4 & 2.8 & 2.3 & 21.3 & 117.5 & 9.3 & 153.1 \\
\cline { 2 - 7 } & 5 & 1.9 & 2.8 & 20.6 & 116.1 & 9.3 & 150.7 \\
\hline pH 6.5 & 8 & 2.7 & 4.0 & 18.6 & 103.8 & 8.8 & 137.8 \\
\hline
\end{tabular}




\section{Appendix}

\begin{tabular}{|c|c|c|c|c|c|c|c|}
\hline & 9 & 2.9 & 4.1 & 21.5 & 109.1 & 9.1 & 146.8 \\
\hline & 11 & 2.9 & 5.8 & 17.4 & 108.5 & 9.7 & 144.2 \\
\hline & 13 & 3.0 & 6.0 & 18.1 & 105.3 & 8.0 & 140.5 \\
\hline \multirow{4}{*}{ pH 6} & 14 & 3.0 & 5.6 & 17.7 & 97.1 & 8.1 & 131.6 \\
\hline & 16 & 3.1 & 6.3 & 17.7 & 97.8 & 8.3 & 133.2 \\
\hline & 18 & 3.1 & 6.2 & 16.9 & 88.3 & 6.2 & 120.6 \\
\hline & 20 & 3.1 & 6.8 & 16.2 & 90.2 & 6.3 & 122.6 \\
\hline \multirow{6}{*}{$\begin{array}{c}\mathrm{pH} \\
\text { Recovery }\end{array}$} & 22 & 3.3 & 6.1 & 16.7 & 93.2 & 6.7 & 126.0 \\
\hline & 24 & 3.2 & 7.0 & 16.7 & 93.0 & 6.5 & 126.3 \\
\hline & 26 & 3.3 & 3.3 & 16.8 & 114.7 & 13.0 & 151.1 \\
\hline & 28 & 3.0 & 2.5 & 16.8 & 112.9 & 14.2 & 149.5 \\
\hline & 34 & 2.9 & 2.4 & 16.3 & 112.7 & 18.4 & 152.8 \\
\hline & 40 & 2.9 & 2.9 & 16.7 & 120.7 & 19.0 & 162.1 \\
\hline
\end{tabular}


Table A.4 Metal content ( $\mu \mathrm{g} / \mathrm{gTSS})$ in each fraction from BCR extraction method at different HRTs $(\mathrm{n}=3)$.

\begin{tabular}{|c|c|c|c|c|c|c|c|}
\hline $\mathbf{F e}$ & Day & Sol & $\mathrm{F} 1$ & $\mathrm{~F} 2$ & F3 & F4 & $\begin{array}{l}\text { Sum of } \\
\text { fractions }\end{array}$ \\
\hline \multirow{4}{*}{$6 \mathrm{~h} \mathrm{HRT}$} & 1 & 6.2 & 861.7 & 4896.7 & 868.8 & 1849.3 & 8482.7 \\
\hline & 2 & 6.1 & 845.9 & 4803.9 & 929.2 & 1859.7 & 8444.8 \\
\hline & 3 & 5.9 & 904.2 & 4947.0 & 893.4 & 1820.3 & 8571.0 \\
\hline & 4 & 6.6 & 893.0 & 4810.7 & 943.3 & 1795.9 & 8449.5 \\
\hline \multirow{5}{*}{$4 \mathrm{~h} \mathrm{HRT}$} & 5 & 16.0 & 909.2 & 4466.8 & 937.8 & 1603.2 & 7933.0 \\
\hline & 6 & 6.6 & 1028.7 & 3980.5 & 916.8 & 1533.8 & 7466.5 \\
\hline & 7 & 6.5 & 1080.4 & 3886.5 & 897.1 & 1681.5 & 7552.0 \\
\hline & 8 & 6.6 & 1218.4 & 3848.9 & 692.2 & 1635.3 & 7401.4 \\
\hline & 9 & 6.5 & 1266.9 & 3535.3 & 632.7 & 1643.2 & 7084.5 \\
\hline \multirow{4}{*}{$2 \mathrm{~h} \mathrm{HRT}$} & 10 & 6.8 & 1309.5 & 3398.3 & 552.5 & 1668.9 & 6936.0 \\
\hline & 11 & 4.3 & 665.1 & 3158.1 & 586.2 & 1096.0 & 5509.8 \\
\hline & 12 & 4.6 & 674.1 & 2953.0 & 564.1 & 957.9 & 5153.7 \\
\hline & 13 & 4.5 & 614.1 & 2843.7 & 559.1 & 903.7 & 4925.0 \\
\hline
\end{tabular}


Appendix

\begin{tabular}{llllllll}
\hline 14 & 4.1 & 547.2 & 2565.9 & 523.7 & 804.1 & 4445.0 \\
\hline
\end{tabular}

\begin{tabular}{|c|c|c|c|c|c|c|c|}
\hline Co & Day & Sol & $\mathrm{F} 1$ & $\mathrm{~F} 2$ & F3 & F4 & $\begin{array}{l}\text { Sum of } \\
\text { fractions }\end{array}$ \\
\hline \multirow{4}{*}{$6 \mathrm{~h} \mathrm{HRT}$} & 1 & 0.0 & 148.9 & 71.4 & 703.1 & 19.5 & 942.9 \\
\hline & 2 & 0.0 & 149.8 & 72.7 & 708.1 & 19.0 & 949.7 \\
\hline & 3 & 0.0 & 153.4 & 75.8 & 709.6 & 18.6 & 957.5 \\
\hline & 4 & 0.0 & 153.5 & 75.3 & 704.5 & 18.1 & 951.4 \\
\hline \multirow{5}{*}{$4 \mathrm{~h} \mathrm{HRT}$} & 5 & 0.0 & 148.0 & 76.4 & 736.7 & 17.6 & 978.7 \\
\hline & 6 & 0.0 & 144.1 & 76.1 & 734.9 & 16.2 & 971.3 \\
\hline & 7 & 0.0 & 145.1 & 77.1 & 721.0 & 16.0 & 959.2 \\
\hline & 8 & 0.0 & 146.0 & 81.6 & 593.4 & 16.2 & 837.1 \\
\hline & 9 & 0.0 & 140.6 & 83.8 & 562.9 & 15.8 & 803.1 \\
\hline \multirow{2}{*}{$2 \mathrm{~h} \mathrm{HRT}$} & 10 & 0.0 & 123.3 & 87.2 & 545.7 & 13.5 & 769.7 \\
\hline & 11 & 0.0 & 119.9 & 91.4 & 507.0 & 11.0 & 729.3 \\
\hline
\end{tabular}


Appendix

\begin{tabular}{rrrrrrrrr}
\hline 12 & 0.0 & 115.3 & 93.4 & 415.3 & 10.4 & 634.3 \\
\cline { 2 - 8 } & 13 & 0.0 & 86.2 & 99.2 & 380.8 & 11.3 & 577.5 \\
\hline 14 & 0.0 & 71.5 & 101.0 & 300.3 & 10.3 & 483.1 \\
\hline
\end{tabular}

\begin{tabular}{|c|c|c|c|c|c|c|c|}
\hline $\mathbf{N i}$ & Day & Sol & $\mathrm{F} 1$ & $\mathrm{~F} 2$ & F3 & $\mathrm{F} 4$ & $\begin{array}{l}\text { Sum of } \\
\text { fractions }\end{array}$ \\
\hline \multirow{4}{*}{$6 \mathrm{~h} \mathrm{HRT}$} & 1 & 12.4 & 303.2 & 128.1 & 551.3 & 16.0 & 1011.0 \\
\hline & 2 & 13.0 & 304.8 & 128.1 & 549.9 & 15.6 & 1011.4 \\
\hline & 3 & 12.7 & 305.5 & 130.5 & 549.0 & 15.3 & 1013.0 \\
\hline & 4 & 11.5 & 301.6 & 127.2 & 549.8 & 14.8 & 1004.9 \\
\hline \multirow{5}{*}{$4 \mathrm{~h} \mathrm{HRT}$} & 5 & 15.2 & 263.2 & 127.2 & 486.6 & 12.8 & 905.0 \\
\hline & 6 & 8.8 & 235.3 & 122.4 & 409.4 & 11.8 & 787.7 \\
\hline & 7 & 8.7 & 225.5 & 124.0 & 376.5 & 11.6 & 746.4 \\
\hline & 8 & 8.1 & 217.6 & 127.6 & 252.8 & 10.3 & 616.5 \\
\hline & 9 & 7.2 & 195.3 & 127.3 & 246.1 & 10.1 & 586.1 \\
\hline
\end{tabular}


Appendix

\begin{tabular}{rlllllll}
\hline & 10 & 14.9 & 195.3 & 116.9 & 228.0 & 9.5 & 564.5 \\
\cline { 2 - 7 } $2 \mathrm{~h} \mathrm{HRT}$ & 11 & 6.7 & 124.8 & 115.9 & 204.5 & 7.3 & 459.3 \\
\cline { 2 - 7 } & 12 & 5.8 & 111.8 & 115.9 & 178.8 & 6.9 & 419.2 \\
\hline 13 & 5.6 & 110.4 & 116.6 & 168.8 & 6.8 & 408.2 \\
\hline
\end{tabular}

\begin{tabular}{|c|c|c|c|c|c|c|c|}
\hline Zn & Day & Sol & $\mathrm{F} 1$ & F2 & F3 & $\mathrm{F} 4$ & $\begin{array}{l}\text { Sum of } \\
\text { fractions }\end{array}$ \\
\hline \multirow{4}{*}{$6 \mathrm{~h} \mathrm{HRT}$} & 1 & 0.0 & 238.5 & 242.5 & 400.6 & 0.0 & 881.5 \\
\hline & 2 & 0.0 & 237.7 & 244.2 & 400.1 & 0.0 & 881.9 \\
\hline & 3 & 0.0 & 236.9 & 244.1 & 400.7 & 0.0 & 881.7 \\
\hline & 4 & 0.0 & 236.2 & 242.8 & 398.1 & 0.0 & 877.2 \\
\hline \multirow{3}{*}{$4 \mathrm{~h}$ HRT } & 5 & 0.0 & 186.4 & 233.6 & 439.1 & 0.0 & 859.1 \\
\hline & 6 & 0.0 & 171.7 & 221.0 & 441.3 & 0.0 & 833.9 \\
\hline & 7 & 0.0 & 167.3 & 216.0 & 446.5 & 0.0 & 829.7 \\
\hline
\end{tabular}


Appendix

\begin{tabular}{|c|c|c|c|c|c|c|c|}
\hline & 8 & 0.0 & 161.8 & 219.1 & 457.0 & 0.0 & 837.9 \\
\hline & 9 & 0.0 & 149.3 & 212.9 & 467.4 & 0.0 & 829.6 \\
\hline \multirow{5}{*}{$2 \mathrm{~h} \mathrm{HRT}$} & 10 & 0.0 & 138.9 & 199.0 & 474.1 & 0.0 & 811.9 \\
\hline & 11 & 0.0 & 90.8 & 175.2 & 480.9 & 0.0 & 746.9 \\
\hline & 12 & 0.0 & 72.9 & 176.7 & 501.4 & 0.0 & 751.0 \\
\hline & 13 & 0.0 & 70.4 & 161.7 & 540.9 & 0.0 & 773.0 \\
\hline & 14 & 0.0 & 70.8 & 157.4 & 567.0 & 0.0 & 795.2 \\
\hline
\end{tabular}

\begin{tabular}{cccccccc}
\hline Mn & Day & Sol & F1 & F2 & F3 & F4 & $\begin{array}{c}\text { Sum of } \\
\text { fractions }\end{array}$ \\
\hline & 1 & 20.4 & 40.3 & 24.4 & 16.1 & 28.4 & 129.5 \\
\cline { 2 - 7 } 6 h HRT & 2 & 19.9 & 39.0 & 24.2 & 14.9 & 27.7 & 28.8 \\
\cline { 2 - 7 } & 3 & 19.5 & 38.6 & 24.6 & 14.6 & 125.8 \\
\cline { 2 - 7 } & 4 & 18.9 & 38.3 & 23.5 & 14.2 & 28.0 & 122.8 \\
\hline 4 h HRT & 5 & 19.2 & 38.4 & 23.6 & 14.5 & 27.2 & 122.9 \\
\hline
\end{tabular}




\section{Appendix}

\begin{tabular}{|c|c|c|c|c|c|c|c|}
\hline & 6 & 17.6 & 37.9 & 22.1 & 13.3 & 25.0 & 115.9 \\
\hline & 7 & 16.7 & 37.1 & 22.2 & 13.2 & 24.7 & 113.9 \\
\hline & 8 & 15.4 & 27.2 & 22.4 & 12.7 & 25.0 & 102.8 \\
\hline & 9 & 16.5 & 27.3 & 22.3 & 12.7 & 24.5 & 103.3 \\
\hline \multirow{5}{*}{$2 \mathrm{~h}$ HRT } & 10 & 14.9 & 27.0 & 20.6 & 11.6 & 24.3 & 98.4 \\
\hline & 11 & 12.2 & 28.1 & 19.0 & 10.6 & 22.0 & 91.9 \\
\hline & 12 & 11.0 & 27.7 & 18.2 & 9.4 & 20.7 & 87.0 \\
\hline & 13 & 8.5 & 23.9 & 17.5 & 9.5 & 20.3 & 79.6 \\
\hline & 14 & 7.7 & 22.3 & 16.2 & 8.2 & 19.5 & 73.8 \\
\hline
\end{tabular}

\begin{tabular}{cccccccc}
\hline Mo & Day & Sol & F1 & F2 & F3 & F4 & $\begin{array}{c}\text { Sum of } \\
\text { fractions }\end{array}$ \\
\hline & 1 & 36.3 & 5.8 & 26.2 & 74.4 & 7.1 & 149.7 \\
6 h HRT & 2 & 45.9 & 6.1 & 26.8 & 77.2 & 6.9 & 162.9 \\
\cline { 2 - 7 } & 3 & 38.1 & 5.5 & 25.8 & 74.0 & 6.8 & 150.3 \\
\hline
\end{tabular}


Appendix

\begin{tabular}{|c|c|c|c|c|c|c|c|}
\hline & 4 & 32.9 & 6.2 & 25.9 & 73.9 & 6.6 & 145.5 \\
\hline & 5 & 40.8 & 5.2 & 22.4 & 72.5 & 12.8 & 153.7 \\
\hline & 6 & 31.6 & 4.8 & 21.0 & 68.4 & 11.8 & 137.5 \\
\hline \multirow[t]{5}{*}{$4 \mathrm{~h} \mathrm{HRT}$} & 7 & 34.9 & 4.4 & 21.1 & 68.0 & 11.6 & 140.0 \\
\hline & 8 & 44.1 & 4.8 & 21.3 & 74.0 & 13.2 & 157.4 \\
\hline & 9 & 26.6 & 5.0 & 21.2 & 74.0 & 14.4 & 141.3 \\
\hline & 10 & 29.1 & 3.0 & 20.3 & 80.8 & 13.5 & 146.7 \\
\hline & 11 & 19.6 & 3.7 & 19.3 & 82.0 & 13.5 & 138.0 \\
\hline \multirow[t]{3}{*}{$2 \mathrm{~h} \mathrm{HRT}$} & 12 & 13.8 & 3.2 & 17.9 & 85.2 & 13.8 & 133.9 \\
\hline & 13 & 12.4 & 2.8 & 16.3 & 91.8 & 13.5 & 136.9 \\
\hline & 14 & 10.3 & 2.6 & 14.1 & 91.3 & 12.3 & 130.6 \\
\hline
\end{tabular}


Table A.5 Metal content $(\mu \mathrm{g} / \mathrm{gTSS})$ in each fraction from BCR extraction method at different SRTs $(\mathrm{n}=3)$.

\begin{tabular}{|c|c|c|c|c|c|c|c|}
\hline $\mathrm{Fe}$ & Day & Sol & $\mathrm{F} 1$ & $\mathrm{~F} 2$ & $\mathrm{~F} 3$ & $\mathrm{~F} 4$ & $\begin{array}{l}\text { Sum of } \\
\text { fractions }\end{array}$ \\
\hline \multirow{3}{*}{$\begin{array}{l}100 \mathrm{~d} \\
\text { SRT }\end{array}$} & 1 & 8.7 & 187.0 & 5215.0 & 835.9 & 1021.7 & 7268.2 \\
\hline & 10 & 9.1 & 285.4 & 5175.8 & 815.5 & 897.7 & 7183.5 \\
\hline & 20 & 9.0 & 713.9 & 4364.7 & 837.4 & 767.9 & 6692.9 \\
\hline \multirow{4}{*}{$\begin{array}{l}75 \mathrm{~d} \\
\text { SRT }\end{array}$} & 22 & 24.3 & 755.6 & 4050.9 & 759.2 & 851.6 & 6441.7 \\
\hline & 24 & 25.1 & 844.9 & 3898.1 & 802.1 & 1100.0 & 6670.2 \\
\hline & 26 & 25.4 & 1010.1 & 4118.0 & 762.2 & 966.7 & 6882.3 \\
\hline & 28 & 25.9 & 1000.5 & 3978.8 & 769.8 & 841.7 & 6616.7 \\
\hline \multirow{3}{*}{$\begin{array}{l}50 \mathrm{~d} \\
\text { SRT }\end{array}$} & 30 & 26.5 & 729.1 & 3839.2 & 706.3 & 983.3 & 6284.4 \\
\hline & 32 & 26.5 & 530.2 & 4092.1 & 892.3 & 745.0 & 6286.0 \\
\hline & 34 & 28.0 & 370.4 & 4305.4 & 880.8 & 741.9 & 6326.5 \\
\hline \multirow{3}{*}{$\begin{array}{l}25 \mathrm{~d} \\
\text { SRT }\end{array}$} & 36 & 29.8 & 697.2 & 3769.6 & 818.1 & 669.6 & 5984.4 \\
\hline & 38 & 32.1 & 564.2 & 4142.0 & 715.9 & 619.8 & 6073.9 \\
\hline & 40 & 32.9 & 1009.3 & 3637.1 & 555.5 & 651.4 & 5886.3 \\
\hline
\end{tabular}


Appendix

\begin{tabular}{rrrrrrr}
\hline 44 & 28.1 & 736.7 & 3503.9 & 560.4 & 668.8 & 5497.9 \\
\hline 48 & 25.4 & 834.1 & 3276.2 & 540.1 & 619.0 & 5294.8 \\
\hline 52 & 9.3 & 849.6 & 3219.4 & 518.6 & 548.8 & 5145.7 \\
\hline 60 & 20.0 & 710.0 & 2905.7 & 473.6 & 445.7 & 4555.0 \\
\hline
\end{tabular}

\begin{tabular}{|c|c|c|c|c|c|c|c|}
\hline Co & Day & Sol & $\mathrm{F} 1$ & $\mathrm{~F} 2$ & F3 & F4 & $\begin{array}{l}\text { Sum of } \\
\text { fractions }\end{array}$ \\
\hline \multirow{3}{*}{$\begin{array}{l}100 \mathrm{~d} \\
\text { SRT }\end{array}$} & 1 & 0.0 & 194.2 & 91.8 & 837.3 & 0.0 & 1123.3 \\
\hline & 10 & 0.0 & 189.4 & 91.9 & 860.0 & 0.0 & 1141.3 \\
\hline & 20 & 0.0 & 162.2 & 87.6 & 854.6 & 4.0 & 1108.3 \\
\hline \multirow{4}{*}{$\begin{array}{l}75 \mathrm{~d} \\
\text { SRT }\end{array}$} & 22 & 0.0 & 157.9 & 83.2 & 829.1 & 1.9 & 1072.1 \\
\hline & 24 & 0.0 & 169.6 & 87.0 & 866.4 & 1.9 & 1124.9 \\
\hline & 26 & 0.0 & 206.9 & 98.9 & 700.7 & 0.0 & 1006.5 \\
\hline & 28 & 0.0 & 194.3 & 100.0 & 855.3 & 0.0 & 1149.6 \\
\hline $50 \mathrm{~d}$ & 30 & 0.0 & 190.5 & 89.4 & 709.8 & 0.0 & 989.7 \\
\hline
\end{tabular}


Appendix

\begin{tabular}{cccccccc}
\hline SRT & 32 & 0.0 & 136.0 & 76.7 & 833.2 & 0.0 & 1045.9 \\
\cline { 2 - 8 } & 34 & 0.0 & 164.0 & 83.3 & 812.6 & 0.0 & 1059.9 \\
\hline & 36 & 0.0 & 150.3 & 81.8 & 772.2 & 0.0 & 1004.3 \\
\cline { 2 - 7 } & 38 & 0.0 & 189.5 & 89.5 & 738.4 & 0.0 & 1017.4 \\
\cline { 2 - 7 } $25 \mathrm{~d}$ & 40 & 0.0 & 243.6 & 86.4 & 699.3 & 0.0 & 1029.3 \\
\cline { 2 - 8 } SRT & 44 & 0.0 & 228.9 & 110.2 & 705.9 & 0.0 & 1044.9 \\
\cline { 2 - 8 } & 48 & 0.0 & 200.8 & 101.6 & 728.0 & 0.0 & 1030.4 \\
\cline { 2 - 7 } & 52 & 0.0 & 207.8 & 101.6 & 741.9 & 0.0 & 1051.2 \\
\hline
\end{tabular}

\begin{tabular}{cccccccc}
\hline Ni & Day & Sol & F1 & F2 & F3 & F4 & $\begin{array}{c}\text { Sum of } \\
\text { fractions }\end{array}$ \\
\hline \multirow{2}{*}{$\begin{array}{c}100 \mathrm{~d} \\
\text { SRT }\end{array}$} & 1 & 22.2 & 269.1 & 97.6 & 492.5 & 3.9 & 885.3 \\
\cline { 2 - 8 } & 20 & 21.2 & 261.6 & 96.5 & 505.2 & 2.0 & 886.5 \\
\hline
\end{tabular}


Appendix

\begin{tabular}{|c|c|c|c|c|c|c|c|}
\hline \multirow{4}{*}{$\begin{array}{l}75 \mathrm{~d} \\
\text { SRT }\end{array}$} & 22 & 14.0 & 205.6 & 92.5 & 485.2 & 1.9 & 799.2 \\
\hline & 24 & 13.5 & 205.8 & 92.3 & 506.4 & 1.9 & 819.9 \\
\hline & 26 & 13.8 & 227.0 & 102.1 & 491.1 & 2.1 & 836.1 \\
\hline & 28 & 12.4 & 214.0 & 102.1 & 508.5 & 4.1 & 841.2 \\
\hline \multirow{3}{*}{$\begin{array}{l}50 \mathrm{~d} \\
\text { SRT }\end{array}$} & 30 & 11.6 & 215.9 & 96.3 & 423.5 & 2.1 & 749.5 \\
\hline & 32 & 9.5 & 185.2 & 87.3 & 494.8 & 10.6 & 787.4 \\
\hline & 34 & 9.7 & 203.8 & 92.5 & 463.2 & 10.8 & 779.8 \\
\hline \multirow{7}{*}{$\begin{array}{l}25 \mathrm{~d} \\
\text { SRT }\end{array}$} & 36 & 9.9 & 159.1 & 86.2 & 465.2 & 8.8 & 729.3 \\
\hline & 38 & 11.1 & 185.2 & 84.0 & 438.0 & 12.3 & 730.6 \\
\hline & 40 & 12.9 & 179.3 & 73.6 & 418.8 & 11.4 & 695.9 \\
\hline & 44 & 1.6 & 169.5 & 68.0 & 384.0 & 9.4 & 632.4 \\
\hline & 48 & 1.6 & 141.3 & 61.9 & 383.7 & 6.3 & 594.8 \\
\hline & 52 & 1.6 & 141.1 & 60.5 & 375.0 & 6.2 & 584.3 \\
\hline & 60 & 1.4 & 126.4 & 52.9 & 328.6 & 5.7 & 515.0 \\
\hline
\end{tabular}




\section{Appendix}

\begin{tabular}{|c|c|c|c|c|c|c|c|}
\hline $\mathbf{Z n}$ & Day & Sol & $\mathrm{F} 1$ & F2 & F3 & F4 & $\begin{array}{l}\text { Sum of } \\
\text { fractions }\end{array}$ \\
\hline \multirow{3}{*}{$\begin{array}{l}100 \mathrm{~d} \\
\text { SRT }\end{array}$} & 1 & 0.0 & 176.8 & 193.2 & 534.3 & 0.0 & 904.3 \\
\hline & 10 & 0.0 & 179.8 & 197.0 & 551.4 & 0.0 & 928.2 \\
\hline & 20 & 0.0 & 156.7 & 201.5 & 544.0 & 0.0 & 902.2 \\
\hline \multirow{4}{*}{$\begin{array}{l}75 \mathrm{~d} \\
\text { SRT }\end{array}$} & 22 & 0.0 & 153.7 & 187.9 & 498.5 & 0.0 & 840.1 \\
\hline & 24 & 0.0 & 158.5 & 193.2 & 512.2 & 0.0 & 863.9 \\
\hline & 26 & 0.0 & 177.8 & 225.9 & 559.3 & 0.0 & 963.0 \\
\hline & 28 & 0.0 & 177.2 & 229.0 & 495.1 & 0.0 & 901.3 \\
\hline \multirow{3}{*}{$\begin{array}{l}50 \mathrm{~d} \\
\text { SRT }\end{array}$} & 30 & 0.0 & 172.5 & 248.1 & 472.8 & 0.0 & 893.4 \\
\hline & 32 & 0.0 & 183.1 & 213.8 & 485.6 & 0.0 & 882.4 \\
\hline & 34 & 0.0 & 194.1 & 205.4 & 486.0 & 0.0 & 885.5 \\
\hline \multirow{4}{*}{$\begin{array}{l}25 \mathrm{~d} \\
\text { SRT }\end{array}$} & 36 & 0.0 & 164.6 & 214.9 & 485.1 & 0.0 & 864.6 \\
\hline & 38 & 0.0 & 199.4 & 217.9 & 456.2 & 0.0 & 873.5 \\
\hline & 40 & 0.0 & 194.3 & 220.7 & 424.8 & 0.0 & 839.8 \\
\hline & 44 & 0.0 & 307.0 & 171.1 & 355.7 & 0.0 & 833.8 \\
\hline
\end{tabular}




\begin{tabular}{ccccccc}
\hline 48 & 0.0 & 261.9 & 178.6 & 385.7 & 0.0 & 826.2 \\
\hline 52 & 0.0 & 268.2 & 180.6 & 376.2 & 0.0 & 825.0 \\
\hline 60 & 0.0 & 267.1 & 155.7 & 343.6 & 0.0 & 766.4 \\
\hline
\end{tabular}

\begin{tabular}{|c|c|c|c|c|c|c|c|}
\hline Mn & Day & Sol & $\mathrm{F} 1$ & $\mathrm{~F} 2$ & F3 & F4 & $\begin{array}{l}\text { Sum of } \\
\text { fractions }\end{array}$ \\
\hline \multirow{3}{*}{$\begin{array}{l}100 \mathrm{~d} \\
\mathrm{SRT}\end{array}$} & 1 & 19.3 & 41.5 & 23.2 & 19.7 & 34.8 & 138.5 \\
\hline & 10 & 20.2 & 40.9 & 22.7 & 20.6 & 36.4 & 140.8 \\
\hline & 20 & 20.9 & 40.3 & 22.4 & 19.4 & 35.8 & 138.8 \\
\hline \multirow{4}{*}{$\begin{array}{l}75 \mathrm{~d} \\
\text { SRT }\end{array}$} & 22 & 18.7 & 36.9 & 21.0 & 18.2 & 33.6 & 128.5 \\
\hline & 24 & 19.3 & 36.7 & 20.8 & 19.7 & 34.8 & 131.3 \\
\hline & 26 & 21.2 & 38.6 & 22.2 & 19.7 & 38.1 & 139.8 \\
\hline & 28 & 19.7 & 36.8 & 22.3 & 20.2 & 37.3 & 136.3 \\
\hline $50 \mathrm{~d}$ & 30 & 14.8 & 32.8 & 18.5 & 33.3 & 29.6 & 129.1 \\
\hline SRT & 32 & 19.0 & 37.6 & 21.2 & 15.7 & 29.6 & 123.1 \\
\hline
\end{tabular}




\section{Appendix}

\begin{tabular}{|c|c|c|c|c|c|c|c|}
\hline & 34 & 19.4 & 37.6 & 21.5 & 16.0 & 30.1 & 124.6 \\
\hline \multirow{7}{*}{$\begin{array}{l}25 \mathrm{~d} \\
\text { SRT }\end{array}$} & 36 & 12.2 & 31.5 & 21.5 & 15.5 & 30.9 & 111.6 \\
\hline & 38 & 12.3 & 32.7 & 23.5 & 17.3 & 34.6 & 120.4 \\
\hline & 40 & 14.3 & 34.3 & 25.0 & 18.8 & 40.0 & 132.3 \\
\hline & 44 & 10.9 & 32.0 & 21.9 & 21.7 & 37.5 & 124.0 \\
\hline & 48 & 11.1 & 31.7 & 21.4 & 20.6 & 38.1 & 123.0 \\
\hline & 52 & 10.9 & 31.0 & 21.7 & 20.2 & 37.2 & 120.9 \\
\hline & 60 & 10.0 & 28.6 & 20.0 & 18.6 & 34.3 & 111.4 \\
\hline
\end{tabular}

\begin{tabular}{cccccccc}
\hline Mo & Day & Sol & F1 & F2 & F3 & F4 & $\begin{array}{c}\text { Sum of } \\
\text { fractions }\end{array}$ \\
\hline \multirow{2}{*}{$100 \mathrm{~d}$} & 1 & 11.6 & 3.9 & 30.0 & 134.2 & 7.7 & 187.3 \\
\cline { 2 - 8 } SRT & 10 & 12.1 & 4.0 & 33.3 & 137.6 & 8.1 & 195.2 \\
\cline { 2 - 7 } & 20 & 11.9 & 6.5 & 37.3 & 137.4 & 8.0 & 201.1 \\
\hline $75 \mathrm{~d}$ & 22 & 11.2 & 5.1 & 31.8 & 121.4 & 7.5 & 177.0 \\
\hline
\end{tabular}




\begin{tabular}{|c|c|c|c|c|c|c|c|}
\hline \multirow[t]{3}{*}{ SRT } & 24 & 14.5 & 5.8 & 31.9 & 125.1 & 7.7 & 185.0 \\
\hline & 26 & 16.9 & 6.9 & 36.0 & 136.1 & 8.5 & 204.4 \\
\hline & 28 & 26.9 & 7.3 & 34.7 & 126.4 & 8.3 & 203.6 \\
\hline \multirow{3}{*}{$\begin{array}{l}50 \mathrm{~d} \\
\text { SRT }\end{array}$} & 30 & 29.6 & 7.9 & 36.5 & 127.8 & 10.6 & 212.4 \\
\hline & 32 & 6.3 & 5.8 & 28.6 & 121.8 & 10.6 & 173.1 \\
\hline & 34 & 7.5 & 4.8 & 38.2 & 111.7 & 10.8 & 173.0 \\
\hline \multirow{7}{*}{$\begin{array}{l}25 \mathrm{~d} \\
\text { SRT }\end{array}$} & 36 & 7.7 & 6.6 & 24.9 & 147.2 & 11.0 & 197.5 \\
\hline & 38 & 8.6 & 6.2 & 27.8 & 124.2 & 12.3 & 179.2 \\
\hline & 40 & 10.0 & 7.9 & 28.6 & 113.0 & 11.4 & 170.9 \\
\hline & 44 & 10.9 & 21.1 & 48.4 & 99.4 & 3.1 & 183.0 \\
\hline & 48 & 9.5 & 19.0 & 46.0 & 92.7 & 3.2 & 170.4 \\
\hline & 52 & 7.8 & 18.6 & 45.0 & 89.1 & 3.1 & 163.6 \\
\hline & 60 & 8.6 & 18.6 & 44.3 & 84.6 & 2.9 & 158.9 \\
\hline
\end{tabular}

Sol - Soluble, F1 - Exchangeable, F2 - Fe-Mn oxides,

F3 - Organic matter and sulfides, F4 - Residual 